\title{
NON-STANDARD WORK, SELF-EMPLOYMENT AND PRECARIOUSNESS
}

\section{EDITED BY: Valeria Pulignano, Annalisa Murgia, Emiliana Armano and Marco Briziarelli}

\section{PUBLISHED IN: Frontiers in Sociology}

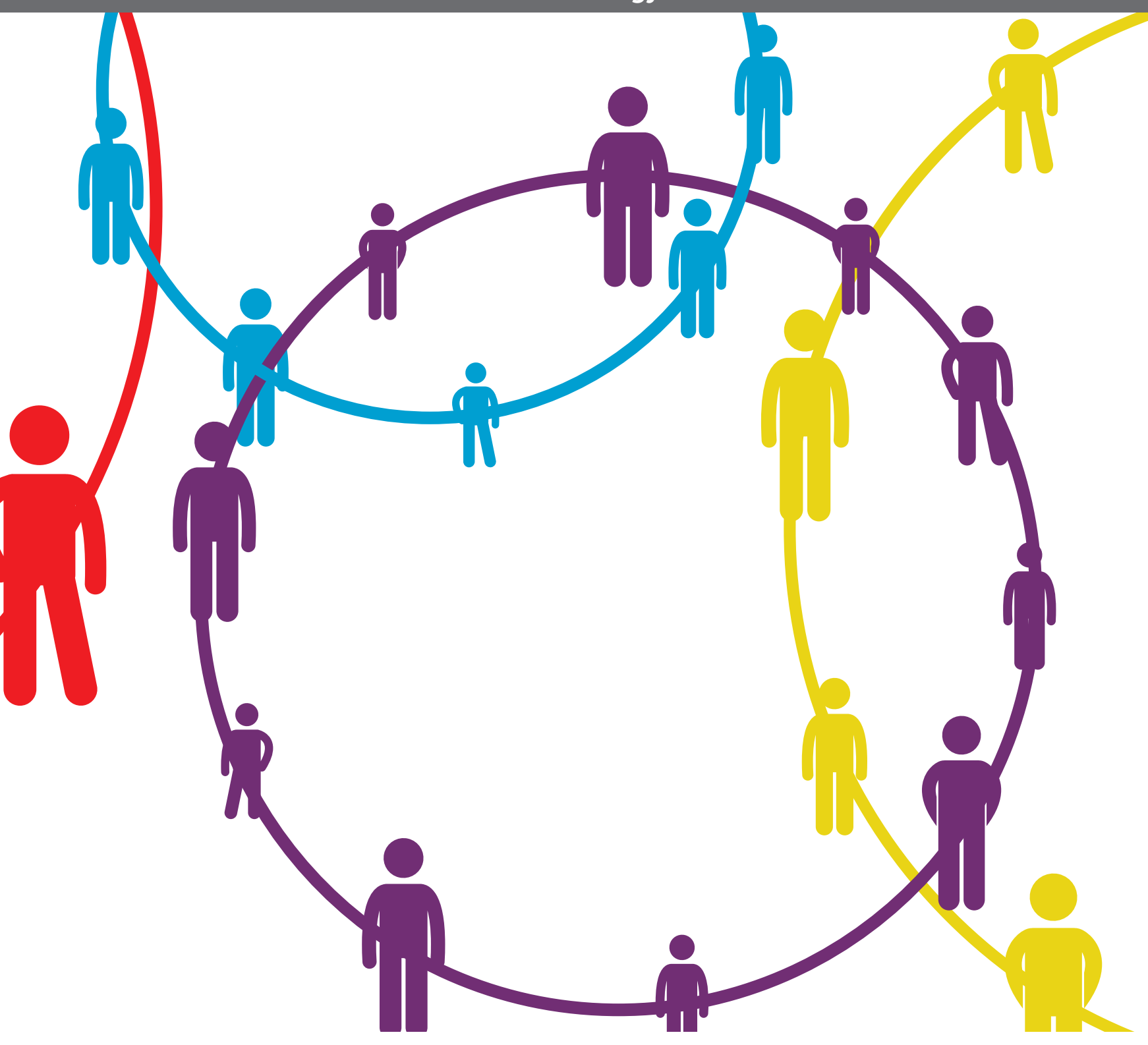




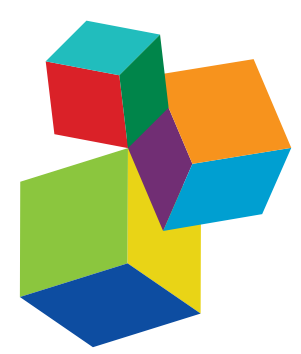

Frontiers eBook Copyright Statement

The copyright in the text of individual articles in this eBook is the property of their respective authors or their respective institutions or funders. The copyright in graphics and images within each article may be subject to copyright of other parties. In both cases this is subject to a license granted to Frontiers.

The compilation of articles constituting this eBook is the property of Frontiers.

Each article within this eBook, and the eBook itself, are published under the most recent version of the Creative Commons CC-BY licence.

The version current at the date of publication of this eBook is CC-BY 4.0. If the CC-BY licence is updated, the licence granted by Frontiers is automatically updated to the new version.

When exercising any right under the CC-BY licence, Frontiers must be attributed as the original publisher of the article or eBook, as applicable.

Authors have the responsibility of ensuring that any graphics or other materials which are the property of others may be included in the

CC-BY licence, but this should be checked before relying on the

CC-BY licence to reproduce those materials. Any copyright notices relating to those materials must be complied with.

Copyright and source acknowledgement notices may not be removed and must be displayed in any copy, derivative work or partial copy which includes the elements in question.

All copyright, and all rights therein, are protected by national and international copyright laws. The above represents a summary only.

For further information please read Frontiers' Conditions for Website

Use and Copyright Statement, and the applicable CC-BY licence.

ISSN 1664-8714

ISBN 978-2-88966-738-3

DOI 10.3389/978-2-88966-738-3

\section{About Frontiers}

Frontiers is more than just an open-access publisher of scholarly articles: it is a pioneering approach to the world of academia, radically improving the way scholarly research is managed. The grand vision of Frontiers is a world where all people have an equal opportunity to seek, share and generate knowledge. Frontiers provides immediate and permanent online open access to all its publications, but this alone is not enough to realize our grand goals.

\section{Frontiers Journal Series}

The Frontiers Journal Series is a multi-tier and interdisciplinary set of open-access, online journals, promising a paradigm shift from the current review, selection and dissemination processes in academic publishing. All Frontiers journals are driven by researchers for researchers; therefore, they constitute a service to the scholarly community. At the same time, the Frontiers Journal Series operates on a revolutionary invention, the tiered publishing system, initially addressing specific communities of scholars, and gradually climbing up to broader public understanding, thus serving the interests of the lay society, too.

\section{Dedication to Quality}

Each Frontiers article is a landmark of the highest quality, thanks to genuinely collaborative interactions between authors and review editors, who include some of the world's best academicians. Research must be certified by peers before entering a stream of knowledge that may eventually reach the public - and shape society; therefore, Frontiers only applies the most rigorous and unbiased reviews.

Frontiers revolutionizes research publishing by freely delivering the most outstanding research, evaluated with no bias from both the academic and social point of view. By applying the most advanced information technologies, Frontiers is catapulting scholarly publishing into a new generation.

\section{What are Frontiers Research Topics?}

Frontiers Research Topics are very popular trademarks of the Frontiers Journals Series: they are collections of at least ten articles, all centered on a particular subject. With their unique mix of varied contributions from Original Research to Review Articles, Frontiers Research Topics unify the most influential researchers, the latest key findings and historical advances in a hot research area! Find out more on how to host your own Frontiers Research Topic or contribute to one as an author by contacting the Frontiers Editorial Office: frontiersin.org/about/contact 


\section{NON-STANDARD WORK, SELF-EMPLOYMENT AND PRECARIOUSNESS}

Topic Editors:

Valeria Pulignano, KU Leuven, Belgium

Annalisa Murgia, University of Milan, Italy

Emiliana Armano, University of Milan, Italy

Marco Briziarelli, University of New Mexico, United States

Citation: Pulignano, V., Murgia, A., Armano, E., Briziarelli, M., eds. (2021).

Non-Standard Work, Self-Employment and Precariousness.

Lausanne: Frontiers Media SA. doi: 10.3389/978-2-88966-738-3 


\section{Table of Contents}

04 Editorial: Non-Standard Work, Self-Employment and Precariousness Valeria Pulignano, Annalisa Murgia, Emiliana Armano and Marco Briziarelli

06 The Hidden Hand of Domestic Labor: Domestic Employers' Work Practices in Chicago, USA

Carolina Sternberg

12 Gender Inequality in Precarious Academic Work: Female Adjunct Professors in Italy Gianluca De Angelis and Barbara Grüning

30 Corrigendum: Gender Inequality in Precarious Academic Work: Female Adjunct Professors in Italy

Gianluca De Angelis and Barbara Grüning

32 Hybrid Areas of Work Between Employment and Self-Employment: Emerging Challenges and Future Research Directions Annalisa Murgia, Rossella Bozzon, Pierluigi Digennaro, Petr Mezihorak, Mathilde Mondon-Navazo and Paolo Borghi

40 Platforms of Work, Labour, and Employment Relationship: The Grey Zones of a Digital Governance

Patrick Dieuaide and Christian Azaïs

54 Precarization via Digitalization? Work Arrangements in the On-Demand Platform Economy in Hungary and Slovakia

Marta Kahancová, Tibor T. Meszmann and Mária Sedláková

65 Anthropomorphic Capital and Commonwealth Value

Andrea Fumagalli and Cristina Morini

78 Emerging Forms of Precariousness Related to Autonomy at Work: Toward an Empirical Typology

Louis Florin and François Pichault

92 A "Hijacked Salaried Status" in French Cooperatives of Freelance Workers: The Political Meaning of Shifts Between Standard and Non-standard Employment

Flora Bajard 


\title{
Editorial: Non-Standard Work, Self-Employment and Precariousness
}

\author{
Valeria Pulignano ${ }^{1 *}$, Annalisa Murgia ${ }^{2}$, Emiliana Armano $^{2}$ and Marco Briziarelli ${ }^{3}$ \\ ${ }^{1}$ KU Leuven, Leuven, Belgium, ${ }^{2}$ Department of Social and Political Sciences, University of Milan, Milan, Italy, ${ }^{3}$ University of \\ New Mexico, Albuquerque, NM, United States
}

Keywords: non-standard work, self-employment, subjectivities, precariousness, social exclusion, hybrid areas of work, social protection

\section{Editorial on the Research Topic}

\section{Non-Standard Work, Self-Employment and Precariousness}

The increased level of insecurity in labor markets has generated much debate on precarious work arrangements-from illegal and temporary work to home working, piecework, freelancing, and online jobs-based on the assumption that the ongoing deregulation and transition to flexible labor markets incur higher risks for the labor force (Eichhorst and Marx, 2015; Pulignano, 2018).

OPEN ACCESS

Edited by:

Magdalena Leszko,

University of Szczecin, Poland

Reviewed by:

Shiona Chillas,

University of St. Andrews,

United Kingdom

*Correspondence:

Valeria Pulignano

valeria.pulignano@kuleuven.be

Specialty section:

This article was submitted to Work, Employment and Organizations,

a section of the journal

Frontiers in Sociology

Received: 26 May 2020

Accepted: 20 July 2020

Published: 15 March 2021

Citation:

Pulignano V, Murgia A, Armano E and Briziarelli M (2021) Editorial:

Non-Standard Work, Self-Employment

and Precariousness.

Front. Sociol. 5:63

doi: $10.3389 /$ fsoc. 2020.00063
Situations of precariousness are measured by the extent to which the emerging work arrangements impact on the stability of employment and the access to social protections (Kalleberg, 2018). With the aim to analyze the social consequences of labor market flexibilization, and to gain better understanding of non-standard work arrangements (Bosch, 2004), more attention is needed on the heterogeneous labor market statuses and types of contracts that are different from what has so far been considered a standard employment relationship. Labor market transformations over time have in fact blurred the differences between the main categories traditionally used to interpret work and employment, eroding the usefulness of concepts such as "standard" and "non-standard" and even blurring the distinction between the statuses of self-employed workers and waged employee.

The proliferating of new and old risks for workers with non-standard forms of employment, including those in a hybrid position between autonomous and dependent work, poses relevant questions for those who are interested in labor market transformations: What are the relations between non-standard and hybrid forms of employment and situations of precarious work? How these work arrangements differ across national contexts in terms of employment protection and workers' rights? What are the main differences and similarities in terms of class, migrant status, gender and age? How are work identities constructed to create new and hybrid types of workers? Under what conditions are these workers able to develop forms of collective representation? How can the collective representation and practices of organizing be articulated, and how do they manage to be widespread and effective?

The goal of this Research Topic is to share innovative theoretical and methodological lenses able to deconstruct what we still call - by difference — "non-standard" or "a-typical" work. In fact, although criticized by many, the current definitions are still anchored in the categories created ad hoc to interpret the Fordist model. To define the emerging work arrangements, and to understand to what extent they produce situations of precariousness, innovative approaches are required, that can only be built through the dialogue between different theoretical and methodological perspectives, able to grasp the 
Pulignano et al.

Editorial: Non-Standard Work, Self-Employment and Precariousness

new forms of work and employment and the connected risks of precariousness and social exclusion.

AUTHOR CONTRIBUTIONS

All authors listed have made a substantial, direct and intellectual contribution to the work, and approved it for publication.

REFERENCES

Bosch, G. (2004). Towards a new standard employment relationship in Western Europe. Br. J. Indus. Relate. 42, 617-636. doa: 10.1111/j.1467-8543.2004.00333.x

Eichhorst, W., and Marx, P. (eds.). (2015). Non-Standard Employment in PostIndustrial Labour Markets. Cheltenham: Edward Elgar.

Kalleberg, A. (2018). Precarious Lives: Job Insecurity and Well-Being in Rich Democracies. London: Polity Press.

Pulignano, V. (2018). "Precarious work, regime of competition and the case of Europe," in Precarious Work, eds A. L. Kalleberg and S. P. Vallas (Bingley: Emerald Publishing), 33-60.
FUNDING

The analysis was partially conducted within the SHARE - Seizing the Hybrid Areas of Work by Representing Self-Employment research project (Grant Agreement no. 715950), funded by the European Research Council as part of the European Union Horizon 2020 research and innovation programme.

Conflict of Interest: The authors declare that the research was conducted in the absence of any commercial or financial relationships that could be construed as a potential conflict of interest.

Copyright (c) 2021 Pulignano, Murcia, Armano and Briziarelli. This is an open-access article distributed under the terms of the Creative Commons Attribution License (CC $B Y$ ). The use, distribution or reproduction in other forums is permitted, provided the original author (s) and the copyright owner (s) are credited and that the original publication in this journal is cited, in accordance with accepted academic practice. No use, distribution or reproduction is permitted which does not comply with these terms.

Frontiers in Sociology | www.frontiersin.org

5

March 2021 | Volume 5 | Article 63 


\section{OPEN ACCESS}

Edited by:

Annalisa Murgia,

University of Milan, Italy

Reviewed by:

Marti Lopez,

University of Leicester,

United Kingdom

Raffaella Sarti,

University of Urbino Carlo Bo, Italy

*Correspondence:

Carolina Sternberg

csternb1@depaul.edu

Specialty section:

This article was submitted to

Work, Employment and Organizations,

a section of the journal

Frontiers in Sociology

Received: 30 May 2019 Accepted: 21 November 2019

Published: 11 December 2019

Citation:

Sternberg C (2019) The Hidden Hand of Domestic Labor: Domestic Employers' Work Practices in

Chicago, USA. Front. Sociol. 4:80 doi: 10.3389/fsoc.2019.00080

\section{The Hidden Hand of Domestic Labor: Domestic Employers' Work Practices in Chicago, USA}

\author{
Carolina Sternberg * \\ Department of Latin American and Latino Studies, DePaul University, Chicago, IL, United States
}

An emergent body of scholarly work exists regarding the manifold dimensions and implications of domestic work, scholarship which draws from various standpoints and discipline traditions. Much existing literature deals specifically with the devaluation of domestic labor. A recent survey conducted in 14 metropolitan areas in the U.S. found that the domestic work industry is profoundly ethnocentric, gendered and racialized, with $23 \%$ of domestic workers earning below their state's mandated minimum wage. In 42 states, it is legal to pay domestic workers below minimum wage, since they are explicitly excluded from the protections of key federal labor laws and standards. In addition, many studies have repeatedly denounced the persistent gendered division of labor in the industry, and in particular have raised concerns about the disproportionate number of women of color in this occupation. Finally, given the private nature of domestic work and the unprotected conditions workers face, studies have pointed to the frequent hostile or even abusive relationships that employers have with their employees. Despite the wealth of research on domestic labor, relatively few studies conducted in the US have focused on the practices of domestic employers. There is also a dearth of research on domestic employment located specifically in the Midwest. The lacuna in this research motivated us to conduct a preliminary study on Midwestern employers' practices, in particular in Chicago and the surrounding suburbs. We argue that overlooking domestic employers' work practices prevents us from tackling the situations of abuse and disrespect that so frequently occur in this particular work environment.

Keywords: domestic workers, informal economy, employers, Latinx population, Chicago

\section{INTRODUCTION}

An emergent body of scholarly work exists regarding the manifold dimensions and implications of domestic work, scholarship which draws from various standpoints and discipline traditions (Burnham and Theodore, 2012; Rosenbaum, 2017). Existing literature deals specifically with the devaluation of domestic labor. A relatively recent survey conducted in 14 metropolitan areas in the U.S. found that the domestic work industry is profoundly ethnocentric, gendered and racialized ${ }^{1}$, with $23 \%$ of domestic workers earning below their state's mandated minimum wage (Burnham and Theodore, 2012, p. 3-33). In 42 states, it is legal to pay domestic workers below minimum wage, since they are explicitly excluded from the protections of key federal labor laws and standards

\footnotetext{
${ }^{1}$ According to this study, for example, U.S. white nannies in 2011 earned 30\% more than other racial/ethnic groups, in
} particular Latina. 
(e.g., bargaining laws, anti-discrimination laws, occupational safety and health, etc.). In addition, many studies have repeatedly denounced the persistent gendered division of labor in the industry, and in particular have raised concerns about the disproportionate number of women of color in this occupation (Metha, 2002; Hart, unpublished). Finally, given the private nature of domestic work and the unprotected conditions workers face, studies have pointed to the frequent hostile or even abusive relationships that employers have with their employees (Hondagneu-Sotelo, 2001, 2004; Hart, unpublished).

Despite the wealth of research on domestic labor, relatively few studies conducted in the US have focused on the practices of domestic employers (Tucker, 1987; Hondagneu-Sotelo, 1997; Young, 2010; Rosenbaum, 2014). In particular, these studies have pointed out that employers of domestic workers refuse to see themselves as employers and they have very little knowledge of, or rely on different rationalizations and sense of self-righteousness, to ignore state regulations governing their obligations as employers, e.g., paying federal taxes, social security, and medicare (Hondagneu-Sotelo, 1997; Young, 2010). Other studies have emphasized that domestic workers' working conditions are deeply shaped by a complex entanglement of racial relationships (Tucker, 1987; Burnham and Theodore, 2012). Following this last aspect, one of the authors notes that employers in Los Angeles characterize domestic workers as "forever foreign, intrinsically inassimilable (...)" (Rosenbaum, 2014, p. 138). Although the above studies have been remarkably influential, there is a dearth of research on domestic employment located specifically in the Midwest. The lacuna in this research motivated us to conduct a preliminary study on Midwestern employers' work practices. We argue that overlooking domestic employers' work practices prevents us from tackling the situations of abuse and disrespect that so frequently occur in this particular work environment.

Our current study explores domestic employers' work practices in Chicago and the surrounding suburbs. The research questions asked were later used to conduct a survey within DePaul community, the institution where am I currently employed. These questions were formulated upon drawing from the literature review discussed with my research assistant and from the information and handouts compiled from the US domestic employer network, Hand in Hand (Hand in Hand, 2019). The research questions were later discussed and slightly refined in one of my class sessions of my undergraduate course: "Domestic Workers Economy in the US and Beyond", offered in January 2018. The following are the questions asked to the participants:

- What are the general demographics of domestic employers?

- What sorts of workers do domestic employers employ?

- What benefits and wages do employers offer their employees?

- What employment-related difficulties do employers encounter?

- What types of resources may be useful in fostering a better work environment for both the domestic employer and their employee(s)?

After collecting the results of the survey, students were also involved in discussing them and offering some conclusions that are included in this report.

\section{METHODS}

We decided to conduct this study using mixed methods in data collection, data analysis and interpretation of the evidence. Purposeful data integration enables researchers to seek a more panoramic view of their research landscape, viewing phenomena from different viewpoints and through diverse research lenses. Thus, this study uses quantitative data to explore domestic employers' work practices in Chicago and the surrounding suburbs. In addition, qualitative data were collected to gain insight into, (a) the different situations employers face when working with a domestic worker and, (b) reflect on their own practices.

We selected DePaul's staff and faculty, between 18 or older, as our sample for recruitment and who had been domestic employers within the past 5 years or were employing domestic help at the time the survey was administered. Research data collected in the survey and in the pre-screening (explained below) remained completely anonymous and the decision whether or not to be in the research did not affect participant's grades, status, or employment at DePaul University. For the purpose of this study we defined domestic employer as someone who is currently hiring or have hired someone in her/his home to clean, cook, assist, or care for members of the household within the past 5 years.

Before we distributed the survey on-line (from midNovember 2017 through late January 2018), we administered a pre-screening of DePaul faculty and staff. The pre-screening consisted of a very short email delivered to all DePaul faculty and staff $(\sim 2,600$ employees) asking whether they were currently employing domestic help or they had done it sometime in the past 5 years. This allowed us to target directly the population that employs domestic help. Ultimately, the pre-screening survey identified 143 domestic employers on campus. Following the pre-screening, an email with a link to the actual survey was sent to the targeted population. In the end, we collected 63 surveys from mid-January to early February 2018. The information collected from the surveys was completely anonymous.

The surveys consisted of eight questions that asked participants about their common work practices as employers of domestic workers (e.g., type of worker, average hourly wage, existence of contract or written agreement between the employer and employee, benefits received, resources needed). We also collected some personal information about the participants, such as gender, age, income, and whether participants live in Chicago or Chicago suburbs to be able to identify some demographic patterns.

At the end of the survey we included a paragraph inviting respondents to participate in a focus group in order to share work experiences, identify positive and negative scenarios, and share best work practices among employers. We discuss this aspect further in the section "focus group analysis."

\section{ANALYSIS}

Respondents were predominantly female (58.7\%) and between 35 and 64 years old. Nearly $70 \%$ (69.8\%, total 44$)$ of the respondents 
TABLE 1 | Types of workers specified by survey and by respondent.

\begin{tabular}{lcc}
\hline Type of worker & Frequency & Percentage of sample \\
\hline SPECIFIED BY SURVEY & 5 & \\
Full-time childcare provider & 8 & 7.9 \\
Part-time childcare provider & 22 & 12.7 \\
Housekeeper & 1 & 34.9 \\
Full-time senior attendant & 2 & 1.6 \\
Part-time senior attendant & 0 & 3.2 \\
Full-time home attendant & 1 & 0 \\
Part-time home attendant & & 1.6 \\
SPECIFIED BY RESPONDENT & 1 & \\
Au Pair & 8 & 1.6 \\
Cleaning lady/service & 1 & 12.7 \\
Dog-walker & 2 & 1.6 \\
Babysitter & 12 & 3.2 \\
Undisclosed & & 19 \\
\hline
\end{tabular}

reported having a household income above $\$ 100,000$, while 13 decided not to answer this question. Respondents were also more likely to live in Chicago vs. the suburbs (50.6\%).

\section{Types of Workers}

Respondents identified a wide range of types of workers they employed in their household (Table 1). More than 34\% of the respondents reported employing a housekeeper and nearly $13 \%$ indicated that they have employed a part-time childcare provider. Twelve respondents chose the "Other" response and specified a type of worker not listed on the survey. However, some of these respondents' answers were actually already included in the categories listed. For example, babysitters are included under the label "childcare provider." All participants' responses are summarized below.

\section{Written Contracts and Benefits}

We also assessed whether employers provided their employees with a contract and/or benefits as domestic employee compensation is inconsistent due to the unregulated nature of this work. Respondents indicated they offered highly variable wages to their employees, with benefits being even more variable. As illustrated in Table 2, the majority of employers who responded to this question did not provide employees with written contracts or benefits such as overtime pay, sick days, parental leave, or medical leave. However, in some instances benefits may not have been applicable to the employers' unique situations. For example, 36 respondents (57.1\% of the sample) said they did not need to offer overtime pay to their employees, as their employees never worked more than $40 \mathrm{~h}$ per week. The chart below shows the frequency of respondents' indication that they did provide the benefit in question.

\section{Wages}

At the time the survey instrument was created, minimum wage in Chicago was $\$ 11.00 / \mathrm{h}$. No standard minimum wage exists for the surrounding suburbs. More than half of the respondents
TABLE 2 | Written contracts and benefits received by employees.

\begin{tabular}{lcc}
\hline Benefits & $\begin{array}{c}\text { Frequency (employees } \\
\text { providing the benefit) }\end{array}$ & Percentage \\
\hline Written contract/agreement & 8 & 12.7 \\
Overtime pay & 2 & 3.2 \\
Sick days & 12 & 19 \\
Parental leave & 4 & 6.3 \\
Medical leave & 6 & 9.5 \\
Undisclosed & 31 & 49 \\
\hline
\end{tabular}

TABLE 3 | Hourly payment.

\begin{tabular}{lcc}
\hline Wage & Frequency & Percent \\
\hline$<\$ 11.00$ & 2 & 3.2 \\
$\$ 11-13$ & 1 & 1.6 \\
$\$ 14-16$ & 8 & 12.7 \\
$\$ 17-19$ & 11 & 17.5 \\
$\$ 20+$ & 21 & 33.3 \\
Undisclosed & 20 & 31.7
\end{tabular}

TABLE 4 | Difficulties experienced in offering benefits or living wages to employees.

Reason

Frequency Percent

I don't have enough information about what to do

$2 \quad 3.2$

It's uncomfortable to discuss these things with my employee

$4 \quad 6.3$

I can't afford to pay a living wage

$3 \quad 4.8$

My employee doesn't want an agreement/contract

Other

Undisclosed

$15 \quad 23.8$

$30 \quad 48$

reported paying their employees above the minimum wage in Chicago, with a full third of the sample paying nearly double the minimum wage (Table 3). Unfortunately, nearly another third of respondents did not respond to the question, which was the highest non-response rate of any question in the nondemographic portion of the survey.

\section{Difficulties in the Workplace}

Respondents were asked to indicate whether they had experienced certain difficulties in offering benefits or living wages to their employees (Table 4). The survey offered a range of difficulties respondents could "check" that they had experienced, as well as an "other" option with a text entry box for respondents to indicate other difficulties not listed. Their responses are summarized below:

Of respondents who chose the "other" option, nine (60\%) commented that they weren't sure what sorts of benefits or wages should be offered an employee who works for them only sporadically/occasionally, or that they did not believe benefits needed to be offered at all in such cases. This was especially true if the employee was contracted by an agency. Examples of such comments were: 
TABLE 5 | Resources for employers.

\begin{tabular}{lcc}
\hline Resource & Frequency & Percent \\
\hline Templates of working agreements & 8 & 12.7 \\
A conversation guide for difficult conversations & 4 & 6.3 \\
A guide about relevant state and federal laws & 12 & 19.0 \\
A checklist listing what you should ideally provide an & 12 & 19.0 \\
employee & & 17.5 \\
A report on the benefits others in your area provide & 11 & \\
employees & & 9.5 \\
Other & 6 & 16 \\
Undisclosed & 10 & \\
\hline
\end{tabular}

- "I pay a service for light housekeeping on a biweekly basis. The service sometimes sends [sic] 2, 3, or 4 people to clean; I pay the same amount each time. I do not know what the workers' hourly rate of pay is."

- "The conversation and finances get complicated with overtime, it's easier to agree on set hours (50 in my case) and a straight hourly rate. Hours above this are at employees [sic] discretion and at a different rate. I pay a living wage, but there's not enough flexibility in what the law prescribes."

- In general, "I pay per job when in terms of housekeeping. [F]or the childcare I do pay more than a minimum wage."

- "This is pay-per-visit work."

- "We are less formal. Childcare providers end up getting 5 weeks + off per year, but we do not count the days like at an office job. We always say yes when she needs time for medical, family, etc., and she does not abuse that."

\section{Resources for Employers}

In the interest of providing domestic employers with resources to guide their employment habits, we asked respondents to select a list of resources that could be useful in navigating workplace situations. Respondents were also able to specify other resources they felt would be useful via text entry (Table 5).

Of the six respondents who specified "other," three indicated none of the above resources would be useful without providing other context. The other responses were as follows:

- "If I were to employ anyone full-time, I would want all of the above except 'difficult conversations'."

- " $[\mathrm{N}]$ one because the agency does this."

Although the answers were succinct and did not provide a great deal of information, the first comment highlights the possibility that employers may be more open to resources if they employed full-time workers. The second comment suggests that employers who contract their workers from an agency may not need the same resources as those who find their workers elsewhere.

\section{Focus Group Analysis}

After collecting the survey data, the next step in this study was to conduct a focus group to further understand domestic employers' work practices. This activity was created for employers to share work experiences when employing domestic workers, identify positive and negative scenarios, and share best work practices among them. In terms of our study, the focus group was geared toward developing a more thorough understanding of the situations employers face when working with a domestic worker and reflect on his or her own practices.

Unfortunately, recruiting DePaul employers for the focus group failed. The close relationship between my role as a researcher and the subject being studied, i.e., both employers and myself work in the same institution, may have discouraged many employers to reveal information they are not comfortable sharing in a focus group. We instead attended a 90 minworkshop on domestic employment organized by "Hand in Hand," a US domestic employer network founded in 2010 by a group of domestic employers and their allies. This workshop had very similar purposes and objectives to the focus group we originally designed, given the fact that we closely followed the past experiences of Hand in Hand in developing workshops of this nature, topic and population. In any case, the Hand in Hand workshop was developed independently from our research and outside the DePaul community; however, we felt it was an interesting opportunity to supplement and integrate with our survey results and further advance our research. The facilitator of this workshop, a young woman in her early 30 s working as a teacher and caregiver was in charge of recruiting participants for this workshop. Roughly seven women in their 20-30 s attended the workshop, including the workshop facilitator. The majority of the participants were expecting a baby or already had young children at home.

\section{Concerns Raised}

Most of the concerns raised by attendees revolved around fair pay. Attendees repeatedly noted that they were unsure how to negotiate wages with employees and were also unaware of resources that could aid such conversations. Questions were also raised regarding overtime pay, vacation time, and sick days. The attendees stressed that they wanted to pay their employees fairly but were struggling to balance this desire with their complex financial situations.

Attendees also stated that they were unsure how to communicate with employees, both in terms of frequency of communication and the level of familiarity. One attendee stated that it was difficult for her to address concerns with her employee without sounding hostile or accusatory. Based on these remarks, the group explored the complexities of treating employees with warmth and friendliness while still maintaining a professional relationship. The workshop facilitator recalled an instance in which a domestic employer confessed to her, "Our employee is like family-so I hope she doesn't ask for a raise!" The facilitator used this example to show that becoming overly familiar with one's employee could lead to a lack of professionalism in the relationship, and further implied that it could result in wage theft or abuse.

\section{Strategies Discussed}

The workshop facilitator later shared strategies and ideas for resolving each issue. Guidance was offered regarding the following topics: 
a) Work agreements: Employers and employees should work collaboratively crafting work agreements, with both parties agreeing to and initialing each portion. Additionally, it is helpful for the employer and employee to have a trial period after the initial contract is drafted; then, based on this trial period, the original contract may be revised with further clarifications.

b) Fair pay: Domestic workers should receive guaranteed income, even during periods in which an employer does not require the worker as often. For instance, if an employer stays at home for a week and does not require their worker's fulltime help during that time, the employer must recognize that the employee still needs that week's income.

c) Communication: There should be transparency and regular communication between the employer and employee. Regular check-ins, even as often as once a week, are crucial to establishing trust.

\section{FINAL REMARKS}

We recognize that the sample size we used for our survey, 63 participants, was smaller than anticipated. However, as a reminder, this size was obtained after the pre-screening and the survey were administered. Given these constraints, we understand that the results obtained may be skewing the central observations offered below.

Scholars, activists, and practitioners who are involved in the industry of care work, would largely agree that the relationship between employers and employees is complex due to the nature of this type of work. Across the global North and South, domestic workers usually perform their work in a non-traditional workplace and behind closed doors, their work is widely unregulated, and has been historically devalued. Ultimately, all these aspects combined constitute strong limitations for improving their working conditions.

In the US, it was not until 2010 that domestic workers slowly began to gain more recognition and rights as a work force. The first Bill of Rights for Domestic Workers was passed in NY, followed by California, Hawaii, Connecticut, Oregon, Nevada, and Massachusetts. Recently, Illinois became the 8th state to pass a comprehensive Bill of Rights on January 1st, 2017 and the city of Seattle on July 23rd, 2018. This bill ensures that domestic workers receive minimum wage, protections against sexual harassment, and the right to 1 day off if they work for more than $20 \mathrm{~h}$ for an employer. However, it will take some time for this new legislation to be enforced.

Drawing on the literature presented above and our preliminary study based in Chicago, we suggest that employers need to understand that domestic work is real work, and be informed about domestic workers' rights, benefits and compensation. As stated previously, the stigmatized and unregulated nature of this work may render employers unaware of best work practices. Secondly, despite the fact that "domestic work is work" explicitly stated in the 2011 ILO convention no. 189, in many cases employers neither formally recognize domestic workers as legitimate "workers," nor do they recognize themselves as employers (Hondagneu-Sotelo, 1997). Finally, there is a general perception among employers that he/she has special constitutional protections in a household setting compared to more traditional workplace settings where federal and state regulations do not fully apply (Young, 2010).

From our preliminary study, it follows that there seems to be no recognition on the part of either party that the employee is performing their duties in a professional workplace, even if it is also someone's home.

In other words, the legal and professional relationship between employer and employee becomes blurred because neither party recognizes the household as the worker's formal work environment. Thus, in order to establish a mutually constructive and beneficial relationship between employer and employee, and to ensure a good work environment and fair conditions for domestic workers, legitimizing this form of labor is essential.

\section{SUCCESSES AND CHALLENGES}

We would like to thank the employers who participated in this study, the BRI fellowship and the Women's and Gender Studies Department (WGS) for supporting this research.

We recognize that the sample size we used for our survey, while adequate, was smaller than anticipated. In addition, employers were very selective in the type and extent of information they disclosed. We recognize the implications and bias of distributing a survey within our own university. The reasons that motivated us to do so were two-fold: (a) Faculty members had already conducted surveys to DePaul's faculty, students, and/or staff on diverse and sensitive topics; these suggested a diversity of interests, concerns and commitment to conducting critical research; (b) DePaul University is committed to promoting diversity, social justice and community engagement among its core values. Our study advocates for social justice in terms of bringing more awareness about best work practices among employers of domestic workers and helping promote public policies that bring respect to domestic workers in each and all of our communities.

Finally, we will consider other populations and ways for recruiting employers for a focus group outside of the university in the future.

\section{SCHOLARLY PRODUCTS DERIVED/DERIVING FROM THIS PROJECT}

This study enhances existing literature on domestic labor, particularly with regards to domestic employers. Yet further research and action is needed to document the complexities of the employer-employee work relationship. This research should:

a) Systematically examine and document the working relationship and practices that employers maintain with domestic workers.

b) Share this information with workers' centers, activists, practitioners, and policy makers that work together to 
improve workers' protections and to reinforce recently available legislation on worker's protections.

c) Share this information with employers, to be better informed about the type of work that domestic workers do as well as their rights, and to encourage them to follow best work practices.

\section{DATA AVAILABILITY STATEMENT}

The datasets generated for this study are available upon request to the corresponding author.

\section{ETHICS STATEMENT}

The studies involving human participants were reviewed and approved by IRB DePaul University. The patients/participants provided their written informed consent to participate in this study.

\section{REFERENCES}

Burnham, L., and Theodore, N. (2012). Home Economics: The Invisible and Unregulated World of Domestic Work. New York, NY: National Domestic Workers Alliance. Available online at: https://community-wealth.org/content/ home-economics-invisible-and-unregulated-world-domestic-work (accessed May 29, 2019).

Hand in Hand (2019). Resources and FAQ. Available online at: https:// domesticemployers.org/resources-and-faqs/resources-regular-evaluation/ (accessed August 16, 2019).

Hondagneu-Sotelo, P. (1997). Affluent players in the informal economy: employers of paid domestic workers. Int. J. Sociol. Soc. Policy 17, 130-158. doi: 10.1108/eb013303

Hondagneu-Sotelo, P. (2001). Doméstica: Immigrant Workers Cleaning and Caring in the Shadows of Affluence. Berkeley, CA; Los Angeles, CA: University of California Press.

Hondagneu-Sotelo, P. (2004). "Blowups and other unhappy endings," in Global Woman: Nannies, Maids, and Sex Workers in the New Economy, eds B. Ehrenreich and A. R. Hochschild (New York, NY: Metropolitan Books), 55-69.

Metha, C. (2002). Chicago's Undocumented Immigrants: An Analysis of Wages, Working Conditions, and Economic Contributions. Center for Urban Economic Development, University of Illinois at Chicago.

\section{AUTHOR CONTRIBUTIONS}

CS contributed in the conception and design of this study and wrote and revised the entire manuscript.

\section{FUNDING}

This research was supported by the Beck Research Initiative for Women, Gender and Community Faculty Fellowship (BRI) for 2017-2018. This Fellowship is housed in the Women's and Gender Studies Department at DePaul University, Chicago, USA.

\section{ACKNOWLEDGMENTS}

I would specially like to thank Jax Witzig for organizing the database, performing the statistical analysis of this study and editing sections of this study.

Rosenbaum, S. (2014). "Domestic disturbances: immigrant workers, middleclass employers, and the American dream in Los Angeles," in When Care Work Goes Global: Locating the Social Relations of Domestic Work, eds M. Romero, V. Preston, and W. Giles (Ashgate: Routledge), 129-138.

Rosenbaum, S. (2017). Domestic Economies. Durham: Duke University Press.

Tucker, S. (1987). A complex bond: southern black domestic workers and their white employers. Front. J. Women Stud. 9, 6-13.

Young, D. E. (2010). The constitutional parameters of new york state's domestic workers bill of rights: balancing the rights of workers and employers. Albany Law Rev. 74, 1769-1788.

Conflict of Interest: The author declares that the research was conducted in the absence of any commercial or financial relationships that could be construed as a potential conflict of interest.

Copyright (c) 2019 Sternberg. This is an open-access article distributed under the terms of the Creative Commons Attribution License (CC BY). The use, distribution or reproduction in other forums is permitted, provided the original author(s) and the copyright owner(s) are credited and that the original publication in this journal is cited, in accordance with accepted academic practice. No use, distribution or reproduction is permitted which does not comply with these terms. 


\section{OPEN ACCESS}

Edited by: Annalisa Murgia,

University of Milan, Italy

Reviewed by:

Stefania Marino,

University of Manchester,

United Kingdom

Pierre Bataille,

Université Grenoble Alpes, France

*Correspondence:

Gianluca De Angelis

gianluca.deangelis@unibo.it

Barbara Grüning

barbara.gruning@unimib.it

Specialty section:

This article was submitted to Work, Employment and Organizations, a section of the journal

Frontiers in Sociology

Received: 19 June 2019 Accepted: 20 December 2019

Published: 17 January 2020

Citation:

De Angelis G and Grüning B (2020) Gender Inequality in Precarious Academic Work: Female Adjunct Professors in Italy. Front. Sociol. 4:87.

doi: 10.3389/fsoc.2019.00087

\section{Gender Inequality in Precarious Academic Work: Female Adjunct Professors in Italy}

\author{
Gianluca De Angelis ${ }^{1 *}$ and Barbara Grüning ${ }^{2 *}$ \\ ${ }^{1}$ Department of Sociologia e Diritto dell'Economia, University of Bologna, Bologna, Italy, ${ }^{2}$ Department of Sociologia e Ricerca \\ Sociale, University of Milan Bicocca, Milan, Italy
}

International research studies and national reports point out two specific aspects which characterize women's academic careers (cf. Eagly, 2003; Glass and Cook, 2016). First, few women advance to senior academic roles. Second, although female academics progress in numbers equivalent to their male colleagues up to a certain point, in most cases their academic career paths either stop before they arrive at tenured positions or they remain in the lower ranks of the hierarchical academic structure. Thus, while the numeric growth and temporal extension of fixed-term positions has, overall, increased women's opportunities for researching and teaching at universities, on the other hand, it has impeded their access to tenured positions. To better highlight this dynamic, this article focuses on the situation of female adjunct professors in Italy. The interest in adjunct professors is twofold: on the one hand, the social and economic status of adjunct professors in the Italian academic system have worsened over time, from independent to formal independent workers; on the other hand, compared with other non-tenured positions, there are substantially fewer female adjunct professors than male. We first provide an overall picture of the historical and juridical transformations of the rank distribution of faculty in Italian universities from the perspective of gender. As a second step, we compare the actual working conditions of female and male adjunct professors on the basis of a survey carried out from January to October 2018 (5,556 respondents corresponding to more than $20 \%$ of the population) and semi-structured interviews with 31 adjunct professors. The aim of the analysis is to pinpoint objective and subjective gender similarities and differences regarding both socio-economic variables and the ways male and female adjunct professors think about their academic and extra-academic work; how they experience the academic environment between paid and unpaid work, construct their professional/academic identity, and imagine their professional future and perceive problems related to the administration and organization of their academic work.

Keywords: unpaid work, adjunct professor, academic career, gender inequalities, Italy 


\section{INTRODUCTION}

The focus of this article are the working conditions and academic aspirations of female and male adjunct professors (APs), as paradigmatic example of a new form of precarious working conditions in the academia ${ }^{1}$. Thus, in light of the existing studies on the relationship between non-standard work arrangements and social inequalities (cf. Standing, 1989, 2014; Bigi et al., 2015; Krinsky and Simonet, 2019), our main interest is to explore how social gender inequalities are produced and practiced in the Italian academic field (cf. Bourdieu, 1984; Murgia and Poggio, 2018), on the basis of its genesis and social structure. More specifically, by choosing adjunct professors as research object we intend to point out two specific questions concerning the transformation of the Italian academic structure in the last four decades. The first one regards the increasing use of adjunct professors as disguised form of self-employment in the academic system, in front of a progressive public disinvestment in the Italian Universities, especially for teaching activities. The second one regards the low prestige (symbolic capital in Bourdieusian term) of adjunct professors also with respect to other precarious academic positions, such as the research fellows and assistants. Thus, most of the adjunct professors are men. This statistic evidence puts in question the various researches on gender inequalities in Academia, which highlight how the so-called "academic housework" is mainly carried out by women (cf. Heijstra et al., 2017). For examining how gender inequalities are produced in academia, our case study shows us that beyond taking into account the different degree of prestige of the various academic activities, further categories are to consider, inherently to the specific historical and social context under investigation.

Then, to investigate our topic, three theoretical premises are needed.

The first regards the ongoing diffusion of non-standard work arrangements in the intellectual field, i.e., the market of symbolic goods (Bourdieu, 1993). The intellectual field and its specific subfields (for example, the literary, artistic, and academic subfields $)^{2}$ have always been places of economically unstable working conditions. Nevertheless, the progressive institutionalization of these subfields has not only radically transformed the social conditions which reproduce precarious positions, but has also been supported by new discourses and rethorics legitimizing the existence of these conditions. The second premise regards the organizational and cultural changes

\footnotetext{
${ }^{1}$ In Italy, adjunct professor (professori a contratto) is a type of academic appointment in higher education. It is a non-tenure-track position and, by law, APs may have only a 1 year contract, which cannot be renewed. Nevertheless, there is no temporal limit for the number of years an AP can teach at the university. As a result, a conspicuous number of APs who answered to our survey have taught for several years at university, but every year they participate in an academic competition for a position as AP. From a juridical point of view, APs are not employed by universities but are hired as external collaborators.

${ }^{2}$ In this regard, many biographies of well-known artists, academics, and writers which are generally structured on the opposition between the geniality of the individual and their adverse working conditions and destiny until their consecration after death.
}

which have affected higher education in the last three decades as a result of the progressive development of new forms of "academic capitalism" (Slaughter and Rhoades, 2004). For our context, one of the main consequences is the increasing centrality of research activities (and output) for evaluating the efficiency of academic actors (institutes and academics) and increasing academic reputations (cf. Deem and Lucas, 2007; Arimoto, 2015), which has come at the expense, however, of the importance given to teaching activities (Fuller, 2009, p. 25; cf. Lyotard, 1979). Finally, the third premise regards the different impact of precarious working conditions on the career paths of women and men in intellectual professions, by worsening existing disparities in the gender structure of academia (cf. Hirsch and Leppel, 1982; Menges and Exum, 1983; Pool et al., 1997; Blickenstaff, 2005; Fox, 2005; Bataille et al., 2017; Heijstra et al., 2017; Argenvall and Beach, 2018; cf. Murgia and Poggio, 2018).

In light of this framework, our hypothesis is that female APs have more difficulty than male APs in pursuing an academic career. This hypothesis would also explain, why female APs are fewer and younger than male APs, that is they are more disposed to abandon their academic path. For supporting this hypothesis we relate the concept of career as developed by Hughes (1958) with the concepts of (academic) field, habitus, and capitals as developed by Bourdieu $(1979,1984,1986)$.

For what concerns Hughes' concept of career we first considers the distinction he stresses between an objective understanding of career as «a series of states and clearly defined offices》 and a subjective understanding of career as «the moving perspective in which the person sees his life as a whole and interprets the meaning of this various attributes, actions, and the things which happen to him》 (Hughes, 1958, p. 63). With respect to our study the question is twofold. On the one hand, it regards the objective effects which the "de-standardization" of the academic career (Bataille et al., 2017) has on the academic working conditions and structure, as the increasing use of different forms of fixed-terms and non-standard contracts. On the other hand, it regards the different ways of experiencing and interpreting the "de-standardization" processes of the academic career by different social groups, i.e., in our case the female and men APs. As Hughes underlines, the career is «by no means exhausted in a series of business and professional achievements. There are other points at which one's life touches the social order, other lines of social accomplishment-influence, responsibility, and recognition》 (Hughes, 1958, p. 64). The latter statement highlights how in the academia there are different (socio-spatial) degrees of "social order" referring either to the workplace(s) or to the wider local academic community or to the (national and international) disciplinary community. Thus, the position an adjunct professor occupies within these social orders depends not only on his/her official tasks and duties, but also on the content and form of his/her social relationships in the different professional settings and networks. In other words, following Bourdieu, we may argue that the position APs occupy within the academic field (in its different socio-spatial dimensions aforementioned) depends not only on their contracts (i.e., as indicative of their economic capital) and academic qualifications 
(scholastic cultural capital, cf. Bourdieu, 1986), but also on their social capital.

The social capital one possesses-which is indicator of the integration in both the everyday life activities of the specific institute and in the broader (inter)disciplinary scientific community-influences in turn the ways of perceiving own position and image own trajectory in the field itself. Not least it influences the building of a specific academic habitus, which vice versa, influences the ways of acting, interacting and building social relationships. Furthermore, in the case of the APs it is to consider that their economic and symbolic capitals depend also on the gain and prestige of their extra-academic activities. The sum and entanglement of these factors conditions the time perception and time budget of the APs. As Heijstra et al. (2017) have already noticed, time is a crucial resource for cumulating academic capital and also one of the reason of the gap between female and male academics. We can then consider time as a resource in two ways. First, time is needed for carrying out and conciliating different professional and academic activities in the everyday life. Second, time is needed for transforming one form of capital (cf. Bourdieu, 1986), in particular the economic one, in other forms of capital, i.e., the social and the scientific ones. In other words, the economic safety provides the condition for thinking long-term strategies, for cultivating social relationships and publishing. This entails, not least, to consider how the different "contingencies of a career" (Hughes, 1958, p. 130) influences also the capability of projecting oneself in the future, predicting about the course of the events, and taking crucial decision (Hughes, 1958, p. 28-29). In Bourdieusian terms, the contingencies of a career influence the way the academic habitus, the «structuring structure, which organizes practices and the perception of practices $\gg$ (Bourdieu, 1979, 1984, p. 170) is built by female and male APs.

Summing up, through the analysis of the empirical data, we will argue that in Academia gender inequalities are a field effect, depending on the different economic, cultural and social resources male and female academics possess for constructing their own strategies both in their everyday life and for the future.

In what follows, we first discuss how, nowadays, discourses around the importance of "subjectivity" in the new labor market represent a new source for legitimating non-standard work arrangements, especially in those sectors which are either traditionally closer to women's working activities (cf., Fürth, 1906; Weber, 1913) or related to intellectual activities. As a second step, we sketch the main transformations of the Italian academic structure over the last four decades, in light of two international trends: (1) the increasing separation of teaching and research in the organization of academic life, with consequences on the structuring of the academic paths of individuals aspiring to academic careers; (2) the increasing weight of a "technical control" over the academic work (Miller, 1995) within universities that follows the logic of the private market.

Within this frame, we will try to better highlight the different academic career paths of women and men in Italy from a longitudinal perspective. In this regard, the fourth and fifth sections are devoted to the analysis of our empirical data on APs in Italy. Thus, on the basis of a survey carried out from January to October 2018 (5,556 respondents corresponding to more than $20 \%$ of the population) and semi-structured interviews with 31 APs, we will compare the actual working conditions and aspirations of female and male APs. The aim of the analysis is to pinpoint objective and subjective gender similarities and differences regarding both socio-economic variables and the ways male and female APs think about their academic and extra-academic work; how they experience the academic environment, moving between paid and unpaid work, construct their professional/academic identity, imagine their professional future, and perceive problems related to the administration and organization of their academic work.

\section{SUBJECTIVITIES AT STAKE: THE OTHER SIDE OF NON-STANDARD WORK}

The diffusion of non-standard work arrangements provides a key perspective for understanding the ongoing transformations in the labor market; however, attempting to catch these transformations through statistical observations risks losing communicative effectiveness because people tend to have difficulty recognizing the peculiarities of their own working conditions in terms of the categories defined by the researchers, which necessarily objectify not only the working conditions but also the subjective dimension of the working experience. Taking this question into account can be crucial not only in investigations for scientific purposes but also in inquiries moved by a pragmatic worldview which aim at influencing the orientation of either specific policies (i.e., active employment policies) or trade union campaigns.

Various scholars have observed how, when analyzing statistical indicators, researchers tend more to construct than describe the reality under investigation (Desrosières, 2010, 2011). In particular, Robert Salais claims that when researchers use a table to represent data, they adopt specific conventions of equivalence which determine what can be considered as similar (Salais, 2009, p. 118). When we consider, for example, the employment rate, we look at all the people who have a job in a certain timespan. But to what extent can we assume that people in similar positions in the labor market feel that they share the same conditions? With respect to the distinction between "employed" or "unemployed," these people have a different status, but we do not know anything about an employed person's job, whether, for instance, it is a part-time or low-wage job which could make his or her life more similar to the lives of the unemployed. In the current labor market, these questions have become increasingly important since they highlight how the idea of human subjectivity is at the core of both non-standard work arrangements and new working methods.

On the other hand, it would be erroneous to believe that the centrality of human subjectivity in the contemporary labor market is a prerogative of post-Fordism or an effect of the diffusion of non-standard work arrangements. As Gramsci had already argued in the 1930's, one of the pivotal aspects and innovations of the Fordist production system was the "creation" of a new human being (Gramsci, 1978). Indeed, Fordist organization needed reliable workers who were able to 
work without interruption. In this sense, new working methods were introduced which, according to Gramsci, followed "puritan policies" which also applied outside the workplace:

"Puritanical initiatives simply have the purpose of preserving, outside of work, a certain psycho-physical equilibrium which prevents the physio-logical collapse of the worker, exhausted by the new method of production. This equilibrium can only be something purely external and mechanical, but it can become internalized if it is proposed by the worker himself, and not imposed from the outside, if it is proposed by a new form of society, with appropriate and original methods" (Gramsci, 1939).

In this regard, Fordism can be seen as a game whose rules are embodied by players to the extent that they forget that it is a game. This equilibrium is very close to Bourdieu's idea of illusio, defined as «the enchanted relation to a game that is the product of a relation of ontological complicity between mental structures and the objective structures of social space $\gg$ (Bourdieu, 1998, p. 77).

From this point of view, the project of Fordism was ambitious. For a new society based on a specific production regime, a simultaneous effort should involve both the productive sphere, thanks to which the workers earned their wages, and the reproductive (or non-directly-productive) sphere of life, in which the workers and their families spent their wages. According to the dominant discourse, the conditions of most workers were justified by the fact the workers could fulfill themselves outside the production sphere. Clearly, this project was based on an intrinsic gender discrimination. While the men of the Industrial Revolution were the "breadwinners" for their families, women's wages, if present, could not be higher or more significant than a complementary resource (Zelizer, 1997; Bellavitis, 2018) and, «At the same time, women, identified as "nature," were excluded from the "public" space of politics, reserved for men $\gg$ (Bellavitis, 2018, p. 10).

In this regard, we can argue, the bourgeois ideology of the family and the separation between the private and public spheres (cf. Weber, 1921; Sennett, 1977) had deeper consequences for women than for men. While for men economic wages were an objective measure of recognition, for women recognition was mostly symbolic and related to their subjective abilities and skills. As the first female sociologists active between the ninetieth and twentieth centuries observed, care activities outside the domestic sphere were rarely considered an objectified form of work by men and, in this regard, such jobs did not deserve the same recognition as the "traditional" objectified male jobs (cf. Weber, 1913). Hence, the realization of the "natural" relational activities of women as mothers and wives outside the private sphere made visible the condition of women's work (and "female" work), but without this work being recognized as "real" since it was not directly "productive" (cf. Simmel, 1902; Delphy, 2004; Simonet, 2018).

In a similar way to the case of women's work in the earlier Fordist era, nowadays many jobs which manifest a subjective dimension are considered "non-productive" activities. Discourses around the vocation and passion of workers in particular mask the objective structures of many employment markets in order to legitimize non-standard work arrangements in which, for example, people perform the same tasks but under unequal contracts and working conditions, or are engaged in gig-jobs or unpaid work. From a constructivist perspective (cf. Berger and Luckmann, 1966; cf. Knoblauch, 2009), we can point out three processes: the internalization, externalization, and objectification of the idea of "vocation." Whereas, the internalization of the idea of vocation is accomplished by the processes of typification and socialization, which mainly concern the everyday dimension, the processes of externalization and objectification of the idea of "vocation" result in the institutionalization and legitimization of non-standard work arrangements.

Thus, the internalization of "vocation" depends on the ways people re-signify and legitimize their work in terms of its originality and innovative qualities (cf. Heinich, 2008). We can notice an upside-down rationality at work here (Bourdieu, 1998) whereby, following Heinich's observation about writers, such people do not work to earn a living, but rather earn a living in order to carry on certain activities (Heinich, 2008, p. 1) which, while providing distinctiveness, also justify precarious working conditions (cf. Giancola et al., 2016). In this regards, as Richard Sennett suggests, vocation can be seen as a sustaining narrative (Sennett, 2008, p. 263-65), that is, a narrative which supports one's own professional identity from the outside and presents a typified structure and form. On the other hand, the objectification of "vocation" goes through socialization processes mediated by key socialization agents or intermediaries. In Contribution à une sociologie de la vocation, Suaud observed, for instance, how the clergy played a pivotal role for the inception of the concept of a religious vocation. Thus, according to Suaud, religious dispositions, which are usually perceived as something exclusively individual, actually depended on how clergymen contributed to forming the perception and thinking schemes through which laymen developed a religious habitus, until a religious career was considered the most desirable of careers (Suaud, 1974).

As in religious and artistic contexts, in many work sectors the precariousness of working and living conditions strengthen the feeling of predestination and vocation. What matters, however, is not the subjective tension itself, but the forces which create this tension. Whereas, for artists and craftsmen the work activity justifies the working conditions, in other careers, such as religious ones, working conditions are justified by something (or someone) that goes further than the "objective reality" of the work itself. Thus, if on the one hand we may agree with Sennett when he highlights how, in the new spirit of capitalism, there is no place for the strong passion the craftsman has for his work (Sennett, 2006, 2008), on the other hand, we can observe how, in certain productive fields, work is represented as an opportunity to realize something greater than the work itself. This is the case in several sectors, including social work (De Angelis, 2017), intellectual work, and work in the broader cultural field (Armano and Murgia, 2012, 2013). In these sectors, the expression of passion and subjective meanings are considered a means of good production, and this "whip of the beyond" (Rastello, 2014) has therefore become a breeding ground for the roots of neoliberal subjectivity (cf. Illouz, 2007). 
In the following section, before exploring the deeper insights of our research findings to see how this tension between the subjectification and objectification of working conditions differently structure the academic work of female and male APs, we will try to shed light on how the international trends of "academic capitalism" have taken root in Italy.

\section{ACADEMIC CAREERS IN THE NEOLIBERAL UNIVERSITY}

In 2008, while investigating how younger academics constructed their professional identities, Louise Archer pinpointed the emergence of a neoliberal subject (Archer, 2008). To better illustrate the difficulties younger academics encountered in trying to keep up with the increasing expectations of the new Public Management logic which rules the academic system, she discussed an excerpt from her interview with Rose $^{3}$. In the interview, Rose stated she began working early in the morning because she had difficulty sleeping due to anxiety. She knew that other colleagues preferred working in the morning, but she tried not to give weight to the fact that she did it as well because she considered it a free choice. Thus, she felt that it was her choice and, in a certain sense it was, but to what extent was she really free to choose?

Actually, Rose's words give a precise description of how neoliberal rules have been internalized. With Foucault, we can say that the power of the neoliberal apparatus ${ }^{4}$ consists in shaping the choices of individuals (Foucault and Gordon, 1980; Foucault et al., 2004; see also: Agamben, 2006; Dardot and Laval, 2013) even to the extent, however, of affecting their psychologic health (Ehrenberg, 1999; de Gaulejac, 2009). To come back, instead, to the Bourdieusian framework (cf. Bourdieu, 1984; Bourdieu and Wacquant, 1992), we can observe how the new neoliberal logic of the academic field has shaped a new academic habitus by redefining the everyday working practices of younger academics, so that the new rules of the game and evaluation system appear "natural" to them and, in this sense, more difficult to criticize. Thus, differently from her older colleagues, Rose and her younger colleagues work in a more and more marketoriented context. Nevertheless, while the evaluation dynamics press them to maintain high productivity standards, maintaining those standards guarantees neither career success nor the timing of this eventual career. In other words, meeting these standards enables access to the competition and, implicitly, the legitimation of one's results, but does not assure the achievement of specific career outcomes.

The case studies carried out by Archer on younger academics of UK universities is paradigmatic of how the diffusion of neoliberal culture in the last 30 years has had a more global impact on the academic system, at least that of Western countries. In particular, the example of Rose well illustrates how structural changes condition the space of possibilities for constructing

\footnotetext{
${ }^{3}$ All the interview-partners used pseudonyms.

${ }^{4}$ There is no corresponding English word for the French dispositif used by Foucault and Gordon (1980), the Editor uses the Latin word apparatus beside the French word (Foucault and Gordon, 1980).
}

career paths and, in turn, affect the strategies, practices, and aspirations of individual actors in the academic field, even modifying their ways of perceiving and thinking about their academic activities and identities.

Turning to the Italian situation, we can observe how neoliberal culture has also taken root here, though it has been adapted to the specific logic and structure of the Italian academic field. One aspect which is important to mention here, and which may also help us in the interpretation of the empirical data, is the tension existing between the central organization of the academic system under the control of the State and local centripetal forces acting as "academic tribes" or "clans" (cf. Deem and Lucas, 2007; Capano and Meloni, 2009) which often prevent the implementation of both national reforms and international standards.

Let us start by sketching the principal changes regarding the academic ladder and careers in Italy since the university reforms of 1980 in order to gradually introduce the question of how academic teaching and the role and tasks of precarious academic staff involved in teaching activities have changed in the last four decades (cf. Moscati, 2001).

Before 1980, the academic structure revolved around a full professor, who was also the holder of a chair. Under him/her, there were several positions devoted mostly to teaching, positions which have been progressively reformed or suppressed over time ${ }^{5}$. Typically, after receiving a degree, a young scholar could accede to the "volunteer assistant" position. After obtaining the so-called libera docenza (a qualification permitting one to teach at university), he/she could become an assistente ordinario (who provided research and teaching support to a full professor) and then, when a post was available, professore incaricato (who was responsible for teaching a specific course, along with all related exams and theses, for one academic year). After several years, usually spent in different universities ${ }^{6}$, the professore incaricato could become a full professor and return to his/her original university. In order to understand the composition of university staff before 1980, the annual statistical report of the education department in 1970 identified, in addition to 2,347 full professors, 2,394 professori incaricati, 6,556 liberi docent, and 15,987 “volunteers" (ISTAT, 1971).

The university reform of 1980 radically restructured the existing formal academic ladder into three levels (full professor, associate professor, and lecturer) without, however, modifying the recruitment process which strictly depended on informal dynamics, generally based on familial power relationships. This reform also introduced the figure of the docente a contratto ${ }^{7}$ (adjunct professor, AP). Similarly to the libero docente, APs

\footnotetext{
${ }^{5}$ The assistente volontario (volunteer assistants) were not paid and generally helped "their" professors in teaching activities (support during exams, tutorials, etc.). Law no. 1962/1967 abolished this figure and introduced the fixed-term positions of "research fellows" and post-graduate "research assistants" (borsisti and assegnisti). ${ }^{6}$ Until the 1990s, there was a specific configuration of university networks. Thus, the bigger universities played a central role in informal recruitment policies, whereas smaller and peripheral universities were under the control of the biggest ones. As a result, in the smaller universities, the permanent staff was continuously changed, with consequences for the organization of teaching and research activities (cf. Moscati, 2001).

${ }^{7}$ Art. 25 of Law no. 382/1980.
} 
stipulated a private contract with the university. But, differently from the libero docente, APs were selected for the professional expertise they had developed outside of academic institutions. As a result, their classes were understood by law as electives supplementing the courses of the standard curriculum.

The State's strong investment in economically supporting the reform made possible the hiring of about 30,000 people as lecturers and associate professors in just 5 years. As a result, it seemed to the legislators that the role of APs could remain "marginal" to the functioning of university teaching activities, while also assuming that, for APs, collaborating with the university would be a sign of prestige.

In the 1990s, growth in the recruitment of new academic staff did not keep pace with the increasing number of students. From 1983 to 1998, the student/professor ratio increased from 24.2 to 29.0. In order to find a solution to the lack of teaching staff, in 1990 Law no. 341 (art. 11) established the possibility for lecturers to teach courses (for no more than $60 \mathrm{~h}$ per academic year). Nevertheless, this measure was insufficient given the ongoing changes in the organization of the courses carried out over subsequent years, in particular the increasing autonomy of academic institutes in establishing their own degree courses and the inception of two levels of undergraduate and specialization courses (Law no. 509/1999). Thus, in 1998, the Minister for Universities, through a further decree, Law no. 242/1998, established that APs were now permitted to teach required courses. Despite the increasing teaching needs, it does not seem that the university policies were aimed at giving a structural answer to the problem. Since 1998, the teaching shortage has been mostly covered by counting on the willingness of lecturers (who until 2010 were not paid for lecturing), increasing the teaching duties and responsibilities of both APs and associate and full professors, and increasing the number of APs.

On the other hand, since the 1990s, the teaching and research activities of professors have become increasingly subject to evaluation (cf. Moscati, 2001; Rebora and Turri, 2011). Nevertheless, whereas evaluation systems concerning teaching activities are mainly oriented toward checking that teachers have fulfilled their duties, the evaluation systems for research activities are oriented toward rewarding those who have "the best impact factor." What matters for our concern is not so much that in both cases the research and teaching capabilities of academics are objectified, according to specific standards that appear to be "neutral." What matters is, rather, that this dual system of evaluation has created an implicit hierarchy between teaching and research activities, so that the former are more and more considered only as a duty, whereas the latter are a source of prestige. The gap between research and teaching duties has increased since 2010 with the new reform of Law no. 240/2010 which introduced the "abilitazione," a national qualification needed to become an associate or full professor, that is essentially based on the evaluation of scientific output (i.e., scientific articles, monographic works, book chapters, patents), excluding teaching experience as relevant criteria.

Summing up, the reform processes carried out during the last 40 years have had two main consequences. The first is the increasing divergence in terms of the rights, social recognition and career opportunities between those who are employed with fixed-term research contracts and those who are mainly employed with fixed-term teaching contracts ${ }^{8}$. The second consequence concerns the increasing split between those employed with fixed-term contracts in the so-called "hard" (scientific) and "soft" (humanities) disciplines, not least because the former have greater possibilities of finding institutional and external research funding. In this second case, the question is not so much whether they may have different career prospects, but rather that they cultivate a different idea of "the University," its mission and social and cultural tasks. This rift has clearly surfaced during the meetings organized by the FLC-CGIL trade union and other independent academic associations on the occasion of their campaign against academic precariousness in Italy (May 2018October 2020). Thus, those who belong to "hard" disciplines consider teaching mainly as a non-prestigious, time-consuming activity that is unhelpful for their careers. Conversely, those who belong to social science and humanities (SSH) disciplines are more concerned with problems regarding the organization of teaching and the teaching duties of academic staff. This does not mean that SSH-scholars are exonerated from the competition based on publishing and research duties. It means, rather, that, in the SSH-disciplines, teaching is often one of the few possibilities scholars have for continuing to work at the university. As a result, such scholars need to work more than others.

In addition to this cultural variable, the impact of two further socio-structural variables on the working conditions and social status of APs need to be considered: age and gender. Younger APs usually have more available time than older ones to spend on teaching activities, but also less economic stability; in addition, male APs may count on a more comfortable labor market and are less embedded in family duties than female APs. Thus, age and especially gender create conditions of inequality, even if these conditions of inequality exist prior to the organization of academic work. Nevertheless, in light of the specific social structure of the academic field, these inequalities take on specific significance, which especially emerges when we look at the temporal dimension of the academic life of precarious academics, partially highlighting how they are generated at the early stage of an academic career, when they are almost invisible (see on the topic: Murgia and Poggio, 2018).

\footnotetext{
${ }^{8}$ As we will show in the following sections, the last juridical changes have brought meaningful social consequences not only with respect to the working conditions of precarious scholars but also the temporal structure of the academic path, in terms of both the possibility of imaging an academic path and the ways of experiencing daily the academic life. This point is especially noteworthy, if we compare the position of the "liberi docent" (similar to the position of the German Privatdozenten, cf. Schultheis, 2000) with that of the adjunct professors. If also the "liberi docent" experienced social and economic precarious conditions within the Academia, they were structurally more integrated in the academic milieu. Indeed, taking the "libera docenza" was noteworthy for achieving an academic career. Conversely, cumulating experiences as adjunct professors nowadays has little relevance. This means, not least, that for the "liberi docent" waiting with the hope of achieving a tenured position was stronger related to concrete social expectations than for adjunct professors.
} 
If we look at the percentage of women at the different stages of the academic career ladder (from "research fellows" to full professors) from a longitudinal perspective, we notice that, in the last two decades, whereas the number of female and male research fellows is almost equal (in some years, the number of female research fellows was higher than the number of male research fellows), the number of women in tenured and tenure-track positions over time decreases, decreasing at a higher rate the more prestigious the academic position is. This phenomenon also concerns the new tenure-track position of junior professor introduced in 2010. Two explanations are here possible. The first one is that recruitment is higher in maledominated disciplines. Nevertheless, data on junior professors collected in April 2019 highlights how, with the exception of life sciences and the arts, all other disciplinary areas are predominantly male (data source: CINECA). The second one is that the number of female research fellows is higher in the early phase of academic careers and decreases progressively in the following years (González Ramos et al., 2015; Komlenac et al., 2019). As a result, according to this interpretation, the number of women who can compete for tenure-track positions is inferior to the number of possible male competitors. The trends of male and female APs in the last two decades are conversely very different from those concerning research fellows. Indeed, over time, the number of female APs has been consistently about 30 percentage points lower than the number of corresponding male colleagues (source: USTAT-MIUR).

In the next section, we will see how this difference in gender distribution among research fellows and APs over time probably depends on two factors: the fact that the average age of APs is higher than the average age of research fellows, and that most APs work more than one job. It seems, then, that for women, working and living as APs is possible up to a certain age. A key question we will try to tackle more widely through the data analysis regards to what extent the structuring of precarious conditions in the academic career path mostly prevents women's access to academic careers.

\section{THE CAREERS OF APS: A GENERAL OVERVIEW}

As mentioned above, the figure of the AP was established in 1980. Nevertheless, its growth became numerically significant only after 2003, we can claim, for three main reasons. First, the application of the degree course reform which started in 2001 (corresponding to the Bologna process) replaced the old "laurea" (4 or 5 years) with two levels of (undergraduate) and (specialization) degree courses. Second, the new law regarding university autonomy (Law no. 509/1999) gave universities the ability to more independently establish new degree courses and curricula. Third, the new wave of recruitment after 2001

\footnotetext{
${ }^{9}$ Due to the juridical framework of the Italian academic structure in which, for example, it is needed to accede to competitions for positions of tenure-track junior professor (a figure introduced in 2010, replacing the previous figure of the tenured lecturer), we consider here the position of research fellow as "privileged" for pursuing an academic career.
}

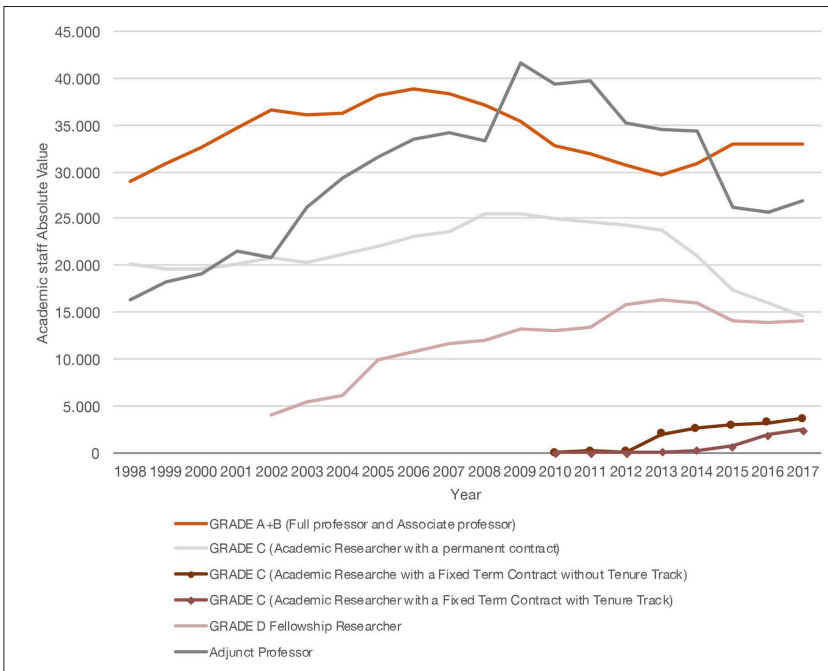

FIGURE 1 | Academic staff contract, absolute value by year (Source: MIUR).

concerned tenured researchers (RTI) without teaching duties, whereas the number of full and associate professors after 2003 decreased consistently. In 2009, with the block on replacing positions lost to turn-over, the number of APs peaked at 40,000. From 2009 to 2013, the number of APs remained higher than the number of full and associate professors together. In recent years, the decrease of AP positions has mostly depended on a special plan (2013-2014) for the professional advancement of the old RTIs to positions as associate professors. Conversely, the number of junior and senior researchers, the two new figures which were introduced in $2010^{10}$, did not significantly impact the trend of AP numbers until quite recently. Indeed, in 2017, the number if APs started increasing again, to 26,869 positions $(+4.3 \%$ over 2016$)$, highlighting how a decrease of their use for teaching activities is not foreseen for the following years (see Figure 1).

Despite APs being the most conspicuous category of academic staff, they are disregarded by the official narratives and statistics of academic institutions as they are considered an exceptional circumstance which each department can manage individually. Representatives of academic institutions often justify this attitude by claiming that APs are "professionals with solid careers outside the academic system," recalling the juridical definition of APs according to Law no. 382/1980, as if their juridical and social status have not changed in the last 20 years.

The results of both our survey and semi-structured interviews clearly disprove this narrative, showing how APs occupy unstable positions not only within the academic system but, in a number of cases, outside it as well, especially in the case of female APs.

\footnotetext{
${ }^{10}$ Both junior and senior researcher positions last three years. For junior researchers, teaching duties are optional. Senior researchers have to teach and, after the national scientific qualification, they can automatically advance to the position of associate professor.
} 
TABLE 1 | Comparison of age of sample and age of total population (source: MIUR data and our survey).

\begin{tabular}{lcc}
\hline & Population (\%) & Sample (\%) \\
\hline$<30$ years old & 2.40 & 2.10 \\
$30-39$ & 23.50 & 31.10 \\
$40-49$ & 28.40 & 31.30 \\
$50-59$ & 23.60 & 21.00 \\
$>60$ years old & 20 & 13 \\
N/D & 2.30 & 1.10 \\
\hline
\end{tabular}

In this section, we will focus on the outputs of the survey ${ }^{11}$, which was based on three main dimensions: (a) the academic career and (b) working conditions of APs, and (c), the ways they perceive their work. The survey was sent to almost 27,000 APs. From January 2018 to October 2018, we received 5,556 answers, covering more than $20 \%$ of the whole survey population. As a first step, we will examine the main structural variables of our sample and try to define a profile of APs, taking the gender variable as a point of comparison. As a second step, we will try to better understand the interplay between working conditions and experiences and professional aspirations, taking into account gender as a comparison parameter.

With respect to the whole AP population, the respondents to our sample are younger. Nevertheless, we can consider this is an effect of online surveys (see Table 1 ).

Men were $54.4 \%$ of the respondents and $45.6 \%$ were women, with the majority working in the universities of northern Italy (59.1\%), followed by those of central Italy (26.9\%), southern Italy (12.8\%), and distance learning/online universities (1.2\%). Despite the official representation of APs as "successful professionals," $48 \%$ of our respondents do not earn more than $€ 15,000$ per year. Furthermore, $58 \%$ of these who earn $<€ 15,000$ per year are women. Last but not least, among our respondents, more than half of the younger APs, female APs, and APs working in southern Italy earn $<€ 10,000$.

Focusing on female APs, Figure 2 shows that, up to the age of 39 , women are the majority of our sample, whereas their numbers decrease progressively in the following age groups.

We can argue that the progressive decrease of women in older age groups is typical of the composition of Italian academic staff. Indeed, as the Ministerial data (data source: CINECA, March 2019) on women's academic careers demonstrate, in almost all disciplines (defined in Italy in terms of scientific disciplinary sectors, SSDs) the majority of students and $\mathrm{PhD}$ graduates are women. As stated above, they are also more than half of the research fellows (data source: CINECA, 2017). Conversely, their number decreases significantly and progressively when we look at the higher positions of the academic career: women make up

\footnotetext{
${ }^{11}$ The research was conducted in compliance with the national regulations governing the protection of personal data (Legislative Decree 196/2003 and following regulations), with the request for an online respondent's informed consent and the authorization to fill in the questionnaire and to process the results ensuring privacy preservation by data anonymization.
}

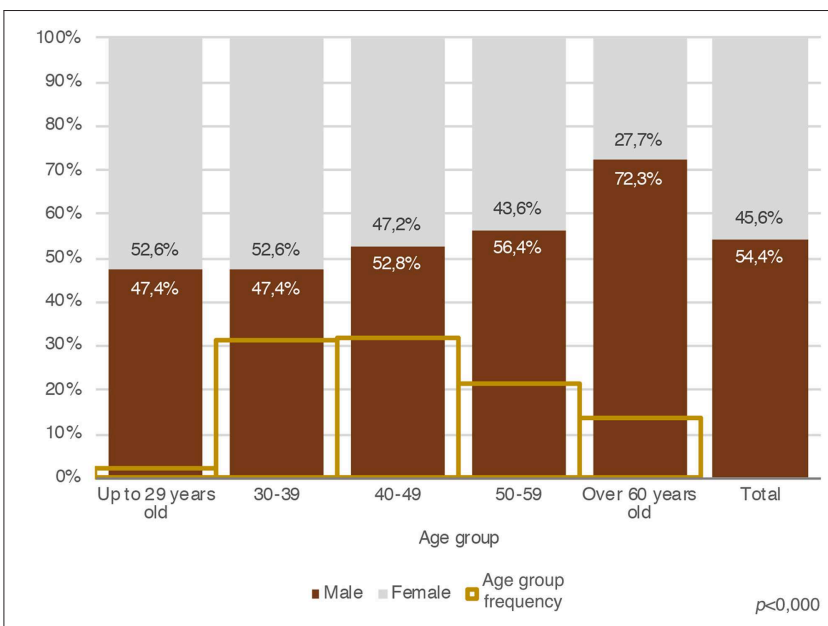

FIGURE 2 | Gender distribution by age group and incidence of total age group (Source: our survey).

$41 \%$ of senior researchers, $38 \%$ of associate professors, and only $24 \%$ of full professors (data source: CINECA, May 2019-see Figure 3).

To explain this trend, we can pinpoint some pivotal factors which generate gender discrimination in international academic contexts: first, enduring over time the uncertainty which characterizes academic careers may be heavier for women than for men, mostly considering gender discrimination regarding family responsibilities (Wolfinger et al., 2009) ${ }^{12}$; second, gender bias may persist within some SSDs (disciplinary scientific sectors) (Morgan et al., 2016); third, this gender bias may also depend on the gender discrimination women experience in the productive fields outside academia. In addition, it is important to consider that, in Italy, the high number of inactive women as well those volunteering part-time mainly depends on the fact they bear the primary responsibility for care activities in the domestic sphere. Thus, we can assume that women are more discouraged than men to pursue academic careers when their academic paths would be characterized by uncertainty, low wages, and shortterm contracts.

Figure 4 shows the distribution of wage ranges by sex and age. In all the age groups, the number of workers earning up

\footnotetext{
${ }^{12}$ This aspect is especially evident in the interviews with female APs. Paradigmatic is the interview with a 55 years old AP who has taught for 12 years in four different universities. To the question about why and how she decided to work as an AP, she answered: "I started working as an adjunct professor after participating in an academic competition for a lecturer position, which had not 'been intended' for me. Working as an adjunct professor has been a sort of compensation. During this period, I have also participated in competitions for research fellow positions, but once I was asked to withdraw my application and it was made clear to me that I was needed as part of the work force but could not aspire to an academic career." To the following question about "extra-academic activities," she answered: "I teach at school, otherwise I could not survive." As we highlight in this section, most female APs carry out traditional female work activities which are usually less prestigious and lower paid than working activities carried out by men. Furthermore, more women than men reported episodes of mobbing in their academic career, highlighting in this way how, in Italy, the phenomenon of "amoral familism" is especially unfavorable for women [translation by Barbara Grüning].
} 

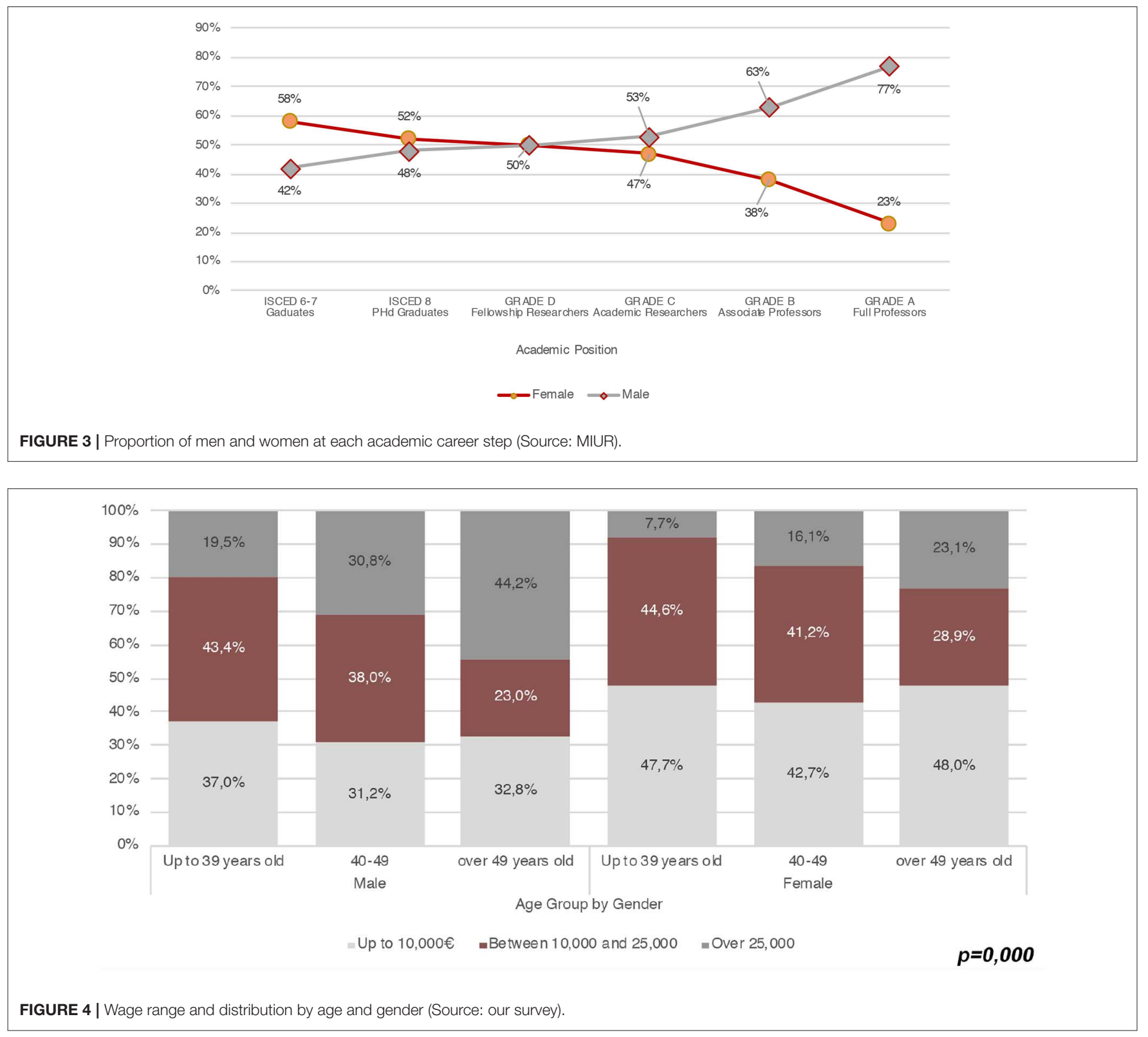

to $€ 10,000^{13}$ is greater among women than men, whereas in all the age groups, the male rate of APs with a wage higher than $€$ 25,000 per year is almost double the female rate. The difference by gender is even greater among younger APs earning more than $€ 25,000$ per year, with an incidence of $19.5 \%$ for men and $7.7 \%$ for women. Furthermore, beyond having lower wages, female APs also have a more fragmented work experience. Indeed, if on average, the majority of APs who declare extra-academic work contracts are either self-employed (30.6\%) or permanent employees, both categories are higher among men (34.1 and $23.2 \%)$ than among women (26.2 and 20.7\%). By contrast, more women than men carry out informal work (20.1\% vs. $17.4 \%)$, have fixed-term employment contracts ( $9 \%$ vs. $6.1 \%$ ), or mixed forms of semi-employed contracts ( $24.1 \%$ vs. $18.8 \%)$.

\footnotetext{
${ }^{13} \mathrm{We}$ considered here all the jobs carried out by the respondents, both within and outside academia.
}

As mentioned above, for APs gender discrimination is reinforced by the gender segmentation which characterizes the SSDs. We have seen that women are a majority of students, graduates, and $\mathrm{PhD}$ graduates. Nevertheless, in the natural sciences, mathematics and statistics, information and communication technology, engineering, manufacturing and construction, women constitute $40 \%$ of graduates and $44 \%$ of $\mathrm{PhD}$ graduates. Furthermore, their number decreases in the subsequent steps of the academic career. This dynamic helps us to understand how gender segmentation in SSDs lead to the ejection of women from those areas which are more favored by the labor market ${ }^{14}$. This kind of segmentation also characterizes

\footnotetext{
${ }^{14}$ Following the Almalaurea data on the work experience of $\mathrm{PhD}$ graduates in 2018, we can observe that, one year after receiving a $\mathrm{PhD}$ in Engineering, 37.1\% of workers had a non-fixed term contract, whereas after a PhD in the Humanities the non-fixed term contract rate was $25 \%$. Moreover, among PhDs in the Humanities,
} 


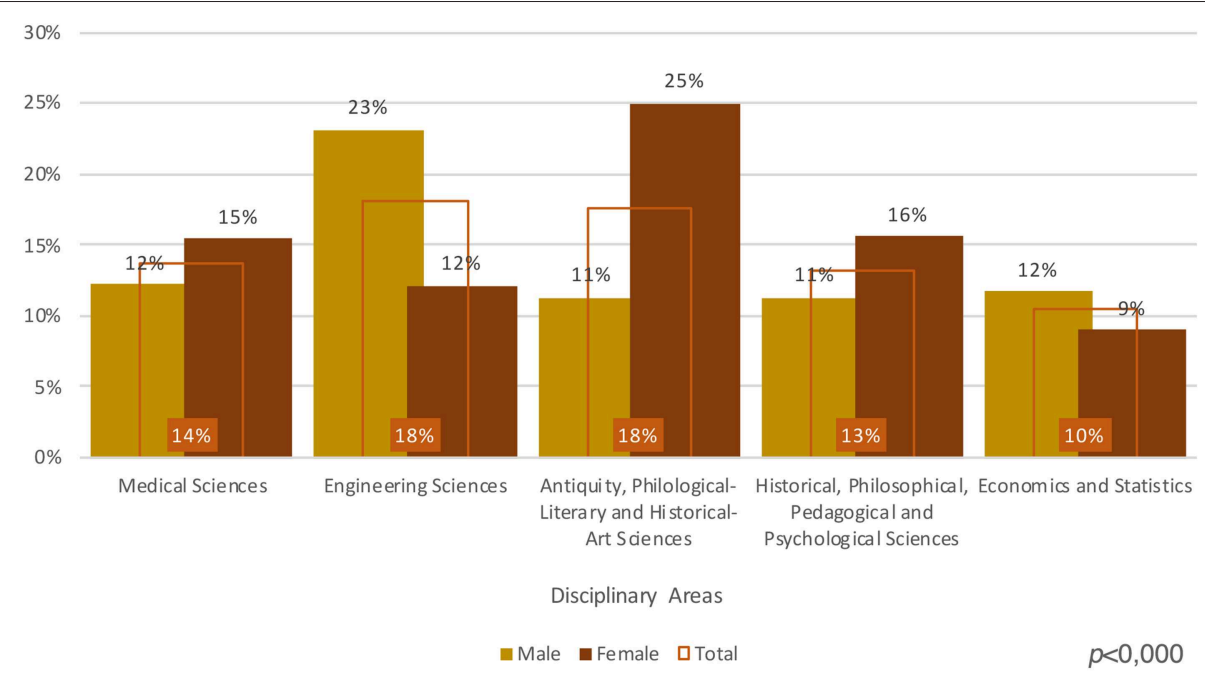

FIGURE 5 | Scientific areas, incidence by gender and total (Source: our survey).

our sample. So, while 23\% of male APs come from Engineering Sciences, $25 \%$ of female APs come from Classics, PhilologicalLiterary Studies, and Art History. Similarly, the rate of APs in History, Philosophy, Pedagogy and Psychology is higher among women (16\%) than men (11\%) (see Figure 5).

Summing up, the comparison between the official data on academic staff and our sample of APs highlights similar patterns of gender discrimination: women are less involved than men in sectors which have a better recognition on the broader labor market.

Turning now to the interplay between work experience and the professional aspirations of APs, a key aspect to consider is the little interest given to them by academic institutions.

Official discourses which represent APs as outsiders with respect to the academic system are symbolically indicative of the precariousness of APs. While we can assume this perception is based on a lack of knowledge of the effective academic work of $\mathrm{APs}^{15}$, on the other hand, it also demonstrates a lack of recognition of their role. Our hypothesis is that the more APs participate in academic life, the more profound their feelings of being unappreciated may be.

If we look at the survey data, the results are quite interesting. First, $64.4 \%$ of the interviewees state that they had previous work

29.6\% had non-standard contracts, while only $17.6 \%$ of PhDs in Engineering had non-standard contracts (https://www.almalaurea.it/sites/almalaurea.it/files/docs/ universita/postlaurea/dottori_occupazione_report2018.pdf).

${ }^{15}$ In particular, in various conversations with representatives of the governance of the University of Bologna, APs have been depicted as professionals who are not oriented toward an academic career. Thus, beyond the legal definition of APs that excludes them from the official faculty, it emerges how in the practices and discourses originating from the university's governance, APs are not considered either for the present or for the future as members of the academic staff. This aspect is also stressed by the various university reform proposals which have been carried out in the recent years by both politicians and academics, which in fact have not brought any improvements for APs as they mainly focus only on academic research activities. Thus, these social discourses highlight the practical effect of the legal separation of teaching and research activities at the lower stages of the academic structure. experience at the university (see Figure 6 for details). Among female APs, however, the rate was $67.2 \%$, whereas among male APs it was $62.2 \%$ (2-tiles correlation 0.01). Second, despite the women in our sample being younger than the men, they have a higher average number of university contracts than male APs. In addition, in the case of contracts as APs, women have a higher average number of contracts than men: 18.05 vs. 12.14 .

However, if we use research activities as an indicator, we can observe a greater "dynamism" among male APs than female APs: so, in the previous 5 years, the men have published 11.51 works and participated in 9.43 conferences, on average, whereas the women have published 9.72 works and participated in 8.06 conferences ${ }^{16}$.

We believe that the greater attention male APs paid to producing research outputs may have an impact on their real chances of pursuing a linear academic career (Wolfinger et al., 2009), that is investing time for both increasing their scientific capital (publications) and their social capital (by participating in conferences) (cf. Bourdieu, 1984, 1986, 1989). This point is, in some ways, corroborated by attitudes toward the National Scientific Qualification (ASN): although more women than men state that they will try to attain the ASN (59.4\% vs. $53.8 \%$ ), more men than women have already received it (13.6\% vs. $10.4 \%$ $\mathrm{K}^{2}$ 0,001 - see Figure 7).

In order to better identify the extent to which APs are interested in pursuing an academic career, we constructed an index of academic aspiration ${ }^{17}$. At a glance, the academic

\footnotetext{
${ }^{16}$ We calculate the statistical average on the basis of a distribution of outputs from 1 to 201. The standard deviation of the distribution corresponds to 16.8 and 13.7, respectively, for the publications and conferences of the male APs and to 12.01 and 9.7 for the publications and conferences of the female APs.

${ }^{17}$ The index was calculated as the sum of answers with respect to the desire to pursue an academic career (Agree Strongly $=3$, Agree Moderately $=2$, Agree Slightly $=1$, Disagree $=0$ ) plus answers about their attitude toward the ASN (Not interested $=0$; Interested $=1$; Have qualification $=3$ ) minus the existence of previous contracts with academic institutions $(\mathrm{Yes}=1 ; \mathrm{No}=2)$. In order to reduce the scale of the index, we synthetized the results into three types: Low academic
} 


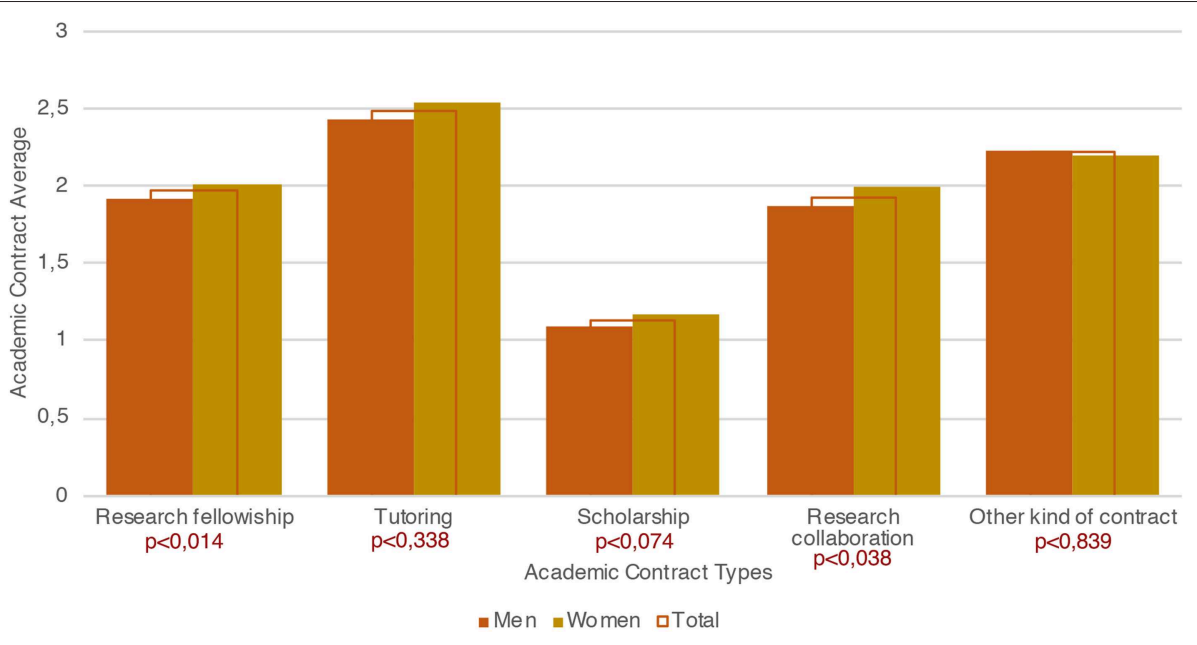

FIGURE 6 | Work experience in the academic sector, average by gender, and total (Source: our survey).

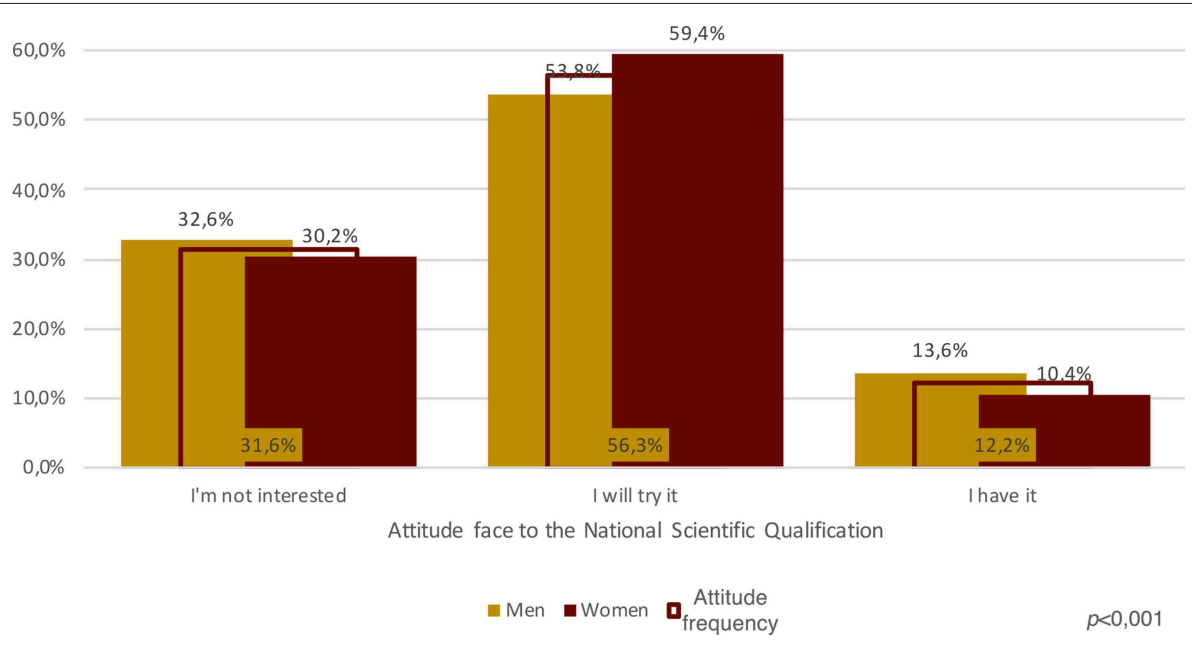

FIGURE 7 | Attitudes toward the National Scientific Qualification, incidence by gender, and total (Source: our survey).

aspiration results are moderate for both men $(38.4 \%)$ and women (37.6\%). However, if we look at the two poles of the distribution, the percentage of male APs with the lowest academic aspiration score is higher than the percentage of women with the lowest score (28.4\% vs. $25.3 \%)$ and, conversely, the percentage of female APs with the highest academic aspiration score is greater than the percentage of male APs with the highest score $(37.2 \% \text { vs. } 33.2 \%)^{18}$.

With respect to our purpose of investigating how gender inequalities increase in correspondence with the worsening of working conditions, we can argue that the index of academic aspiration, is correlated to two crucial aspects of APs' working

aspiration (score between 1 and 2), Moderate (between 3 and 4), Strong (between 5 and 6).

${ }^{18}$ The index distribution is not significantly correlated to the gender $\left(\mathrm{K}^{2}=\right.$ $0,025)$. Nevertheless, our purpose is not to identify those APs with high academic aspiration. Rather, it's an useful instrument for investigating what happens to those APs with the highest academic aspiration. conditions: the fact part of their work is unpaid, and the fact they often work beyond the terms of their contracts.

By law (no. 313/2011), APs are only paid for their time spent lecturing in the classroom. Thus, according to the results of our survey, for each paid hour, on average, they also work: $0.56 \mathrm{~h}$ for office hours, $1.6 \mathrm{~h}$ for preparing lectures, $0.45 \mathrm{~h}$ for administrative tasks, $0.8 \mathrm{~h}$ for exams, $0.86 \mathrm{~h}$ for travel, $0.81 \mathrm{~h}$ for thesis and $0.2 \mathrm{~h}$ for further activities. As a result, for $1 \mathrm{~h}$ of lecturing, APs work $5.3 \mathrm{~h}$ for free. Thus, if on average for $1 \mathrm{~h}$ they are paid $€$ $46.58^{19}$ (gross), they effectively earn $€ 6.71$ (gross, and generally without additional costs for the university) ${ }^{20}$. To analyze the relationship between paid and unpaid hours, we constructed an index of "unpaid work." When the relationship is lower than

\footnotetext{
${ }^{19}$ Excluding errors and missing data, the average was calculated from data provided by 3,131 APs.

${ }^{20}$ Depending on the kind of contract, net earnings are 22 or $33 \%$ lower than the gross.
} 


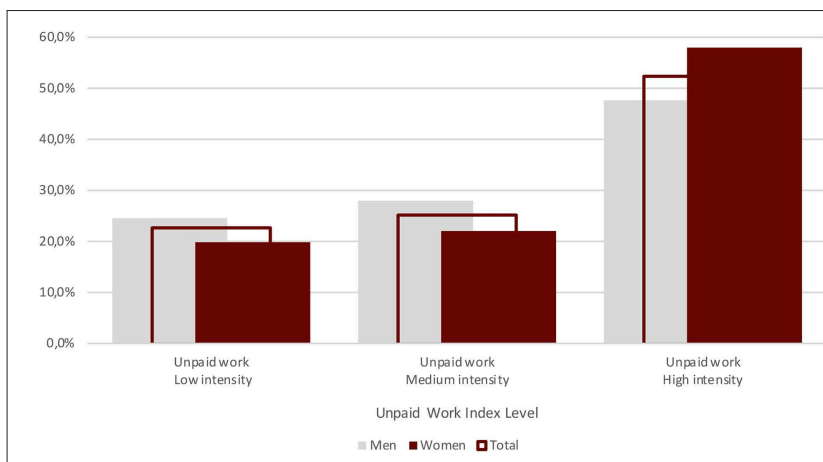

FIGURE 8 | Unpaid work index, level incidence by gender and total (Source: our survey).

2, we consider it a low intensity of unpaid work; when the relationship is between 2 and 3.5, we consider the intensity medium; finally, when the relationship is more than 3.5 , the intensity is high.

As Figure 8 show us, the majority of respondents $(52.3 \%)$ present the highest intensity of unpaid work. However, female APs with a high intensity of unpaid work are $10 \%$ more than male APs. Furthermore, women work beyond the end of their contracts more than men $(70.3 \% \text { vs. } 66.7 \%)^{21}$. Hence, the lack of economic recognition affects more women than men. This result raises meaningful questions about the fact that APs who are more engaged in teaching activities, while it seems they increase their participation in the academic life, on the other hand have less time to devote to research activities, therefore, to other forms of participation to the academic life, which are more symbolically acknowledged (cf. Heijstra et al., 2017).

As we have seen, the difference between women and men in terms of unfair working conditions may be explained by a different degree of motivation to pursue an academic career. Nevertheless, to the questions concerning their motivations for working as APs, they answer similarly. Generally, both men and women give great importance to the pleasure of teaching (nearly $100 \%$ ), and both men and women consider the AP experience important for enhancing their professional competences (nearly 90\%). We can observe some slight differences only with respect to the desire to pursue an academic career, which is higher for women than men (probably depending on the higher average age of men), and economic motivation, which is also higher for women than men (Figure 9). The latter result is probably the most interesting, since women are, in general, more vulnerable than men to the lack of economic recognition in the labor market. Thus, we can assume that, on average, every additional source of income is more important for women than for men. In the next section, by analyzing the semi-structured interviews, will also try to better investigate whether, and in which ways, the different economic importance given to their work as APs influences their acceptance of their working conditions.

A final aspect we considered, and which we will more fully explore in the next section, concerns the academic relationships

${ }^{21}$ The relation is significant at $0,000\left(\mathrm{~K}^{2}\right)$.

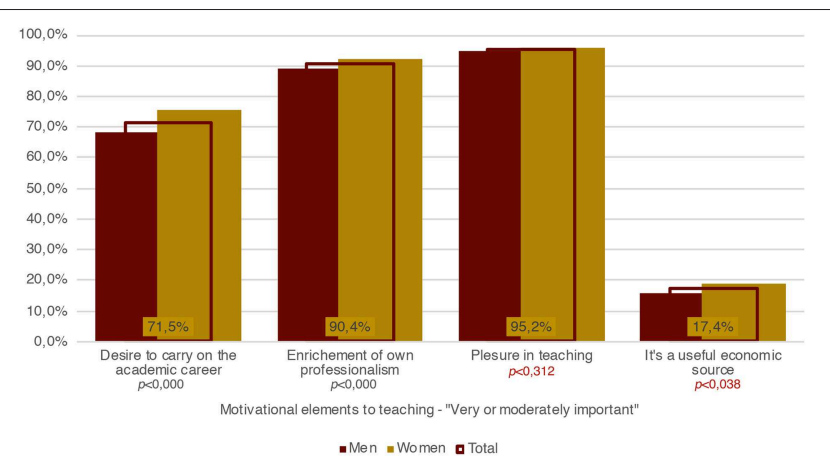

FIGURE 9 | Motivational elements for teaching - "very or moderately important," incidence by gender and total (Source: our survey).

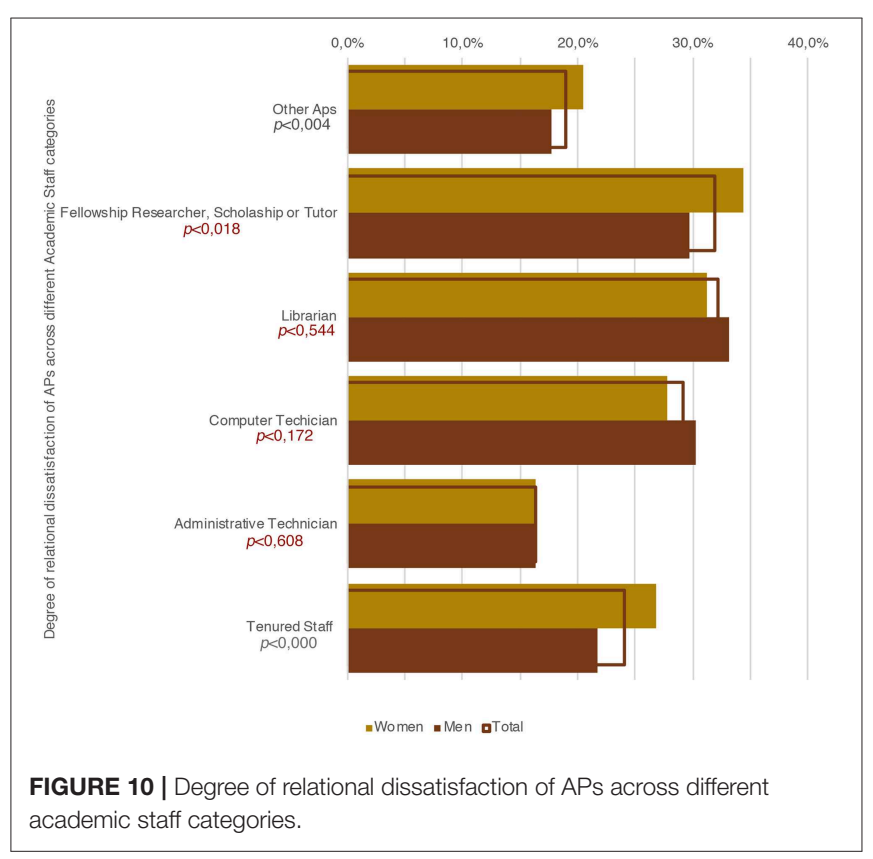

of APs with the academic staff. As Figure 10 shows us, women have generally more difficulty interacting and constructing relationships with professors and researchers with both tenured and fixed-term positions. Conversely, their relationships with the administrative staff (mostly female, 58.8\%, data source: USTAT-MIUR) are better than men's relationships with the administrative staff. Also considering the previous results, two aspects may be considered as meaningful. The first concerns the fact that female APs are more engaged in teaching duties than male APs. However, despite this engagement, their social relations within academia are poor; or, in other words, they endure a greater condition of social isolation and "invisibility" (Honneth, 2003). This aspect also reinforces the idea that teaching activities are less important for building "social capital" (Bourdieu, 1986) than research activities. The second aspect concerns the fact that female APs find it easier to construct relationships with the administrative staff than with professors 
TABLE 2 | Distribution of interview-partners by gender and age.

\begin{tabular}{lccc}
\hline Gender/Age & $<\mathbf{4 5}$ & $\mathbf{4 5 - 5 5}$ & $>\mathbf{5 5}$ \\
\hline Men & 8 & 3 & 5 \\
Women & 9 & 4 & 2 \\
\hline
\end{tabular}

and researchers, that is, with people who enjoy less prestige, meaning those who have less scientific and academic capital. Thus, from a Bourdieusian perspective (Bourdieu, 1984, 1986, 1993), beyond the fact that they juridically occupy the same position as male APs, on average, the objective position of female APs employed within the located social space of the academic field (i.e., the institutes where they work) is lower than the position occupied by male APs, at least in terms of the amount and composition of their capitals.

\section{EXPERIENCING ACADEMIC LIFE: A GENDER PERSPECTIVE}

In this last section ${ }^{22}$, by adopting a gender perspective we will look more in detail at how female and male APs interpret their academic experiences, position within the academic field, and academic/professional identities. To achieve this objective, we carried out 31 interviews with APs from northern (20), central (9), and southern (6) Italy ${ }^{23}$, and from different disciplinary macro-areas (Humanities: 11; Political and Social Sciences: 9; Natural Sciences: 3; Medicine: 3; Law: 2; Engineering: 3$)^{24}$. Fifteen of our interview-partners were women and 16 were men. In terms of age, seven of them were over 55 years old, seven between 45 and 55 years old, and 16 under 45 years old $^{25}$ (see Table 2). Further data we considered to be crucial for understanding the ways in which APs perceive

\footnotetext{
${ }^{22}$ The qualitative analysis is here mainly considered as support for better interpreting the findings of the quantitative analysis. We refer to a further article in preparation, where more space is devoted to the interviews.

${ }^{23}$ Since some of the APs worked or are working in more than one university, we have considered them twice here. For what concerns more generally the geographic cultural dimension of the Italian Universities, we have not analyzed in depth how this produced meaningful consequences on the career paths. Nevertheless, two observations are noteworthy. First, in the last decade the universities of Southern Italy have more suffered from the relevant cutbacks to the financing of public universities. This had a twofold consequence: on the one hand there are her fewer permanent positions than in northern Italy, on the other hand, however, there are also fewer tenured positions, since Universities in Southern Italy have difficult also to fund them. Thus, scholars who aim at working in Academia should often working (completely) for free as "volunteer assistant" or "cultori della materia." This entails, not least, that in these situations the familistic academic culture is stronger than in Northern Universities, as also some of the interviews highlight. The second point concerns the peripheral and isolated position of many universities of Southern Italy. As a result, precarious academic workers find here greater difficulty to build academic networks, which could increase their opportunities in the academic market and the possibility of pursuing an academic path outside the original academic milieu (cf. Giancola et al., 2016).

${ }^{24}$ It is important to note here that, proportionally to the disciplinary macro-areas, most of the APs are either humanists or social/political scientists.

${ }^{25}$ We have chosen this kind of age division since, in Italy, on average people reach tenured positions when they are older than 40 years old.
}

their academic experiences are: whether they carried out extraacademic activities (26) or had additional fixed-term contracts with universities (5), and the number of years they had been working as APs. This last information is especially useful to understand whether they had experienced the academic system before the last university reform (2010), which radically changed the career path and structure in academia.

Nevertheless, although this information can be viewed as pivotal for determining the ways APs experience academic life and narrate this experience, the comparative analysis is not strictly dependent on one or another of these factors. Rather, by comparing the narrative structure of each interview, we try to identify the underlying structure of meanings (cf. Demazière and Dubar, 1997) in order to understand how APs perceive their academic careers and which kinds of academic identities (cf. Henkel, 2005; Leisyte, 2015) they have developed over time.

In this regard, the gender perspective we adopted did not condition the interpretation itself. Indeed, if the survey highlights meaningful differences between men and women's working conditions, as well as differences in judging their degree of integration within academic life, we do not assume $a$ priori that these differences deterministically influenced the ways individual APs narrated their own professional paths. The main question we have asked was, instead, whether it is possible to pinpoint a different academic/professional habitus between male and female APs. While this habitus depends on the structural position APs occupy in the wider academic field, it also influences the different ways they perceive and think about their positionality within the academic field.

To answer this question, we have considered three significant aspects. The first concerns the time structure of the narrated experience (cf. Berger and Berger, 1972); the second concerns the different levels of recognition or non-recognition felt by the interview-partners; the third concerns the global view they have of the academic system. With regard to the first aspect, we have examined how APs understand and reconstruct both their work routines and the relationship between their academic experiences and aspirations. With regard to the second aspect, we have looked at the interplay between self-representation and the representation by others in the formation of their own professional social identity (cf. Dubar, 2000). Thus, we have focused on how APs define, classify and evaluate their own scientific/academic competences and express their feeling of belonging within academia. Finally, the third aspect concerns the different interpretation of formal and informal academic dynamics. Indeed, the different ways of understanding these dynamics conditions the practices and strategies APs have adopted for constructing their own professional social trajectories.

Summing up, we assumed that a better understanding of each interview was possible only by taking into account these three aspects together. This analytical procedure allows us to dig into the deeper layers of meaning in each narrative, in spite of the fact they put forward similar topics in similar ways. So, for example, all the interview-partners claimed that the remuneration for their work is disproportionate to the time they employ for the work itself, data, as we have seen in the previous section, 
that is important to grasp their concrete working conditions. Furthermore, all the interview-partners maintained that, despite this disproportionality, they make every effort to prepare their lessons optimally. Indeed, all the interview-partners (according to the responses of the survey - see Figure 9) assert that the main satisfaction of their work is derived from relationships with their students and from the pleasure of teaching itself. Not least, all of them declared that they go to their departments almost exclusively when they have class, exams, or office hours, mainly for two reasons: either because they have no place to stay or because they carry out many working activities in order to live and it is difficult to organize their working time so as to spend more time at the institute outside of their required activities.

Hence, if we examine the individual answers APs gave on specific issues, we can claim that male and female APs experience their work in very similar ways. However, if we consider instead the whole narrative of their "academic/professional life," several differences emerge with respect to these points.

The main contrasting aspect among male and female APs concerns the fact that the former declare that, though they are more involved in the research activities of faculty members, they are also more frustrated at being excluded from the political decision-making procedures of their institutes. Furthermore, some of them declare that they have reduced their presence at university over time because of a sense of unease they feel after working as APs for years without any prospects of stabilization. This answer has been mainly given by older male $\mathrm{APs}^{26}$. However, if we compare the interviews of the corresponding age group of female APs, we do not notice a similar feeling. More interesting is the fact that six of the male APs belonging to the older age group are either independent professionals or permanent employees outside of academia (see footnote 15). Hence, while their social and economic status are apparently ensured by their extra-academic profession (engineer, lawyer, doctor, etc.), they consider their academic work as primary for their professional identity. Indeed, in their professional identity narratives, they stress how, since taking their degree, they have had a continuous relationship with the university (in some cases for more than two decades).

In the case of the older female APs, we do not observe such a long-term relationship with the university, even though most of them point out that they began working as APs after finishing their PhD dissertations. Furthermore, on average, their extra-academic activities are less prestigious than the extraacademic activities of the older male APs. Nevertheless, their interviews highlight how the uncertain prospects for the short and long-term oblige them not simply to find additional work to economically support their desire of pursuing an academic

\footnotetext{
${ }^{26}$ So, for example, the striking answer of a 59 year-old male AP to the question about the main positive and negative aspects of working as an AP: "The gratification does not derive from the legal or economic recognition of the work. The damage consists in the frustration of fulfilling high office, without having any recognition for your career." To the question about his feeling part of academia, he stressed that "it is intermittently psychologically devastating." This aspect also emerges in the ambivalent relationship with his colleagues: "I'm respected by my colleagues, but in general, as an adjunct professor, you are considered 'a child of a lesser God"' [translation by Barbara Grüning].
}

career, but to search for jobs that could become an alternative professional strategy. This double professional strategy, in addition to the awareness of occupying a marginal position, leads them to feel that they only partially belong to the academic world.

Thus, from this perspective, if we compare the whole sample of interviews, we find more affinities if we consider the gender variable rather than age. So, for instance, even the younger female APs express a similar "strategic perspective" of constructing more than one professional path. Furthermore, they make clear how most of them have been following this double professional strategy since receiving their undergraduate or $\mathrm{PhD}$ degree. It is probably not the case that more younger female APs than younger male APs have obtained permanent employment outside academia (in either the public or private sector). What is not taken-for-granted, however, is that this job also constitutes, in some cases, their main professional identity. On the other hand, this position is also shared by those younger female APs who are or have been research fellows. By explaining, then, to what extent they feel they belong within academia, they restrict their membership to the specific activities they carry out and to the temporal limit of their contracts. Some of the older female APs even emphasize that, while they feel they do belong to the university where they work, they do not feel part of the scientific community, implying that belonging to it would require further qualifications and crossing institutional boundaries.

Turning now to the interviews of the older and younger male APs, we also notice an ambivalent feeling between being included in and excluded from academia. What differs from the women's narratives are the different temporal meanings given to this feeling, the foundation of their self-image as academics, and the image attributed by others from within the "institution" (colleagues, administrative staff, students) as members (or not) of "academia." Thus, more than their female counterparts, male APs claim they possess personal scientific competences which are often underestimated by the "institution" or the "system" (the economic parameter is also crucial, see footnote 22), even though they are recognized by their colleagues (permanent and non-permanent staff). Part of these competences, however, cannot be objectified. Thus, differently from women, who pay more attention to reaching the objective criteria defined by the universities for "measuring" their competences both in teaching and research, male APs believe that their value as "scholars" or "professors" cannot be reduced to these objective criteria. Moreover, some of them consider these criteria as penalizing their experience within the university, which is defined not only by their past and present teaching activities, but also by their higher tendency and intention to participate in the whole academic life. Hence, having constructed their academic identity on the basis of the time they have spent over the years working at the university, they perceive their "exclusion" from it more deeply than women, who mainly base their sense of belonging on their "temporary" routines ${ }^{27}$. So,

\footnotetext{
${ }^{27}$ So, for example, the answer of a 49 year-old female AP about her relationship with her colleagues: "usually I meet my colleagues who have a tenured position at conferences. I can say that our relationships are very good. Well, they all know my desperate situation and that I will probably never get a tenured position.
} 
the sense of "exclusion" acquires different meanings between male and female APs. For male APs, it is strongly related to a still missing, and probably never arriving, stabilization of their "position," which could ensure their academic identity. For female APs, instead, it is more related to their everyday academic practices and relationships, which are often negative or inexistent ${ }^{28}$.

Almost all the female APs mention negative episodes they experienced in the workplace, which in turn highlight three kinds of negative relationships. The first concerns a general disregard on the part of the permanent staff toward their difficulties in carrying out their jobs, that is, of completing the same tasks as the tenured professors, despite their very different working conditions. The second concerns a higher perception of the existence of academic power relationships. If these power relationships structurally depend on the different positions that tenured and contract professors occupy, they are also practiced and performed daily, limiting in part the teaching autonomy of APs. The third concerns "competition" either among peers (APs and/or research fellows) or with those who have recently obtained a tenured position. Despite these negative experiences, in their narratives they stress how they cognitively and practically react by creating emotional distance from the academic world. As a result, they also have a less idealized concept of academic life and relationships than male APs (see, for instance, footnote 28). Those who are still active in research state that they are part of scientific networks which they construct mainly outside the university where they teach. Not less, they also add that they see these networks as temporary until they have the economic possibility of carrying out research activities (publications, participation in conferences and seminars, etc.). Finally, differently from male APs, female APs more strongly emphasize a lack of collaboration and organization in their degree courses. In this way, they also stress again how their position and life as APs are strictly related to the concrete activities they carry out and to the concrete relationships they establish for carrying them out. In the case of male APs, in contrast, it seems that the "exclusion" they feel is mainly a personal question, that is, it is more related to the fact that they still have not obtained a tenured position.

Thus, to move toward our conclusions, whereas factually both the survey and the semi-structured interviews, supported by the international literature we reviewed, confirm that women's experiences of academic life are more negative than men's, the latter express more negative feelings toward their conditions. This stems from the fact that they have invested more personally

Nevertheless, I don't have to thank them for anything, and they don't owe me anything. So, the relationship is friendly" [translation by Barbara Grüning].

${ }^{28}$ In this regard, the answer of a 42 year-old female AP to a question about positive and/or negative episodes concerning her work within the university, is paradigmatic: "I'd like to start with a negative episode. I will never forget when a professor-nowadays a full professor, with whom I was working at the time in a University in southern Italy-told me "Grazia" [author's note the name of the AP has been changed] you may be both smart and qualified, but academically speaking, you are an orphan, so you cannot go anywhere" [translation by Barbara Grüning]. in academic life as the sphere of their self-realization, even though they possess more prestigious positions outside academia than female APs. Furthermore, the aspirations that male APs have to pursue an academic career are more supported by the presence of informal relationships, at least ideally. Conversely, women measure their possibilities of pursuing an academic career on the basis of both objective evaluation criteria and the objective power relationships which structure the specific academic or disciplinary fields in which they participate (cf. Bourdieu, 1984), that is, they are also more adherent to an objective understanding of career (cf. Hughes, 1958). Thus, whereas men see their lack of stabilization as a sign that undermines their whole identity as a person, women consider it more as the result of the logic of their academic/disciplinary fields, that is their general more precarious economic condition, which also influence on their temporal strategies, result in a sharp knowledge of the "career realities" (cf. Hughes, 1958, p. 128). As a result, for men the lack of recognition they experience as APs is more difficult for them to accept than for women.

On the other hand, male APs have a stronger "sense of belonging" than female APs, precisely because this feeling is not based on their temporary working conditions, but on their interior feeling of "being made" for teaching and researching. This belief makes it probable that male APs are more inclined to expect something and to continue to work at the university, until at least, as someone of them stressed, they are able to sustain these working conditions more psychologically than economically. Conversely, female APs, when they decide to stop (or are considering stopping) working at universities, put as the first reason a lack of time and the fact that this job causes a lot of physical stress, which also depends on the fact that they carry out additional work activities (often in different cities). Furthermore, more than male APs, they show that they have been more aware since they started as APs that this activity would not be very helpful for their academic careers, apart from the possibility of building their CVs.

In short, whereas male APs perceive a discrepancy between their self-image and the position they occupy, female APs adopt a viewpoint more in line with that of the institutions in order to understand, practically, what realistic possibilities they have within academia and which professional strategies they can pursue.

\section{CONCLUSIONS AND DISCUSSION}

In this article, we have tried to highlight specific forms of unpaid work, by looking at non-standard works within academia and by taking Italian APs as a paradigmatic case study. This choice was also due to the increasing split within the national and international academic market between research and teaching positions in terms of economic and social status, as well as job security. In this regard, we carried out a survey which reached 5,556 Italian APs, and we conducted semi-structured interviews in order to better understand their working conditions and how 
these working conditions influence both their concrete academic careers and aspirations.

We decided to conduct an analysis from the perspective of gender in order to investigate whether and to what extent differences among male and female APs can be observed even at this lowest social order of the academic structure. On the other hand, we consider the research results also to be meaningful for a wider reflection on the problematic role that women still occupy in the academic market, as well as in other productive fields (in Italy as well as abroad), especially those related to intellectual professions and informal forms of work.

The survey highlights how female APs are more exposed to the risk of unpaid work, earn less on average, and have a more fragmented work experience (considering both their academic and extra-academic activities) than male APs. Thus, from an economic and temporal viewpoint, they are more disadvantaged than men for investing in building an academic career. On the other hand, a further striking output of the survey is that female APs invest more time in teaching duties than their male counterparts, whereas their research outputs are inferior to the those of the latter. While this might depend on the fact that, in our sample, the male APs are older than the female APs, on the other hand, the more time the latter spend on teaching and the more their economic conditions oblige them to work at other jobs, the less time they have to devote to research. Two further indicators we considered in analyzing the data were the "degree of relational satisfaction within academia," and the degree of academic aspiration. With respect to the former, it is clearly evident that women perceive the academic milieu as unfriendly more than men do. With respect, instead, to the latter index, we did not find meaningful differences.

The semi-structured interviews have been useful for an indepth analysis of the meanings that male and female APs give to their jobs in order to better understand how their different working conditions concretely influence their academic aspirations. The main remarkable result is that female APs seem less interested than men in pursuing an academic career. In their narratives, women stress a more practical view of their position within the academic system and their academic work, which in turn derives from their economic conditions and more acute perception than men of the social structure of power relationships in their workplaces, which in Italy are strongly influenced by a familistic culture. As a result, it seems that women more than men, look for job opportunities outside of academia. Conversely, men seem to have a more idealistic vision of their working and being at the university, that is they have deeper interiorized the academic illusio, which is more based on a traditional (and familistic) view of the academic life, formally modified by the University reforms of the last four decades. Thus, independently from their economic and social status outside academia, male adjunct professors interiorize a greater sense of vocation to the academic profession than women, which is therefore pivotal in forming their habitus and orienting their practices. This sense of vocation seems, at the same time, to be supported by the fact that they feel more integrated than women in the workplace, which may also depend on a greater temporal (and mental) investment in academic relation and life. On the other hand, however, their stronger academic identity causes them more frustration when facing a perceived lack of recognition which they interpret as the lack of the possibility of obtaining a permanent position.

\section{DATA AVAILABILITY STATEMENT}

Due to the outlined ethical reasons, the dataset generated by this study is not publicly available. However, other datasets used in this study can be found in USTAT-MIUR (http://dati.ustat. miur.it/organization/ace58834-5a0b-40f6-9b0e-ed6c34ea8de0? tags $=$ Universit\%C3\%A0\&tags $=$ Personale) and CINECA (https:// cercauniversita.cineca.it).

\section{ETHICS STATEMENT}

In Italy, no local legislation was in effect when the authors began the survey. Furthermore, the authors did not consider it necessary to require an ethical review process since, for social research of this kind, neither the University of Bologna nor Bicocca required ethics committee approval, and no personal or sensitive data have been asked of the survey respondents. Individuals gave their consensus to participate in the survey by responding to a specific question, after having been informed about researcher contacts and purpose, and were assured that data would be anonymized and used only in aggregate and anonymized forms. The program we used for the survey allows the anonymization of the IP.

\section{AUTHOR CONTRIBUTIONS}

This article is the result of a collaborative common research work. We declare that BG wrote the introduction, experiencing academic life: a gender perspective, and conclusions and discussion sections. GD wrote the subjectivities at stake: the other side of non-standard work, academic careers in the neoliberal university, and the careers of APs: a general overview sections.

\section{ACKNOWLEDGMENTS}

We would like to thank the FLC-CGIL Trade Union and the network of precarious academic workers of the University of Bologna for their organizational support in the initial phases of the research and for supporting the dissemination of our research outputs.

\section{REFERENCES}

Agamben, G. (2006). Che cos'è un dispositivo? Rome: Nottetempo.

Archer, L. (2008). The new neoliberal subjects? Young/er academics' constructions of professional identity. J. Educ. Policy 23, 265-285. doi: 10.1080/02680930701754047 
Argenvall, P., and Beach, D. (2018). The exploitation of academic work: women in teaching at Swedish University. High. Educ. Policy 31, 1-17. doi: 10.1057/s41307-017-0041-0

Arimoto, A. (2015). "The teaching and research Nexus from an international perspective," in The Relevance of Academic Work in a Comparative Perspective, eds W. K. Cummings and U. Teichler (Cham: Springer), 91-106. doi: 10.1007/978-3-319-11767-6_6

Armano, E., and Murgia, A. (2012). Mappe della precarietà. 2, 2. Bologna: Emil di Odoya.

Armano, E., and Murgia, A. (2013). The precariousnesses of young knowledge workers: a subject-oriented approach. Glob. Discour. 3, 486-501. doi: 10.1080/23269995.2013.865313

Bataille, P., Le Feuvre, N., and Kradolfer Morales, S. (2017). Should I stay or should I go? The effects of precariousness on the gendered career aspirations of postdocs in Switzerland. Eur. Educ. Res. J. 2-3, 313-331. doi: $10.1177 / 1474904116673372$

Bellavitis, A. (2018). Women's Work and Rights in Early Modern Urban Europe. Cham: Springer International Publishing. doi: 10.1007/978-3-319-96541-3

Berger, P., and Luckmann, T. (1966). The Social Construction of Reality. New York, NY: Anchor Books.

Berger, P. L., and Berger, B. (1972). Sociology. A Biographical Approach. New York, NY: Basic Groups.

Bigi, M., Cousin, O., Méda, D., Sibaud, L., and Wieviorka, M. (2015). Travailler au XXIe siècle: des salariés en quête de reconnaissance. Paris: Laffont.

Blickenstaff, J. C. (2005). Women and science careers: leaky pipeline and gender filter? Gender Educ. 4, 369-386. doi: 10.1080/09540250500145072

Bourdieu, P. (1979). La distinction. Critique sociale du jugement. Paris: Les Editions de Minuit, English translation, Distinction: A Social Critique of the Judgement of Taste. Harvard University Press, 1984.

Bourdieu, P. (1984). Homo Academicus. Paris: Les Editions de Minuit.

Bourdieu, P. (1986), "The forms of capitals," in Handbook of Theory and Research for the Sociology of Education, ed. J. Richardson (New York, NY: Greenwood), 241-258.

Bourdieu, P. (1989). La Noblesse D'Etat. Paris: Editions de Minuit.

Bourdieu, P. (1993). The Field of Cultural Production. New York, NY: Columbia University Press.

Bourdieu, P. (1998). Practical Reason: On the Theory of Action. Stanford, CA: Stanford University Press.

Bourdieu, P., and Wacquant, L. (1992). "The logic of fields," in An Invitation to Reflexive Sociology, eds P. Bourdieu and L. Wacquant (Chicago, IL: University of Chicago Press), 115-140.

Capano, G., and Meloni, M. (eds.). (2009). Il Costo dell'ignoranza. L’università Italiana a la Sfida Europa 2020. Bologna: Il Mulino.

Dardot, P., and Laval, C. (2013). La nouvelle raison du monde. Essai sur la société néolibérale. Paris: La Découverte.

De Angelis, G. (2017). Soggettività in gioco: la gratuitizzazione del lavoro in una cooperativa sociale. Sociol. Lavoro 145, 133-150. doi: 10.3280/SL2017-145008

de Gaulejac, V. (2009). La société malade de la gestion: idéologie gestionnaire, pouvoir managérial et harcèlement social. Paris: Seuil.

Deem, R., and Lucas, L. (2007). Research and teaching cultures in two contrasting UK policy contexts: academic life in education departments in five english and Scottish Universities. High. Educ. 54, 115-133. doi: 10.1007/s10734-0069010-z

Delphy, C. (2004). Pour une théorie générale de l'exploitation: Deuxième partie: repartir du bon pied. Mouvements 31:97. doi: 10.3917/mouv.031.0097

Demazière, D., and Dubar, C. (1997). Analyser les Entretiens Biographiques. L'exemple de Récits dinsertion. Paris: Nathan.

Desrosières, A. (2010). Est-il bon, est-il mechant? Le rôle du nombre dans le gouvernement de la Cité neoliberale. Milan: Milano Bicocca.

Desrosières, A. (2011). The economics of convention and statistics: the paradox of origins. Hist. Soc. Res. 36, 64-81. Available online at: https://www.jstor.org/ stable/23032285

Dubar, C. (2000). La Socialisation. Construction des identités sociales et professionelles. Paris: Armand Colin.

Eagly, A. H. (2003). "Few Women at the top: how role incongruity produces prejudice and the glass ceiling," in Leadership and Power, eds D. van Knippenberg and M. A. Hogg (London: Sage), 79-93.

Ehrenberg, A. (1999). Lindividu incertain. Paris: Hachette.
Foucault, M., Ewald, F., Fontana, A., and Senellart, M. (2004). Naissance de la biopolitique: cours au Collège de France, 1978-1979. Paris: Gallimard : Seuil.

Foucault, M., and Gordon, C. (1980). Power/Knowledge: Selected Interviews and Other Writings, 1972-1977. New York, NY: Pantheon Books.

Fox, M. F. (2005). Gender, family, characteristics and publication productivity by scientists. Soc. Study Sci. 1, 131-150. doi: 10.1177/03063127050 46630

Fuller, S. (2009). The Sociology of Intellectual Life. Thousand Oaks, CA: Sage.

Fürth, E. (1906). Kulturideale und Frauentum. Leipzig: Dietrich.

Giancola, O., Grüning, B., and Toscano, E. (2016). "Luniversità dei precari: la destrutturazione di un ruolo e le strategie individuali di risposta," in (R)esistenze precarie. Capitalismo cognitivo e Università, ed. V. Pellegrino (Verona: OmbreCorte), 89-98.

Glass, C., and Cook, A. (2016). Leading at the top: Understanding women's challenges above the glass ceiling. Leadersh Q. 27, 51-63. doi: 10.1016/j.leaqua.2015.09.003

González Ramos, A. M., Navarrete Cortés, J., and Cabrera Moreno, E. (2015). Dancers in the dark: scientific careers according to a gender-blind model of promotion. Interdiscip. Sci. Rev. 40, 182-203. doi: 10.1179/0308018815Z.000000000112

Gramsci, A. (1939). "Quaderno. 22: Americanismo e fordismo," in Selections from the Prison Notebook eds Q. Hoare and G. N. Smith (New York, NY: International Publication)

Gramsci, A. (1978). Americanismo e fordismo: quaderno 22, ed. F. De Felice. Turin: G. Einaudi.

Heijstra, T. M., Steinthorsdóttir, F. S., and Einarsdóttir, T. (2017). Academic career making and the double-edged role of academic housework. Gender Educ. 6, 764-780. doi: 10.1080/09540253.2016.1171825

Heinich, N. (2008). Régime vocationnel et pluriactivité chez les écrivains: une perspective compréhensive et ses incompréhensions. Socio-logos. Revue de l'association française de sociologie. Available online at: http://socio-logos. revues.org/1793\#quotation (accessed February 21, 2015).

Henkel, M. (2005). Academic identity and autonomy in a changing environment. High. Educ. 49, 155-176. doi: 10.1007/s10734-004-2919-1

Hirsch, B. T., and Leppel, K. (1982). Sex discrimination in faculty salaries: evidence from a historically women's university. Am. Econ. Rev. 4, 829-835.

Honneth, A. (2003). Unsichtbarkeit. Frankfurt: Suhrkamp.

Hughes, E. (1958). Men and Their Work. Glencoe: The free press.

Illouz, E. (2007). Cold Intimacies: the Making of Emotional Capitalism. Cambridge: Polity.

ISTAT (1971). Annuario statistico dellistruzione italiana. IPZS Available online at: https://ebiblio.istat.it/digibib/Istruzione/ TO00176479AnnStatIstrItaVol22Ed1970.pdf.

Knoblauch, H. (2009). "Phänomenologische Soziologie," in Handbuch sociologische Theorien, eds G. Kneer and M. Schroer (Wiesbaden: VS Verlag), 299-322. doi: 10.1007/978-3-531-91600-2_15

Komlenac, N., Gustafsson Sendén, M., Verdonk, P., Hochleitner, M., and Siller, H. (2019). Parenthood does not explain the gender difference in clinical position in academic medicine among Swedish, Dutch and Austrian physicians. Adv. Health Sci. Educ. 24, 539-557. doi: 10.1007/s10459-01909882-9

Krinsky, J., and Simonet, M. (2019). Who Cleans the Park? Public Work and Urban Governance in New York City. Chicago, IL: The University of Chicago Press.

Leisyte, L. (2015). "Changing academic identity in the context of a managerial university - Bridging the duality between professions and organizations," in The Relevance of Academic Work in a Comparative Perspective, eds W. K. Cummings and U. Teichler (Cham: Springer), 59-73. doi: 10.1007/978-3-319-11767-6_4

Lyotard, J.-F. (1979). La condition postmoderne: Rapport sur le savoir. Paris: Editions de Minuit.

Menges, R. J., and Exum, W. H. (1983). Barriers to the progress of women and minority faculty. J. High. Educ. 2, 123-144. doi: 10.2307/1981567

Miller, H. (1995). "States, economies and the changing labour process of academics: Australia, Canada and the United Kingdom," in The changing Labour Process in Higher Education, ed. J. Smith (London: Open University Press), 40-59.

Morgan, R., George, A., Ssali, S., Hawkins, K., Molyneux, S., and Theobald, S. (2016). How to do (or not to do)... gender analysis in health systems research. Health Policy Plan. 31, 1069-1078. doi: 10.1093/heapol/czw037 
Moscati, R. (2001). Italian university professors in transition. High. Educ. 41, 103-129. doi: 10.1023/A:1026766829752

Murgia, A., and Poggio, B. (eds). (2018). Gender and Precarious Research Careers. London: Routledge. doi: 10.4324/9781315201245

Pool, M., Bornolt, L., and Summers, F. (1997). An international study of the gendered nature of the academic work: some cross-cultural exploration. High. Educ. 3, 373-396. doi: 10.1023/A:1003075907126

Rastello, L. (2014). I buoni. Prima edizione. Milan: Chiarelettere.

Rebora, G., and Turri, M. (2011). Critical factors in the use of evaluation in Italian universities. High. Educ. 61, 531-544. doi: 10.1007/s10734-010-9347-1

Salais, R. (2009). La democrazia deliberativa e le sue basi informative: lezioni dall'approccio delle capacita. la Rivista delle Politiche Sociali 3, 107-136.

Schultheis, F. (2000). Un inconscient universitaire fait homme : le Privatdozent. Actes de la recherche en sciences sociales 135, 58-62. doi: 10.3406/arss.2000.2701 Sennett, R. (1977). The Fall of Public Man. New York, NY: Norton.

Sennett, R. (2006). The Culture of the New Capitalism. New Haven, CT: Yale University Press.

Sennett, R. (2008). The Craftsman. New Haven, CT: Yale University Press.

Simmel, G. (1902). Weibliche Kultur. Neue Deutsche Rundschau 5, 504-515.

Simonet, M. (2018). Travail gratuit: la nouvelle exploitation? Paris: Textuel.

Slaughter, S., and Rhoades, G. (2004). Academic Capitalism and the New Economy. Baltimore, MD: John Hopkins University Press.

Standing, G. (1989). Global feminization through flexible labor: a theme revisited. World Dev. 17, 1077-1095. doi: 10.1016/0305-750X(89)90170-8
Standing, G. (2014). A Precariat Charter: From Denizens to Citizens. London; New York, NY: Bloomsbury.

Suaud, C. (1974). Contribution à une sociologie de la vocation : destin religieux et projet scolaire. Revue française de sociologie 15, 75-111. doi: 10.2307/ 3320263

Weber, M. (1913). Die Frau und die objektive Kultur. Logos 4, 328-363.

Weber, M. (1921). Wirtschaft und Gesellschaft. Tübingen: Mohr Siebeck.

Wolfinger, N. H., Mason, M. A., and Goulden, M. (2009). Stay in the game: gender, family formation and alternative trajectories in the academic life course. Social Forces 87, 1591-1621. doi: 10.1353/sof. 0.0182

Zelizer, V. A. R. (1997). The Social Meaning of Money. Princeton, NJ: Princeton University Press.

Conflict of Interest: The authors declare that the research was conducted in the absence of any commercial or financial relationships that could be construed as a potential conflict of interest.

Copyright $\odot 2020$ De Angelis and Grüning. This is an open-access article distributed under the terms of the Creative Commons Attribution License (CC BY). The use, distribution or reproduction in other forums is permitted, provided the original author(s) and the copyright owner(s) are credited and that the original publication in this journal is cited, in accordance with accepted academic practice. No use, distribution or reproduction is permitted which does not comply with these terms. 


\section{OPEN ACCESS}

Edited and reviewed by: Annalisa Murgia,

University of Milan, Italy

*Correspondence:

Gianluca De Angelis gianluca.deangelis@unibo.it

Barbara Grüning

barbara.gruning@unimib.it

Specialty section:

This article was submitted to Work, Employment and Organizations,

a section of the journa

Frontiers in Sociology

Received: 04 April 2020

Accepted: 17 April 2020

Published: 19 May 2020

Citation:

De Angelis G and Grüning B (2020)

Corrigendum: Gender Inequality in

Precarious Academic Work: Female

Adjunct Professors in Italy.

Front. Sociol. 5:31.

doi: 10.3389/fsoc.2020.00031

\section{Corrigendum: Gender Inequality in Precarious Academic Work: Female Adjunct Professors in Italy}

\author{
Gianluca De Angelis ${ }^{1 *}$ and Barbara Grüning ${ }^{2 *}$ \\ ${ }^{1}$ Department of Sociologia e Diritto dell'Economia, University of Bologna, Bologna, Italy, ${ }^{2}$ Department of Sociologia e Ricerca \\ Sociale, University of Milan Bicocca, Milan, Italy
}

Keywords: unpaid work, adjunct professor, academic career, gender inequalities, Italy

\section{A Corrigendum on}

Gender Inequality in Precarious Academic Work: Female Adjunct Professors in Italy by De Angelis, G., and Grüning, B. (2020). Front. Sociol. 4:87. doi: 10.3389/fsoc.2019.00087

In the original article, there was a mistake in the legend for Figure 4. The second wage range is Between $10,000 €$ and $25,000 €$, so the third is Over 25,000 $€$. The same error affects the text describing the figure. The correct legend appears below and a correction has been made to the The Careers of APs: A General Overview section, paragraph 10:

"Figure 4 shows the distribution of wage ranges by sex and age. In all the age groups, the number of workers earning up to $€ 10,000^{13}$ is greater among women than men, whereas in all the age groups, the male rate of APs with a wage higher than $€ 25,000$ per year is almost double the female rate. The difference by gender is even greater among younger APs earning more than $€ 25,000$ per year, with an incidence of $19.5 \%$ for men and $7.7 \%$ for women. Furthermore, beyond having lower wages, female APs also have a more fragmented work experience. Indeed, if on average, the majority of APs who declare extra-academic work contracts are either self-employed (30.6\%) or permanent employees, both categories are higher among men (34.1 and 23.2\%) than among women (26.2 and 20.7\%). By contrast, more women than men carry out informal work (20.1\% vs. $17.4 \%)$, have fixed-term employment contracts ( $9 \%$ vs. $6.1 \%$ ), or mixed forms of semi-employed contracts (24.1\% vs. $18.8 \%) . ”$

The authors apologize for this error and state that this does not change the scientific conclusions of the article in any way. The original article has been updated.

Copyright (C) 2020 De Angelis and Grüning. This is an open-access article distributed under the terms of the Creative Commons Attribution License (CC BY). The use, distribution or reproduction in other forums is permitted, provided the original author(s) and the copyright owner(s) are credited and that the original publication in this journal is cited, in accordance with accepted academic practice. No use, distribution or reproduction is permitted which does not comply with these terms.

\footnotetext{
${ }^{13}$ We considered here all the jobs carried out by the respondents, both within and outside academia.
} 


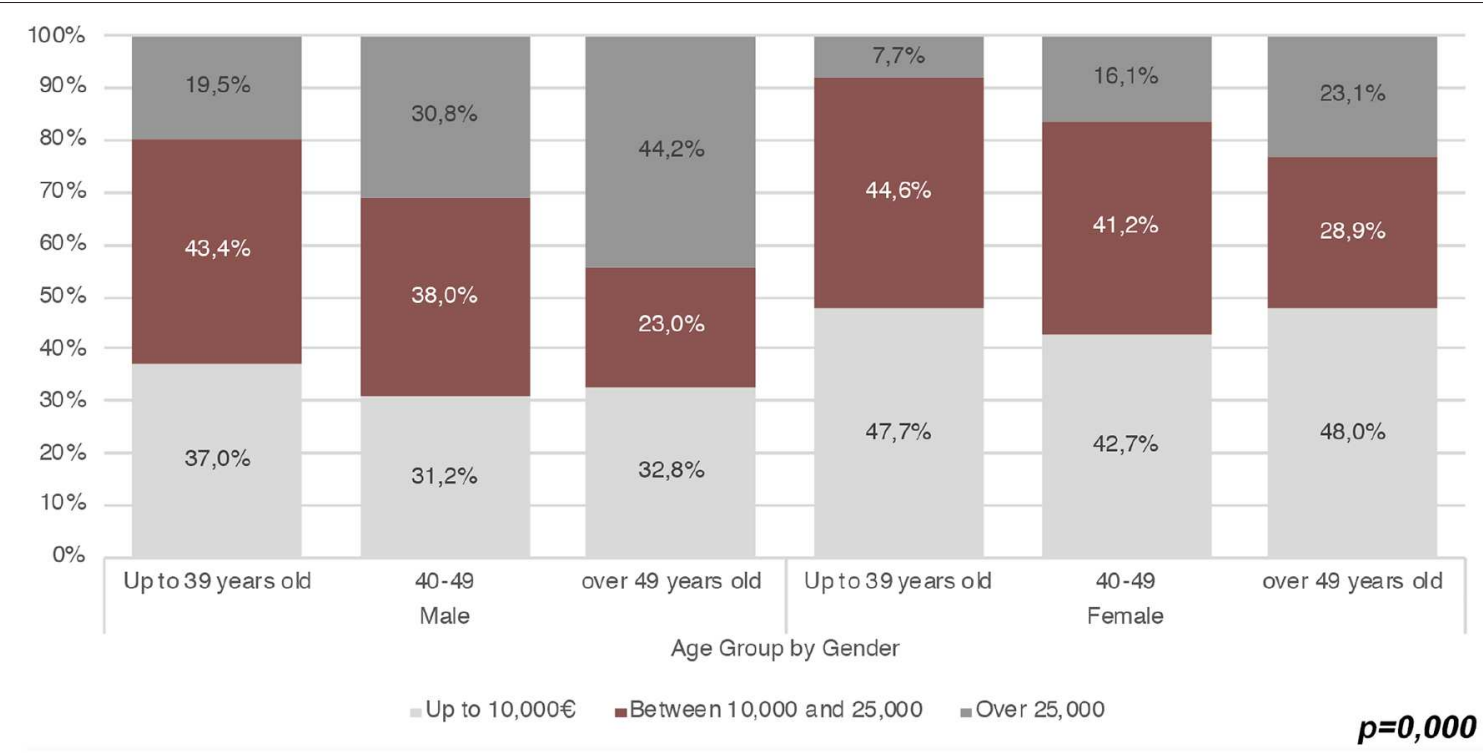

FIGURE 4 | Wage range and distribution by age and gender (Source: our survey). 


\section{OPEN ACCESS}

Edited by:

Andrzej Klimczuk,

Independent Researcher,

Białystok, Poland

Reviewed by:

Robert MacKenzie,

Karlstad University, Sweden

Ines Wagner,

Institute for Social Research Norway,

Norway

*Correspondence:

Annalisa Murgia

annalisa.murgia@unimi.it

Specialty section:

This article was submitted to Work, Employment and Organizations,

a section of the journal

Frontiers in Sociology

Received: 13 August 2019 Accepted: 10 December 2019 Published: 21 January 2020

Citation:

Murgia A, Bozzon R, Digennaro $P$ Mezihorak $P$, Mondon-Navazo $M$ and Borghi P (2020) Hybrid Areas of Work

Between Employment and

Self-Employment: Emerging Challenges and Future Research

Directions. Front. Sociol. 4:86

doi: 10.3389/fsoc.2019.00086

\section{Hybrid Areas of Work Between Employment and Self-Employment: Emerging Challenges and Future Research Directions}

\author{
Annalisa Murgia*, Rossella Bozzon, Pierluigi Digennaro, Petr Mezihorak, \\ Mathilde Mondon-Navazo and Paolo Borghi
}

Department of Social and Political Sciences, University of Milan, Milan, Italy

The growth of non-standard employment relations has created one of the major challenges in terms of workers' rights as well as collective representation in European societies. Among non-standard employment relations, so-called "solo self-employed" - self-employed workers without employees-are challenging the very foundations of our labor markets, that is to say the opposition between employers and employees, fostering the development of emerging "hybrid" areas of work. The heterogeneity of the solo self-employed is difficult to capture from official statistics, which are still based on traditional classifications, and questions also the legal categories that qualify these workers. Moreover, the fact that solo self-employed workers do not form a homogenous group, and are diverse in terms of their activities, interests and needs, calls for changes in the way trade unions, employer organizations, and new freelancer associations develop collective actions, claims-making activities, and strategies of organizing. With the aim to achieve an in-depth understanding of the increasingly extensive and populated categories of the solo self-employed, this contribution aims at reconstructing the state of the art within different fields of study, such as employment relations, labor law, industrial relations and social movements, and at offering some possible future research directions.

Keywords: hybridity, solo self-employment, comparative research, cross-national ethnography, labor laws, collective forms of representation

\section{INTRODUCTION}

The growth of non-standard employment relations has created one of the major challenges in terms of workers' rights as well as collective representation in European societies (Cordova, 1986; Supiot et al., 1998). Among non-standard employment relations, the so-called "solo self-employment"-self-employed workers without employees or "own account workers"-is increasingly intertwined with precarious forms of work, in which individuals have low legal protection, a limited coverage in terms of social security provisions, little capacity for savings, insurance or pensions, and are hardly included in traditional interest representation (Stanworth and Stanworth, 1995; Schulze Buschoff and Schmidt, 2009; Dekker, 2010; Keune, 2013; Spasova et al., 2017; Jansen and Sluiter, 2019). On top on this, solo self-employment is a category that is challenging our understanding of the nature of employment relationship, that is to say 
the opposition between employers and employees, and is also encouraging discussion around the emergence of "hybrid" areas of work (Murgia et al., 2016; Armano and Murgia, 2017; Murgia and Pulignano, 2019).

The heterogeneity of the solo self-employed is difficult to capture from official statistics, which are still based on traditional classifications, and also questions the legal categories that that these workers qualify for (D'Amours and Crespo, 2004; Muehlberger and Pasqua, 2009; Cappelli and Keller, 2013; Cieślik, 2015; Bennaars, 2019). Moreover, the fact that solo selfemployed workers do not form a homogenous group, and are diverse in terms of their activities, interests and needs, calls for changes in the way trade unions, employer organizations, and new freelancer associations develop collective actions, claimsmaking activities and strategies of organizing (Heery and Abbott, 2000; Pernicka, 2006; Gumbrell-McCormick, 2011; Wynn, 2015; Jansen, 2017). This contribution aims at introducing the main emerging challenges discussed within different fields of study, such as employment relations, labor law, industrial relations and social movements. In the conclusions, a future agenda for research is proposed, with the aim of contributing to the development of transdisciplinary and multi-method approaches, more able to grasp the emerging "hybrid areas of work" and achieve an in-depth understanding of the increasingly extensive and populated categories of the solo self-employed.

\section{TRENDS AND HETEROGENEITY OF SOLO SELF-EMPLOYMENT}

The twentieth century was marked by a constant decline in selfemployment in favor of an increase in salaried employment, mainly due to the rise of the "Fordist model" (OECD, 2000; Supiot, 2001). In recent decades, however, there has been a reversal of this trend and a progressive increase in the number of self-employed workers in Europe, particularly when looking at the self-employed without employees (or "own account workers"). At the macro level, three main drivers have been identified to explain this trend. Firstly, solo self-employment has been a response to the shift from the industrial to a service economy and to the deep (de)regulation processes that have affected all European countries, including the erosion of the social position of many workers and, in some cases, the increased levels of unemployment (see Arum and Müller, 2004). Secondly, there have been unprecedented changes connected to internationalization, new technologies and decentralization of production, with increasing outsourcing activities by enterprises (see Bologna, 2018). Finally, socio-cultural trends have played a crucial role too, mainly by promoting autonomy and the idea of becoming "entrepreneurs of themselves" (Foucault, 2008) as the model to aspire.

In this common frame, however, the heterogeneity of solo selfemployed workers is extremely high. In terms of sectors, they can be found in areas with many high-skilled professionals as well as in low-skilled jobs: from civil engineering, journalism and ICT, to care homes, agriculture and construction (Eichhorst et al., 2013). As regards their composition, women are increasingly involved in these work arrangements, as well as young people and migrant workers (both among those starting micro-businesses and those hired on a solo self-employed contract because of a lack of other options, possibly related to their migrant status) (Mills and Blossfeld, 2005; Muehlberger and Pasqua, 2009; Galgóczi et al., 2012; Bozzon and Murgia, 2020). Moreover, the solo selfemployed are variously distributed within the European Union (see Figures 1, 2). Indeed, in 2015, some countries had selfemployment rates below 10\% (8\% in Denmark and 9\% in Estonia and Luxembourg) and some countries had quite high rates, such as Greece (31\%) and Italy (23\%) (Eurofound, 2017).

Official statistics are then able to distinguish between selfemployed workers with and without employees. In some cases, it is also possible to identify "dependent self-employed workers," who do not have neither employees nor economic autonomy and control over their business (Eichhorst et al., 2013; Eurofound, 2017; Mondon-Navazo, 2017). However, beyond these classifications, statistics do not currently allow for consideration of the high heterogeneity of solo self-employment, where we can find genuine self-employment, but also a growing precariousness (including among workers who enjoy working as freelancers), as well as bogus or imposed false selfemployment (Schulze Buschoff and Schmidt, 2009; Westerveld, 2012; Leighton, 2015; Borghi et al., 2018; Conen and Schippers, 2019). Moreover, these conditions may occur to the same person, and possibly even simultaneously, especially to those people who perform different jobs at the same time. Therefore, the increasingly blurred boundaries between self-employment and employment are challenging not only the indicators used by labor force surveys, but the very analytical categories used by academic scholars. The current debate is struggling to analyse these emerging hybrid areas of work, which are, in addition, differently regulated by welfare systems and labor laws at national level.

\section{SELF-EMPLOYMENT IN THE FRAME OF LABOR LAW}

As mentioned in the previous section, the concept of selfemployment embraces a large variety of situations-such as bogus self-employment, economically dependent autonomous workers, platform workers, self-employed persons offering personal work or service to a multitude of clients/customers, small entrepreneurs and so on-that are also challenging the current juridical categories. Despite the described rapid changes in the few last decades, most of the national labor law systems still revolve around a dichotomy between subordinate/dependent employment, on the one hand, and autonomous/independent self-employment, on the other.

The self-employment concept is normally carved out in contrast with that of subordination. If one looks both at the statutory definitions of the concepts of employment, employee or contract of employment, as well as at the tests that courts have developed in many European countries, it is possible to realize that there is a common core of criteria that have been used to identify subordinate employment (Davidov et al., 2015; Countouris and De Stefano, 2019). The main criteria generally 

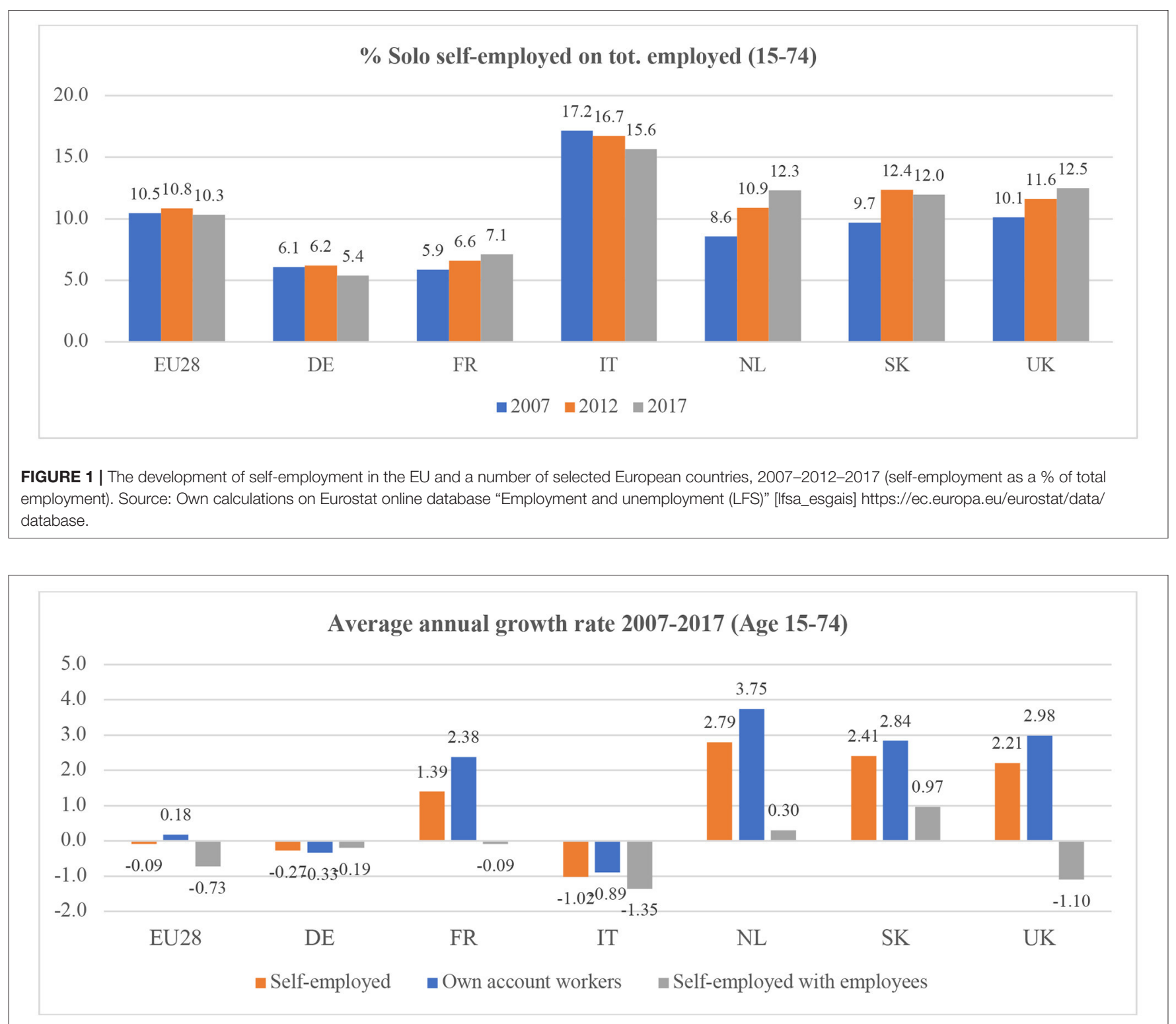

FIGURE 2 | Average annual growth of self-employment in the EU and a number of selected European countries, 2007-2017. Source: Own calculations on Eurostat online database "Employment and unemployment (LFS)" [lfsa_esgais] https://ec.europa.eu/eurostat/data/database.

adopted, among others, can be brought back to three related macro-sets: hetero-direction of the work and its external control, which implies the power for the employer to give instructions and direct the employee's work; hetero-organization, which means that the performed work is integrated into someone else organization and business; and risk assessment, which essentially investigates whether the worker takes the ultimate risk of loss or chance of profit (Digennaro, 2019). Since the employment contract can also be described as a set of powers in favor of the employer, a different perspective assembles the criteria utilized in different legal traditions worldwide around the investigation into the presence of hierarchical power (which entails directional, control and disciplinary powers) (Casale, 2011).
Considering the above criteria, it is easy to observe how they match well with the "Taylor-Fordist model," in which large companies were engaged in mass production on big factories, where the workforce was arranged according to a pyramidalhierarchical organization. When the way of production changed and vertical integration was abandoned, many workers who performed tasks as employees in substance started to be formally engaged as self-employed or sub-contractors to reduce costs. Therefore, the new social reality has made it more complicated for normative systems to organize work organization through the category of subordination. The issues that this phenomenon raised are 2-fold. First, since the set of laws directed at protecting labor relied on the concept of subordination, the consequence of 
an extensive recourse to self-employment has been the exclusion from the domain of the employment protection legislation of broad classes of the active workforce (Collins, 1990). In many countries, the legislators' response has consisted in the extension, to varying degrees, of portions of labor and social rights to workers who are in a position of economic dependence or quasi-subordination by means of different techniques. Secondly, despite the similar position that the bogus and economically dependent self-employed share with subordinate employees, the former category does not always have access to the full enjoyment of trade union rights, and particularly to the right of collective bargaining, because of the competition law both at national and EU levels (Rubiano, 2013; De Stefano and Aloisi, 2018).

\section{THE COLLECTIVE REPRESENTATION OF SOLO SELF-EMPLOYED WORKERS}

The progressive erosion of the standard employment relations has also prompted debate on the adequacy and effectiveness of structures and methods of collective representation. In the attempt to explore the substantial gap in union density between standard and non-standard workers, the current scientific debate is mainly focused on explaining national differences in unions' responses to the expansion of atypical jobs. Everywhere, unions have to deal with the emergence of a variety of atypical employment relationships-fixed-term, temporary agency and wage-limited part-time contracts, as well as solo self-employed positions-with low employment security and pay levels, which weaken the collective agreements and the minimum-wage bargained for dependent and permanent employees (Hyman, 1999; Heery and Abbott, 2000). However, in many countries, unions-whose members traditionally formed a homogeneous group of workers-struggle to deal with such fragmentation and different interests, and often continue to use their traditional strategies to curb temporary employment and tackle the precarious aspects of such contracts (Pernicka, 2005). It is especially in national contexts with strong legal employment protections that unions have belatedly developed bargaining capacities that addressed temporary workers. In more deregulated institutional regimes, like that of the UK, there are instead many examples of trade unions organizing in areas of casual or insecure employment, such as transport and construction, as well as the creative industries (Heery et al., 2004; Böheim and Muehlberger, 2006; Saundry et al., 2006; MacKenzie, 2009, 2010; Simms and Dean, 2015).

At present, despite the fact that most national trade unions have the right to recruit and organize self-employed workers, they are at the same time aware that they had not done enough for this category of workers in the past. Therefore, organizing and extending collective bargaining to the self-employed is now perceived as a priority across Europe (Fulton, 2018). Over the last 10 years, a number of scholars have studied the integration of the self-employed into union movements in Europe (Pernicka, 2006; Pedersini and Coletto, 2009; Gumbrell-McCormick, 2011; see Countouris and De Stefano, 2019), including the representation of platform workers, who are also part of the kaleidoscopic world of self-employment (Lenaerts et al., 2018; Vandaele, 2018). In general, there are differing views on the changing face of collective representation, and specifically on the future of collective bargaining for the solo self-employed (Keune, 2013). To use a standard categorization, they can be distinguished in the industrial unionism providing vertical integration of individuals in the same workplace regardless of occupation, and in the craft unionism providing horizontal extension by enlarging similar occupational groups instead. Also, in some countries, trade unions have even opposed the growth of solo self-employment, fearing that it would have undermined both standard employment relations and union solidarity (Goslinga and Sverke, 2003; Pernicka, 2006).

More recently, research has begun to investigate to what extent and under which conditions the solo self-employed are able to develop collective practices of organizing, focusing not only on unions, but also on chambers of commerce, business associations, cooperatives, new freelancers associations, and more grassroots claims-making activities (Murgia and Selmi, 2012; Battisti and Perry, 2015; Wynn, 2015; Brandl and Lehr, 2016; Hyman and Gumbrell-McCormick, 2017; Jansen, 2017; Bologna, 2018; Mezihorák et al., 2019; Murgia and de Heusch, 2020). In fact, given their heterogeneous composition, it is not surprising that this hybrid group of workers encounters difficulties in being represented by traditional systems of collective representation. The forms of organization through which self-employed workers mobilize are very different from one another, as is the range of what they are able to offer. For instance, collective bargaining is mainly carried out by unions and employer organizations, while other services can be offered by different types of association, such as legal and financial advice, work insurance, training, better access to social protection, involvement in collective consultation by government or local authorities, and new forms of mobilizing to improve working conditions.

\section{OUR PROPOSAL FOR A FUTURE RESEARCH AGENDA}

Having critically discussed the main emerging challenges about the growing group of solo self-employed workers in different fields of study, this contribution aims at participating in this articulated debate by proposing a future research agenda able to allow a more fine-grained analysis of the heterogeneous category of solo self-employment. With this in mind, a transdisciplinary and multi-method original research approach is discussed, through which to study the "hybrid areas of work" and their impacts on national labor force surveys, labor laws and collective forms of representation.

From a theoretical perspective, the research on solo selfemployment is fragmented into different fields of study and methodological approaches, which rarely open conversations to discussions from different disciplinary and epistemological angles. Many studies have been conducted with a quantitative causal-comparative approach, focused on the impact of these forms of employment on the enjoyment of workers' rights, social protection, and collective representation (e.g., Arum and 
Müller, 2004; Eichhorst et al., 2013). Other authors have instead explored the same phenomenon focusing on the meanings that solo self-employed workers attribute to their positions in the labor market (e.g., Barley and Kunda, 2004; Osnowitz, 2010; Armano and Murgia, 2017). This non-communicability of perspectives has proved to be an opportunity to reflect on the significance of engaging with different approaches and fields of study.

In studying solo self-employment, a promising future research pathway could be paved by opening a conversation between labor law, employment and industrial relations, and social movements studies, therefore fostering a "transdisciplinary approach" to the study of the hybrid areas of work. Differently from the idea of interdisciplinarity, where diverse disciplines are combined and integrated, along with their methodologies and assumptions, transdisciplinarity defines research focused on problems that cross disciplinary boundaries, aiming at a holistic approach and at a unity of knowledge (Arthur et al., 1989; Zaman and Goschin, 2010). In particular, a "subject-oriented" perspective (Beck and Beck-Gernsheim, 1996; Armano and Murgia, 2013) could be particularly appropriate for pursuing this objective. This means to systematically take into account reciprocal impacts between subjects and social structures, keeping together a micro- and a macro level analysis, in order to understand how subjects are affected by social norms and institutions, but also how they can shape them in turn. In the attempt to adopt this perspective, and to better understand the consequences of solo self-employment for social and legal protection and collective representation, different levels of analysis need to be addressed at the same time:

- How national and European statistics illustrate the world of self-employment, focusing on how data are differently collected through surveys on the labor force and whether they allow for the understanding of how the world of work is evolving;

- How the figure of the solo self-employed is regulated in labor laws at national and supranational levels, taking into account both the individual and the collective dimensions;

- How forms of collective representation are emerging, focusing both on the more institutionalized collective actors, such as unions and employer organizations, and the more fluid and new associations, cooperatives, grassroots groups, and forms of social movement unionism.

From a methodological perspective, pursuing this research agenda requires the use of a "multi-method research design" (Morse, 2003), which means that different methods are used in the same project, each conducted rigorously and complete in itself, and then used together to form essential components of a single research programme. In particular, multi-sited and cross-national ethnographies (Marcus, 1995; Mangen, 1999) can be particularly suited to the exploration of an emergent and transnational process-as it is the case of the emergence of "hybrid areas of work"-because of its capacity to combine interpretative "thickness" with comparability among different national contexts. Moreover, the "ethnography of contemporary worlds" is considered to be a multiple method on both a theoretical and technical level. In terms of research techniques, participant observation has become one among several tools of ethnography, which cannot renounce the analysis of documents, the reconstruction of the legal framework, the use of statistical data, and every technique that allows researchers to grasp and show the complexity and the relations that converge on a given object of analysis (Colombo, 2001).

This approach is being adopted, both from a theoretical and a methodological standpoint, in the frame of the transdisciplinary and multi-method project SHARE-"Seizing the Hybrid Areas of work by Re-presenting self-Employment", with the rationale of achieving a thorough understanding of solo self-employment in six European countries: France, Germany, Italy, Slovakia, the Netherlands, and the United Kingdom. The national cases were selected on the basis of two main criteria. The first is a good balance between comparability and heterogeneity between the cases. In terms of comparability, in all the selected countries, selfemployment plays a particularly important role, either because it has grown considerably over the last 20 years or because its rate is particularly high in relation to the European average. In terms of heterogeneity, these countries differ in the ways they manage the solo self-employed, and are characterized by different welfare systems. Germany and France are usually classified as conservative welfares, but with different strategies concerning women employment (Palier, 2010); the Netherlands is a hybrid case between the social-democratic and conservative models (Kammer et al., 2012); Italy represents a Southern European welfare system, with a strong reliance on family support (Ferrera, 1996); the UK is a liberal welfare state and the Slovak welfare state has shifted from a universalistic approach to a residual social system and it has recently been characterized by several employment reforms (Fenger, 2007). The second criterion is the dynamism of the cases, which has meant selecting countries where there are, or have been, documented experiences of collective actions aimed at representing solo self-employed workers, union activities, the creation of new unions and more fluid associations, with the emergence of diverse social collective actors. One of the main objectives of the project is to understand how the processes of collective organizing among the solo selfemployed are connected to the spread of this category of workers, how they are culturally represented, and their level of inclusion in legal and social protection systems.

In the SHARE project, the aim is therefore, on the basis of the quantitative, qualitative and legal data collected at national level, to provide a comparative transdisciplinary analysis of how the figure of the solo self-employed differs across national contexts in terms of indicators used for their classification in national labor force surveys, employment regulations and protections, and collective representations. After this step, and on the basis of the comparative analysis, the aim is to conduct a European in-depth study on how the solo self-employed are measured, classified and represented. This means critically revising the European surveys on labor force to propose a new classification of solo self-employment; to analyse the European Union law taking into account the national legal frameworks by means of a comparison carried out with the help of cross-national ethnographic studies; and to explore the 
main European networks of solo self-employed workers-trade unions, associations and auto-organized networks-and to involve them in a common discussion on the data collected.

The future research agenda proposed in this contribution forms, therefore, the foundation of the ERC project SHARE, which is expected to bring a significant contribution to a more grounded understanding of the hybrid areas of work, with a particular focus on solo self-employment. The main aim is to be able, by applying the proposed transdisciplinary and multimethod approach, to construct interpretative categories able to reinvigorate the theoretical debate and challenge the old categories developed by difference with the Fordist model, such as "non-standard" or "a-typical." Indeed, the general agreement in the scientific debate on the erosion of "standard" work arrangements has not been enough to construct new conceptual categories and challenge the binary opposition between standard and non-standard, typical and a-typical, resulting in a contrast between "the One and the Other" (Derrida, 1967). In fact, although criticized by many, the current definitions are still anchored in the categories created ad hoc to interpret the Fordist model. In our view, however, to define the emerging hybrid areas of work, it is not sufficient to add or subtract some properties related to traditional employment categories, since the emerging work arrangements have specific distinguishing characteristics, and the criteria to identify them have completely changed. It is for this reason that they require original theoretical lenses and research techniques, which can be built by setting a research agenda based on collective transdisciplinary and multi-method approaches.

\section{DATA AVAILABILITY STATEMENT}

Publicly available datasets were analyzed in this study. This data can be found here Eurostat (2018).

\section{REFERENCES}

Armano, A., and Murgia, A. (2017). "Hybrid areas of work in Italy. Hypotheses to interpret the transformations of precariousness and subjectivity," in Mapping Precariousness, Labour Insecurity and Uncertain Livelihoods: Subjectivities and Resistance, eds E. Armano, A. Bove, and A. Murgia (London: Routledge), 47-59. doi: $10.4324 / 9781315593838-5$

Armano, E., and Murgia, A. (2013). The precariousnesses of young knowledge workers: a subject-oriented approach. Glob. Discourse 3, 486-501. doi: 10.1080/23269995.2013.865313

Arthur, M. B., Hall, D. T., and Lawrence, B. S. (eds.). (1989). "Generating new directions in career theory: the case for a transdisciplinary approach," in Handbook of Career Theory, eds M. B. Arthur, D. T. Hall, and B. S. Lawrence (Cambridge: Cambridge University Press), 7-25. doi: 10.1017/CBO9780511625459.003

Arum, R., and Müller, W. (eds.). (2004). "Self-employment dynamics in advanced economy," in The Reemergence of Self-Employment: A Comparative Study of Self-Employment Dynamics and Social Inequality, (Princeton: Princeton University Press), 1-35.

Barley, G., and Kunda, S. (2004). Gurus, Hired Guns, and Warm Bodies: Itinerant Experts in a Knowledge Economy. Princeton, NJ: Princeton University Press.

Battisti, M., and Perry, M. (2015). Small enterprise affiliations to business associations and the collective action problem revisited. Small Bus. Econ. 44, 559-576. doi: 10.1007/s11187-014-9607-z

\section{ETHICS STATEMENT}

The studies involving human participants were reviewed and approved by The research project SHARE has been reviewed and given a favorable opinion from:

- The ERC ethical review board on 22/02/2017Ref. Ares(2017)960489;

- The Research Ethics Committee of the University of Leeds on 13/09/2017, ethics reference LTLUBS-175;

- The Research Ethics Committee of the University of Milan on 08/11/2018, ethics reference No. 50/18;

- The Data Protection Officer of the University of Milan on 10/11/2018. The patients/participants provided their written informed consent to participate in this study.

The ERC ethics officer approved all the new elements submitted for ethics on $28 / 05 / 2019$.

\section{AUTHOR CONTRIBUTIONS}

This paper is an entirely collaborative effort by the all authors. If, however, for academic reasons individual responsibility is to be assigned. AM: wrote introduction and our proposal for a future research agenda. RB: trends and heterogeneity of solo self-employment. PD: the self-employment in the frame of labor law. PM, MM-N, and PB: the collective representation of solo self-employed workers.

\section{FUNDING}

The project SHARE-Seizing the Hybrid Areas of work by Re-presenting self-Employment-has been funded from the European Research Council (ERC) under the European Union's Horizon 2020 research and innovation programme (Grant Agreement No. 715950).

Beck, U., and Beck-Gernsheim, E. (1996). "Individualization and 'precarious freedoms': perspectives and controversies of a subject-oriented sociology," in Detraditionalisation: Critical Reflections on Authority and Identity, eds P. Helas, S. Lash and P. Morris (Cambridge: Blackwell), 23-48.

Bennaars, H. (eds.). (2019). "Social protection for the selfemployed: an EU legal perspective" in Self-Employment as Precarious Work: a European Perspective, (Cheltenham: Edward Elgar), 40-47. doi: 10.4337/9781788115032.00009

Böheim, R., and Muehlberger, U. (2006). Dependent Forms of Self-employment in the UK: Identifying Workers on the Border Between Employment and Selfemployment, IZA Discussion Paper No. 1963. (Bonn). doi: 10.2139/ssrn.932060

Bologna, S. (2018). The Rise of the European Self-Employed Workforce. Milano: Mimesis.

Borghi, P., Mori, A., and Semenza, R. (2018). Self-employed professionals in the European labour market. A comparison between Italy, Germany and the UK. Transfer Eur. Rev. Lab. Res. 24, 405-419. doi: 10.1177/1024258918761564

Bozzon, R., and Murgia, A. (2020). "Subjective work-family conflict. The challenge of studying self-employed workers," in Research Handbook on Work-life Balance, eds S. Bertolini and B. Poggio (Cheltenham: Edward Elgar).

Brandl, B., and Lehr, A. (2016). The strange non-death of employer and business associations: an analysis of their representativeness and activities in Western European countries. Econ. Indus. Democ. doi: 10.1177/0143831X16 669842

Cappelli, P., and Keller, J. R. (2013). Classifying work in the new economy. Acad. Manage. Rev. 38, 575-596. doi: 10.5465/amr.2011.0302 
Casale, G. (ed). (2011). The Employment Relationship: a Comparative Overview. Geneve: ILO

Cieślik, J. (2015). Capturing statistically the intermediate zone. between the employee and employer firm owner. Int. Rev. Entrepreneur. 13, 205-214.

Collins, H. (1990). Independent contractors and the challenge of vertical disintegration to employment protection laws. Oxf. J. Leg. Stud. 10, 353-380. doi: $10.1093 /$ ojls/10.3.353

Colombo, E. (2001). Etnografia dei mondi contemporanei. Limiti e potenzialità del metodo etnografico nell'analisi della complessità [Ethnography of contemporary worlds. Limits and potential of the ethnographic method in the analysis of complexity]. Rass. Ital. Sociol. 42, 205-230. doi: 10.1423/2565

Conen, W., and Schippers, J. (eds.). (2019). "Self-employment: between freedom and insecurity," in Self-Employment as Precarious Work: a European perspective, (Cheltenham: Edward Elgar), 1-21. doi: 10.4337/9781788115032.00006

Cordova, E. (1986). From full-time wage employment to atypical employment: a major shift in the evolution of labour relations. Int'l Lab. Rev. 125, 641-657.

Countouris, N., and De Stefano, V. (2019). New Trade Unions Strategies for New Forms of Employment. Brussels: ETUC. doi: 10.1177/2031952519872323

D'Amours, M., and Crespo, S. (2004). The dimensions of heterogeneity among own-account self-employed: Elements for a typology. Indus. Relat. 59:3.

Davidov, G., Freedland, M. R., and Countouris, N. (2015). "The subjects of labour law: "employees" and other workers,". in Research Handbook in Comparative Labour Law, eds M. Finkin and G. Mundlak (London: Edward Elgar), 115-131. doi: $10.4337 / 9781781000137.00011$

De Stefano, V., and Aloisi, A. (2018). Fundamental labour rights, platform work and human-rights protection of non-standard workers. Lab. Bus. Hum. Rights Law. 359-379. doi: 10.2139/ssrn.3125866

Dekker, F. (2010). Self-employed without employees: managing risks in modern capitalism. Politics Policy 38, 765-788. doi: 10.1111/j.1747-1346.2010. 00257.x

Derrida, J. (1967). L'écriture et la Différence [Writing and Difference]. Paris: Seuil.

Digennaro, P. (2019). Más allá del límite de la subordinación y la regulación de la parasubordinación [Beyond the limit of subordination and the regulation of parasubordination]. Análisis Laboral 500, 17-18.

Eichhorst, W., Braga, M., Famira-Mühlberger, U., Gerard, M., Horvath, T., Kahanec, M., et al. (2013). Social Protection Rights of Economically Dependent Self-employed Workers, IZA Research Report, 54. Available online at: http:// www.iza.org/en/webcontent/publications/reports/report_pdfs/iza_report_54. pdf (accessed November 02, 2019).

Eurofound (2017). Exploring Self-Employment in the European Union. Luxembourg: Publications Office of the European Union.

Eurostat (2018). Eurostat Online Database. Your Key to European Statistics. Available online at: https://ec.europa.eu/eurostat/data/database (accessed November 02, 2019).

Fenger, H. M. (2007). Welfare regimes in Central and Eastern Europe: Incorporating post-communist countries in a welfare regime typology. Contemp. Issues Ideas Soc. Sci. 3, 1-30.

Ferrera, M. (1996). The 'Southern model' of welfare in social Europe. J. Eur. Soc. Policy 6, 17-37. doi: 10.1177/095892879600600102

Foucault, M. (2008). The Birth of Biopolitics: Lectures at the Collège de France 1978-1979. Basingstoke: Palgrave Macmillan.

Fulton, L. (2018). Trade Unions Protecting Self-Employed Workers. Brussels: ETUC.

Galgóczi, B., Leschke, J., and Watt, A. (eds.). (2012). "EU Labour Migration and Labour Markets in Troubled Times," in EU and Labour Migration in Troubled Times-Skills Mismatch, Return and Policy Responses, (Adlershot: Ashgates), 1-45.

Goslinga, S., and Sverke, M. (2003). Atypical work and trade union membership: union attitudes and union turnover among traditional versus atypically employed union members. Econ. Ind. Democ. 24, 290-312. doi: 10.1177/0143831X03024002007

Gumbrell-McCormick, R. (2011). European trade unions and 'atypical' workers. Ind. Relat. J. 42, 293-310. doi: 10.1111/j.1468-2338.2011.00628.x

Heery, E., and Abbott, B. (2000). "Trade unions and the insecure workforce," in The Insecure Workforce, eds E. Heery and J. Salmon (London: Routledge), 155-180. doi: 10.4324/9780203446485.ch8

Heery, E., Conley, H., Delbridge, R., and Stewart, P. (2004). Beyond the enterprise: trade union representation of freelances in the UK. Hum. Resour. Manage. J. 14, 20-35. doi: 10.1111/j.1748-8583.2004.tb00117.x
Hyman, R. (1999). An Emerging Agenda for Trade Unions? Geneva: International Institute for Labour Studies, International Labour Organization.

Hyman, R., and Gumbrell-McCormick, R. (2017). Resisting labour market insecurity: old and new actors, rivals or allies? J. Ind. Relat. 59, 538-561. doi: $10.1177 / 0022185617714423$

Jansen, G. (2017). Solo self-employment and membership of interest organizations in the Netherlands: economic, social, and political determinants. Econ. Ind. Democ. doi: 10.1177/0143831X17723712

Jansen, G., and Sluiter, R. (2019). "The matter of representation: precarious selfemployment and interest organizations," in Self-Employment as Precarious Work: a European Perspective, eds W. Conen, and J. Schippers (Cheltenham: Edward Elgar), 216-237. doi: 10.4337/9781788115032.00020

Kammer, A., Niehues, J., and Peichl, A. (2012). Welfare regimes and welfare state outcomes in Europe. J. Eur. Soc. Policy 22, 455-471. doi: $10.1177 / 0958928712456572$

Keune, M. (2013). Trade union responses to precarious work in seven European countries. Int. J. Lab. Res. 5, 59-78.

Leighton, P. (2015). Independent professionals: legal issues and challenges. Int. Rev. Entrepreneur. 13, 81-92.

Lenaerts, K., Kilhoffer, Z., Akgü., and M. (2018) Traditional and new forms of organisation and representation in the platform economy. Work Organ. Lab. Glob. 12, 60-78. doi: 10.13169/workorgalaboglob.12.2.0060

MacKenzie, R. (2009). Union responses to restructuring and the growth of contingent labour in the Irish telecommunications sector. Econ. Ind. Democ. 30, 539-563. doi: 10.1177/0143831X09342626

MacKenzie, R. (2010). Why do contingent workers join a trade union? Evidence from the Irish telecommunications sector. Eur. J. Ind. Relat. 16, 153-168. doi: $10.1177 / 0959680110364829$

Mangen, S. (1999). Qualitative research methods in cross-national settings. Int. J. Soc. Res. Methodol. 2, 109-124. doi: 10.1080/136455799295087

Marcus, G. E. (1995). Ethnography in/of the world system: the emergence of multi-sited ethnography. Annu. Rev. Anthropol. 24, 95-117. doi: 10.1146/annurev.an.24.100195.000523

Mezihorák, P., Murgia, A., Mondon-Navazo, M., and Borghi, P. (2019). (De)fragmenting Representations. The Case of Solo Self-Employment in France, Italy and Slovakia. Vienna: International Labour Process Conference, 24-26 April.

Mills, M., and Blossfeld, H. P. (2005). "Globalization, uncertainty and the early life course. A theoretical framework," in Globalization, Uncertainty and Youth in Society: The Losers in a Globalizing World, eds H. P. Blossfeld, E. Klijzing, M. Mills, and K. Kurz (London: Routledge), 1-23. doi: 10.4324/9780203 003206

Mondon-Navazo, M. (2017). Analyse d'une zone grise d'emploi en France et au Brésil: les Travailleurs Indépendants Economiquement Dépendants (TIED) [Analysis of a grey zone of employment in France and Brazil: the economically dependent self-employed workers]. Revue Interventions Économiques, 58. doi: 10.4000/interventionseconomiques.3545

Morse, J. M. (2003). "Principles of mixed methods and multimethod research design," in Handbook of Mixed Methods in Social and Behavioural Research, eds A. Tashakkori and C. Teddlie (Thousand Oaks: Sage), 189-208.

Muehlberger, U., and Pasqua, S. (2009). Workers on the border between employment and self-employment. Rev. Soc. Econ. 67, 201-228. doi: 10.1080/00346760701875215

Murgia, A., and de Heusch, S. (2020). "It started with the artists and now it concerns everyone.' The case of Smart, a cooperative of 'salaried autonomous workers," in Pathways into Creative Working Lives, eds S. Taylor and S. Luckman (London: Palgrave).

Murgia, A., Maestripieri, L., and Armano, E. (2016). The precariousness of knowledge workers (part 1): hybridisation, selfemployment and subjectification. Work Organ. Lab. Glob. 10, 1-8. doi: 10.13169/workorgalaboglob.10.2.0001

Murgia, A., and Pulignano, V. (2019). Neither precarious nor entrepreneur: the subjective experience of hybrid self-employed workers. Econ. Ind. Democ. doi: 10.1177/0143831X19873966

Murgia, A., and Selmi, G. (2012). Inspire and conspire. Italian precarious workers between selforganization and self-advocacy. Interface J. Soc. Move. 4:181-196.

OECD (2000). "The partial renaissance of self-employment," in OECD Employment Outlook (Paris: Organisation for Economic Co-operation and Development), 
155-199. Available online at: https://www.oecd.org/employment/emp/ 2079593.pdf

Osnowitz, D. (2010). Freelancing Expertise: Contract Professionals in the New Economy. New York, NY: Cornell University Press.

Palier, B. (2010). A Long Goodbye to Bismarck? The Politics of Welfare Reforms in Continental Europe. Amsterdam: Amsterdam University Press. doi: $10.5117 / 9789089642349$

Pedersini, R., and Coletto, D. (2009). Self-Employed Workers: Industrial Relations and Working Conditions. Dublin: European Foundation for the Improvement of Living and Working Conditions.

Pernicka, S. (2005). The evolution of union politics for atypical employees: a comparison between German and Austrian trade unions in the private service sector. Econ. Ind. Democ. 26, 205-228. doi: 10.1177/0143831X05051516

Pernicka, S. (2006). Organizing the self-employed: theoretical considerations and empirical findings. Eur. J. Ind. Relat. 12, 125-142. doi: $10.1177 / 0959680106065024$

Rubiano, C. (2013). Precarious workers and access to collective bargaining: What are the legal obstacles? Int. J. Lab. Res. 5, 133-151.

Saundry, R., Stuart, M., and Antcliff, V. (2006). "It's more than who you know"Networks and trade unions in the audio-visual industries. Hum. Resour. Manage. J. 16, 376-392. doi: 10.1111/j.1748-8583.2006.00026.x

Schulze Buschoff, K., and Schmidt, C. (2009). Adapting labour law and social security to the needs of the "new self-employed"-comparing the UK, Germany and the Netherlands. J. Eur. Soc. Policy 19, 147-159. doi: $10.1177 / 0958928708101867$

Simms, M., and Dean, D. (2015). Mobilising contingent workers: an analysis of two successful cases. Econ. Ind. Democ. 36, 173-190. doi: $10.1177 / 0143831 \mathrm{X} 13501000$

Spasova, S., Bouget, D., Ghailani, D., and Vanhercke, B. (2017). Access to Social Protection for People Working on Non-standard Contracts and as Self-Employed in Europe. A Study of National Policies. Brussels: European Commission.
Stanworth, C., and Stanworth, J. (1995). The self-employed without employees-autonomous or atypical? Ind. Relat. J. 26, 221-229. doi: 10.1111/j.1468-2338.1995.tb00739.x

Supiot, A. (2001). Beyond Employment. Changes in Work and the Future of Labour Law in Europe. Oxford: Oxford University Press.

Supiot, A., Casas, M. E., Hanau, P., and Johansson, A. (1998). A European perspective on the transformation of work and the future of labor law. Comp. Lab. L. Pol'y J. 20:621.

Vandaele, K. (2018). Will Trade Unions Survive in the Platform Economy? Emerging Patterns of Platform Workers' Collective Voice and Representation in Europe. Brussels: ETUI Research Paper. doi: 10.2139/ssrn. 3198546

Westerveld, M. (2012). The 'new' self-employed: an issue for social policy? Eur. J. Soc. Security 14, 156-173. doi: 10.1177/138826271201400301

Wynn, M. (2015). Organising freelancers: a hard case or a new opportunity? Int. Rev. Entrepreneur. 13, 93-102.

Zaman, G., and Goschin, Z. (2010). Multidisciplinarity, interdisciplinarity and transdisciplinarity: theoretical approaches and implications for the strategy of post-crisis sustainable development. Theor. Appl. Econ. 12, 5-20.

Conflict of Interest: The authors declare that the research was conducted in the absence of any commercial or financial relationships that could be construed as a potential conflict of interest.

Copyright (c) 2020 Murgia, Bozzon, Digennaro, Mezihorak, Mondon-Navazo and Borghi. This is an open-access article distributed under the terms of the Creative Commons Attribution License (CC BY). The use, distribution or reproduction in other forums is permitted, provided the original author(s) and the copyright owner(s) are credited and that the original publication in this journal is cited, in accordance with accepted academic practice. No use, distribution or reproduction is permitted which does not comply with these terms. 
OPEN ACCESS

Edited by:

Valeria Pulignano,

KU Leuven, Belgium

Reviewed by:

Daniele Di Nunzio,

Fondazione Giuseppe Di Vittorio, Italy

Carlos J. Fernández Rodríguez,

Autonomous University of

Madrid, Spain

*Correspondence:

Patrick Dieuaide

Patrick.Dieuaide@sorbonne-nouvelle.fr

Christian Azaiis

christian.azais@lecnam.net

Specialty section:

This article was submitted to Work, Employment and Organizations,

a section of the journal

Frontiers in Sociology

Received: 28 June 2019

Accepted: 10 January 2020

Published: 19 February 2020

Citation:

Dieuaide $P$ and Azaïs C (2020) Platforms of Work, Labour, and Employment Relationship: The Grey

Zones of a Digital Governance.

Front. Sociol. 5:2

doi: 10.3389/fsoc.2020.00002

\section{Platforms of Work, Labour, and Employment Relationship: The Grey Zones of a Digital Governance}

\author{
Patrick Dieuaide ${ }^{1 *}$ and Christian Azaïs ${ }^{2 *}$ \\ ${ }^{1}$ Université de la Sorbonne Nouvelle, Paris, France, ${ }^{2}$ Conservatoire National des Arts et Métiers (CNAM), Paris, France
}

Drawing on numerous case studies, the article examines the specific conditions for organising and managing the employment relationship on digital labour platforms. We show that these conditions are largely due to the disruptive nature of the process of digitising the employee-employer relationship. Digitisation replaces the employment contract of the standard employment relationship with a triangular "worker-platform-customer" relationship. In this model, the boundaries of the employment relationship become opaque and more uncertain: the bond of subordination disappears, labour law gives way to commercial law, and the figures of the employer and the employee lose institutional visibility. The article seeks to clarify the contours of this "in-between" model and proposes the notion of the "grey zone," borrowed from geopolitics. This notion of the "employment grey zone" makes it possible to shift the researcher's perspective by focusing attention on practices and "intermediate spaces of regulation," which are relatively autonomous and endowed with their own dynamics. This framework of analysis broadens the perspective and helps to better understand the impact on the employment relationship of new forms of governance in a context of a digital turning point. The article first returns to the notion of the "grey zone" and argues on the foundations and interest of mobilising this notion in the field of industrial relations studies. The links between digital platforms and grey zones are then examined. In particular, we show that digital governance is based on a confusion of powers between coordination and leadership. The reflection continues in a third phase with an examination of digital management practices in two areas: the control of the activity of connected workers, and the production and management of externalities resulting from the operation of platforms. The article concludes with a discussion on the heuristic value of the notion of grey zones of employment.

Keywords: digital governance, grey zones, employment relationship, nudges, labour

\section{DIGITAL PLATFORMS AND EMPLOYMENT GOVERNANCE: INTRODUCTIVE ISSUES}

We are all familiar with the multinational company Uber and its legal wrangling with professional taxi drivers, and also with the conflict between Airbnb and the hotel industry. Uber experimented with an original business model based on bringing together customers and connected workers who have their own private car, a driving licence, a transport network company (TNC) drivers licence (for a chauffeur-driven car), and professional insurance; the premise behind 
Airbnb is to make private apartments available, renting them to customers, usually tourists, for a short time only. In both cases, neither the drivers' labour power nor the different types of capital involved belong to these companies. Uber owns no cars, and the workers who drive them are legally independent contractors; Airbnb, similarly, owns no accommodation; these two American giants are content to be merely intermediaries in the market.

With no real assets and a minimum number of permanent employees and allocating most of their budget to developing search engines and marketing (Acquier, 2017), digital platforms are companies that are also difficult to define in legal, institutional, and fiscal terms. For example, Uber-France is classified by statisticians at National Institute of Statistics and Economic Studies (INSEE) in the national classification of activities under code APE 8299Z ("other business support activities"), in fact in the similarly vague subset "enterprises not classified elsewhere," a heading that does not correspond to any of these businesses' known activities (catering service and mobility service). What is Uber's activity? Is Uber a service enterprise or a technology enterprise as its directors claim? Or is it a transport company, as it was recently described by the judges at the European Court of Justice? Similarly, one can wonder about the founding principles of the business model of this company, which after 8 years in business continues to record a loss, which declares a turnover of only 52 million euros (compared with an estimated turnover of 240 million for the G7 taxi company) and which, thanks to tax optimisation, pays the French state a derisory 1.4 million euros in taxes. More generally, and although not all platforms have such a high profile as Uber, the digitisation and transformation of these enterprises into hollow corporations enable them to free themselves from many legal and regulatory frameworks, whether in competition law, labour law, or tax law.

In addition, the activity of digital platforms like Uber's has its foundation in a very real technological and social base, with firm local attachments. Equipped with a data centre, smartphones, and an application (algorithm), their platforms underpin vast networks of local social relations. Players and/or activities are scattered geographically but are brought together, and among themselves, they create many market transactions on the basis of which these companies receive remuneration by charging a commission. From a management point of view, this role as market intermediary, with their ear as close to the ground as possible, is the provision of information services. Their aim is to facilitate exchanges by ensuring the quality of matches between the different platform users, by perfecting the algorithms in order to meet expectations better, and by guaranteeing the smooth running of transactions (Tirole, 2018).

In their role as market intermediary, digital platforms have proliferated in a growing number of sectors, and as a result, the scope of the triangulation principle (Dieuaide, 2018) has been widened considerably. At the boundaries between professional relations and the employment relationship, an alternative model is emerging, consisting of services between customers (suppliers) and independent contractors via a company (or a third party) that is largely autonomous vis-à-vis existing institutional frameworks (see Figure 1).

Based on the "click" economy (Casilli, 2019), digital labour platforms have been repeatedly denounced as the gravediggers of wage labour (Abdelnour, 2017). On the one hand, they encourage the outsourcing of business and corporate jobs (Drahokoupil and Fabo, 2016); on the other hand, they increase competition in the labour market and lead to a sharp deterioration of wages and working conditions (Eurofound, 2018).

However, we believe that many of these approaches underestimate the disruptive effects associated with the widespread dissemination of digital technologies (Wajcman, 2006). Digital platforms are not companies "like any other." By working on data collected from the internet community, platforms not only act as third party mediators for the production of informational services but also behave like prescribers in that
Company (Third party) / Digital platform

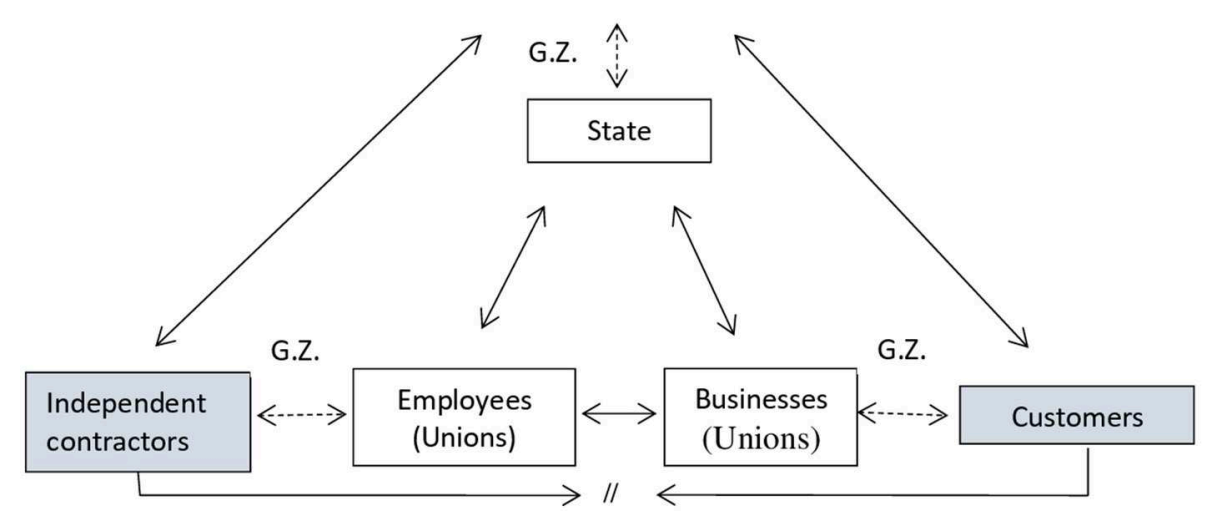

FIGURE 1 | Industrial relations, digital platform, and triangulation of the employment relationship. 
disseminated information enters directly into the agents' decision-making processes. Platforms are not only technological devices but also psychologically relevant entities (Carolus et al., 2018, p. 21). As many surveys have shown, this prescriptive power is a source of stress and addiction for the workers (Huws et al., 2016). Whether intentionally or not, it is therefore a source of confusion: in addition to being a service relationship, it is a relationship of influence that independent workers and customers must endure and in which they have no way of intervening. In other words, platform workers are neither completely independent nor completely subordinate. Similarly, platform companies are not quite market intermediaries, nor quite employers.

How do we characterise the employment relationship in such a context? Can we still talk about an employment relationship when the employer is nothing more than a matching algorithm? What autonomy and what work are we talking about in the context of an employment relationship that is governed digitally?

To answer these questions, it is not enough to invoke deviations from the standard employment norms or to point out the existence of non-law zones. The employment relationship attached to labour platforms cannot be reduced to disorder or even institutional chaos. It is more of a social, political, and historical construct, based on hybrid discourses and practices, neither too visible, nor too invisible, neither legal, nor illegal. As mentioned above, the terms "self-employed," "employers," and even "clients" are not self-evident (Eurofound, 2017). Behind each of them lies an ambivalent and complex reality, and it would be a very unsatisfactory method if we were to transpose the traditional analytical frameworks from industrial relations studies to reveal all their facets.

This ambivalence and complexity of the employment relationship require researchers to shift their focus. To do this, we propose to use the notion of the "grey zone," a notion that comes from geopolitics and that, when imported into the field of industrial relations studies, offers the advantage of a better contextualisation of our research object and thus leads to new questions and new perspectives for analysis.

The approach we propose takes up and extends the discussion in a number of studies on the subject (Transfer, 2018). With some of the usual precautions, to which we will return later, the term "grey zone" makes it possible to draft a framework for interpreting transformations in the employment relationship on the basis of the observation of a divergence between institutions and the behaviour and practices of the actors. More precisely, two possible interpretations of the notion of grey zone emerge from these studies: a first reading equates the grey zone of employment with a loss of effectiveness of existing institutions and/or legal instruments; a second reading considers the notion of the grey zone of employment as the expression of a "non-standard" regulation, that is, a regulation implemented and/or directly carried out by actors or a community of actors unofficial who act or behave "without" or "outside" the rules.

As part of this contribution, we intend to take this framework of analysis and use it to decipher the specific terms of organisation and management of the employment relationship in these unprecedented productive worlds, commonly known as "capitalism platforms ${ }^{1}$."

The interest of this approach is to open up discussion on the transformations of the employment relationship by paying particular attention to the new forms of governance that have emerged with the development of digital information management and processing technologies. This viewpoint will lead to questions about the impact of this dematerialisation process on the organisation and implementation of the management power held by the owner-managers of the labour platforms.

This reflection will be in three stages. In the first part, we will present our general framework for analysing employment grey zones. We will specify the terms of the rupture brought about by the "digital turn" (Valenduc, 2019) by insisting on two closely related disruptive effects: the rejection or negation of the standard employment relationship on the one hand, and the recognition of the notion of the grey zone of employment as an "intermediate space of regulation" on the other. In the second part, we discuss the close and ambivalent link between platforms and grey zones. First, we clarify the foundations of this dual structure of the power held by the platform managers, both a power to connect and a power to direct. Second, we draw up a typology of grey zones. In the third part, we examine the impact of digitisation on management practices. Based on numerous case studies, two key areas will be addressed: monitoring the activity of connected workers, and the production and management of externalities. The article concludes with an overview and a discussion of the heuristic interest of the notion of an employment grey zone.

\section{A GENERAL FRAMEWORK FOR ANALYZING EMPLOYMENT GREY ZONES}

"Capitalism of surveillance" (Zuboff, 2019), "cognitive capitalism" (Boutang, 2012), "platform capitalism" (Srnicek, 2017): the proliferation of terms betrays the difficulty of grasping contemporary mutations linked to digital technology diffusion. The following developments are part of the continuity of this debate. We will question why platform leaders have always refused to consider themselves as employers and therefore recognise connected workers as employees.

\section{Rejection of the Standard Employment Relationship in Platform Capitalism}

To understand the close relationship between digital platforms and grey zones, it is worthwhile to first remind ourselves of Marx's conception of the labour process, as developed in Volume 1 of Capital. For Marx, the labour process is a combination of several components: the worker's labour power

\footnotetext{
${ }^{1}$ As part of this contribution, we will focus on labour platforms, understood in a broad sense as service operators. Uber drivers, Deliveroo couriers, Amazon Mechanical Turk (AMT) "taskers," self-employed workers connected to Upwork fall into this category. For Eurofound (2018), five criteria are used to define a working platform: paid work is organised through online platforms; three parties are involved-the online platform, the worker, and the client; work is contracted out; jobs are broken down into tasks; and services are provided on demand. In this work, we will focus in particular on the second criterion, which refers to the function of platforms as market intermediaries.
} 
on the one hand and intermediate consumption and the means of production used or consumed on the other hand, giving the result or product of labour. For Marx, these different components are the property of capitalists. All the more so because the way in which these components are organised and the way in which the products of labour are designed and distributed on the goods market mean that they are placed directly under its responsibility and control. In this approach, the employment relationship is the hub of the capitalist business: it represents this specific moment when the worker's labour power, negotiated and sold to "moneybags" for a given time, is consumed in a productive fashion before being remunerated; this relationship then makes wages (and wage earners) the keystone of social relations of domination as well as being an essential condition to reproduce the workers' living conditions (Lautier and Tortajada, 1978).

In contrast, since the end of the 2000s, businesses like Uber (2009) and Deliveroo (2013) have emerged, whose productive characteristics are the complete antithesis of this "labour" model of the employment relationship. These multinationals present themselves as businesses with no factories and who are backed massively by risk capital; they produce nothing directly for the goods and services market and pay no wages to their thousands of connected crowdworkers. In other words, at first glance, there is nothing in the characteristics of these market intermediaries that suggests the slightest hint of direct involvement by its managers in the organisation. On the AMT type of work platform, these companies provide no explicit work goals; they set no tasks and assign no place in any organisation whatsoever. In short, and with all due respect to Marx, platform capitalism appears to be embodied in a business model that is virtually empty of any social form of employment or labour relationship.

On the other hand, as Benavent points out (Benavent, 2016, p. 86), digital platforms are very powerful tools for networking and coordination and have no boundaries in space or time. Platform managers will know perfectly well how to derive benefit from this characteristic, in that the digitisation of "productive meetings" organised and managed by the platforms need have no regard for the general and concrete conditions of organising the activities and operation of the markets. The result is a radical reversal of perspective: in exercising their power of coordination, managers no longer need to be backed locally by private ownership of the human and material components of the labour process, nor is it even necessary to draw up a contract of employment setting out the conditions of use and remuneration for the worker's labour power. Through digitisation, the platforms control and manage remotely the information base that governs the organisation and management of labour relations at the local level. As SerranoPascual and Jepsen point out (2018, ch. 14), the employment relationship has become a notion whose meaning is at stake in a semantic and political battle between different social groups.

There is therefore no need, in principle, to create value as a stakeholder in community governance embedded locally in the organisational (Havard et al., 2006) and institutional framework of a company in a given country. In platform capitalism, the institutions and collective social rights that make up the employment relationship and wage relations, in general, are literally subsumed by digitisation and the network rationale.
With digitisation, work is perceived by management as supply and demand for services. In other words, the reason these institutions were created in the time of Fordism no longer has a place in this new configuration. Legal protection and social rights attached to the workers' person are no longer guaranteed. In the digital world of platforms, the standard employment relationship is no longer the norm (Brishen, 2016), apart from appearing in a negative way, either by putting up a legal obstacle to connecting platform users or as examples of institutions that are expensive to run and not compatible with the principles of a business model founded on flexibility (De Stefano, 2018) and on collecting, processing, and disseminating information to the greatest number of platform workers.

\section{The Notion of "Employment Grey Zone" as an Intermediate Space of Regulation: The Contribution of Geopolitics to Analysis}

From the preceding reflection, it emerges that digital platform managers are not keen to take on the role of employer, even if, by processing and using the information they collect, these same managers can sometimes act as managers or at least behave as if they were, if unwittingly (Cardon, 2019). The many appeals to the courts by Uber drivers to convert service contracts into employment contracts in France, the United States, England, and elsewhere are an illustration of this ${ }^{2}$.

"Being an employer" or "behaving like one": the nuance may go unnoticed but it is key to the analysis. This highlights the extreme vagueness surrounding the responsibilities incumbent on those who manage work platforms. More fundamentally, it demonstrates the existence of a legal "no man's land" where managers' actions can sometimes slip from a power of matching (or coordinating), which is essentially global or transverse, to a power to direct, with a local or limited dimension.

In a work devoted to the notion of grey zones, the political scientist G. Minassian describes this confusion of genres as a "symptom of social pathologies in the world space" (Minassian, 2018 , p. 22) and proposes a definition of the notion of grey zone that is very relevant for our purpose. For Minassian, a grey zone is:

"a space-with or without a fence-of social deregulation, of a political nature (self- determination, separatism or sanctuarisation) or socioeconomic nature (criminality spaces, dehumanised spaces, desocialised spaces), essentially terrestrial, sometimes maritime, dependent on a sovereign State whose central institutions are unable (either through powerlessness or abandonment) to penetrate it in order to assert their domination, which is ensured by alternative micro-authorities" (Minassian, 2018, p. 16).

\footnotetext{
${ }^{2}$ According to an Uber judgment of 20 December 2017 by the European Court of Justice (ECJ), "The service of connecting with non-professional drivers provided by Uber is part of the transport services (the connecting service is a secondary element and it is the provision of transport which is, from an economic point of view, the main element). Such a service must therefore be excluded from the scope of the freedom to provide services in general and from the Directive on services in the internal market and the Directive on electronic commerce" https://curia. europa.eu/jcms/upload/docs/application/pdf/2017-12/cp170136en.pdf, consulted on 25 July 2019.
} 
From this long definition, Minassian draws three essential principles that characterise a grey zone (Chapter 2, we summarise):

- a principle of competition with authority where the state is openly challenged in its role of keeper of the peace and in its capacity to ensure the safety and protection of its people;

- a principle of social deregulation that reflects a lack of social contract between the state and society and manifests itself in a certain number of social pathologies (unemployment, recession, poverty, etc.) and a deterioration in social relations (violence, incivility, and rise in communitarianism);

- a principle of privatisation of the territory, driven on the one hand by the arrival of huge numbers of transnational players (multinational firms, financial capital, non-governmental organisations NGOs, and social networks) and on the other by the many locally based interest groups and defenders of particularistic and traditional values.

By analogy, we propose to define the grey zone in the field of employment and labour relations as an intermediate space of regulation, closely linked to the development of digital platforms, a space that we characterise according to Minassian's three principles:

- The principle of competition with authority refers to the power of platforms to choose freely the place where their company headquarters are located. The ubiquity of computer systems makes it possible not only to escape the payment of taxes (O'Keeffe and Jones, 2015) but also to avoid, to a large extent, any obligations under the Labour Code, as in the case of France. Thus, the employer of Uber drivers working in France, Uber BV, is domiciled in the Netherlands. For the lawyer A. Supiot, freedom of choice masks a practice known as "law shopping" (Supiot, 2010), which in fact pits national legislations against each other and places pressure on national parliaments in favour of social dumping.

- The principle of social deregulation refers to various legal loopholes, either because the labour law currently in force is not applicable or because, quite simply, it is not applied because such law does not exist: these are all scenarios that have been observed with the arrival of these businesses in cities, especially in the mobility and catering service sectors (Uber, Lime, Deliveroo, etc.). Note that this lack of protection is found in highly standardised professions such as helicopter pilot (Azaiis, 2019a), a sure sign that the grey zone affects all types of profession, from the most "traditional" (i.e., closer to the Fordist regulatory norm) to the newest. The expression "the uberisation of jobs" gives a fairly good idea in everyday language of the phenomenon of deinstitutionalising the employment relationship or distancing platform workers from wage earners' institutions (unemployment insurance, collective bargaining, and recognition of rights and status associated with employee status).

- The principle of privatisation (or appropriation) of the territory is based on mobilising all available social wealth on which the platforms rely in order to operate. This may be urban and rural road infrastructure (as in the case of Uber), residential buildings (Airbnb), business premises (restaurants), and more broadly, any use value (bicycle, boat, private car, helicopter, etc.) and any available person who may be digitally connected (or interrelated). As they are firmly anchored locally, digital platforms perform their activity of matching people at the same time as they occupy the public space, dividing it up, and, depending on the type of activity, exploiting the productive and creative potential. In short, it is as if the platforms perceive local territories not only as resources distributed in an open space, free to access, but also as potential markets that they compete for control over via digitisation (Ashton et al., 2017). Embedded in their digital networks, territories are an inexhaustible reservoir of data that the platforms collect, transform, and disseminate to their members as usable information. In this operation, the economic and commercial interests of the platforms do not necessarily match those driven by the local areas, which are institutional players and spaces regulated according to more general and collective norms or interests. This divergence accounts for the appearance of tensions that has resulted in some municipalities banning Uber from operating in their territory: among them Barcelona, Frankfurt, Rome, or Sofia. From some municipalities, such as Austin (Texas), both Uber and Lyft companies have left not wanting to meet the fingerprint requirement, in 2016. They came back in 2017, because the regulations were more flexible.

In Rio de Janeiro, for example, the municipality is proposing the coupling of the transport pass Giro with Uber, offering a 30\% discount on the price displayed on the meter for the route made with Uber.

However, other scenarii are possible, such as in Dublin, California, where Uber has negotiated a partnership that allows them to cover sections of their urban territory that are poorly served by public transport but stipulates that they apply a single price of US \$5 for any fare within their boundaries. But more often than not, local authorities are very suspicious of platforms. For example, the City of Paris has decided to sue Airbnb for illegal advertising of rentals on its site (Serafini, 2019). For Cannon and Summers (2014), more dialogue would bring many benefits in terms of job creation, tax revenue, attractiveness, or services offered to users or consumers. These retaliatory measures against the platforms are simply a sign of a reaction against a power perceived as invasive and disrupts the socio-political balances that previously existed.

In the field of employment and labour relations, this becomes clear: in the world of the digital workplace, employment is no longer part of an employee-employer face-to-face relationship but takes place in an open, transnational, public and private, local and global space. In this grey zone, at different levels and at different times, there is a diversity of stakeholders involved in a plural and complex regulation (Azaïs and Pepin-Lehalleur, 2014). In the words of the sociologist J.D. Reynaud, the employment grey zone is based on the existence of a plurality of sources of regulation (Reynaud, 2003).

As we have observed in France in the Uber case (Azaiis et al., 2017), regulation becomes the issue and the stage for 
consultations and often for disputes involving a diverse collection of public entities (platform users, local authorities, professional associations, civil society, government, etc.), depending on the questions asked (training of drivers, competition with taxis, safety, use of the public space, etc.) and the interests that are challenged. In France, regulation is therefore multilevel, mediated by the state and to a large extent focused on maintaining a balance with the taxi driver profession in the discord that has gradually emerged with the arrival of Uber in the mobility market. However, the comparative study conducted by Thelen also shows that countries did not all react in the same way to the Uber shock. In the United States, Uber has established itself by forging an alliance with consumers against unpopular taxi lobbies, albeit at the cost of long legal battles with the lawyers of the workers connected to the platform. In contrast, in Germany, the alliance of taxis with public transport professionals, in the name of defending a high-quality and reliable service, has resulted in the closure of market access (except Berlin and Munich). Similarly, in Sweden, a broad coalition of taxi companies, trade unions, and state actors lobbied to tax Uber's activity in order to defend the equity standards on which the Swedish social system is based (Thelen, 2018). In Brazil, the municipality of Rio de Janeiro decided to lower the taxi drivers' fare to compete with Uber's fares. To do so, it created an app, app.taxi.rio. The meter price is systematically reduced by $30 \%$.

In this context, regarding regulation, the "ability to make rules can [therefore] be characterised by the place in an interaction for those whose initiative it is" (Reynaud, 2003, p. 103), so there is every chance that governance of the employment relationship will come up against too many forms of mediation and will always appear partial and unable to contain the conflicts and dynamics that are operating.

In short, the employment grey zone appears as a place of concentration of micropowers. In this multifaceted space, work platforms and the employment grey zone go hand in hand. The former feed on the latter, which in turn tends to continue and prosper with the development of the former. This codetermination has the effect of crystallising well-understood interests, consolidating acquired positions, and possibly sealing relatively stable compromises, which may or may not last. This dynamic should not be underestimated. It carries with it the springs of its own development to the point of imposing itself as an essential cog in the mode of operation of the platforms.

\section{BETWEEN DIGITAL PLATFORMS AND GREY ZONE: CLOSE AND AMBIVALENT LINKS}

Reduced to their basic function, digital platforms are information processors. As Srnicek emphasises, platforms are central models for extracting data as raw material to be used in various ways (Srnicek, 2017, p. 45). They collect data and transform them into usable information for the connected users. But this activity is also the moment when they take control of these data in the absence of an exchange ${ }^{3}$. This control is usually framed in a legal context in a document displayed on the platform websites and spells out for the users the terms and conditions for using these data $^{4}$. However, this limitation is usually ill-founded because the distinction between collected data and new data produced and transmitted by the platform to users is very unclear. How is this new concept defined? There is a grey zone here that is pushing against the boundaries of the platforms' freedom to use these data in the way they want.

\section{Dualism and the Power of Prescription of Digital Platforms}

In general, the economic and sociological literature considers digital platforms as market operators (Tirole, op. cit., Cardon, op. cit.). By facilitating meetings between suppliers and customers of goods and services, they increase market effectiveness and improve the level of utility or well-being of its users. In this way, platforms have a regulatory power by carrying out an entire series of actions, for example (Tirole, op. cit.):

- They host many applications and ensure a degree of competition between businesses.

- They regulate prices by imposing maximum price levels, and they protect consumers by monitoring contents and behaviours.

- They monitor the quality of services offered (dating agencies and standards at Uber).

- They check the reliability of sellers (examine drivers' background) and arbitrate disputes (deactivate drivers).

This service-based approach to the activity of the platforms is only partial and even restrictive as it overlooks the conditions under which the platforms intervene in the setting up the organisation and the management of the markets. As Gauron points out, the innovation that the platforms introduced "lies in the fact that they have replaced a direct relationship between individuals and they have killed the free aspect and the solidarity that oversaw this relationship when it had existed" (Gauron, 2017).

This comment adds a new and important element to the analysis of the grey zones carried out earlier. It shows that the purpose of the matching process on the platforms was not only to facilitate relations between suppliers and customers, in exchange for payment, especially by classifying, filtering, and ranking information disseminated to users; this process is also based on a technical mechanism to create a relationship that establishes a market trade link between users and platforms. In the result, the relationship between the customer-supplier and the service provider is duplicated and any possibility of direct

\footnotetext{
${ }^{3}$ This hold that the platforms have over the data can be explained by the fact that the connection is based on a digital link that is the private property of the platform (for example, the "like" link on Facebook is the property of Facebook).

${ }^{4}$ In Europe, see the General Data Protection Regulation (GDPR), which came into force on 25 May 2018. This legislation deals with the processing and circulation of data in the EU by giving people whose data have been collected and processed a certain number of rights (right to access, right to correction, right to objection, right to erasure, and right to portability).
} 


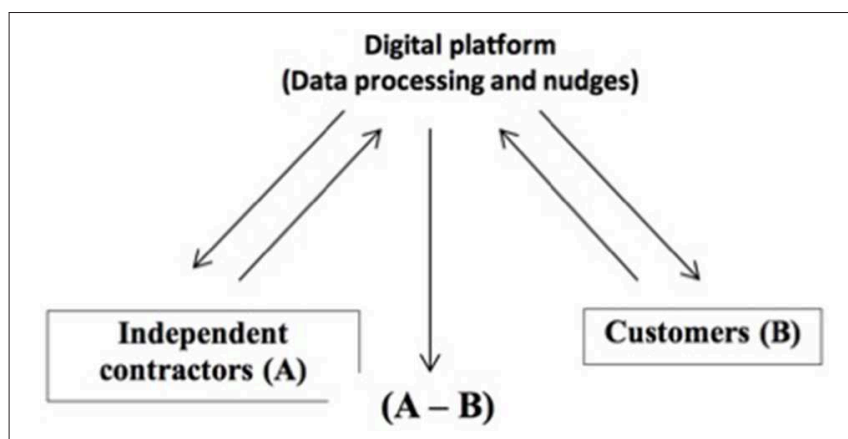

FIGURE 2 | Digital platforms as the intermediary of information management.

communication between them becomes impossible (see diagram in Figure 1).

Consequently, the creation of markets by the platforms imposes not one but two levels of constraint on users: the first level is accepting the digital format as the only possible way of entering into the relationship; the second level is accepting that, on this basis, the platforms have direct and exclusive access to the digitised data that is transmitted upstream to organise and manage these relations. In these circumstances, the activity of the platforms is identical in many ways to the work carried out by the Gosplan office ${ }^{5}$ : platforms are permanently fed data transmitted by the community of users, operating on the one hand like an information system that is infinitely (re)programmable (via the algorithms) while on the other hand imposing itself as a means of communication, organising and directing users' behaviours and choices (see Figure 2).

This dual structure breaks from the principle of neutrality generally attached to the role of market intermediary. In return, it gives platforms the opportunity to govern markets that they are able to create from scratch (!). As direct and exclusive interlocutors of A and B (see Figure 2), platforms are active and in a monopoly position on both sides of the market (Rochet and Tirole, 2003). This position provides them a power of influence that allows discretionary management of exchanges between $\mathrm{A}$ and $\mathrm{B}$, taken directly from the information that guides the choices and behaviours of each. If we take the case of Uber, discretionary management is confirmed, among other things, by the platform's power to set the price of the ride and to change the percentage of commission the driver receives unilaterally, also by its power

\footnotetext{
${ }^{5}$ As Gauron points out: "Contrary to a presentation firmly anchored in economic history, the specific feature of platforms cannot be found in technology. It lies in a change in convention compared with Fordism, the transition from an industrial convention to a market convention" (Gauron, 2017). To complement these remarks, it should be noted that the market convention is a means of coordination by the market with prices fixed during the exchange. However, it is never totally so: in the case of Uber, the price of the trip is not freely set, and nor is it based on an agreement between the customer and the driver. It is fixed by algorithms managed by the company and is exactly the same for all drivers. The diffusion of the platforms leads to the revival of long-standing criticisms of the neoclassical approach to markets, which considered the market secretary (the famous auctioneer by Walras) not as a metaphor for the invisible hand but as the embodiment of a centralised economy regulated by a planning state (Guerrien, 2006).
}

to deactivate drivers whose customer ratings are not high enough (Birgillito and Birgillito, 2018).

\section{An Attempt at a Typology of Grey Zones}

Consequently, from the point of view of employment and labour relations, the way that digital platforms operate highlights a radical transformation in the governance mechanism that coordinates and carries out the activities of connected workers.

Whereas, in the standard employment relationship these activities were supervised under the direct and contractual responsibility of the employer, the governance of these activities in the case of platforms is no longer legally regulated. The employee-employer relationship, built on a common desire and the reciprocity of the parties' commitments to the employment contract, is replaced by a service relationship with no obligations in terms of social protection and working conditions. On platforms like those of Uber or Deliveroo, governance is limited to an information system that has at its heart a price fixing algorithm coupled with incentive schemes or sanctions (deactivation), surveillance (geolocation), and rating of the service provided (delegated to the customers in the case of Uber). In such a context, three types of grey zone can be identified.

The first type relates to the nature and extent of the coordination or matching power wielded by the platform managers. Where does this matching power begin and end? This is a very discerning question to ask, because in the case of Uber and Deliveroo, the fact of making a digital connection, which is necessary in order to open an account, is equivalent to "self-declaration:" the connected worker makes a quasi-unilateral commitment (Aloisi, 2016). By signing up on the platform and becoming a member, he becomes an independent contractor-this status is the sine qua non condition for being able to carry out one's future activity-and declares his availability to provide the service at any time. This matching of driver and customer is therefore not symmetrical but asymmetrical (Kingsley et al., 2015): this is a direct consequence of the platform's taking over the customer relationship, which becomes a relationship of economic dependency with the worker dependent on the platform. Thus, the information sent to the drivers is the equivalent of an order (no matter how small the value of this order may be) and the platform acts implicitly as the ordering party. Between the platform and the connected workers, there is the same kind of relationship as that between a large company and its suppliers or subcontractors. The boundary between coordinating power and management power is therefore a tenuous one. It stems only from the leaders' management style or more broadly from the degree of external economic pressure such as competition or the profitability requirements of the shareholders, which could modify its boundaries and lead to a change in the terms of the contractual relationship.

The second type of grey zone lies in the vagueness of the boundary that separates the professional autonomy and dependence of the connected workers with regards to the requirements of the platforms (Prassl and Risak, 2016; TodolíSignes, 2017). Where does the workers' freedom of action in carrying out their work begin and end? In France, the Supreme 
Court ruling of 28 November 2018 on the "Take Eat Easy" affair has partly answered this question. The court agreed that the existence of a geolocation system and a system of bonuses and penalties were two digital management tools characteristic of a relationship of subordination between a platform and a delivery rider (on behalf of their restaurant-members) and declared that the rider's service agreement should be converted into an employment contract. However, this is a specific example and is intended more to protect the worker than to define the conditions under which these tools should be used. The vague area surrounding workers' autonomy or freedom of action does not therefore entirely disappear. While labour law allows some limitations to be placed ex post, it does not allow intervention ex ante to control the use of these digital tools and to reduce the specter of contentious work situations arising. Workers will therefore never have full and unqualified freedom of action because it will always be marred by uncertainty or restrictions. From this perspective, there is an entire group of grey zones associated with the digital work environment, which, in the field, replace hierarchical surveillance and control techniques with monitoring techniques that are more or less moderate, midway between information and manipulation (see next section).

The third type of grey zone lies in the difficulty in distinguishing between the positive and negative externalities that can be seen on both sides of the platform market. The classic case often cited as an example is that of the online newspaper where the subscription is almost free or even completely free in order to increase readership. In turn, the rising number of readers attracts advertisers and increases the price of advertising space and hence cash flow for the newspaper. When looked at in this light, activity of the platform as intermediary would appear to be the reason for added value or positive pecuniary externalities. But there are also negative (non-pecuniary) externalities generated by both sides of the market and are not related to price structure but to the social cost of running the platforms (Brishen, 2017). In the case of mobility platforms, we note the impact of the Uber drivers' activity on the environment (traffic jams, pollution, etc.) or the impact of Airbnb on the hotel industry, the availability of housing, and the gentrification of cities. More broadly, the users who benefit from the lower transaction costs on platforms are often high-income and educated people. This is why the impact of platforms in terms of inequalities is significant. In addition, people significantly increase their consumption via a "rebound effect," which contributes to an increase in their carbon footprint. In sum, beyond the immediate direct effects of time savings and lower transaction costs, the indirect, economic, social, and environmental effects are many and largely unknown (Frenken and Schor, 2017). This results in a problem of identification and management of these grey zones linked to interdependencies ("cross network externalities") generated by the activity of the platform and includes a strong spatial dimension (Duranton, 1997).

In all, the grey zones can be considered as markers of the functioning of digital platforms whose impact on the activity, behaviours, and choices of users is far from neutral. In practice, the grey zones are a place of decoherence (Bureau and Dieuaide, 2018) of which the most visible sign is the distancing of wage earners' institutions (employment law and social protection). Yet the grey zones are not empty places where anarchy and chaos reign (Minassian, op. cit.). This is an area populated by a variety of "figures" (Azaïs, 2019b), both professional and non-professional, who work, discuss, and interact. The grey zones can therefore be zones of conflict, withdrawal, or closure, or conversely they are zones of cooperation or social innovation. In all cases, they outline a public space that is non-regulated as it is dominated by the effects of socio-spatial networks, which are cumulative and fairly stable and whose spread raises the delicate and complex problem of the non-market regulation of platform activity.

\section{EMPLOYMENT GREY ZONE AND NEW POWER OF MANAGEMENT}

Digital platforms are architectures whose functioning profoundly disrupts the way in which workers activity is organised and managed. The break with the Fordist model of production organisation is clear and unequivocal at this level. The notion of a platform ruins any conception of employment as a "place in the organisation," owing to the lack of any organisational attachment: the workplace is no longer physically circumscribed or even geographically located; similarly, the worker's professional identity is no longer linked to the characteristics of the workplace (Huws, 2014).

In order to work, simply open an account on the platform via a smartphone and a dedicated application. This is a major difference from the employment contract, the execution of which by the signatory parties is based on a common will and a mutual commitment. On working platforms at least, no counterpart relationship of the "subordination for protection" type is possible. The opening of an account is a "self-declaration": the connected worker unilaterally commits himself by becoming a member-person of the platform and declares his availability to work at any time. In summary, and to use the terms of Supiot, the allegiance relationship follows the subordination relationship (Supiot, 2015).

These changes are significant in terms of grey area analysis. Whereas under Fordism the employment relationship appears as an "effect of the employment contract," in platform capitalism, the employment contract is replaced by a digital attachment. On the one hand, this digital attachment frees the worker from the centralised power arrangements of the hierarchical company. On the other hand, it makes the Uber driver or Deliveroo cyclist a Homo Connecticus, a connected worker but available and free to respond to the service or mission offers communicated by the platform. In such a context, the information collected, organised, and disseminated by the platforms is inseparable from the interpretation and decisions taken by connected workers to define and organise their actions. This is why the power to coordinate and manage platform information is also a power to manage behaviour and conduct (Deng and Joshi, 2016).

As a result, the digitisation of the worker's connection to platforms masks an opaque and deeply asymmetrical power relationship. This asymmetry is the focus of all the attention of the employers (Irani, 2015; Möhlmann and Zalmanson, 2017). It is the subject of a quasi-continual strategic reflection as to how to influence or guide the behaviour of connected workers. Taking 
the notion of notification as an example, the following paragraph gives an example of these "technologies of the mind" and analyses the intimate springs. A second paragraph complements these developments by emphasising a relatively unnoticed dimension in the debates, namely, the uncontrolled or undesirable effects of these techniques on the workers themselves and the different environments with which they interact.

\section{Notifications and Digital Governance of Labour Relations: Between Dependence and Manipulation of Connected Workers}

For the connected (self-employed) worker, the working environment is summed up by the various features and applications downloaded to his or her personal mobile phone. These functions and applications are interfaces through which he is informed of the work proposals submitted to the platform. But these functions and applications are also integral components of a digital architecture placed directly under the control of platform managers. From this point of view, the instrumental and commercial rationality of management dominates with all its height and penetrates to the deepest level of the worker's cognitive processes (Fumagalli et al., 2018).

At the level of working platforms, one of the main instruments of this cognitive rationalisation is the "notification" (written or oral), even called the "nudge" (coup de pouce in French). We define a nudge as digital information sent to mobile phone screens or any other medium. The nudge is a "decision support" tool, as conceived by Thaler and Sunstein (2003), economist and lawyer, respectively. This tool has been used by D. Kahneman, Nobel Prize winner and a leader in the field of behavioural economics. There are many examples of nudges: the fly etched into the porcelain at the bottom of a urinal in the toilets at Amsterdam Airport, the automatic opening of a savings plan for American employees to increase the US savings rate, the marking on the ground of the words "look right" or "look left" in the streets of London to prevent accidents to tourists, or the marking on the ground of the Uber logo in several Brazilian airports to make it clear to the passenger who has just disembarked where he must go as soon as he reaches the central hall of the airport! From a more theoretical point of view, a nudge aims to correct decisions considered irrational, to fight against passivity and inertia in habits of all kinds, and to choose the "right" default options. Thaler and Sunstein use the terms "libertarian paternalism" to describe these practices, which they consider do not prohibit anything and do not restrict anyone's options (Thaler and Sunstein, 2003).

In the hands of platform managers, however, experience shows that these soft techniques for "staging" people's decisions have been recovered to serve very different objectives, such as the development and growth of corporate profits. Uber is an exemplary case in this respect. In a summary article on management practices at Guillaud (2017) identifies three main categories of nudges developed and distributed to his drivers in the debates:

- nudges encouraging people to "work harder and harder," such as sending shopping proposals before the drivers have finished the ones in class;
- nudges to overcome "earnings loss aversions," by informing them about high-demand areas that drivers could respond to; nudges seeking to "develop involvement, pleasure or play at work" by setting up a bonus system for achieving objectives defined daily by the drivers themselves.

The use of nudges by Uber management is obviously at the border between information and manipulation. The ambiguity is all the more obvious because, in return, Uber mobilises the subjectivity of "its" drivers, by playing on the lure of profit. In a masterful reversal of libertarian philosophical doctrine, Uber's research director's response to his detractors- "no one is obliged to do anything" (quoted by Guillaud) - is symptomatic of management's indifference to the drivers' working conditions, which in itself is not paradoxical because no relationship of subordination is established a priori. The nudges are violently denounced as denying any option for drivers to say "no" to notifications sent by the platform. Also, the absence of safeguards deprives them of any autonomy, which leads a certain number of them to work in conditions that are close to exhaustion, conditions that are contrary to their personal interest-if not that of earning more-and to that of their clients.

Thus, the nudges illustrate to a real innovation in managerial techniques for controlling the activity of connected workers. There is no physical pressure on the "bodies" as in the case of companies in the Taylorised industrial sector where work intensity is central; nor is there any need to contract workers' objectives through monetary incentives. Because of their "confinement" in a digital relationship from which workers cannot escape without disconnecting and losing their jobs, the object of control, as Benavent points out, "is no longer performance, behaviour, the sharing of common values, but the information that makes it possible to act" (Benavent, 2016, p. 30) and we will add, intelligent information, sent "to the right place and at the right time." From this perspective, it is possible to speak of "digital Taylorism."

In other words, the control of information systems appears to be the cornerstone of digital governance, which tends to modulate workers' ability to act by directly, relying on their full and complete availability, owing to their situation of "digital dependence" on the platform (Deleuze, 1992). The downside of this mode of governance is that it is blind to the reality of the world in which and through which workers operate. This reality is systematically obscured; it can even be perceived as an obstacle by managers who only have eyes for maximising the volume of commitments they organise on the platform and the payments that result from them.

However, this attitude finds its stumbling block in territories that appear to be places of resistance. These territories, whatever the type of administrative division or size, seem to be the only places where resistance to platforms can be expressed, with disputes from users or customers that may have a certain desire to consume, live, or produce in a sustainable way (Schor and Wengronowitz, 2017). Territories, and more generally metropolitan areas, are the infrastructure for hosting platforms. They refer not only to the world experienced by workers in the exercise of their activity but also to their socio-professional environment, that is, to all economic and non-economic actors 
who, directly or indirectly, individually or collectively, are the means and stakeholders who work alongside them.

\section{Out-of-Control and Adverse Effects Generated by Platforms}

As mentioned in the Introduction to this article, digital technologies contain virtualities that allow them to a large extent to escape the regulations imposed by tax law, labour law, and competition law. But this ability to escape legal norms, particularly labour law, does not eliminate the various points of contact between these workspaces and the territories. Whether it is virtual space available on platform servers by means of terminals (case of Upwork), urban space such as the road network used by drivers (case of Uber), or public or domestic spaces such as stations, airports, or homes for the exercise of micro-tasks, for example (case of ATM), these workspaces are very real, physically anchored in the host territories (Orlikowski, 2007). Notably, this anchoring poses a problem if the conditions for organising and managing the resources consumed, the resources mobilised, and even the space occupied locally by workers in the very process of their activities are not (sufficiently) regulated.

The exemplary case is, here again, that of Uber drivers whose driving can constitute a danger in other public spaces if no measures are decided to ensure the safety or health of the inhabitants (pollution standards, traffic schedules and directions, speed limits, etc.). In San Francisco, for example, a team of researchers found that instead of reducing traffic jams, TNCs such as Uber and Lyft are helping to increase traffic jams. They explain that "between 2010 and 2016, the number of hours of vehicle delay during the week increased by $62 \%$ compared to $22 \%$ in a hypothetical 2016 scenario without TNCs." Nevertheless, "the results show some substitution between TNCs and other car trips, but that most TNC trips are adding new cars to the road" (Erhardt et al., 2019, p. 10). According to the authors, municipalities face a new problem as TNCs are still growing and force local authorities "to integrate TNCs into the existing transport system" (Erhardt et al., 2019, p. 1). The researchers also point out that a large proportion of the kilometers travelled correspond to empty trips.

In other words, the functioning of the platforms is a potential source of social and collective disruption of all kinds locally. This is why it is understandable that the employment relationship, dis-institutionalised on the one hand by digitisation, is being reinvested on the other hand by a requirement to regulate professional practices, taking into account the externalities of workers' activity on the different environments that surround them or with which they interact:

- The management of externalities does not aim to protect the worker's person from the risks associated with the exercise of his profession (illness and accident) or the probability of losing his job (unemployment insurance). Managing externalities requires the involvement of all stakeholders. In the case of Uber, there are many actors: municipalities concerned with combating pollution or promoting safe mobility; driver collectives wishing to improve their remuneration and working conditions; professional unions wishing to strongly supervise the TNC profession; and chambers of commerce and industry involved in the provision of driver training, NGOs, and consumer associations concerned with the management ethics of platform managers, the quality of service, or the good morality of drivers.

- This regulation does not aim to develop a general and collective framework for the protection of all connected workers, as there is for salaried workers. The very opposite is the case. For example, by regulating the activity of Uber drivers, this regulation protects the population as a whole, active and inactive, living in an area or locality, from the effects of the inadequacy or even absence of regulation of the Uber drivers' professional activity. This regulation of the activity of connected workers can be considered as a response of local stakeholders to the disruptive power of platform managers in their function and position as third party (Collier et al., 2018). It aims to frame the reticular and sprawling dimensions of this form of power "in the field" through the mobilisation of institutional actors, what Courlet and Pecqueur call intermediation institutions (Courlet and Pecqueur, 2013). These institutions act or function locally as counter-powers, sometimes as delegated representatives of workers' interests (cf. the status of superrogates of alter-labour organisations in the United States, cf. Collier et al., 2017) and sometimes as defenders of broader and general interests with the aim of reintegrating the digital environment into society. Through the action of these institutions, a struggle is therefore emerging around the establishment of rules to control how platforms make use of public space, resources, and infrastructure, sometimes to the detriment of the interests of other local working and living communities. The reconquest of protection requires a struggle to impose more democracy in the definition and organisation of access to these appropriable resources, which are therefore understood as common goods for all.

To conclude this part, one would be tempted to equate the management of the externalities generated by the working platforms with the development of regulations, observed here and there, even occasionally and partially. This rapprochement highlights a process that is probably irreversible, of reestablishing the employment relationship around local (metropolitan), collective, and plural norms regulating the working conditions and context of connected workers. This process would be accompanied by the establishment of a conventional legal system that is relatively autonomous from labour law and the law, thus accrediting the thesis of the emergence of a legal pluralism (Coutu et al., 2013). At least, it can also be observed that this "remediation" is being carried out by new actors within the framework of an expanded, open, and multi-scalar public sphere by construction (Azaiis et al., 2017). So would this new standard, built on a practical territorial foundation for organising and managing the activity of platform workers, herald a co-management of the employment relationship? 


\section{DISCUSSION}

After these few developments, we would like to return to the heuristic interest of the notion of the grey zone. Several insights can be drawn from this study.

The notion of the grey zone starts from the observation of a lasting "lack of coherence" (decoherence in French) between the institutions in place and the practices or behaviours they are supposed to regulate (Bureau and Dieuaide, 2018). This "decoherence" means a loss of effectiveness of both the institutions and the legal instruments available. It also means the existence of "nonstandard" social regulation, directly driven by actors or communities acting, intentionally or unintentionally, "without or outside" the established rules. The notion of a grey zone is not a catch-all category. Although it testifies to the "existence of a multidimensional crisis" (Minassian, 2018, p. 35) in existing social regulation, it is also marked by a number of perfectly identifiable characteristics, as we have tried to show. The notion of a grey zone thus makes it possible to focus on the nature and play of the extra-legal forces from which a social regulation order originates and whose dynamics coexist, overflow, or extend the instituted space of legal regulation.

The notion of "employment grey zone" is closely linked to the emergence of new professional figures. The presence of these figures can be explained to a large extent by the disruptive nature of the digital revolution (Valenduc and Vendramin, 2017). Digital platforms are learning machines that support many cognitive tasks (diagnosis, monitoring, forecasting, translation, etc.). Not only do they eliminate routine jobs, but they also encourage the development of polarisation in the labour market between skilled and unskilled workers and expose the latter to global competition. From these upheavals has come a multiplicity of professional situations and figures, more or less stable and identifiable over time. The shift of status toward precariousness, positioning on professions with an uncertain future or on upward trajectories, career development scenarios, and professional identities are never clearly defined in advance. This is why, at the heart of this grey zone, platform workers form a population of "emerging figures," which are difficult to identify. Without being exhaustive, this population can be classified into three main categories (Azaiis, 2019b): declining figures, described as emerging as they are part of an involutionary process; intermediate figures, located in an in-between area where the short-term future is impossible to predict; and ascending figures, which provide new opportunities.

- Declining figures are the most vulnerable workers who demand more protection and apply to the courts for employee status. As they cannot find a steady job, they are compelled to use digital platforms in order to survive. More and more, TNC drivers and bicycle riders are finding themselves in such a situation. More broadly, these are workers whose work status has deteriorated and whose autonomy, pay, rights, and protection have been reduced.

- The intermediate figure corresponds to a period of transition or stagnation for the individual waiting for a more suitable job. They are individuals on stand-by, young people, women, who temporarily accept an internship or precarious status in the hope of obtaining a stable and properly paid job later. In France, this is the case for some young people in the suburbs who may have imagined that a job as an Uber driver or a bicycle rider (Jan, 2018) could allow them to reach a higher status or social position. For these young people, this was the first time they were socially recognised (Courrier international, 2016). In this category, we also find a significant proportion of women who are often the first to be threatened by the shift of jobs to digital occupations (Vendramin, 2011).

- Third, emerging figures refers to "knowledge workers," defined as "mastering a significant part of cognitive knowledge: knowing how to master some basic transversal cognitive skills and mobile technologies, how to understand and report written and digitally transmitted instructions and, on this basis, how to relate to others, how to cooperate actively and interact" (Armano and Murgia, 2019, p. 282). We find, among this third type of emerging figure, engineers or highly skilled and very mobile workers, who will not hesitate to leave a startup where they are already well paid to join a new one, where they will receive a better salary.

The time dimension is central to the analysis, owing to the non-permanent and shifting nature of individuals in the labour market. This typology aims to look beyond dualism, which is still significant in analyses of the current change in the employment relationship and the categories that define it. This typology also makes it possible to take into account many studies conducted on the informal sector in countries of the Global South, describing complex labour markets that cannot be confined to a binary formal vs. informal interpretation. This form of analysis, which has now been exported to the North, defines the dynamics and plurality of the forms of work and employment that can be found there. Finally, all three types of emerging figure are the expression of the multiplicity of forms of work; they also reflect people's subjectivity and their collective and personal involvement (Armano and Murgia, 2017).

There is no clear-cut demarcation between these three figures, and a single situation may illustrate two or even three types of emerging figure, as everything depends on people's lived experience and their individual and collective customs. The same situation can be lived subjectively in completely opposite ways and can be analysed as corroborating the hypothesis of generalised insecurity or as a deliberate choice on the part of individuals waiting (or not) to integrate the labour market differently. Both interpretations are possible.

The notion of grey zone provides the means to draft a framework of analysis that does not separate connected workers from the context and particular conditions in which they carry out their activities. Employment and work are thus captured in an "in-between space" (Cattaruzza, 2012), a lawless zone that does not oppose wage labour and self-employment but places them in a continuum of more or less stable forms of social relations and power. From this perspective, grey zones must be considered as open spaces, crossed by multi-actor and multidirectional dynamics. This perspective is close to the work developed by Streeck and Thelen (2005), who have established a 
very precise typology of the forms of institutional change centred on the actors (displacement or evolution of rules; superposition or addition of new rules; drift or laissez-faire; conversion or reinterpretation of rules; exhaustion or gradual rupture). In our approach, we have paid particular attention to territories, both as a support for digital infrastructures and as a "host country" for the (negative) externalities generated by digital platforms. Territories are also institutional actors concerned to guarantee the quality and access to all of the resources available within the (public) space of the division of labour. Although it remains to be demonstrated, this first overview highlights the importance of territories as important actors in the definition and implementation of a possible trajectory for the reintermediation of the employment and labour relationship. They are both carriers and pilots of a new space-time reference system in the organisation and management of work activities, and the integration of territories into the analysis is from this point of view a fruitful entry into studying the new forms of codification of the subordination link specific to digital environments.

The notion of the grey zone has emerged as a space of social relations and work immersed in the City. It is therefore a space of a directly political nature inhabited by disparate figures (emerging and non-emerging) with diverging strategies and interests. A grey zone can therefore be a zone of conflict, withdrawal, or closure, or conversely a zone of social cooperation or innovation. The notion of an emerging figure put forward in our approach responds to this concern to characterise this population more precisely in these very particular digital environments. This reflection is still in its infancy, but more broadly, we believe that the notion of the emerging figure is a

\section{REFERENCES}

Abdelnour, S. (2017). Moi, Petite Entreprise. Paris: PUF.

Acquier, A. (2017). Retour vers le futur? Le capitalisme de plateforme ou le retour vers le «domestic system 》. Dossier Évolutions du Travail, Plates-Formes et Digital, Le Libellio d'AEGIS, 13, 87-100.

Aloisi, A. (2016). Commoditized workers: case study research on Labor law issues arising from a set of "on-demand/gig economy" platforms. Compar. Labor Law Policy J. 37.

Armano, E., and Murgia, A. (2017). "Hybrid areas of work in Italy: hypotheses to interpret the transformations of precariousness and subjectivity," in Mapping Precariousness, Labour Insecurity and Insecurity Livelihoods, eds E. Armano, A. Bove, and A. Murgia (Taylor and Francis), 47-59.

Armano, E., and Murgia, A. (2019). "Knowledge workers," in Les Zones Grises des Relations de Travail et D'emploi, un Dictionnaire Sociologique, eds M.-C. Bureau, A. Corsani, O. Giraud, and F. Rey (Buenos Aires: Teseo), 281-290.

Ashton, P., Weber, R., and Zook, M. (2017). The cloud, the crowd, and the city: How new data practices reconfigure urban governance? Big Data Soc. 4, 1-5. doi: $10.1177 / 2053951717706718$

Azaïs, C., Dieuaide, P., and Kesselman, D. (2017). Zone grise d'emploi, pouvoir de l'employeur et espace public: une illustration à partir du cas Uber. Indus. Relat. Relat. Indus. 72, 433-456. doi: 10.7202/1041092ar

Azaïs, C., and Pepin-Lehalleur, M. (eds.). (2014). Modes de Gouvernance dans Quatre métropoles Latino-Américaines (Buenos Aires, Caracas, Mexico et São Paulo): Entre Logiques Institutionnelles et Acteurs (Bruxelles: P.I.E. Peter Lang Ed).

Azaïs, Ch. (2019a). "Pilote d'hélicoptère au Brésil, Les zones grises des relations de travail et d'emploi," in Un dictionnaire Sociologique, eds M.-C. Bureau, A. very useful tool to understand how and in what form politics emerges in these "off-camera" regulations. This notion also helps to shed light on the reasons why these forces block or, on the contrary, push for institutional change. At the level of analysis, it would then be a question of identifying and understanding the emergence of new professional figures through the new problems whose work and conditions of practice are conducive to them (intervention of ecological themes, emergence of civil society actors, new forms of struggle, emergence of new trade union practices, organising, etc.). This knowledge of the field could, for example, support the idea that the notion of digital worker refers less to professions, qualifications, and new skills acquired in the digital age than to the range of rights that characterise the conditions of use or access to these tools. The notion of a grey zone would reflect a tension in the search for a sociopolitical balance between the exercise of work guided by necessity (working to earn a living) and work that promotes emancipation and/or freedom (cf. Marx's notion of "free activity").

\section{DATA AVAILABILITY STATEMENT}

All datasets generated for this study are included in the article/supplementary material.

\section{AUTHOR CONTRIBUTIONS}

All authors listed have made a substantial, direct and intellectual contribution to the work, and approved it for publication.

\section{JEL: J23, J53, J8, L86, M54}

Corsani, O. Giraud, and F. Rey (Buenos Aires: Teseo), 365-376. Available online at: https://www.teseopress.com/dictionnaire/

Azaïs, Ch. (2019b). "Figures émergentes," in Les zones Grises des Relations de Travail et D'emploi, Un Dictionnaire Sociologique, eds C. Bureau, A. Corsani, O. Giraud, and F. Rey (Teseo), 613-625. Available online at:https://www. teseopress.com/dictionnaire/

Benavent, C. (2016). Plateformes. Limoges: Fyp Éditions.

Birgillito, G., Birgillito, M. (2018). Algorithms and ratings: tools to manage labour relations. Labour Law Issues 4:2.

Boutang, Y. M. (2012). Cognitive Capitalism. Cambridge: Polity Press.

Brishen, R. (2016) Employment Rights in the Platform Economy: Getting Back to Basics, March 20, Temple University Legal Studies, Research Paper No. 2015-33. Available online at SSRN: https://ssrn.com/abstract=2641305

Brishen, R. (2017). The social costs of uber. Univ. Chicago Law Rev. Online 82, Art. 6.

Bureau, M.-C., and Dieuaide, P. (2018). Institutional changes and transformations in labour and employment standards: an analysis of 'grey zones'. Transfer Eur. Rev. Labour Res. 24, 261-277. doi: 10.1177/1024258918775573

Cannon S., and Summers L. H. (2014). How Uber and the Sharing Economy Can Win Over Regulators. Harvard Business Review. Available online at: https://hbr. org/2014/10/how-uber-and-the-sharing-economy-can-win-over-regulators/

Cardon, D. (2019). Culture numérique, col. Les petites humanités, Presses de Sciences Po, Paris.

Carolus, A., Maximilians, J., Binder, F. F., Muench, R., Schmidt, C., Schneider, F., et al. (2018). Smartphones as digital companions: characterizing the relationship between users and their phones. New Media Soc. 21, 914-938. doi: $10.1177 / 1461444818817074$

Casilli, A. (2019). En Attendant les Robots. Paris: Éd. du Seuil. 
Cattaruzza, A. (2012). «Zones grises 》, interstices durables de la carte politique? Relecture critique d'un concept géopolitique. Bull. Assoc. Géogr. Français 89, 104-120. doi: 10.3406/bagf.2012.8247

Collier, R., Dubal, V., and Carter, C. (2018). Disrupting regulation, regulating disruption: the politics of uber in the United States. Perspect. Politics 16, 919-937. doi: 10.1017/S1537592718001093

Collier, R. B., Dubal, V. B., and Carter, C. (2017). "Labor platforms and Gig work: the failure to regulate, IRLE (Institute for Research on Labor and Employment)," in Working Paper $n^{\circ}$ 106-17, September (Berkeley: Ucla), 29.

Courlet, C., Pecqueur, B. (2013). L'économie Territorial. Grenoble: Presse Universitaire de Grenoble.

Courrier international (2016). "Uber, une voie de sortie pour la banlieue," in Financial Times - Londres, 22/04 (France). Available online at: https://www. courrierinternational.com/article/france-uber-une-voie-de-sortie-pour-labanlieue (accessed June 25, 2019).

Coutu, M., Le Friant, M., and Murray, G. (2013). Broken paradigms: labor law in the wake of globalization and the economic crisis. Compar. Labor Law Policy J. $34,565-583$.

De Stefano, V. (2018). Platform Work and Labour Protection. Flexibility is Not Enough. Regulating for Globalization 23th May. Available online at: http://regulatingforglobalization.com/2018/ 05/23/platform-work-labour-protection-flexibility-not-enough/ |relax\$\@@underline \hbox \{\}$\backslash$ mathsurround $\backslash z @ \$ \backslash$ relax

Deleuze, G. (1992). Postscript on the Societies of Control. The MIT Press. Available online at: http://links.jstor.org/sici?sici=01622870\%28199224\%2959 \%3C3\%3APOTSOC\%3E2.0.CO\%3B2-T

Deng, X. N., and Joshi, K. D. (2016). Why individuals participate in microtask crowdsourcing work environment: revealing crowdworkers' perceptions. J. Assoc. Inform. Syst. 17, 711-736.

Dieuaide, P. (2018). Grey zones and triangulation of the employment relationship in globalisation: a business policy approach. Transfer Eur. Rev. Labour Res. 24, 297-315. doi: 10.1177/1024258918775533

Drahokoupil, J., and Fabo, B. (2016). The platform economy and the disruption of the employment relationship. ETUI Policy Brief. 1-6. doi: 10.2139/ssrn.28 09517

Duranton, G. (1997). La nouvelle économie géographique: agglomération et dispersion. Écon. Prév. 131, 1-24. doi: 10.3406/ecop.1997.5882

Erhardt, G. D., Roy, S., Cooper, D., Sana, B., Chen, M., and Castiglione, J. (2019). Do Transportation Network Companies Decrease or Increase Congestion? Available online at: http://advances.sciencemag.org/content/5/5/ eaau2670 (accessed June 15, 2019).

Eurofound (2017). Classifying Self-Employment and Creating an Empirical Typology. Available online at: https://www.eurofound.europa.eu/sites/default/ files/wpef17002.pdf

Eurofound (2018). Employment and Working condItions of Selected Types of Platform Work. Luxembourg: Publications Office of the European Union.

Frenken, K., and Schor, J. (2017). Putting the sharing economy into perspective. Environ. Innov. Soc. Trans. 23, 3-10. doi: 10.1016/j.eist.2017.01.003

Fumagalli, A., Lucarelli, S., Musolino, E., and Rocchi, G. (2018). Digital labour in the platform economy: the case of facebook. Sustainability 10:1757. doi: $10.3390 /$ su10061757

Gauron, A. (2017). En quoi le Capitalisme des Plateformes Numériques est-il Singulier ? Available online at: https://www.metiseurope.eu/2017/12/15/enquoi-le-capitalisme-des-plateformes-numriques-est-il-singulier/ (accessed June 10, 2019).

Guerrien, B. (2006). Le marché en tant qu'utopie. Mouvements 3, 62-69. doi: $10.3917 /$ mouv.045.69

Guillaud, H. (2017). De la Conception Comportementale des Environnements de Travail, 22 Avril. Available online at: https://www.lemonde.fr/ blog/internetactu/2017/04/22/de-la-conception-comportementale-desenvironnements-de-travail/ (accessed June 15, 2019).

Havard, C., Rorive, B., Sobczak, A. (2006). "Client, employeur et salarié: cartographie d'une triangulation complexe," in Économie et Société, Série AB, Économies du Travail (Paris: ISMEA).

Huws, H. (2014). Labor in a Global Digital Economy. New York, NY: Monthly Review Press.
Huws, U., Spencer, N. H., and Joyce, S. (2016). Crowd Work in Europe: Preliminary Results From a Survey in the UK, Sweden, Germany, Austria and the Netherlands, Foundation for European Progressive Studies (FEPS) (Brussels), 58.

Irani, L. (2015). Difference and dependence among digital workers: the case of amazon mechanical turk. South Atlantic Q. 114, 225-234. doi: $10.1215 / 00382876-2831665$

Jan, A. (2018). Livrer à vélo... en attendant mieux. Nouvelle Revue du Travail 13. doi: 10.4000/nrt.3803

Kingsley, S. C., Gray, M. L., and Suri, S. (2015). Accounting for market frictions and power asymmetries in online labor markets. Policy Internet 7, 383-400. doi: $10.1002 /$ poi3.111

Lautier, B., Tortajada, R. (1978). Ecole, Force de Travail et Salariat. Grenoble: Presses universitaires de Grenoble.

Minassian, G. (2018). "Zones grises," in Quand les États Perdent le Contrôle. Biblis: CNRS Editions, coll.

Möhlmann, M., and Zalmanson, L. (2017). "Hands on the wheel: Navigating algorithmic management and Uber drivers' autonomy", in Proceedings of the International Conference on Information Systems (ICIS 2017) (Seoul).

Murgia, A., Pulignano, V. (2019). Neither precarious nor entrepreneur: the subjective experience of hybrid self-employed workers. Econ. Indus. Democr. 1-27. doi: 10.1177/0143831X19873966

O'Keeffe, B., and Jones, M. (2015). How uber plays the tax shell game. Fortune. Available online at: https://fortune.com/2015/10/22/uber-tax-shell/ (accessed October 22, 2015)

Orlikowski, W. (2007). Sociomaterial practices: exploring technology at work. Organ. Stud. 28, 1435-1448. doi: 10.1177/0170840607081138

Prassl, J., and Risak, M. (2016). Uber, Taskrabbit, \& Co: platforms as employers? Rethinking the legal analysis of crowdwork. Compar. Labor Law Policy J. 37, 619-649.

Reynaud, J.-D. (2003). "Réflexion I. Régulation de contrôle, régulation autonome, régulation conjointe," in La théorie de la Régulation Sociale de Jean-Daniel Reynaud, ed G. de Terssac (La Découverte), 103-113.

Rochet, J. C., and Tirole, J. (2003). Platform competition in two-sided markets. J. Eur. Econ. Assoc. 1, 990-1029. doi: 10.1162/154247603322493212

Schor, J. B., and Wengronowitz, R. (2017). "Chapter 2: The new sharing economy. Enacting the eco-habitus," in Social Change and the Coming of Post-consumer Society, eds M. J. Cohen, B. C. Szejnwald, and P. J. Vergragt (London: Routlege), 25-42.

Serafini, T. (2019). Contre Airbnb, Paris se Prend une porte. Libération.

Serrano-Pascual, A., and Jepsen, M. (eds.). (2018). The Deconstruction of Employment as a Political Question. 'Employment' as a Floating Signifier. Brussels: Palgrave Macmillan.

Srnicek, N. (2017). Platform Capitalism. London: Polity.

Streeck, W., and Thelen, K. (2005). Beyond Continuity: Institutional Change in Advanced Political Economies. Oxford: Oxford University Press.

Supiot, A. (2010). Contribution à une analyse juridique de la crise économique de 2008. Rev. Int. Droit Travail 149, 165-176. doi: $10.1111 / \mathrm{j} .1564-9121.2010 .00081 . \mathrm{x}$

Supiot, A. (2015). La Gouvernance par les Nombres. Coll. Poids et Mesures. Genève: Fayard.

Thaler, R. H., and Sunstein, C. R. (2003). Paternalism libertarian. Am Econ Rev. 93, 175-179. doi: 10.1257/000282803321947001

Thaler, R. H., and Sunstein, C. R. (2003). Nudge: la Méthode Douce pour Inspirer la Bonne Decision. Paris: Pocket.

Thelen, K. (2018). Regulating Uber: the politics of the platform economy in Europe and the United States. Perspec. Politics 16, 938-953. doi: $10.1017 /$ S1537592718001081

Tirole, J. (2018). Économie du Bien Commun. Paris: PUF.

Todolí-Signes, A. (2017). The "gig economy": employee, self-employed or the need for a special employment regulation? Trans. Eur. Rev. Labour Res. 23, 193-205. doi: $10.1177 / 1024258917701381$

Transfer (2018). Work and employment grey zones: new ways to apprehend emerging labour market norms. Special Issue, 24.

Valenduc, G. (2019). "Chapter 3: New form of work and employment in the digital economy," in The Deconstruction of Employment as a Political Question, eds A. Serrano-Pascual and M. Jepsen (Brussels: Palgrave Macmillan), 63-80. 
Valenduc, G., and Vendramin, P. (2017). Digitalisation, between disruption and evolution. Transfer: European Rev. Labour Res. 23, 121-134. doi: $10.1177 / 1024258917701379$

Vendramin, P. (2011). TIC et genre: des regards multiples. Tic Soc. 5. doi: $10.4000 /$ ticetsociete. 938

Wajcman, J. (2006). New connections: social studies of science and technology and studies of work. Work Employ. Soc. 20, 773-786. doi: 10.1177/0950017006069814

Zuboff, S. (2019). The Age of Surveillance Capitalism: The Fight for a Human Future at the New Frontier of Power, Public Affairs. New York, NY.
Conflict of Interest: The authors declare that the research was conducted in the absence of any commercial or financial relationships that could be construed as a potential conflict of interest.

Copyright (๑) 2020 Dieuaide and Azais. This is an open-access article distributed under the terms of the Creative Commons Attribution License (CC BY). The use, distribution or reproduction in other forums is permitted, provided the original author(s) and the copyright owner(s) are credited and that the original publication in this journal is cited, in accordance with accepted academic practice. No use, distribution or reproduction is permitted which does not comply with these terms. 


\section{OPEN ACCESS}

Edited by:

Emiliana Armano,

University of Milan, Italy

Reviewed by:

Mariya Aleksynska,

Université Panthéon

Sorbonne, France

Jan Drahokoupil,

European Trade Union

Institute, Belgium

*Correspondence:

Marta Kahancová

marta.kahancova@celsi.sk

Specialty section:

This article was submitted to Work, Employment and Organizations,

a section of the journal

Frontiers in Sociology

Received: 15 August 2019

Accepted: 14 January 2020

Published: 26 February 2020

Citation:

Kahancová M, Meszmann TT and Sedláková M (2020) Precarization via Digitalization? Work Arrangements in the On-Demand Platform Economy in

Hungary and Slovakia.

Front. Sociol. 5:3.

doi: $10.3389 /$ fsoc. 2020.00003

\section{Precarization via Digitalization? Work Arrangements in the On-Demand Platform Economy in Hungary and Slovakia}

\author{
Marta Kahancová*, Tibor T. Meszmann and Mária Sedláková \\ Central European Labour Studies Institute, Bratislava, Slovakia
}

The concept of precarity is increasingly used for an analysis of standard and non-standard (atypical) employment forms-yet among atypical employment forms, platform-driven work is rarely included. This paper aims to fill this gap and provide a refined analytical framework for an evaluation of precarity in employment arrangements applicable to on-demand platform work. The legitimacy of such an analytical framework is two-fold. First, it allows identifying the dimensions of precarity in on-demand platform work. Second, it extends the understanding of how a general situation in the labor market connects to work precarity in on-demand platform work. The analytical framework is applied to evidence from two countries in Central and Eastern Europe-Hungary and Slovakia, where the rise of precarious employment went hand in hand with the rise of work via digital platforms. The central claim of the paper is that precarity in on-demand platform work is especially manifest in the dimensions of autonomy at work and of interest representation. Furthermore, digitalization enforces precarity, while at the same time, it mitigates labor market segmentation between standard and non-standard workers as distinct groups of workers.

Keywords: precarity, digitalization, on-demand work, platform work, Central and Eastern Europe

\section{INTRODUCTION}

This paper seeks to establish a systematic conceptual and empirical relationship between two phenomena that recently sparked great research attention. The first one is the rise of non-standard work arrangements, some of which are considered precarious because of being uncertain and lacking appropriate social and statutory protection (Keune, 2011; Doellgast et al., 2018; Kalleberg, 2018; Keune and Pedacci, 2019). The second phenomenon is the emergence of a platform economy where work is directly mediated or indirectly led by digital platforms (De Stefano, 2015; Irani, 2015; Stewart and Stanford, 2017; van Doorn, 2017; Gandini, 2019). Despite the literature's increased attention to the role of platform work in the labor markets, a systematic analytical approach to reasons and dimensions of precarity in platform work has not yet been established.

This paper applies the existing conceptualization of precarity to specific characteristics of ondemand platform work to respond to two research questions. First, it seeks to identify particular dimensions of precarity in on-demand platform work. Second, the paper engages in a debate on the implications of precarity in platform work on broader efforts at mitigating precarity in the labor market and on the transformation of labor market institutions such as workers' protection and 
interest representation. Seeking to draw implications of platform work for overcoming precarity and for transforming labor market institutions, the paper selectively focuses on on-demand platform work that embraces customer-driven tasks and can be localized in a concrete geographical, economic, social, and political setting - the type of platform economy that is associated with mobile labor markets (Codagnone and Martens, 2016; WillZocholl, 2017). These include both work in labor and capital platforms, such as taxi transport services (Uber and Taxify), and work related to short-term flat rentals (Airbnb), respectively. The framework seeks empirical underpinning in two countries in Central Eastern Europe-Hungary and Slovakia. While both countries demonstrate general weaknesses in enforcement of employment regulation, and the capacities of labor market institutions are modest and further eroding (Ost, 2009; Bohle and Greskovits, 2012; Doellgast et al., 2018; Trif et al., submitted), they differ in their policy responses to regulate work in the platform economy (Meszmann, 2018; Sedláková, 2018).

The contribution of the paper is two-fold. First, it sharpens and redefines the framework on work precarity by incorporating newer types of precarious work arrangements in digitalized labor markets. Second, based on original empirical evidence, it evaluates the interaction of the specificities of on-demand platform work with broader developments in labor market institutions in two Central and Eastern European (CEE) countries. Whereas, platform work in Hungary and Slovakia still appears as marginal in labor participation-compared, e.g., to Western EU member states (Eurofound, 2018; Piasna and Drahokoupil, 2019), the intensity of changes and their effects on labor market institutions are expected to differ due to different policy approaches in these regulated neoliberal market economies (Bohle and Greskovits, 2012).

In turn, understanding precarity in platform work in the empirical conditions of CEE then helps in developing the paper's main argument that while digitalization blurs labor market dualization between standard and precarious workers (cf. Rueda, 2006; Palier and Thelen, 2010; Schwander, 2018), it reinforces the existing institutional weaknesses in CEE labor markets (Ost, 2009; Bohle and Greskovits, 2012; Trif et al., submitted). The paper shows that in the case of on-demand platform work, precarity is especially pronounced in the dimension of autonomy at work and interest representation. It argues that the reason why on-demand platform work is not explicitly exposed to pressures for decreasing precarity lies neither in cases when platform work coexists with work in the traditional economy nor in cases when platform work is isolated from the traditional economy. In the former case, on-demand platform workers are able to claim social rights and job security from their jobs in the traditional economy, while in the latter case, full-time platform workers are labor market outsiders without sufficient means to organize and to influence labor market institutions. This explains the lack of pressure from platform workers to improve their labor market situation in a non-transparent regulatory framework and the lack of attention from interest representation organizations. At the same time, the coexistence of on-demand platform work with traditional jobs also blurs the lines of the established divide between labor market insiders and outsiders as distinct groups of workers (cf. Rueda, 2006; Palier and Thelen, 2010).

The paper is structured as follows. The first section conceptualizes precarity in on-demand platform work using a multidimensional understanding of precarity. The second section provides contextual information on the rise of work precarity, governing institutions of labor markets, and the status of on-demand platform workers in Hungary and Slovakia. The third section presents empirical evidence demonstrating which dimensions of precarity are found in on-demand platform work in Hungary and Slovakia and which reasons drive this precarity in different types of platform work. In turn, this evidence feeds into the concluding exploratory discussion on the impact of precarity in platform work onto a broader reconfiguration of precarity and related labor market institutions in the concluding section.

\section{A MULTIDIMENSIONAL CONCEPTUALIZATION OF WORK PRECARITY ADAPTED TO ON-DEMAND PLATFORM WORK}

To identify how different types of platform work differ in their extent and type of precarity and how this informs the impact of platform work on the overall reconfiguration of work precarity and related labor market institutions, the first step is to conceptualize precarity in platform work.

Platform work, or work for digital platforms, belongs to the newest phenomena facilitated by digital technologies (Akgüç et al., 2018; Berg et al., 2018). Digital platforms facilitate work arrangements where the relationship between the worker and a consumer is established via a digital market intermediary acting as a shadow employer (Friedman, 2014; Schor, 2016; Gandini, 2019). Platform work has been categorized along several dimensions. A distinction has been made between labor and capital platforms, and divisions exist also within the labor platforms. These include (a) crowd work or "clickwork" platforms where workers are hired for digital-based micro-tasks (De Stefano, 2015; Gandini, 2019), (b) platforms facilitating the meeting of workers with their clients for manual labor (Heeks, 2017; Gandini, 2019), and (c) work-on-demand, or consumer-led service work including deliveries or driving where the job is organized through online platforms that retain control over important aspects of the work (De Stefano, 2015; Heeks, 2017; Stewart and Stanford, 2017; Gandini, 2019). In addition, "capital platforms," which facilitate rent of assets, also require the application of productive labor (Stewart and Stanford, 2017). It often covers highly precarious, sometimes unpaid, types of domestic work including cleaning, maintenance, and other related services.

While crowdsourcing platforms cover predominantly online work without demonstrating geographically localized features of work, for all other types of platform work, "the local embeddedness of work and workers remain significant" (WillZocholl, 2017, p. 63). This is because workers meet with their clients or deliver services for them in a specific location. In turn, 
this paper excludes crowd work platforms from the analysis and focuses on the visible work arrangements of on-demand work, which are potentially in the scope of collective regulation by employers and trade unions (De Stefano, 2015). Thus, the paper's empirical focus is exclusively related to on-demand platform work represented by the case studies of taxi driving services (Uber/Taxify) and home rentals with associated cleaning and maintenance services (Airbnb). Such work is visible to other segments of the labor market. Despite the limited overall size of the on-demand platform economy, there is a strong qualitative pressure on regulation of platform-based work that bears implications also for labor market institutions and employment standards in general. That is, in on-demand platform work, locally embedded "broader" employment standards both inform and influence the very workers who perform these jobs, but these jobs also have a practical significance for local industrial relations and employment protection regulation.

Defining the paper's focus on on-demand platform work is instrumental to adapting the existing conceptualizations of work precarity to the specificities of this type of work arrangement. The established definition of precarious work is derived from a benchmark definition of standard employment relationship (SER). Aust and Holst (2006) define SER as a socially secured, long-term, and full-time employment with a wage that allows for a decent living. In contrast, non-standard, or atypical, work refers to the notion of a contingent workforce (cf. Heery, 2009) and involves temporary, fixed-term, part-time work, temporary agency work, and dependent self-employment (Trif et al., 2016). Kalleberg $(2009$, p. 2) defined precarious employment as "employment that is uncertain, unpredictable, and risky from the point of view of the worker." While precarity is often associated with atypical work, the two are not necessarily the same (Keller and Seifert, 2013). For example, part-time employment often results from a conscious choice of an individual employee. At the same time, some standard full-time employment relationships may be precarious, e.g., because of low pay, an excessive amount of unpaid overtime, or constrained social rights and entitlements of the concerned employee.

Workers performing on-demand platform work are likely to be exposed to precarity because of their irregular work schedules and fragmented employment trajectories that are driven by fluctuations in demand for their services (Stewart and Stanford, 2017; Drahokoupil and Piasna, 2019). In addition, potential sources of precarity derive from reduced access to benefits and social security, confusion around tax issues and administrative requirements for platform workers as "serviceproviding individuals," isolation and lack of interaction with co-workers, lack of on-the-job training regarding health and safety and other issues, significant occupational stress, increased workload and time pressure, and comparatively lower average net earnings than in the traditional economy (e.g., Fidler, 2016; Garben, 2017; Huws et al., 2017).

Despite evidence on exposure to precarity, a conceptualization of dimensions of precarity [e.g., (International Labour Organization (ILO), 2016), p. 19-20; (Trif et al., 2016)], specifically tailored to the unique characteristics of ondemand platform work, has not yet been established. Such a conceptualization is essential, because precarity derives not only from the type of one's employment contracts but also from seemingly invisible working conditions. In turn, workers in seemingly stable jobs may face precarity due to rising work intensity, increasing workload, work-related stress, and exposure to low pay (Pulignano et al., 2016; Grimshaw et al., 2018). In addition, precarity in on-demand work via digital platforms may be hidden in the distinct form of managerial control and the use of feedback, ranking, and rating systems that are embedded in platform work (e.g., Gandini, 2019).

Dörre (2005) identifies precarity in three spheres of work, which are well-applicable also to on-demand platform work. First, these include precarity in the material sphere, because precarious jobs do not secure decent living and job security (economic rights). Second, precarity relates to the sphere of social communication, because precarious workers are excluded from social networks at their workplace. Finally, there is a legal/institutional sphere of precarity because precarious employees are often excluded from access to certain social rights. Taken together, precarity in platform work needs to be analyzed in a multidimensional framework that acknowledges, on the one hand, how this type of work arrangement is formally anchored in the relevant labor legislation and, on the other hand, how precarity applies to particular working conditions (cf. Keller and Seifert, 2013).

First, the formal status of on-demand workers on the labor market is a source of precarity because platform work is not regulated per se by labor law and/or labor codes but by labor legislation governing work arrangements beyond an employment relationship. This is because most platforms differ from real employers in not recognizing workers as employees in the traditional sense (cf. Berg et al., 2018). Instead, platforms usually require for workers to take over responsibility regarding compliance with regulations and adopt a status of self-employed or individual contractor. In turn, in platform work, the concept of wages does not apply if there is no employment relationship. Instead, the concept of income, as explained below, is more feasible. Second, the need for customer-driven flexibility in ondemand platform work raises questions about autonomy at work. Embedding autonomy of work within the notions of supervision, control, and access to training and information, on-demand platform work is consistently identified as precarious (Pichault and McKeown, 2019). Autonomy at work is thus broader than the role of the labor market status of platform workers: it relates to unstable work schedules and highly personalized, even emotional, perceptions of precarity based on lacking access to career development and training, an information deficit, but also exposure to stress and to a metric customer evaluation (Leighton and Wynn, 2011; Deakin, 2013; Gandini, 2019; Pichault and McKeown, 2019). Taken together, the above considerations inform the multidimensional conceptualization of precarity in platform work where the six dimensions are identified.

1. Income: This dimension of precarity relates to the incidence of low income identified as income below two-thirds of median gross hourly wages. The concept of income captures the fact that on-demand platform workers often work on 
service contracts not regulated by relevant labor codes and are thus formally not in an employment relationship with wage entitlements.

2. Job security: Along this dimension, precarity refers to lower job security as in an SER, i.e., in terms of flexible work arrangements, seasonal fluctuations in work and fluctuations directly derived from customer ratings and evaluation systems by the platform, and lack of employment protection in case of firing.

3. Social security: Precarity derives from limited or no social security entitlements, including constrained holiday and collective benefit entitlements, depending on the specificities of work arrangements (small contracts, zero hours, selfemployment, and similar).

4. Working time: Precarity derives from unpredictable working hours and overall working time, meaning also excessive and often unpaid overtime.

5. Autonomy at work: Precarity may originate from the lack of appropriate working conditions including limited access to training and skill development, lack of career opportunities, greater exposure to work-related stress, lack of information, and exposure to immediate feedback, ranking, and rating systems of platform workers' work from their service users/.

6. Collective interest representation: Precarity in this dimension originates from limited access to interest representation. This derives, first, from the lack of interest of traditional interest representation organizations to focus on platform workers and, second, from the character of platform work where workers have little opportunity to interact with each other and thus lack enabling conditions to raise their collective identity and articulate their interests.

The above conceptualization serves as an analytical tool for an assessment of dimensions of precarity in on-demand platform work in the next section. The empirical exercise focuses on two types of (a) on-demand platform work in Hungary and Slovakia: taxi/drivers via Uber and (b) workers delivering microwork, cleaning or other maintenance tasks related to property rentals via Airbnb. Evidence originates from two research projects where the authors participated: one on precarious work (PRECARIR ${ }^{1}$, 2014-2016) and one on platform work (IRSDACE ${ }^{2}$, 20162018). Both projects paid particular attention to monitoring and evaluating practical issues, problems, and trends related to the nature of work in given legislative, economic, and employment policy frameworks, as well as collective interest representation conditions. Data collection and analysis relied on a combination of qualitative and quantitative methods. Quantitative evidence on the character of platform work has been collected via a survey among platform workers in both countries. Qualitative evidence on the character of work and the extent of precarity has been collected via interviews with workers as well as interest representation organizations including trade unions, employer organizations, and other stakeholders, practitioners, and experts.

\footnotetext{
${ }^{1}$ https://www.dcu.ie/link/current-projects/precarir2014-2016.shtml

${ }^{2}$ https://www.ceps.eu/ceps-projects/industrial-relations-and-social-dialogue-inthe-age-of-collaborative-economy-irsdace/
}

The IRSDACE project also embraced individual and focus group interviews with platform workers. These interviews addressed the demographic and social background of on-demand platform workers, description of their working conditions and income, perceived advantages and disadvantages compared to standard employment, but also the workers' knowledge about their rights and opportunities for collective interest representation. In total, 26 interviews were conducted in Hungary and 21 interviews in Slovakia. All interviews were face-to-face, conducted by the authors in the local language, recorded, and transcribed. Before analyzing these interview data to identify precarity in platform work, the next section briefly accounts for the embeddedness of on-demand platform work in the context of Hungarian and Slovak labor markets and legislation.

\section{LABOR MARKET INSTITUTIONS AND THE STATUS OF ON-DEMAND PLATFORM WORKERS}

Hungary and Slovakia underwent a transition from state socialism to democracy and a market economy since the early 1990s. Legacies during the transition period account for important similarities in their labor market institutions, including weak law enforcement, declining trade union density and collective bargaining coverage, low levels of legally stipulated employment protection, and trends of labor market liberalization upon joining the EU. Nevertheless, there is a degree of variation in institutional regimes that are affected by particular national traditions (Bohle and Greskovits, 2012). Whereas, the significance of both national and sectoral social dialogue eroded in Hungary, along with the regulatory strength or relevance of intermediary organizations, in Slovakia, due to the existence of sector-level social dialogue and bargaining in many sectors (including transportation and tourism), social partners could potentially exert greater influence.

After 2008, both Hungary and Slovakia faced a rise in precarious work in the traditional economy via an increased use of temporary agency work, fixed-term contracts, and service contracts (Kahancová, 2016; Meszmann, 2016). In addition, low incomes push many workers to seek additional work via household work, family support work, or platform work. Such work may be on the edge of informal employment, as "invisible workers" are sometimes employed without a legal status and therefore do not have social security entitlements or access to interest representation (Kelemen, 2013; Fleck et al., 2017; Meszmann, 2018).

The rise of flexibility and precarity in the traditional economy is accompanied by the rise of platform work. Survey evidence on platform workers suggests that this form of work is overall still marginal compared to Western Europe (Drahokoupil and Piasna, 2019). Nevertheless, on-demand platform work is more widespread in Hungary than in Slovakia and localized in the capital cities Budapest and Bratislava.

The labor market status of locally embedded on-demand platform workers is informed by specific national employment legislation. In both countries, legislation does not recognize a 
TABLE 1 | Assessment of precarity in six dimensions.

\begin{tabular}{|c|c|c|c|c|c|}
\hline Income & Working time & Autonomy at work & Job security & Social security & Representation \\
\hline $\begin{array}{l}\text { Minimum wage not } \\
\text { applicable } \\
\text { Variation regarding } \\
\text { discretion over pay setting: } \\
\text { more price-setting } \\
\text { coordination (taxi services) } \\
\text { vs. direct exposure to } \\
\text { self-exploiting competition } \\
\text { (e.g., in price setting for } \\
\text { cleaning, guest reception, } \\
\text { maintenance, etc.) } \\
\text { Hidden costs of on-demand } \\
\text { platform work (e.g., } \\
\text { investments in work tools) }\end{array}$ & $\begin{array}{l}\text { High variation with } \\
\text { potential high risk. } \\
\text { Irregular working hours, } \\
\text { difficult reconciliation } \\
\text { with other activities, and } \\
\text { at the same time } \\
\text { more flexibility }\end{array}$ & $\begin{array}{l}\text { Low } \\
\text { Exposure to direct } \\
\text { evaluation by customers } \\
\text { with direct impact on } \\
\text { expected demand for } \\
\text { services and thus } \\
\text { income level } \\
\text { Lack of information on } \\
\text { requirements and } \\
\text { on-the-job training rights }\end{array}$ & $\begin{array}{l}\text { Medium } \\
\text { Worker-driven, pressure } \\
\text { to work more to } \\
\text { increase income, } \\
\text { indirect dependence on } \\
\text { customer ratings, } \\
\text { flexibility in } \\
\text { accommodation sector }\end{array}$ & $\begin{array}{l}\text { Low } \\
\text { (informal employment) or } \\
\text { medium if self-employed } \\
\text { status or if there is a } \\
\text { combination with other } \\
\text { jobs (or student status, } \\
\text { retired, etc.) }\end{array}$ & $\begin{array}{l}\text { Low (accommodation } \\
\text { service and transport in } \\
\text { Hungary) or non-existent } \\
\text { (Slovakia, microworkers } \\
\text { in Hungary) } \\
\text { Marginal access to } \\
\text { collective interest } \\
\text { representation; workers } \\
\text { do not engage in social } \\
\text { interaction with } \\
\text { co-workers or } \\
\text { only virtually }\end{array}$ \\
\hline
\end{tabular}

Authors' assessment based on original empirical evidence (on-demand platform work in Hungary and Slovakia).

specific category of platform work and does not offer targeted regulation acknowledging the specificities of platform work. Moreover, platform workers received marginal attention by trade unions in both countries. This fact, together with the fact that digital platforms do not consider themselves as employers (except for Uber in Slovakia, which joined the National Union of Employers), contributed to the fact that platform workers mostly have less formal, non-standard work arrangements. In Hungary, the most widespread form of on-demand platform work is bogus self-employment where most interview respondents described on-demand platform work as an entrepreneurial or "service" activity and a temporary arrangement overlapping with a swift or sometimes desperate need to find an income-generating activity. Especially for younger workers and foreigners, it overlapped with their entry into the Hungarian labor market. Similarly, in Slovakia, self-employment is also a common labor market status for on-demand platform workers. Since the majority of Slovak interview respondents justified their platform work as a source of additional income, their employment status is usually a combination of several labor market statuses, for instance, solo self-employment combined with a standard employment contract or service contracts (Sedláková, 2018). This situation may change for platform taxi drivers after the 2019 legislative changes to road transport legislation, which re-regulates the taxi service provision including the service via online platforms and facilitates a greater use of standard employment contracts. In platform work in accommodation services, Airbnb providers utilize the advantage of a gray zone between two labor market statuses: a natural person offering short-term rentals with a local tax payment obligation and a licensed provider of accommodation services (including additional services such as cleaning) according to the Trade Licensing Act (Sedláková, 2018). In addition, students are often hired as seasonal cleaners without an official contract. Cash payments, which are also common for microwork and undeclared or under-declared household work, were also reported in the interviews.

In sum, in the conditions of weak law enforcement and weak interest representation, digital platforms facilitating on-demand work possess great discretion over defining the labor market status of their workers. This includes shifting all risks and formal obligations related to licensing and tax issues onto the workers. Nevertheless, most of our interviewed on-demand platform workers, especially in Slovakia, had their first jobs in traditional sectors or were students. This means that their labor market status was not predominantly defined through their platform work. In turn, they did not highlight the volatility of on-demand platform work per se.

\section{PRECARITY IN ON-DEMAND PLATFORM WORK}

The status of on-demand platform workers on the Hungarian and Slovak labor markets suggests distinct features that may qualify on-demand platform work in itself as precarious. This section goes deeper and identifies the sources of precarity in on-demand platform work in Hungary and Slovakia across the six dimensions of precarity presented earlier. Attention is also paid to differences between two broadly defined on-demand platform sectors: taxi driving for Uber and Taxify and work related to property rental services via Airbnb. Table 1 presents a qualitative-comparative evaluation of precarity according to six dimensions.

\section{Income}

The income of on-demand platform workers likely differs between the two sectors. Whereas, in on-demand taxi services, income is usually based on a well-defined, set rate with less discretion over pay setting, in accommodation services, the income generated by apartment rent hides the labor part behind it (reception, cleaning) that thus might be a hotbed of (self-)exploitation. In both cases, there is a radical exposure of workers to risks of market demand, with a varying level of autonomy to calculate the benchmark of a decent income. Whereas, in taxi services, the market demand is, in general, high in both countries, in accommodation, such as cleaning, it is lower. Especially in Slovakia, the demand for Airbnb and associated services in the capital city (with the highest concentration of apartment renting) is not comparable to that in Budapest. Thus, it can function only as an additional, supplementary income. 
For microworkers, especially in Slovakia, remuneration was not seen as fair, especially when pushed down by inexperienced, unqualified, and/or younger workers (students, but even migrant workers). In personal transport of both countries, taxi drivers have no control over their pay, which is set by the platform, and drivers have no negotiating powers over it. In Slovakia, this fact was cited as one of the barriers to full-time employment in the sector (Sedláková, 2018). In Hungary, taxi drivers responded with quantitative flexibility, $10-12 \mathrm{~h}$ of work, in order to increase the likelihood of generating sufficient income. On the contrary, Airbnb hosts set their income for accommodation themselves. Yet, this autonomy could backfire, as shown in the example of Hungary: there was a constant complaint that there was a "selling at any price" logic present among Airbnb hosts, which further exerts a downward pressure on income levels.

In Hungary, interview respondents confirmed that hourly income in on-demand platform work is either significantly higher than in other jobs across CEE or more difficult to calculate due to hidden costs related to investments, maintenance, etc. This is why compared to other countries, in Hungary and Slovakia, calls for minimum wages applicable to platform work are scarce, both from workers themselves and from trade unions.

In sum, on the dimension of income, on-demand platform work cannot be classified as precarious, but for full-time platform workers, the risk of precarity is quite high. As long as platform work generates secondary income, as most of the cases especially in Slovakia show, workers may be less concerned about low income levels from their platform work and more concerned about competition with other service providers and maximizing their individual income. On the negative end, non-transparent income levels hide precarity on the income dimension, and apart from increasing the workload, there are no available mechanisms to positively influence the workers' own income levels - a finding that we will deal with more in the interest representation dimension.

\section{Working Time}

Precarity in on-demand platform work is manifested in unpredictable working hours (in the case of the accommodation sector) and length of working time (more in taxi transport). Nevertheless, most interview and survey respondents in both countries identified flexibility of working time as the major advantage of platform work. This seemed to be the case especially among those who had defined, or could clearly define, their working time, and for those who were working as on-demand workforce on a part-time basis. However, after detailed scrutiny, irregular working hours and difficult reconciliation with other, more stable jobs and family time became the critical aspect of this "not-so-flexible flexibility." Especially in accommodation services, a push for a constant availability, enhanced by the exposure to direct customer ratings, motivates workers to be available at virtually any time.

Flexibility in working time appears to be a central dimension in unpacking precarity as it taps back into income levels, job security, and especially autonomy at work-due to fear and implications of negative ratings. For platform-driven taxi drivers in both countries, working extended long hours was voluntary, but it raised health and safety issues. In providing accommodation services and associated microwork, one had to know how to manage and organize one's own time in order to come to terms with high variations and daily rhythms of on-demand work. The more informed and skillful workers translated extra, non-regular work hours to extra benefits or fees from customers. For those who were unprepared for this fluctuation, undefined working time caused high stress. Hence, the source of precarity in working time arrangements was especially interconnected with autonomy at work, related to unpreparedness, lack of power, information, or autonomy to definite or limit one's own working time for on-demand work (see below), and risks of self-exploitative practices.

\section{Autonomy at Work}

Lack of information, concerns over liability, and health and safety of on-demand platform workers came up as strongly voiced concerns. Interviewed platform workers were typically unsure what happens in case of accidents or problems. Most fulltime platform worker interviewees in Hungary listed the lack of information and training for the job as the most problematic dimension. This was not the case in Slovakia, where the issues of professional training were voiced only in relation to taxi services. Interviewees mentioned lack of information on rules of taxation and administration for novices and lack of training for the job, with the necessary skills in communication, conflict management, and problem solving, especially in Hungary (Meszmann, 2018). Although not explicitly, similar concerns were recorded among taxi drivers in Slovakia, who often worried about the background of the workers and state of their professional knowledge (Sedláková, 2018). Last but not least, some Hungarian platform workers felt that their economic activity enjoyed a very low social prestige. Moreover, they also felt that conflicts that platforms generated in the broader society translated into an unfavorable, unsupportive social environment vis-à-vis on-demand platform workers.

\section{Job Security}

The dimension of job security is particularly obscure in ondemand platform work. From a legal perspective, job security of platform workers is very low. This is due to widespread operation of platform workers as independent contractors or economically dependent workers (bogus civil law contractees), or even undeclared workers (especially apartment cleaners). Nevertheless, the interviewed platform workers across both studied types of on-demand work experienced their job security as moderate and depending mostly on the (seasonal) business cycle, as well as on insecurities stemming from a changing regulation of the sector. In Hungary, the character of on-demand cleaning jobs as platform-mediated accommodation services was considered to be temporary only, due to its seasonal character. In taxi transport of both countries, the line between platform work and traditional taxi driving was less pronounced, given that both groups, platform-based taxi services and traditional taxi providers, introduced software applications. Thus, in taxi transport in both countries, job security was significantly higher. 
Despite dependency on customer rankings and ratings, neither of the interviewees except one spelled this out as a major factor causing lower job security. On the other hand, indirectly, the demand for flexible work and adaptation to a changing regulatory environment caused, at times, higher rates of quitting the platform, especially among platform workers providing accommodation services. As aptly formulated by one respondent providing accommodation-related services, in the triangle between the (intermediary) employer, customer, and worker, the last had the weakest position, without a real voice. Due to the seasonal character of on-demand work, or its combination with other forms of employment, job security was not judged as problematic.

In sum, job security is low to moderate in on-demand platform work. There is a strong influence of seasonality and a more obscure effect of customer ratings. Interactions with other forms of work in the economy again demonstrate the importance of assessing precarity in on-demand platform work only in the context of workers' overall labor market positions.

\section{Social Security}

Social security of platform workers appears to be dependent on their labor market status and can thus range from highly precarious (as in informal economy) to low-standard, in cases of part-time platform work, when a social security arrangement was gained from the main job. In Hungary, platform workers work at best under civil law relationship-based service contracts and thus do not enjoy all elements of social protection. Except equal treatment, free movement, and access to social security services, other elements of social protection are thus not available to the self-employed, such as paid leaves, redundancies, family benefits, etc. Moreover, the work of individual entrepreneurs is not considered "organized work"; thus they do not fall under the Hungarian Health and Safety Act. Simplified employment for seasonal work is based on the labor code, but provisions on unpaid leave, sick leave, etc. do not apply. However, in the case of self-employment, irrespectively of the increasingly flexible income threshold, the beneficial taxation scheme also translates into a default of low long-term social security, i.e., extremely low retirement savings. Likewise, due to no specific regulation of platform work on the labor market in Slovakia, platform workers have no specific entitlements for social protection. In addition, based on the evidence from the interviews, platform workers do not consider this aspect as problematic and rarely think about the consequences of it, unless platform work becomes their main source of income.

\section{Interest Representation}

Platform workers in both countries are neither associated with nor represented by trade unions. Microworkers as well as individual entrepreneurs in Hungary fulfill the criteria for membership with some civil and interest-based associations but do not fulfill the established criteria to become trade union members. Moreover, workers are even more atomized than in traditional sectors, and the possibility of interest articulation via trade unions or alternative organizations is typically not recognized. In Slovakia, the discussion among the traditional trade unions of whether to include platform workers into their structures was not even raised yet, and trade unionists point out the structural obstacles within their traditional organizations for the new types of workers to join the unions (Sedláková, 2018). Most interviewees in Hungary and Slovakia were not aware of trade unions or of any associations that could provide useful information, let alone serve as an agency of their interest representation. This situation is reinforced by the fact that those working or providing the bulk of labor in these sectors come from social groups which typically provide the most precarious work in patriarchal and closed clientelist societies, including youth, women, and immigrants.

In Hungary, there was only one association that approximated an interest representative organization of on-demand platform workers, the association of small, individual accommodation providers (MAKE-“Magyar ApartmanKiadók Egyesület”Association of apartment renters). However, the association was first of all gathering individual owners of apartments and acted as their voice for pressing local government for a low threshold of regulation-and it was not associated with labor that came with renting out apartments. Nevertheless, it provided useful information and training to its members and filled an important gap in raising awareness in platform workers' voice. Similar attempts have been recorded in Slovakia, where the civic association "Vitaj Doma" (Welcome Home) was formed by the owners and providers of Airbnb services. The organization, whose functioning remains mostly visible via discussions on social networks, functions rather as a forum offering information on legal changes, tax requirements, and vacant jobs (mostly in cleaning).

\section{Summary}

Considering the presented dimensions of precarity, we conclude that the risk and source of precarity in on-demand platform work does not come from low income or irregular working time but is especially manifest in lacking autonomy at work and collective interest representation. On all other dimensions, precarity depends on sector-specific regulation and hidden risks, e.g., consumer rating for income or job security, or net incomes given the costs of engagement in the activity.

The working time of on-demand workers indeed turns into a burden when reconciling work with family and leisure. It creates challenges for coordinating working times in the case of multiple jobs and pushes workers to be available around the clock and respond to customers' queries quickly. This connects with precarity in autonomy at work: on-demand platform workers are often not informed about requirements and (a lack of) their rights and may experience administrative, market demand risks and customer ratings only when already engaged in ondemand platform work. Finally, on-demand platform workers have limited to no access to interest representation due to little contact with other workers and an unclear formal status of the platform worker on the labor market (between a worker, an entrepreneur, a freelancer, and even an owner of capital in the case of accommodation), which structures access to established institution representation channels in traditional sectors of the economy. 
TABLE 2 | Coexistence between traditional and platform work as a factor in explaining precarity.

\begin{tabular}{|c|c|c|}
\hline & & Platform work \\
\hline \multirow[t]{2}{*}{$\begin{array}{l}\text { Traditional } \\
\text { work }\end{array}$} & Yes & $\begin{array}{l}\text { Workers willing to accept precarious on-demand platform } \\
\text { work because of drawing their social rights from traditional } \\
\text { work. Explains lack of initiatives to decrease precarity in } \\
\text { platform work. }\end{array}$ \\
\hline & No & $\begin{array}{l}\text { Workers in on-demand platform work would possibly be } \\
\text { motivated to decrease precarity but lack access to job } \\
\text { security, decent income, and interest representation in the } \\
\text { traditional economy. Their weakness to organize to mitigate } \\
\text { precarity explains its persistence. }\end{array}$ \\
\hline
\end{tabular}

Authors' elaboration.

\section{DISCUSSION}

Uncovering the sources of precarity in on-demand platform work fuels a discussion on how such precarity in new forms of work contributes to reconfiguration of a general understanding of precarity and related employment regulation within broader labor market conditions. Evidence in this paper allows identifying four factors that are crucial in understanding how digitalization facilitates, or even reinforces, precarity and has direct implications for labor market segmentation and broader labor market institutions. These factors include:

- Complementarities between platform work and work in the traditional economy

- A delayed regulatory response to precarity in platform work

- Crisis of interest representation of platform workers via established structures

- Scope of the platform economy within the entire economy.

\section{Complementarity Between Platform Work and Work in the Traditional Economy}

Evidence reveals that platform work in Hungary and Slovakia is perceived by most platform workers as an additional source of income but not their institutional anchor to the labor market. For the majority of platform workers, their on-demand platform work is secondary or serves as an entry point for labor market outsiders (especially in Hungary). The structure of platform workers, their overall labor market situation, and the structure of their income are thus central in understanding why precarity in on-demand platform work persists. The presented evidence allows us to frame the argument on persistence of precarity in the platform economy through its coexistence with working conditions in the traditional economy (see Table 2).

Based on Table 2, we argue that if on-demand platform workers simultaneously have a non-precarious, stable job and predictable income in traditional economic sectors, their social rights, job security, and access to interest representation is secured. Therefore, platform work, with its inherently precarious character, is not exposed to pressures to improve its dimensions of precarity. And even if the primary jobs of platform workers are precarious in the traditional economic sectors, there is a lack of pressure from workers to improve their situation due to lacking access to interest representation, or voice, both in the traditional and in the platform economy. Precarious forms of platform work thus enjoy stability in their coexistence with other forms of employment in Hungarian and Slovak economies.

\section{Delayed Regulatory Response to Working Conditions in On-Demand Platform Work}

As outlined above, understanding the nature of work in the platform economy is only possible when analyzing platform work as part of the overall system where the traditional and the platform economy coexist. Regulation of employment conditions in Hungary and Slovakia has been subject to adjustment and stabilization in the past three decades since both countries embarked on a transition to democracy and a market economy. Employment legislation as well as the structures of interest representation and collective bargaining have thus evolved and stabilized prior to the 2008 crisis. Still, the post-crisis period resembled a modest shock to this system in both countries. While employment levels quickly recovered in the private sector despite an initial decrease in production and in the public sector despite austerity measures, a crisis in employment regulation served as a factor enabling the rise of other forms of precarious work including platform work (Srnicek, 2017).

The legislative response to precarious work in the traditional economy after the crisis is now repeated in response to a platform economy. Meanwhile, during the period of a regulatory gap, work precarity in the platform economy has been further embedding in order to embody the currently typical features of on-demand platform work. One of the few examples of the regulatory responses is recent legislative changes establishing the same professional requirements for drivers working in traditional taxi services as well as drivers working for platforms like Uber and Bolt. This regulation facilitates convergence in working conditions between traditional sectors and the platform economy, but the criterion of reducing precarity has not yet been met due to too few similar regulatory initiatives. In addition, attempts to regulate the platform economy focus on operational aspects of platforms at the national level while leaving the responsibility to mitigate precarity in the workers' hands.

\section{Crisis of Interest Representation}

The wider effect of precarity relates to the fact that it may create a large group of vulnerable employees detached from the rest of the labor market participants and society (cf. Dörre, 2005). Nevertheless, this paper shows that in fact, workers in standard jobs and on-demand platform workers may be the same persons, because on-demand platform work is often used as a second job next to a job with a more stable labor market status. Thus, the dividing lines between standard and precarious workers are blurred. Since on-demand workers using platforms as their second job have access to social rights and employment protection through their standard jobs, they do not seek ways to decrease precarity in their platform work. On the opposite spectrum are full-time platform workers, who are true labor market outsiders without social protection and job security, with 
little autonomy at work, lack of access to interest representation, and high exposure to risks. Nevertheless, pressures to decrease precarity do not come from this group either, because of their overall weakness to organize and voice their interests. The blurred line between standard and precarious platform workers also has implications for interest representation. Employee representatives not only face a challenge to represent two groups of workers with different interests from among the standard and the contingent workforce but also need to address different interests embodied in the same group of workers who are simultaneously in precarious and non-precarious labor market positions. In fact, trade unions' attention to the interests of platform workers is marginal, and they do not exert any significant pressure to reduce their precarity.

Despite the weakness of on-demand platform workers to organize, the authors' focus group interviews with platform workers in Hungary and Slovakia revealed their potential interest to organize and seek collective interest representation in the future. In Slovakia, Uber joined the peak-level employers' association National Union of Employers (RUZ) in April 2018, which may give additional impetus for trade unions to seek representation of platform workers. Still, in general, the paper shows that a precondition for mobilization of ondemand platform workers is a growing size of the platform economy, further deterioration of working conditions that would mobilize workers to be more attentive to their social rights, and also changes on the side of established trade unions in their willingness to represent platform workers. As long as platform work is treated merely as an additional source of income, greater mobilization both from trade unions as well as from the side of workers is not expected.

\section{Scope of Platform Work Within the Labor Market}

Finally, the size of the on-demand platform economy and its coexistence with work arrangements in the traditional economy are crucial in understanding the impact of the platform economy on the general framing of precarity in the labor market and related labor market institutions. We have shown in this paper that the platform economy in Hungary and Slovakia still consists of a marginal source of the population's income and labor market attachment. Nevertheless, there are signals from neighboring countries, e.g., Czechia, but already partly in Hungary, that a growing demand for Airbnb housing services further deepens

\section{REFERENCES}

Akgüç, M., Beblavý, M., Cirule, E., and Kilhoffer, Z. (2018). Industrial Relations and Social Dialogue in the Age of Collaborative Economy (IRSDACE) Comparative Report. Brussels: CEPS Research Paper. Available online at: https://www. ceps.eu/ceps-publications/industrial-relations-and-social-dialogue-agecollaborative-economy-comparative-report/

Aust, A., and Holst, H. (2006). Von der ignoranz zur organisierung? Gewerkschaftliche Strategien im Umgang mit atypisch Beschäftigten am Beispiel von Callcentern und Leiharbeit. [From ignorance to organizing? Trade precarity especially in the dimensions of working time and autonomy at work due to stress exposure and flexibility in cleaning jobs. As demand will increase for platform-mediated housing and transport services, the share of on-demand platform work is expected to grow. In that case, the analysis presented in this paper needs to be revisited with updated analytical tools and empirical evidence.

\section{DATA AVAILABILITY STATEMENT}

All datasets generated for this study are included in the article/supplementary material.

\section{AUTHOR CONTRIBUTIONS}

MK, TM, and MS contributed with equal share to the original research piece by discussing its focus, evidence and scientific contribution. They worked together in the two research projects where data for this paper have been collected. In terms of writing, the authors contributed the following way: MK-introduction, conceptual framework, discussion and conclusions, overall review. TM-introduction, evidence on precarious work (section: Labour Market Institutions and the Status of On-Demand Platform Workers), and evaluation of platform work (section: Precarity in On-Demand Platform Work), overall review. MS-evidence on precarious work (section: Labour Market Institutions and the Status of On-Demand Platform Workers) and evaluation of platform work (section: Precarity in On-Demand Platform Work), overall review, assembling the final version and formatting the article.

\section{FUNDING}

The original research is based on evidence collected within the following projects, funded by the European Commission: Grant No. VS/2014/0534 (PRECARIR), funded by the European Commission, DG Employment, Social Affairs and Inclusion, project website: https://www.dcu.ie/link/current-projects/ precarir2014-2016.shtml. Grant No. VS/2016/0359 (IRSDACE), funded by the European Commission, DG Employment, Social Affairs and Inclusion, project website: https://www.ceps.eu/cepsprojects/industrial-relations-and-social-dialogue-in-the-ageof-collaborative-economy-irsdace/. union strategies towards atypical workers in the example of call centres and temporary agency work]. Indus. Beziehungen 13, 291-313. Available online at: https://nbn-resolving.org/urn:nbn:de:0168-ssoar-343004

Berg, J., Furrer, M., Harmon, E., Rani, U., and Six Silberman, M. (2018). Digital Platforms and the Future of Work: Towards Decent Work in the Online Work. Geneva: ILO.

Bohle, D., and Greskovits, B. (2012). Capitalist Diversity on Europe's Periphery. Ithaca, NY: Cornell University Press.

Codagnone, C., and Martens, B. (2016). Scoping the Sharing Economy: Origins, Definitions, Impact and Regulatory Issues. Institute for Prospective 
Technological Studies Digital Economy Working Paper. Available online at: https://ec.europa.eu/jrc/sites/jrcsh/files/JRC100369.pdf (accessed August 9, 2019).

De Stefano, V. (2015). The Rise of the 'Just-in-Time Workforce': On-Demand Work, Crowdwork and Labour Protection in the 'Gig Economy'. Conditions of Work and Employment Series 71. Geneva: ILO.

Deakin, S. (2013). Addressing Labour Market Segmentation: The Role of Labour Law. Cambridge: Centre for Business Research, University of Cambridge.

Doellgast, V., Lillie, N., and Pulignano, V. (eds) (2018). Reconstructing Solidarity: Labour Unions, Precarious Work, and the Politics of Institutional Change in Europe. Oxford: Oxford University Press Publications. doi: 10.1093/oso/9780198791843.001.0001

Dörre, K. (2005). 'Die Zone der Verwundbarkeit. Unsichere Beschäftigungsverhältnisse, Prekarisierung und die Gewerkschaften' [Zone of Vulnerability: Insecure employment relations, precarization and trade unions]. In: M. Sommer; K. Dörre and U. Schneidewind, Die Zukunft war vorgestern: der Wandel der Arbeitsverhältnisse: Unsicherheit statt Normalarbeitsverhältnis? [The future was the day before yesterday: Transformation of Employment Relations: Insecurity instead of standard employment relations?] (Oldenburg: Bibliotheks- und Informationssystem der Universität), 19-55.

Drahokoupil, J., and Piasna, A. (2019). Digital Labour in Central and Eastern Europe: Evidence from the ETUI Internet and Platform Work Survey. ETUI Working Paper. Brussels: ETUI.

Eurofound (2018). Employment and Working Conditions of Selected Types of Platform Work. Luxembourg: Publications Office of the European Union. Available online at: https://digitalcommons.ilr.cornell.edu/cgi/viewcontent.cgi? article $=1640 \&$ context $=$ intl

Fidler, D. (2016). Work, Interrupted the New Labor Economics of Platforms. IFTF Research Report. Available online at: www.iftf.org/fileadmin/user_upload/ downloads/wfi/IFTF_Work-Interrupted_FullReport.pdf (accessed August 9, 2019).

Fleck, Z., Kiss, V., Tóth, F., Neumann, L., Kenéz, A., and Bajnok, D. (2017). A Jogtudat Narratív Értelmezése. Budapest: ELTE - Eötvös Kiadó.

Friedman, G. (2014). Workers without employers: shadow corporations and the rise of the gig economy. Rev. Keynes. Econ. 2, 171-188. doi: $10.4337 /$ roke.2014.02.03

Gandini, A. (2019). Labour process theory and the gig economy. Hum. Relat. 72, 1039-1056. doi: 10.1177/00187267187 90002

Garben, S. (2017). Protecting Workers in the Online Platform Economy: An Overview of Regulatory and Policy Developments in the EU. European Risk Observatory Discussion Paper. EU OSHA. Available online at: https://osha. europa.eu/en/tools-and-publications/publications/regulating-occupationalsafety-and-health-impact-online-platform/view

Grimshaw, D., Marino, S., Anxo, D., Gautié, J., Neumann, L., and Weinkopf, C. (2018). "Negotiating better conditions for workers during austerity in Europe: unions' local strategies towards low pay and outsourcing in local government," in Reconstructing Solidarity: Labour Unions, Precarious Work and the Politics of Institutional Change in Europe, eds V. Doellgast N. Lillie, and V. Pulignano (Oxford: Oxford University Press), 42-66. doi: 10.1093/oso/9780198791843.003.0002

Heeks, R. (2017). Decent Work and the Digital Gig Economy: A Developing Country Perspective on Employment Impacts and Standards in Online Outsourcing, Crowdwork, etc. Development Informatics Working Paper Series No. 71. doi: 10.2139/ssrn.3431033

Heery, E. (2009). Trade unions and contingent labour: scale and method. Camb. J. Reg. Econ. Soc. 2, 429-442. doi: 10.1093/cjres/rsp020

Huws, U., Spencer, N. H., Syrdal, D. S., and Holts, K. (2017). Work in the European Gig Economy: Research Results From the UK, Sweden, Germany, Austria, the Netherlands, Switzerland and Italy. Brussels: Foundation of European Progressive Studies and UNI Europa.

International Labour Organization (ILO) (2016). Non-Standard Employment Around the World: Understanding Challenges, Shaping Prospects. Geneva: ILO.

Irani, L. (2015). Difference and dependence among digital workers: the case of amazon mechanical turk. South Atlant. Q. 114, 225-234. doi: 10.1215/00382876-2831665

Kahancová, M. (2016). The Rise of the Dual Labour Market: Fighting Precarious Employment in the New Member States through Industrial
Relations (PRECARIR) Country Report: Slovakia. Research Report No. 19. Bratislava: CELSI.

Kalleberg, A. L. (2009). Precarious work, insecure workers: employment relations in transition. Am. Sociol. Rev. 74, 1-22. doi: 10.1177/000312240907 400101

Kalleberg, A. L. (2018). Precarious Lives: Job Insecurity and Well-Being in Rich Democracies. Cambridge: Polity Press.

Kelemen, M. (2013). A háztartási alkalmazottak foglalkoztatásának kérdései Magyarországon - a láthatatlan munkaero [Questions related to domestic workers in Hungary - the invisible workforce]. Esély 3, 3-24. Available online at: http://www.esely.org/kiadvanyok/2013_3/kelemen.pdf

Keller, B., and Seifert, H. (2013). Atypische Beschäftigung Zwischen Prekarität und Normalität. Entwicklung, Strukturen und Bestimmungsgründe im Überblick [Atypical Employment Between Precarity and Normality. Overview of Developments, Structures and Determining Factors]. Berlin: Edition Sigma.

Keune, M. (2011). Trade union responses to precarious work in seven European countries. Int. J. Lab. Res. 5, 59-78. Available online at: https://hdl.handle.net/11245/1.398035

Keune, M., and Pedacci, M. (2019). Trade union strategies against precarious work: common trends and sectoral divergence in the EU. Eur. J. Indust. Relat. doi: $10.1177 / 0959680119827182$.

Leighton, P., and Wynn, M. (2011). Classifying employment relationships: more sliding doors or a better regulatory framework? Indus. Law J. 40, 5-44. doi: 10.1093/indlaw/dwq029

Meszmann, T. T. (2016). The Rise of the Dual Labour Market: Fighting Precarious Employment in the New Member States through Industrial Relations (PRECARIR) Country Report: Hungary. Bratislava: CELSI. Research Report No. 12.

Meszmann, T. T. (2018). Industrial Relations and Social Dialogue in the Age of Collaborative Economy (IRSDACE) National Report: Hungary. CELSI Research Report No. 27/2018. Available online at: https:/celsi.sk/en/publications/ research-reports/download/28/industrial-relations-and-social-dialogue-inthe-age-of-collaborative-economy-irsdace-national-report-hungary/

Ost, D. (2009). The consequences of postcommunism: trade Unions in Eastern Europe's future. East Eur. Politics Soc. 23, 13-33. doi: $10.1177 / 0888325408326791$

Palier, B., and Thelen, K. (2010). Institutionalizing dualism: complementarities and change in France and Germany. Polit. Soc. 38, 119-148. doi: $10.1177 / 0032329209357888$

Piasna, A., and Drahokoupil, J. (2019). Digital labour in central and eastern Europe: evidence from the ETUI Internet and Platform Work Survey. ETUI. Available online at: https://www.etui.org/content/ download/37603/377074/file/WP+2019+12++Digital+Labour+Web+ version.pdf

Pichault, F., and McKeown, T. (2019). Autonomy at work in the gig economy: analysing work status, work content and working conditions of independent professionals. New Technol. Work Employ. 34, 59-72. doi: 10.1111/ntwe.12132

Pulignano, V., Doerflinger, N., and De Franceschi, F. (2016). Flexibility and security within European labour markets: the role of local bargaining and the "trade-offs" within multinationals' subsidiaries in Belgium, Britain and Germany. ILR Rev. 69, 605-630. doi: 10.1177/0019793916628862

Rueda, D. (2006). Social democracy and active labour-market policies: insiders, outsiders and the politics of employment protection. Br. J. Polit. Sci. 36, 385-406. doi: 10.1017/S0007123406000214

Schor, J. (2016). Debating the sharing economy. J. Self Govern. Manage. Econ. 4, 7-22. doi: 10.22381/JSME4320161

Schwander, H. (2018). Labor market dualization and insider-outsider divides: why this new conflict matters. Polit. Stud. Rev. 17, 14-29. doi: $10.1177 / 1478929918790872$

Sedláková, M. (2018). Industrial Relations and Social Dialogue in the Age of Collaborative Economy (IRSDACE) National Report: Slovakia. Bratislava: CELSI. Research Report No. 28.

Srnicek, N. (2017). The challenges of platform capitalism: understanding the logic of a new business model. Progr. Rev. 24, 254-257. doi: 10.1111/newe.12023

Stewart, A., and Stanford, J. (2017). Regulating work in the gig economy: what are the options? Lab. Relat. Rev. 28, 420-437. doi: 10.1177/1035304617722461

Trif, A., Koukiadaki, A., and Kahancová, M. (2016). The Rise of the Dual Labour Market: Fighting Precarious Employment in the New Member States Through 
Industrial Relations (PRECARIR), Comparative Report. DCU Research Report. Available online at: https://www.dcu.ie/link/current-projects/precarir20142016.shtml (accessed August 9, 2019).

van Doorn, N. (2017). Platform labor: on the gendered and racialized exploitation of low-income service work in the 'on-demand' economy. Commun. Soc. 20, 898-914. doi: 10.1080/1369118X.2017.1294194

Will-Zocholl, M. (2017). "Virtual temptations: reorganising work under conditions of digitisation, virtualisation and informatisation," in The New Digital Workplace: How New Technologies Revolutionise Work, eds K. Briken, S. Chillas, M. Krzywdzinski, and A. Marks (Palgrave: MacMillan), 62-86. doi: 10.1057/978-1-137-61014-0_4
Conflict of Interest: The authors declare that the research was conducted in the absence of any commercial or financial relationships that could be construed as a potential conflict of interest.

Copyright (c) 2020 Kahancová, Meszmann and Sedláková. This is an open-access article distributed under the terms of the Creative Commons Attribution License (CC $B Y)$. The use, distribution or reproduction in other forums is permitted, provided the original author(s) and the copyright owner(s) are credited and that the original publication in this journal is cited, in accordance with accepted academic practice. No use, distribution or reproduction is permitted which does not comply with these terms. 


\section{OPEN ACCESS}

Edited by: Annalisa Murgia,

University of Milan, Italy

Reviewed by:

Federica Giardini,

Roma Tre University, Italy

David Tyfield,

Lancaster University, United Kingdom

*Correspondence:

Andrea Fumagall

andrea.fumagalli@unipv.it

Specialty section:

This article was submitted to Work, Employment and Organizations, a section of the journal

Frontiers in Sociology

Received: 15 August 2019 Accepted: 20 March 2020

Published: 30 April 2020

Citation:

Fumagalli A and Morini C (2020) Anthropomorphic Capital and

Commonwealth Value.

Front. Sociol. 5:24.

doi: 10.3389/fsoc.2020.00024

\section{Anthropomorphic Capital and Commonwealth Value}

\author{
Andrea Fumagalli ${ }^{1 *}$ and Cristina Morini ${ }^{2}$ \\ ${ }^{1}$ Department of Economics and Management, University of Pavia, Pavia, Italy, ${ }^{2}$ Effimera.org, Milan, Italy
}

In this essay, we intend to analyze the process of accumulation of contemporary capitalism, in which the regime of valorization derive from the notion of "common" a "results of social production that are necessary for social interaction and further production, such as knowledges, languages, information affect, and so forth" (Hardt and Negri, 2009) and from its expropriation. When we deal with the concept of "common," the reference is made to a heterogeneous category. In this text we refer to two modalities of expression of the "common:" the digital common (section network value) and the common of social reproduction (section social reproduction value or the economy of the interiority and anthropomorphic capital). Regarding the first case study, the concept of "network value" is investigated and defined as a product of individual life in a relational context increasingly controlled and subsumed by the social media and big data industry. Regarding the second, we discuss how the activity of social reproduction of individuals is today central in the process of accumulation of the economy. "Social reproduction" is a useful concept to investigate what we call the "anthropomorphic capital," that is the capacity by the contemporary labor organizations to capture and make productive the essence of today's life and its complexity. In short, it transpires better and better how all activities are productive, i.e., accumulation generators. We observe the apparent paradox of a generalization of surplus value in the era of the decline of waged employment and with it a tension of capital contemporary to the general mortification of living labor. In fact, we note how capital claims to transform the human being into capital itself, explicitly assuming the whole of human existence as a field from which accumulation can be generated (human being, enterprise or human capital). This is what, at this point, we call anthropomorphic capital or the economy of interiority. In the last section, we report some results of an empirical research "Commonfare-Pie News," able to underline how life is more and more subsumed to the logic of capitalistic valorization, to the point that today we can speak not only of the subsumption of labor to capital but of a real life subsumption.

\footnotetext{
Keywords: life-value, network-value, social reproduction, bio-cognitive capitalism, life subsumption, commonwealth, anthropomorphic capital
}

\section{INTRODUCTION}

In an essay that appeared about 10 years ago (Morini and Fumagalli, 2010), we discussed the need to adapt the Marxian labor theory of value to the new forms of accumulation and valorization of contemporary capitalism. After the crisis of the Fordist paradigm, in the last four decades, the processes of accumulation and valorization of the capitalist system have undergone a profound 
transformation. New factors of production have become ever more relevant in determining the transition to a new type of capitalism, one which we can define as bio-cognitive capitalism (Fumagalli, 2019a). These new factors of production are often the direct expressions of existential processes inherent to human action and its vital faculties, from learning, to language, relationships, feelings and affection. It was in this context that we began to discuss the need to extend and enrich the concept of value by not confining it only to the certified work activity (labor theory of value) but also to the broader spectrum of life (life theory of value). In that essay, the theme of affection and socalled affective work had been the subject of in-depth study, with reference to care work.

In this essay, we intend to continue to broaden this analysis in light of the novelties that have been introduced in recent years in the processes of accumulation of contemporary capitalism, with special regard to "network value" as produced by social media activity and to "social reproduction value," a broader concept than care or affective work. In paragraph 1, we discuss the concept of commonwealth, a concept that is very often abused, in a particular diction, that is, as an expression of the linguistic and relational practices that are at the base of that social cooperation that is today the main basis of contemporary capitalist valorization and that imposes the putting to labor of life itself. In section network value, we deal respectively with the theme of knowledge and relationships as primary sources of capitalist value (network value), while in sections social reproduction value or the economy of the interiority and anthropomorphic capital we discuss the reproductive commonwealth. Then in the final paragraph we offer some preliminary conclusions by introducing the concept of life subsumption (Fumagalli, 2019b).

\section{ABOUT THE COMMON AND COMMONWEALTH: SOME PRELIMINARY CONSIDERATIONS}

The concept of commonwealth, or the common (singular), refers to very different aspects ${ }^{1}$. In the first place, and in general, the common, unlike common goods, is not subject to rivalry and therefore to scarcity. This is due to the fact-the second difference-that the common is not confinable in a good, but exceeds it, as part of human nature; we can say that, at the limit, the common re/produces goods.

As Vercellone, Brancaccio, Giuliani, and Vattimo write:

"The common is not a simple political principle, but a social relationship of production that has its roots and finds its

\footnotetext{
${ }^{1}$ On the definition of common to singular, Michael Hardt, Antonio Negri, Commonwealth, Harward, Harward University Press, 2010, e Carlo Vercellone, Francesco Brancaccio, Alfonso Giuliani, Pierluigi Vattimo, Il Comune come modo di produzione, Per una critica dell'economia politica dei beni comuni, Ombre Corte, Verona, 2017, in particolar ch. 2. "We consider the common also and more significantly those results of social production that are necessary for social interaction and further production, such as knowledges, languages, codes, information, affect, and so forth," M. Hardt, A. Negri, Commonwealth, Harward University Press, Cambidge, Mass., 2009, Usa, p.. viii.
}

ontological foundation historically determined in the potential autonomy of cognitive labor. This is all the more true if we consider that today one of the fundamental grounds in which capital/labor ratio manifests itself is precisely the development of the productive forces. In short, the social relations of the common innervate the same dynamics of technological and social innovation, and in this very dynamics the common manifests itself as a mode of production" (Vercellone et al., 2017, p. 47).

This quotation aims to underline the fact that in bio-cognitive capitalism $^{2}$ the driving forces of the accumulation are not simply and only based on traditional input like machinery, natural commodities and the labor activity (both manual and intellectual), defined as the capacity of human being to transform physical elements, but more and more on a social relationship, involving the essence of human life itself, regardless of how it is organized.

From this point of view, the common, as mode of production, condenses all the characteristics of an input and at the same time is something more, as it is the fruit of a social relationship. It is not a "stock," rather a "flow." It creates as an output a commonwealth. For the common to produce value, i.e., to be transformed into a commonwealth, a minimum of organized process is necessary. It is reasonable that, as a social relationship between human beings, the common has its own autonomy and its own selfvalorization (use-value). The common presents itself, in its pure state, as an expression of human vital capacity, but in order to be functional to the process of capitalist accumulation it requires its transformation into exchange value: it requires an organization that can expropriate it.

The common is constituted by the vital and cognitive faculties of the human being, from knowledge to the body/soul, from relations to sensations, from language to movement, from sensuality to thought: there is always a production of surplus that derives from the simple fact of existing and living, the moment it is bent to the needs of accumulation. For this reason, the common pre-exists cognitive bio-capitalism as much as the surplus-labor pre-exists the system of capitalist production. Biocognitive capitalism is able to exploit the common only in part

\footnotetext{
${ }^{2}$ Bio-cognitive capitalism (Fumagalli, 2019a) is preferable to more neutral locutions such as knowledge economy or knowledge-based economy to capture the inseparable hybridization between the development of productive forces and the development of social relations of production. It is thus intended to focus attention on the dialectical relationship between the two terms that make it up:

- the term capitalism designates the permanence, even in their metamorphosis, of the fundamental variables of the capitalist system (the leading role of profit in the distribution of social work, wage labor, or rather, the forms of heterodirection of labor with respect to which surplus is extracted);

- the bio-cognitive attribute highlights, instead, the new nature of work, the sources of valorization and the structure of property on which the process of accumulation is based and the contradictions that are generated there.

In particular, bio-cognitive capitalism pays attention to the life directly put to value, not only through the intermediation of work, but also through the concept of "free labor." As Terranova wrote in 2004 (p. 94): "Free labor is a desire of labor immanent to late capitalism and late capitalism is the field which both sustains free labor and exhausts it. It exhausts it by determining the means through which that labor can sustain itself: from the bum-out syndromes of internet startups to under-compensation and exploitation in the cultural economy at large." We can say that free labor is an expression of the common when it is source of self-valorization and not of exploitation.
} 
and for this reason it needs an adequate proprietary status and to create operative devices to be able to expropriate and capture.

The traditional dichotomy between private and state property needs an overrun For example, knowledge cannot be considered a State asset, since it cannot be expropriated by the individual. But if it remains only the property of the individual and does not socialize, it has no economic and social value.

When Vercellone, Brancaccio, Giuliani, Vattimo define the common as "mode of production," they refer to Negri's approach (Negri, 2016) and not to Sohn-Rethel's approach (Sohn-Retel, 1977).

Sohn-Rethel speaks of "common production:" that is, the production logic in which "work" and "society" coincide. For Sohn-Rethel "production in common" is the result of a mode of social organization that was present in tribal societies-primitive communism-where there was no private property and the activity of exchange was exclusively aimed at the production of use-value $^{3}$. For Negri, instead, one can speak of the common as mode of production when "work" and "life" coincide. And for what to happen, a process of "abstraction" must occur in the labor activity of the two elements that define the power of life: reproduction and language/knowledge. When capital is able to define abstract labor as a marriage of reproduction and language/knowledge, then it is the common that becomes the pivot of capitalist accumulation itself and creates wealth (commonwealth). The forms of its expropriation represent the cornerstones of the process of exploitation and valorization of bio-cognitive capitalism.

Starting from this point of view, it can hence be useful to make a distinction between the common aimed to directly generate the reproduction activity (reproductive commonwealth) and the linguistic, learning and network activities (cognitive commonwealth). These two types of common are strictly interrelated; they are two sides of the same coin. The bridge between them is represented by social relationships and cooperation. The common tends to be immaterial, it is an expression of the biopolitical existence of the human being: it's neither rival nor scarce, or better, as such, it is as limited as life and the human race are limited. Knowledge and its diffusion represented the core of the accumulation process in the Nineties during the so-called "net-economy." In that context, the common was able to put life faculties, in particular learning and networking, into the labor performance and, therefore, to transform them in exchange value (cognitive commonwealth).

A further metamorphosis starts to be evident at the beginning of the new millennium with the rise of social media and big data industries. The diffusion of new technologies deriving from and improving AI (Artificial Intelligence), machine learning processes, increasing speed in the classification, and manipulation of data, experiments to artificially create living material (bio-genetics) and so on, represent the way to valorize life directly, without the mediation of labor activity. We can say that cognitive capitalism becomes bio-cognitive capitalism. Bio-cognitive valorization is thus based on two main,

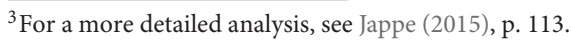

among others, factors of valorization: network value and social reproduction value.

\section{NETWORK VALUE ${ }^{4}$}

The use and collection of data has always been part of human history since its beginning. But it was only with the birth of the industrial revolution that the calculation techniques, refined by the "methodological" break-up by Descartes and Galileo, began to be applied not only to the need to "measure" the physical-natural field (a need that, as is well-known, was at the basis of the development of geometry and mathematics in ancient times, from the Egyptians to the Greeks and Arabs) but also to the control and management of production activities. At the same time, with the advent of the capitalist system of production, we are witnessing the eruption of the "machine" as an immediate productive factor: the act of production (aimed at accumulation) becomes more and more discretionary, detached from the whims of nature, and therefore requires, precisely, one or more units of measurement. The (plus) value produced by the capitalist accumulation needs, in fact, to be known in order to be distributed according to the existing social relationships. As long as capitalist production was mainly material, both in nineteenth century artisan capitalism and in the Taylorist period of the twentieth century, the units of measurement conventionally fixed for the measurement of nature (meter, kilo, liter, volt, watt, horsepower, decimal numbering, etc.) were more than sufficient. When, instead, with the crisis of the Fordist paradigm, production tends to become more and more immaterial and capital more and more intangible, the problem of measurement acquires a dimension that goes beyond the traditional natural geographies. The same sources of valorization are changing and technological innovation, based yesterday on ICT and today on bio-technologies, requires a completely new approach.

Since the spread of information technology, the speed of calculation has exponentially increased. The volume of data created has required, not by chance, new forms of measurement, continuously undergoing redefinition, because they quickly become obsolete. If initially the data-mining techniques were the sophisticated evolution of statistical calculation techniques [and they are studied in this apolitical and neutral perspective, see Giudici (2005), Dulli et al. $(2009)^{5}$ ], today they are more and more strongly related to personal characteristics, able to define differentiated (individualized) collections of data to be freely traded.

A well-known example, on which Matteo Pasquinelli has dwelt, concerns the Google Pagerank algorithm (Pasquinelli, 2009a). This is how this algorithm is described by Carr (2008):

"At the heart of [Google] is the PageRank algorithm that Brin and Page wrote while they were graduates student at Stanford University in the 1990. They saw that every time a person with

\footnotetext{
${ }^{4}$ This chapter refers to some analysis contained in Fumagalli et al. (2018). ${ }^{5}$ Data-mining is defined as "the set of techniques and methodologies that have as their object the extraction of a knowledge or a knowledge from large amounts of data (through automatic or semi-automatic methods) and the scientific, industrial or operational use of this knowledge": https://en.wikipedia.org/wiki/Data_mining
} 
a Web site links to another site, he is expressing a judgment. He is declaring that he considers the other site important. They further realized that while every link on the Web contains a little bit of human intelligence, all the links combined contain a great deal of intelligence far more, in fact, that any individual mind could possibly possess. Google's search engine mines that intelligence, link by link, and uses it to determine the importance of all the pages on the Web. The greater the number of links that lead to a site, the greater its value. As Jonh Markoff put it, Google's software systematically exploits human knowledge and decisions about what is significant. Every time we write a link, or even click on one, we're feeding our intelligence on Google's system. We are making the machine a little smarter and Brin, Page and all of Google's shareholders a little richer" (p. 27).

The algorithm, today, is establishing itself as the expression of the general intellect, as its phenomenological expression. An expression that varies and is flexible according to the field.It does not directly concern the bios but the cognitive (Fumagalli, 2017). Today it is the instrument for measuring the value of cognitive intensity. It is, at the same time, a real and formal subsumption. But it is also something more. It is a mathematical measure of network value, able to condense wetware and netware on the basis of software. It is therefore the basis of accumulation and enhancement.

\begin{abstract}
"What PageRank identifies and measures is a network value in a very numerical form. If a commodity is traditionally described by a value of use and an exchange value, the network value can be considered an additional level attached to the previous ones that describes the network of social relations. This term can be somewhat ambiguous as it can be misunderstood as the "value of networks" according to the much celebrated "wealth of networks" described by Benkler (2006). On the contrary, a notion of network added value should be introduced here for the sake of clarity ${ }^{6}$. In fact, PageRank produces what Deleuze and Guattari (1972) described as machine surplus value by referring to the surplus value accumulated through the cybernetic domain, i.e., the transformation of a code surplus value into a flow surplus value. Through PageRank, Google has not simply gained a dominant position in the control and possession of extensive web indices, but above all a monopoly in the production of such network value" (Pasquinelli, 2009a, p. 9).
\end{abstract}

The example cited is paradigmatic of the evolution of contemporary valorization processes that, starting from the cognitive, have increasingly pervaded the bios, to the point that the evolution between human being and machine tends to increasingly diversify along two parallel and synergic directions: the relationship between subjectivity and machine and that between physical body and machine. Much has been written about the former, starting in the early 1970's when the relationship between mind and machine was investigated. And it is on this hybridization that Franco Berardi coined in the early 2000's the term cognitariat (Berardi, 2002, 2004). The definition

\footnotetext{
${ }^{6}$ This network value should be distinguished from the scientific definition: according to Metcalfe's law, the "value" of each telecommunications network is directly proportional to the square of the number of nodes or users connected to the system.
}

provided by the Garzanti dictionary ("precarity of those who do intellectual labor"7 does not capture the whole complexity of the term. It is in fact the concept of intellectual labor that is put into question. If in the last decade of the last century, we can see a sort of "Taylorisation of intellectual labor and intellectualization of manual labor" (Fumagalli, 2017), today this process has gone far beyond the dichotomy, albeit redefined, between manual and intellectual activity, and has overcome this difference. A difference that has been included within the term "cognitive labor" and expanded into that of "relational labor."

In fact, it is from this labor that the value of the network originates, which today tends to pervade, in differentiated and diversified ways, different productive activities, from logistics (increasingly digitalized), to shopping centers and up to immaterial consulting. Everywhere there is an app, there is network value, that is, biopolitical value.

In the face of recent developments, Romano Alquati's observation of the value of information at the time of the Olivettian factory is extremely topical, with reference to the Taylorist context:

"The productive work is defined in the quality of the information
elaborated by the worker to the means of production, with the
mediation of the constant capital" (Alquati, 1963, p. 121).

The value of the network is at the same time the result of a process of exploitation (Fumagalli, 2017, 2019b), extraction (Mezzadra and Nielsen, 2017), and imprinting (Chicchi et al., 2016). It is the form of surplus-value of the cognitive, to which it will be necessary to add the surplus-value of the bios. It is the result of the interpenetration of the human sensory system with the informational and digital network that increasingly envelops the activities of production and accumulation. From this point of view, we are witnessing the machine becoming more humanlike (Braidotti, 2013), the spatial (or rather, relational) becoming more human-like (Pasquinelli, 2009b) ${ }^{8}$, but at the same time, the human becoming more machine-like (Raunig, 2010, 2016; Fumagalli, 2017).

The creation of network value, through the processing of Big Data, takes place mainly in some sectors. The data, in itself and for itself, is characterized by use value, such as the labor power or the common (in singular, Fumagalli, 2017; Vercellone et al., 2017). As productive input in an immaterial production context, it is transformed into an exchange value, within production contexts able to use the appropriate algorithmic technology. Such a process, however, is far from being homogeneous and

\footnotetext{
${ }^{7} \mathrm{http}: / /$ www.garzantilinguistica.it/ricerca/?q=cognitariato

${ }^{8}$ Pasquinelli (2015) writes: "The general intellect is therefore not only "crystallized" in the machines but spread through the entire "factory society" of the metropolis. Therefore, logically, if industrial knowledge designed and operated machines, even collective knowledge outside the factory must be somehow machinic. Here we have to look carefully at the manifestations of the general intellect through the metropolis to understand when we find it "dead" or "alive," already "fixed" or potentially autonomous. For example, at what level today are the much celebrated Free Software and the so-called free culture complicit in the new forms of accumulation of digital capitalism? And at what level, do the ideology of creativity and Creative Cities simply prepare the ground for real estate speculation and new forms of metropolitan rents?"
} 
precise. In fact, in the management of the clouds of Big Data, confusion, approximation, and heterogeneity reign, as does the imperfection of the technologies, continuously in process, thanks to the involvement of the same suppliers and users of data. Consider, for example, the translation service offered by Google: the difference with other systems is precisely the use of a larger and very chaotic dataset. It does not provide a word-for-word translation, but an analysis of millions of official texts that come from sources such as the UN and that provide a large amount of data:

\footnotetext{
"Despite the confusion of input, Google's system works better. Its translations are more accurate than those offered by other systems. And it is much, much richer. By mid-2012 its dataset covered over 60 languages. It was even able to accept voice input in 14 languages to make translations smoother. And because it treats language simply as a chaotic mass of data to which to apply probability calculation, it can even translate between two languages like Hindi and Catalan" (Mayer-Schonberger and Cukier, 2013, p. 76).
}

Exactness plays a secondary role, after vastness, in identifying the general trend and capturing the whole phenomenon. Take for example the disordered and flexible mechanism of "tagging," widely used on Internet. This system allows users to label mainly photos or videos, making it possible to trace different content on the network through tags created by users. The confusion in this case may be due to the wrong writing of the tags and the way they are organized. Therefore, the managing and the governance of such large amounts of data need a specific business section that it is called Business Intelligence (Dataskills., 2017). It is a business function that has the function of extracting value for the different productive purposes from the processing and distribution of data (Camiciotti and Racca, 2015).

It refers: "to the set of business processes to collect data and analyze strategic information, to the technology used to implement these processes and to the information obtained as a result of these processes" (Camiciotti and Racca, 2015).

Business Intelligence is therefore a system of models, methods, processes, people and tools that make possible the regular and organized collection of data generated by a company and through processing, analysis and aggregation transform data into information that is storable, retrievable, and presentable in a simple, flexible, and effective way to support strategic decisions, tactics and operations.

The Business Intelligence system therefore involves (see Figure 1):

- the collection of the data of the company's patrimony

- their cleaning, validation and integration

- subsequent processing, aggregation and analysis

- the fundamental use of this amount of information in strategic and valorisation processes (Dataskills., 2017).

The structure of the real life cycle and valorization of big data systems can be described in the following figure, on the basis of a succession of operations that begin

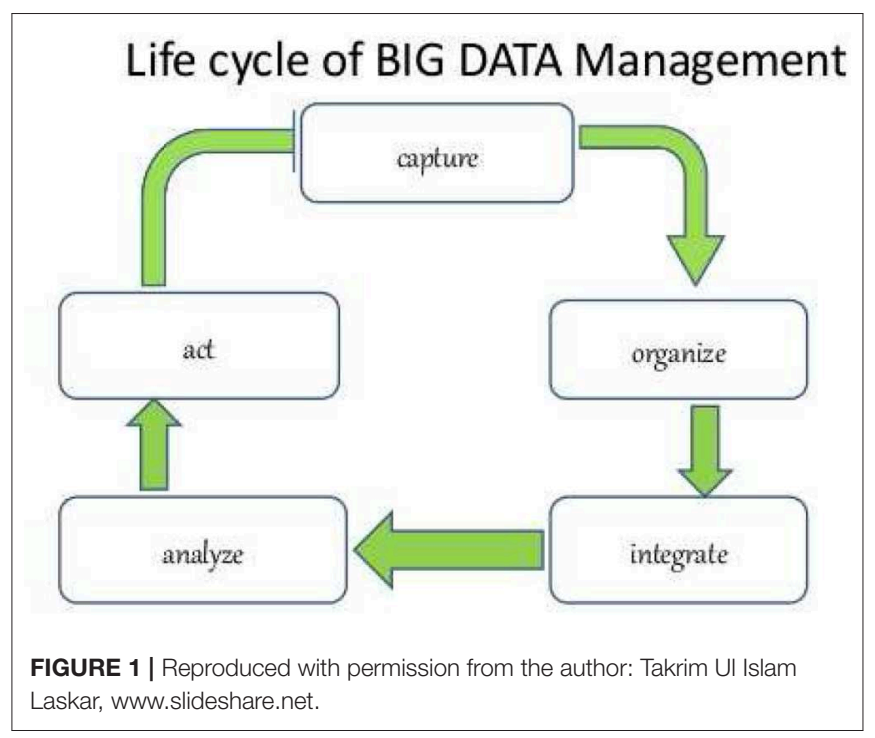

with the "capture/appropriation" of data, their "organization," "integration," "analysis," and their transformation into "action."

In most cases, especially with respect to unstructured data (about $80 \%$ of the total), these data are presented as use value, produced and socialized by users/consumers in the performance of the acts of cooperation and relationship that are carried out daily. It is not by chance that we speak of capture, or rather of moderately forced or voluntary expropriation.

This life cycle describes, in a nutshell, the process of valorisation of big data. It is worth considering the two operations of "organizing" and "integrating." These are two operations that only in recent years have been able to reach a certain degree of sophistication, thanks to the technological evolution of the 2 nd generation algorithms. The organization and integration of the data is at the base of the production of the network value. It is the productive aspect of exchange value, while the "analysis" and the "action" represent its commercialization, that is the monetary realization on the outlet markets.

It is in these two phases that "platform capitalism" begins to structure itself. With the term platform capitalism, we intend an organization of labor and production in which the demand-supply ratio is intermediated by an algorithm and a digital platform (Srnicek, 2017). In this new context, companies need to define a new capital composition able to manage an increasingly automated process of data division according to its potential commercial use. It is based on the more or less conscious participation of individual users, now transformed into prosumers. It is in fact the users of the different platforms, whether they provide information to satisfy desires or virtual spaces for communication, play and development of relationships, that provide the raw material that is then subsumed in the capitalist productive organization.

We can say that if today human relations, social cooperation, the production of collective intelligence, and social reproduction are the expression of the common as a mode of production (Negri, 2016; Fumagalli, 2017; Vercellone et al., 2017), at the present time they are the basis of the communism of capital, 
that is, the capacity of capital to subsume and capture the instances of life of human beings ${ }^{9}$. The main tool of this ability to capture the common human being is machine learning. Until recently, very few people knew what algorithms were, while today they are present in everyday life as a fundamental aspect of modern society:

\begin{abstract}
"They are not only in your mobile phone or laptop, but also in cars, at home, in your appliances and in toys. Your bank is a gigantic web of algorithms and humans just turn a few knobs here and there. The algorithms decide the time of the flights and govern the airplanes. They operate the factories, buy and ship goods, collect the proceeds and keep the accounts. If all of a sudden all the algorithms stopped working, it would be the end of the world as we know it" (Domingos, 2015, p. 32).
\end{abstract}

The algorithms work without us realizing their presence and functioning. By algorithm we mean "a calculation procedure" or a method for solving a problem, "a sequence of instructions that tells a computer what to do" (Domingos, 2015). Algorithms are the basis of machine learning. To understand the power of machine learning we can use an analogy reported by Pedro Domingos, in which this type of technology is compared to agriculture: the learning algorithms are the seeds, the data are the soil and the programs learned are adult plants. The machine learning expert is the farmer who plants the seeds, irrigates and fertilizes the soil without interfering further. Thanks to this metaphor, two aspects emerge. The first is related to the large amount of data, because the more we have, the more we can learn about it. The spread of machine learning is closely linked to the appearance of Big Data. The second aspect, on the other hand, shows how a large amount of available data can increase the velocity that characterizes these processes. With machine learning, the process undergoes a strong acceleration:

\footnotetext{
"The Industrial Revolution has automated manual work, and the Information Revolution has done the same with intellectual work. Machine learning, on the other hand, automates automation itself: if it were not there, programmers would become the bottlenecks that hold back progress" (Domingos, 2015, p. 12).
}

Algorithms help us navigate through the vast amount of data on the net, but above all they can influence our decisions and the cultural context. The ones that do this most are the algorithms of social networking platforms: every time we use them, we leave information that is recorded, processed and used for other users. The collection of individual information is then sent to the community. As the algorithms suggest what we like and help us in our relationships, they begin to shape our identity and influence our choices (Fumagalli et al., 2018). In the information society, the main problem lies in more or better, in the unlimited choice that Big Data creates: among the multiplicity of products to choose from or occasions to seize, which one can be the most suitable for us? Algorithms and machine learning offer a

\footnotetext{
${ }^{9}$ In this regard, the concept of Bio-ipermedia, coined by Giorgio Griziotti, is very interesting: "Bioipermedia can be broadly defined as the field in which the body in its entirety connects to network devices so intimate as to enter into a symbiosis in which changes and mutual simulations occur" (Griziotti, 2016, p. 120).
}

solution. In the same companies, the number of operations to be carried out increase exponentially over time, as do the number of customers. As a result, machine learning becomes fundamental:

\begin{abstract}
"Amazon cannot properly encode the tastes of all its customers in a program, and Facebook is not able to write a program that chooses the best updates to show to each of its users. Walmart, the giant of distribution, sells millions of products and has to make billions of decisions a day: if its programmers tried to write a dedicated program, they would never end. The solution adopted by such companies, on the other hand, is to unleash the learning algorithms on the mountains of data they have accumulated and let them guess what the customers want" (Domingos, 2015, p. 52).
\end{abstract}

These algorithms are not perfect, but in providing their results they affect the user and his decisions. They are the intermediaries between the data and the consumer and concentrate power and control within them. They are the modern-day assembly lines.

\section{SOCIAL REPRODUCTION VALUE OR THE ECONOMY OF THE INTERIORITY AND ANTHROPOMORPHIC CAPITAL ${ }^{10}$}

Social reproduction plays an increasing and paradigmatic role in bio-cognitive capitalism. It represents the main factor of the enlargement of the accumulation basis.

The contemporary (re)production context is mainly based on processes of exploitation and control of the organic (Cooper and Waldby, 2014; Villani, 2018) and the emotional (Hochschild, 1983) aspects of bodies-mind. It refers to a capitalist paradigm based on forms of social reproduction, or directly of social production, observing the meticulous tendency of capital to deepen the mechanisms of extraction of surplus value through an expansion of the fields to which it applies its domination. It happens due to multiple processes of abstraction and mortification which affects a multitude of concrete and living activities (originated by needs, therefore marked by the use value, not immediately transformed to exchange value); they are passivated by capital in order to reproduce itself, that is, becoming capable of directly producing accumulation. We observe that more jobs, linked to needs, affections (affěctu $(m)$, derived from afficĕre "hitting, provoking a state of mind"), knowledge of bodies-mind, today explicitly produce value for capital, while remaining unchanged the fact that these services remain, as yesterday, placed outside of wage mediation.

The concept of labor has been described by Marx as an expression of capacity, of power in the worker's corporeal existence, and of production as a process of intentional transformation of nature in order to produce the tools of his own existence ${ }^{11}$; "the worker is in relationship with his labor []

\footnotetext{
${ }^{10}$ This paragraph deals with some issues analysed in Morini (2019a,b).

${ }^{11}$ The fundamental point is in the concept of "labour power" introduced by Marx, according to which the worker does not sell his "work" to the capitalist, but rather himself as working capacity, for a certain number of hours a day. Marx writes: "By labour power or work capacity we mean the set of physical and intellectual attitudes that exist in the body, that is, in the living personality of a man, and that he sets in motion every time he produces values of use of any kind" (Marx, 2013, p. 200). For more details, see Ciccarelli (2018).
} 
as a foreign object" (Marx, 1990, p. 227) but also in the sense that labor "cannot exist without the objects on which to practice. In a certain way, it is clear and precise, in this context, the identification of materiality, appropriability, exchange allowed by the material labor of the worker. However, Marx anticipates the overall mortifying, alienating tendency of capital, since in this objectification, in this production of external existence that is fixed in the object into which the worker already puts "his inner world," "his life, which no longer belongs to him but to the object" (Marx, 1990, p. 227). And then it will come to appear that "a growing number of functions of the labor power is grouped in the immediate concept of productive labor, and an increasing number of people who perform it in the concept of productive workers, directly exploited by capital and subject to its process of production and valorization" (Marx, 1969, p. 749).

Thus, the reflections of Marx on alienation in the 1844 Manuscripts are at the root of the problems with which we are confronted in the contemporary world. In times of exploitation of an ever-increasing mass of workers placed outside the wage relationship by the generalization of labor precarity and by technological innovations, the reflections of Marxist feminism, insisting on the concealment of women's work in reproductive pathways (Dalla, 1972) and on the decisive role played by reproduction for accumulation (Federici, 2004), remain fundamental and continue to offer inspiration. Alisa del Re in an issue of Viewpoint Magazine dedicated to Social Reproduction helps us to define the broad field we are talking about and the spheres in which it is applied:

\footnotetext{
"The reproduction of individuals can have different connotations: biological, material, emotional, cultural, relational. It is obvious that all these aspects are generated by an historical social context and at the same time they characterize it" (Del Re, 2015, p. 4).
}

The great novelty of the current paradigm of social productionin this phase of history and society-lies in its capacity to extract economic value exactly from these different connotations of the human capacity to re-produce itself (biological, material, affective, cultural, relational), that is, exploiting precisely the capacity to "take care of" or even "pay attention to." It is to be understood as a broad action of relating and communicating the subjectivity allowed by language, guaranteed by the new machines based on artificial intelligence that have made possible a totalization of the labor capacity (Berardi, 2016). What stands out is the increased alienating force of capital, which, by placing reproductive matter at the center of processes, risks to generate forms of human self-alienation.

The various digital devices act as stimulators and catalysts for the social production process. The social factory has, in a certain sense, been concentrated in a smart-phone, which condenses messages of love and data of all kinds, eradicating attention and paid services with free apps, perennial availability and personalized induction to consumption, definitive control of movements through GPS, quantitative evaluations of the body (steps, beats, hours of sleep). It is a factory that we buy and maintain ourselves voluntarily, that allows us to have news in real time and to keep us connected to the rest of the world, to which we give (all) our time (life). An offshoot of bodies that derealizes bodies and dematerializes their actions. Deprivation of social knowledge allowed by algorithmic governance (Baranzoni and Vignola, 2016). Inter-passiveness induced by the dependence on the stimulus and by the communicative excitement (Fisher, 2009), which moves affections, that is, generates states of mind.

To better examine the complexities of the present it can be useful, above all, to find suitable suggestions to understand the general enlargement of the regime of gratuitousness of the current re-productive work performance, so full of subjectivity and social connections as it is. Since the substance of labor today also resides (and not only, obviously) within ourselves, it is part of the bodies-mind of human beings; we try to make the economic value coincide with the value of human beings itself, it is therefore the life value (Morini and Fumagalli, 2010). Life that is worth if objectified, recognized, made visible, taken as a model by others, followed by followers, confirmed by the metrics, by the number of quotations. The capital earns thanks to the photo of and information on your private life (births, marriages, holidays, deaths,...): you have thus created an economic ego (Cesarano, 1979, p. 7).

Moreover, since, returning to Alisa del Re, the matter of reproduction is "biological, material, affective, cultural, relational," we are confronted, also in this case, with the rigidity of reproduction: one cannot leave, refuse, if not leaving, rejecting, parts of oneself or of the worlds, of the forms of life to which we are linked, which recognize us, with the risk of remaining isolated. Today it is the social person who is the collector of the value produced in the contemporary world, with all its organic sexual corporeity, including linguistic, that is, emotional and relational abilities. It is an extraordinary complication. Alienation from the object yesterday created a relationship with a foreign object, enemy, independent of him (outside); today this object of production is (can be) part of the Self, inside the communicative carousel of the new machines, bringing alienation into the worker, the worker herself (inside). Will this be the heart of the psychic malaise that seems to pervade the greedy Western society? What creative, imaginative effort do we need? How do we get out of this inter-passiveness? How to find networks instead of platforms, real communities instead of virtual communities?

It is also essential to take into account the growth of an economy of new reproductive services to the social person, aimed to reduce life time and make it more productive: it is a clear effect of the regime of social production of social work: the majority of platforms (from Arbnb to Deliveroo, from Uber to Amazon) are based primarily on the provision of reproductive services and leisure (ready food; houses, cars or bicycles for rent; tourism; online shopping...). These platforms are part of the framework of the libidinal economy or of the interiority that constitutes the real engine of contemporary accumulation.

As the productivity of the industries which take part in the reproduction of the labor power increases, we see how the establishment of the gratuitousness of the living work of reproduction represents today a determining factor in lowering the value of the whole labor power, and therefore in the increase of the surplus value. The tendency to generalize the gratuitousness of work is not only the effect of the generalization 
of precariousness. It is the most precise indicator of the contemporary confusion of levels brought about by the economy of interiority, which takes us "beyond the formal dominion of capital" within its "real dominion" (capitalist realism), where there is no separation between structure and superstructure, "circulation of ideas and circulation of goods, being both causes and reciprocal effects in a concatenation that repeats the serial module of the bolt and the vine" (Cesarano, 1979, p. 8).

If, as Christian Marazzi has pointed out ${ }^{12}$, in the emerging anthropogenetic model of contemporary capitalism, the "living being" contains within itself both the functions of fixed and variable capital, "that is, of material and instruments of past work and of present living work." We can talk about an anthropomorphosis of capital. We can glimpse the risks of a paradoxical alienation of the subject from his own existence to live the life that capital imposes to live, in a passive way. There is therefore a danger: the activity to which the system would like to oblige everyone within the new mesh of the present economic paradigm, risks to abstract people from themselves, forcing them to adapt to a know-how, which is functional to the society of performance. In this false movement, affections (i.e., to "do something for") are integrated in the current macroeconomic process, within a sort of "interiority economy." The first effective representation of this process was, as mentioned, the domestic labor of women, where the value was taken from the work of the mother or wife and taken out of consideration of the salary for the male worker. We owe to feminism the understanding of what has happened and what is happening even more intimately today, that is to say the risk of an integration of life, with its scope of relationships, sexuality, knowledge, education, care within the cycle of capitalist production. Every aspect of social life risks being selected by the logic of capitalist valorization, in the same way indicated by the model of reproductive work, feminized, historically incarnated in the bodies of women.

\section{COMMONFARE-PIE NEWS PROJECT: SOME QUALITATIVE RESULTS ON THE PERCEPTION OF PRECARIOUS CONDITION AND EMERGING NEEDS ${ }^{13}$}

In this paragraph, we illustrate some first empirical findings, the analysis of which forms one of the sources of the theoretical framework we illustrated in the previous sections. The dataset is provided by the European Horizon2020 research project

\footnotetext{
${ }^{12}$ Christian Marazzi speaks of "the emergence of an "anthropogenetic model." According to him, the production of knowledge by means of knowledge is in fact a model of "production of human being by means of human being," in which the possibilities of endogenous and cumulative growth have to do mainly with the development of the educational sector (investment in human capital), of the sectors of health (demographic evolution, biotechnologies, and of culture (innovation, communication, creativity). "In other words, the growth factors are ascribed directly to human activity..., that is, to the production of life forms and, therefore, create of added value, which defines the human activity" (Marazzi, 2005).

${ }^{13}$ The interviews which are here partially reproduced are part of a broader research report (PIE News, 2017). These interviews are not the same of the original ones but modified for the Italian edition, but without changing the contents.
}

"Commonfare-Pienews"14. The aim of the project is to create a collaborative platform capable of networking some good practices of self-organization of Welfare from below in the three pilot countries considered (Croatia, Italy, Netherlands). In order to achieve this objective, field research was conducted (Pie News Report., 2017), to determine the emerging needs of some segments of the population deriving from precarious labor conditions ${ }^{15}$.

First of all, the 252 interviews show the dominance of the perception of a job as segmented, devalued, and humiliating. Even in the Netherlands, where there is a more advanced welfare system than in the Mediterranean, the interviews highlight the progressive disappearance of work ("jobs are simply disappearing"), and the desire to be able to reject some trivial jobs, investing their time instead "in projects that I really believe in” (Pie News Report., 2017, p. 71).

In the interviews, this type of capture process partly worked for a first group of precarious workers who invested a lot of energy in the work environment, absorbing a lot of rhetoric related to the participation and creativity of new jobs. In the Italian context, it has been estimated that this first generation of precarious workers, defined as postfordist or first generation, includes a group of people aged between 30 and 49 years. They experienced the beginning of the transformations of a job that,

\footnotetext{
${ }^{14}$ www.Pienews.eu, www.commonfare.net

${ }^{15}$ H2020-ICT-2015, ICT10 - Collective Awareness Platforms for Sustainability and Social Innovation (CAPSSI), Grant Agreement No. 687922: Title: "PieNewsCommonfare"
}

As Chiara Bassetti, one of the coordinators of the project for the University of Trento and leader of the research, describes: "The involvement and the active and repeated participation of people, groups and communities are therefore fundamental elements, both for the success and for the conduct of the research and co-planning project considered. Hence the centrality of the three "pilot" studies conducted in Croatia, Italy and the Netherlands thanks to and through the mediation of three partner organizations of the consortium. Each national study involves different categories of people and focuses on some cities. In particular, Museu de Crise (MdC) operates in the Netherlands, Amsterdam, Rotterdam and The Hague, and works with freelancers, welfare recipients and migrants; the association Basic Income Network - Italy (BIN) is active in Milan and Rome and focuses on precarious workers and unemployed young people; Finally, the Centar za MirovneStudije (CMS, Centre for Peace Studies) works in Croatia, especially in Zagreb but also in Rijeka, Split and Osijek, with the so-called NEETs, as well as in the archipelago, with the so-called island movement. Since October 2016, multi-sited research and co-design activities have been conducted in the three considered countries, through interviews, focus groups and design workshops. To date, more than 250 people have been involved and more than 50 collective meetings between focus groups and workshops have been held in the different local communities. Most of these communities have also been contacted on several occasions by researchers, researchers, designers, developers and developers from the other partner organizations of the consortium, which includes the University of Trento (Italy), project coordinator, Abertay University (Scotland), Madeira Interactive Technologies Institute (Portugal), Bruno Kessler Foundation (Italy) and Dyne.org, a "forge of free software" based in Amsterdam (Netherlands). A pilot case study for the commoncoin was conducted in Milan, with the self-managed group MACAO - New Centre for Arts, Culture and Research.

The approach adopted is rooted in the tradition of participatory design, with which it shares the attention to practices endogenous to the context considered, the qualitative methods of ethnographic imprint, as well as the idea of an open and "endless" design process, based on the sharing of information and knowledge and on collective action, in a word, co-design (Bassetti, 2018, p. 22).

The field research activity produced 252 in-depth individual interviews, 20 focus groups were organized, in order to investigate emerging social needs. 
on the one hand, went beyond the cornerstones of the Fordist enterprise and its iron organizational disciplines, meeting the desire for autonomy of the subjects, and on the other hand it was loaded with new investments, passing from the ethics of "obligation" to that of "self-realization" (travail-self-fulfillment) (Meda, 2016, p. 11). Between technological innovations and higher professionalization, work gradually becomes the field where one's skills can be perfected (Meda, 2016, p. 12). On this subject, in the PieNews report relative to the Italian case (Basic Income Network Italia, 2018, p. 55), we speak, in fact, for this sample, of "construction of the imaginary" and "voluntarist efforts;" of "sacrificial overload" and of "continuous performanceism" (Basic Income Network Italia, 2018, p. 55).

However, looking at the results of the interviews and focus groups carried out in the Italian context, it should not be forgotten that the first generation of precarious workers is still politically aware. The language of rights, protections, guarantees of welfare, of some practices of struggle and social claim, on which the political discourse of the traditional workers' movement was based for decades, is still alive and present (Pie News Report., 2017, pp. 48-49). By this we mean to refer to networks of proximity and political and trade-union affiliations, to experiences of militancy and activism which strengthen knowledge and trust, to the capacity of the subject to position himself with respect to the socio-political context, in spite of the imperative of individualization introduced by precariousness. In fact, we will also talk about a precarious point of view, referring to the need to create knowledge useful to make a correct diagnosis of the situation: experience becomes a method of discourse that can never be completely constrained by power relations (Harding, 1986).

\section{The Precarious Inclusion}

This condition is explicitly described as a battle, or even a war, by Edoardo, a 41 years old man who works in the arts sector:

\begin{abstract}
"In the 1990's, in order to cope with extreme job insecurity and intermittent employment we were facing; we were very aggressive and savage. It was as if we were ascetic-predators. We were nomads, we constantly moved where we could plunder anything, always carrying the burden of anxiety [...]. We followed whatever could bring in income, wherever there was funding you could find us. We put on a sort of tortoise shell to protect ourselves and to be able to deal with the labor market. We found a way to survive but to the detriment of social and emotional dimension."
\end{abstract}

These precarious workers were, therefore, consciously in search of a pro-active approach to flexibility which could improve their working and living conditions, and thus they carried out many activities and nurtured many interests in order to achieve greater autonomy and independence. However, between the construction of the imaginary and voluntary efforts, an element of "compulsion" simultaneously emerged, namely the sacrifice required to distinguish themselves in the jungle of job insecurity. As Costanza highlighted:

\footnotetext{
"In order to face critical situations in my life I had to roll up my
} sleeves and fight, even though it means being totally dependent on
work...I had been working harder...I will have to work forever...I had to work also to help my parents (my mother is a widow now...), I gave up the idea of having a child because of my job. Working becomes a full exploitation [...] I am totally servant of my master, of the firm I work for [...] work has totally bought me."

Matilde, 38 years old, talked about the obligation for "continuous job performance," and Mattia, 45 years old, pointed out how this continuous solicitation resulted in psychological fatigue, hence the need to introduce forms of psychological counseling:

\begin{abstract}
"They should invest in social services in the coming years. After having worked for 14 years in the television industry, I have absorbed so much discomfort associated with work that I think psychological counseling is necessary."
\end{abstract}

When Monica (45 years old, teacher) said "those who cannot stand the loop are doomed to drop out," she perfectly described as work has been, willingly or by force, the center of gravity of precarious lives, in the effort to keep the pace requested. This tension resulted in a pervasive strategic individualism, as Alessandro said:

"The transient experience we live is certainly not a condition of well-being. It rather forces us to be always otherwise intelligent. For sure, today's work is mainly based on challenge and conflict with others: I succeed only if I lose myself in my work, thus resulting in isolation and absence of relations."

From the early years of the new Millennium, when talking about precarious workers one can speak of "second-generation" or "native precarious workers" as well as "crisis-related precarious workers" (Gobetti and Santini, 2009, 2016). It is the youngest generation: people aged between 18 and 34. They were born and raised in the time of job insecurity and crisis, and they are fully engaged in "occasional odd jobs" first and in the gig economy later. They seem to have a more disenchanted, less "ideological" and more pragmatic approach to work. There is no longer inside and outside, there are no standards one wishes to stick to in order to exit the precariousness which is the denial of a reference model: in fact, the precarious worker, from the semantic point of view, encompasses first of all a lack of identification; he "belongs to the sphere of "non," he is exposed to anything resulting from precariousness, he is on the edge of risk" (7Blu, 2005). As precariousness is institutionalized, it becomes the norm, the atypical turns into typical, it is maybe easier to assess some "tricks" more immediately: precarious workers are less emotionally invested in their work; they are aware that their job will not help them to fulfill themselves or gain social mobility; they face the challenge and risk of job insecurity in a more positive and above all concrete way.

\section{Life Itself Is Put to Work}

This generation seems to be doomed to this condition which has now become structural andhas permeated life as a whole to such an extent that "work has invaded all aspects of social life, it ended 
up swallowing space and time and conquering the whole life" (Aronowitz, 2006, p. 58).

"If I had to express my working time as a percentage of my financial condition I should say that $99 \%$ corresponds to the former and $1 \%$ to the latter....besides, when I finish working for the day I keep thinking about work" Luca, a freelance architect, told us, and Giorgia said, echoing his words: "It is very difficult to quantify my working hours. I think this happens to everyone...I feel like I never stop working." Despite the effects of this pervasive dimension, a first element of novelty emerges from the words of Alice who introduces an issue that we often found in our focus group meetings:

"I do not want to do without my life, my relationships and my activities beyond work, which become discriminating factors to relate to work itself."

There is no reference to the previous labor guarantee systems, as Stefano said:

"We are no longer in the phase where the workplace allows us to build social relationships that lead us to recognize each other."

Fordism and the rights it entailed seem to be definitively gone, historicised.

Native precarious workers face the problem of an economic crisis which is no longer linked to society and its actual needs, and therefore it does not know what to produce and why. Such an economy is just as uncertainty about its capital accumulation process. The content of work seems considerably devalued and standardized.

\section{Beyond the Ideology of Work}

However, the feeling of permanent and universal randomness in daily life has resulted in a change in terms of planning, thus contributing to inflict a heavy blow on the ideology of work. Native and crisis-related precarious workers are increasingly engaged in occasional and contingent work. As a result, the bundle of affection, social, relational and communication skills that the Post-Fordist precarious worker was still willing to put in the production process, seems now largely transferred beyond and outside of work, thus reconfiguring work attractiveness and regarding work as a mere activity that ensures the reproduction of the material conditions of existence. This situation is described by Alice who said:

\footnotetext{
"People who work in the same workplace do not know and recognize each other. In the last three years, in my workplace there has been a high turnover of staff to such an extent that the changing room lockers are completely scribbled because of the many names written and erased on them...this high turnover of employees does not allow to start a relationship."
}

Native and crisis-related precarious workers are contemporaneous with the descending parabola of the ideology of work, as work is no longer regarded as the only factor of self-recognition and subjectification. Precariousness is perceived as an inevitable horizon and, consequently, the effort to be made is to bend it to one's individual needs.

Without ideologies and with pragmatism, the new precarious subjects frankly wonder whether, in the current crisis, it is convenient or not to activate themselves into work ${ }^{16}$.

In this regard, Francesca, a student engaged in odd jobs, said:

"I know people who have accepted bad job offers, without any rights and with absurd working hours. I do not want that for me and above all I do not want to do the same job all my life as well as I would not like to do a job that does not interest me. I wish I could turn down a job offer that allows me just to survive."

The mass casualisation of employment involves the end of the centrality of work; home, income, time, recognition of civil and social rights, these are some of the common needs expressed that may trigger a new political discourse.

\section{Impermanence (Morini, 2015) and Lightness of Native Precarious Workers}

This continuous transition experienced by precarious workers seems to require a greater lightness despite the highest levels of intermittent work and poverty in terms of income (most young people aged between 18 and 24 years earn between 1,000 and 5,000 Euros per year). Caterina, 29 years old, a University teacher who is employed on a precarious contract, said to hang in the balance between "resignation and a sort of gratitude for having a job even if it is temporary;" Cosimo, 24 years old, added: "I do not regret not having a permanent job. Working all day is not my aspiration."

Native precarious workers do not define themselves in terms of lack (of income and employment for instance) or absence (of answers or certainties). These elements have characterized the stories of the first-generation precarious workers who tried to manage a paradigm shift and who were pioneers of that sort of anxiety which resulted from the uncertainty of the present and the future. Native precarious workers were born in a post-wage-based society, and in addition in "the time of crisis" (international, economic, financial, etc.): they have not experienced conflicts between abundance and scarcity, they have taken their first steps on fragile terrains and on such terrains they have learnt to walk with lightness ${ }^{17}$. This situation becomes even

\footnotetext{
${ }^{16}$ Mangiarotti, in Corriere della Sera, July 16th, Mangiarotti (2009) "Malena, in her bedroom packed with books, nods: «I fight for what I like to do. So far so good. Maybe my parents and my old professor of literature do not feel at ease because they have always foreseen a "promising" future for me (what a bad word). Besides, our society does not accept those who seek a different way of living, far from a one-thousand-euro job as the one my sister got despite she is graduated and holds a $\mathrm{PhD}$ degree $\gg$. «There was a chance at least - Daniele added - they stole it from me. My brother did everything to please this society and ended up without a job》. Enrico B., 26 years old, does not work nor does he study but he has a girlfriend and a young son to look after: $\ll$ My job? For months my job has been looking for a job. Now I take what comes». And who does look after the baby? «My mother and my father. For now we live with them, then we will see what happens》.

${ }^{17}$ In this context, the authors use the term "lightness" to mean a condition characterized by reduced anxiety and a greater predisposition to face things as they are.
} 
more evident in the complicated dialectics between generations as Anna highlighted:

\begin{abstract}
"for my parents it is unthinkable that at the age of $25 \mathrm{I}$ am not able to see the next steps that are aimed at building paths for my future. Although I have a job-I am self-employed-I do not see my future so different from my present."
\end{abstract}

Learning to walk with lightness puts us in front of young precarious workers who are very active, who are able to manage their time and relationships and adapt them to the contexts they live. Then again, although in Italy second-generation precarious workers suffer the highest levels of unemployment, it seems they better understand the risks of a design that induces a paradoxical competitive spirit and undermines solidarity. That is why Antonio defined modern society as "super competitive" and spoke of "a war among the poor," and conversely, through the experience of his father, who was a blue-collar worker in the 1970's, he identified an opposite pattern:

\section{"My father tells me that at that time there was the ability to hold a large mass of people together and that the unions led real struggles. While today we live in a competitive society that isolates and leaves people alone."}

From these sketches, we can see that in recent years the perception of work activity has changed profoundly, between forms of rejection, often on an individual basis, and a sense of impotence. This apparently contradictory situation, however, is based on a realistic approach that leads young people to concentrate more on the existential condition of the present and re-appropriation of themselves, often outside the dimension of "dependence" imposed on the single by the forms of contemporary accumulation/valuation.

\section{SOME PRELIMINARY CONCLUSIONS}

In the previous sections we discussed how within the context of bio-cognitive capitalism, the two factors of valorization that appear to be among the most relevant are: the network value and the value of social reproduction. These two factors do not exhaust the problem of valorisation in contemporary capitalism. In fact, it is necessary to add to them also sources of value creation that refer to the traditional labor activity, increasingly permeated with knowledge. The labor value, in fact, is far from having disappeared. But, following the enlargement of the accumulation base, waged and heterodirect labor is no longer the only way of extracting surplus value. We are thus faced with a heterogeneity of the processes of subsumption and exploitation of human life. The greater the hybridization between labor time and non-labor time, between human work performance and the machine element, between production and reproduction, the greater the complexity.

The two productive factors par excellence of capitalism, labor and capital, decompose and tend to mix between the tangible (machines, buildings, transport) and the intangible component (brand, learning, R\&D), as far as capital is concerned, and between certified (and therefore remunerated) working time and uncertified (and therefore unpaid) productive life time, as far as labor is concerned. Networking and social relations, on the one hand, within the production organization by the social media and big data industries, and reproduction and care, on the other, within the modalities dictated by the biogenetic industry, health, prevention and welfare, social creativity and time management, thus become paradigms of a new accumulation regime.

The ambivalence of the current transformations leads to the need to redefine the salient factors that underlie both social cooperation as a source of accumulation and the forms in which such cooperation is captured and exploited by the new architecture of capitalist command. The concept of anthropomorphic capital, developed in paragraph 3 , is paradigmatic from this point of view. It refers to the concept of human capital, developed by the Chicago school in the 1980's, but at the same time it irreversibly distances itself from it. If the idea, within the neoliberal thought of the Chicago school, was to show that between capital and labor there is no longer a conflicting dialectic but rather a synergy of growth of individual power, able to develop a universal entrepreneurial capacity, the version adopted here by the seminal studies of Cesarano shows us how the becoming human of capital is actually a new way of exploitation and expropriation of the sphere of life no longer enclosed in the increasingly narrow sphere of traditional wage work.

To better understand this aspect, it is also necessary to take up and remodel the philosopher's concept of subsumption (rather than strictly economic) developed by Marx in the 1844 Manuscripts. If the economic declination of this concept, the most purely economic terms is then developed by Marx in the two modes of formal subsumption (manufacturing system) and real subsumption (factory system), today this dichotomy tends to mix more and more, to the point of creating a subsumption process of a new nature, which is not limited to the length of the working day (formal subsumption), nor to the technological intensification of the themes of production (real subsumption).

Bio-cognitive capitalism is characterized by the simultaneous presence of formal subsumption and real subsumption at the same time. Formal subsumption, implicit in bio-cognitive capitalism, has to do with the redefinition of the relationship between productive work and non-productive work, making productive what was unproductive in the Fordist paradigm. The real subsumption has to do with the relationship between living and dead labor, as a consequence of the passage from repetitive mechanical technologies to linguistic and relational ones. Static technologies, at the base of productivity growth and work performance intensity (dimensional economies of scale), are transformed into dynamic technologies capable of exploiting learning and network economies, and simultaneously combining manual and relational activities. In recent years, the organization of work is increasingly reliant on the use of algorithms, able to directly organize a work activity, apparently characterized by a high degree of autonomy. The 
separation between execution and production of services is also becoming more difficult to analyse. They become inseparable within the production chain. As far as material production is concerned, the introduction of new computerized production systems requires professional skills and knowledge that make the relationship between man and machine increasingly inseparable, to the point that now living work can dominate the dead work of the machine, but within a new form of work organization and social governance. On the service production side (financialisation, research and development, communication, branding, marketing, personal services), we are witnessing a predominance of downstream valorisation, accompanied by a growing role of new forms of automation (based on algorithms).

In bio-cognitive capitalism, the real and the formal subsumption are thus two sides of the same coin and feed on each other. Together they create a new form of subsumption, which we can define as a vital subsumption, with reference not only to the sphere of knowledge and training, but also to the sphere of human relations, in the broadest sense.

The discussion on this subject is only just beginning.

\section{DATA AVAILABILITY STATEMENT}

Publicly available datasets were analyzed in this study. This data can be found here: H2020-ICT-2015, ICT10Collective Awareness Platforms for Sustainability and Social Innovation (CAPSSI), Grant Agreement No. 687922: Title: PieNews-Commonfare.

\section{REFERENCES}

7Blu (2005). Falso Movimento. Dentro lo Spettacolo Della Precarietà. Roma: DeriveApprodi.

Alquati, R. (1963). “Composizione organica del capitale e forza-lavoro alla olivetti," in Quaderni Rossi. 63-98.

Aronowitz, S. (2006). Post-Work. Per la Fine del Lavoro Senzafine. Roma: DeriveApprodi.

Baranzoni, S., and Vignola, P. (2016). "Biforcare alla radice. Su alcuni disagi dell'accelerazione," in Moneta, Rivoluzione, Filosofia Dell'avvenire. Nietzsche e la Politica Accelerazionista in Deleuze, Foucault, ed O. Capitalism (Free PressRizosfera), 97-112. Available online at: https://issuu.com/obsoletecapitalism/ docs/moneta_rivoluzione_e_filosofia_del

Basic Income Network Italia (2018). Generazioni precarie. Una conricerca tra percezioni del rischio, bisogni emergenti e Welfare dal basso, Commonfare Book Series, Trento: Università degli studi di Trento. Available online at: https:// pieproject.eu/2018/02/09/commonfare-book-series-1-generazioni-precarieuna-conricerca-tra-percezione-del-rischio-bisogni-emergenti-welfare-dalbasso/ (accessed August 15, 2019).

Bassetti, C. (2018). "Il progetto Commonfare. Supportare forme di welfare alternative e collaborative," in La rivolta della cooperazione. Sperimentazioni sociali e autonomia del possibile, ed A. Fumagalli, G. Giovanni, M. Cristina. (Milano: Mimesis), 17-24.

Benkler, Y. (2006). The Wealth of Networks: How Social Production Transforms Markets and Freedom. New Haven: Yale University Press.

Berardi, F. (2002). La fabbrica dell'infelicità. New economy e movimento del cognitariato. Rima: DeriveApprodi.

Berardi, F. (2004). Il sapiente, il mercante, il guerriero. Dal rifiuto del lavoro all'emergere del cognitariato. Roma: Derive Approdi.

Berardi, F. (2016). Ĺanima al lavoro. Alienazione, estraneità, autonomia. Roma: DeriveApprodi.

\section{ETHICS STATEMENT}

The studies involving human participants were reviewed and approved by H2020-ICT-2015, ICT10-Collective Awareness Platforms for Sustainability and Social Innovation (CAPSSI), Grant Agreement No. 687922: Title: PieNews-Commonfare. The patients/participants provided their written informed consent to participate in this study.

\section{AUTHOR CONTRIBUTIONS}

AF is professor of economics in the Department of Economics and Management at University of Pavia. He teaches also Theory of Firm at University of Bologna. He is member of Effimera Network, founder member of Bin-Italy (Basic Income Network, Italy. His latest book is: Cognitive Capitalism, Welfare, Labour, Routledge, London, 2019 (with A. Giuliani, S, Lucarelli, C. Vercellone). CM is a journalist, essayist, and independent researcher. She deals with issues related to gender and the processes of transformation of labour. She collaborates with various newspapers and websites. She is a founding member of the Bin-Italia association (Basic Income Network Italia) and of Effimera network. Her most relevant publications are The Feminilization of Labour in Cognitive Capitalism Feminist Review, vol. 87, 2007, 40-59, 2007; Per amore o per forza. Femminilizzazione del lavoro e biopolitiche del corpo, Ombre Corte, Verona 2010 and Lo sciopero delle donne. Lavoro, trasformazioni del capitale, lotte Manifestolibri, Rome, forthcoming 2019.

Braidotti, R. (2013). Post-Human. Cambridge: Polity Press.

Camiciotti, L., and Racca, C. (2015). Creare valore con i Big Data. Glistrumenti, iprocessi, le applicazioni. Milano: Edizioni LSWR.

Carr, N. (2008). The Big Switch: Rewiring the World, from Edison to Google. New York, NY: W.W. Norton.

Cesarano, G. (1979). Critica dell'utopia capitale. Milano: Varani Editore.

Chicchi, F., Emanuele, L., Stefano, L., and Logiche, S. (2016). Oltre la dissoluzione del rapporto salariale. Verona: Ombre Corte.

Ciccarelli, R. (2018). Forza lavoro. Il lato oscuro della rivoluzione digitale. Roma: DeriveApprodiEditore.

Cooper, M., and Waldby, C. (2014). Clinical Labor: Tissue Donors and Research Subjects in the Global Bioeconomy. Durham: Duke University Press.

Dalla, C. (1972). Mariarosa Potere femminile e sovversione sociale. Padova: Marsilio.

Dataskills. (2017). "Cos'è la Business Intelligence," in Understanding the World. Available online at: https://www.dataskills.it/servizi/business-intelligence/ (accessed February 23, 2019).

Del Re, A. (2015). "Collective Spaces", in Viewpoint Magazine. Available online at: https://www.viewpointmag.com/2015/10/31/collective-spaces/ (accessed October 31, 2015).

Deleuze, G., and Guattari, F. (1972). L'Anti-Oedipe. Capitalisme et schizophrénie. Paris: Minuit.

Domingos, P. (2015). The Master Algorithm: How the Quest for the Ultimate Learning Machine Will Remake Our World. New York, NY: Basic Books.

Dulli, S., Sara, F., and Edmondo, P. (2009). Data Mining. Roma-Berlino: Springer Verlag.

Federici, S. (2004). Caliban and the Witch: Women, the Body and Primitive Accumulation. New York, NY: Autonomedia.

Fisher, M. (2009). Capitalist Realism: Is There No Alternative? London: O books.

Fumagalli, A. (2017). Economia politica del comune. Roma: DeriveApprodi. 
Fumagalli, A. (2019a). "Twenty theses on contemporary capitalism (bio-cognitive capitalism)," in Cognitive Capitalism, Welfare and Labour. The Commonfare Hypothesis, eds A. Fumagalli, A. Guliani, S. Lucarelli, C. Vercellone (London: Routledge), 61-76.

Fumagalli, A. (2019b). "New forms of exploitation in bio-cognitive capitalism: towards life subsumption," in Cognitive Capitalism, Welfare and Labour. The Commonfare Hypothesis, eds A. Fumagalli, A. Guliani, S. Lucarelli and C. Vercellone (London: Routledge), 77-93.

Fumagalli, A., Stefano, L., Elena, M., and Giulia, R. (2018). Digital labour in the platform economy. Sustainability 10:1757. doi: 10.3390/su10061757

Giudici, P. (2005). Data Mining. Milano: Mc Graw-Hill.

Gobetti, S., and Santini, L. (2009). "La necessità dell'alternativa: precari della crisi e reddito garantito," in Reddito per tuttill'utopia concreta nell'era globale, ed B. Italia (Roma: ManifestoLibri), 46-57.

Gobetti, S., and Santini, L. (2016). "The crisis of labour, widespread pre carity and basic income," in Cadmus, Vol. 2 (Geneva), 158-167.

Griziotti, G. (2016). Neurocapitalismo. Milano: Mimesis.

Harding, S. (1986). The Science Question in Feminism. Ithaca: Cornell University Press.

Hardt, M., and Negri, A. (2009). Commonwealth. Harward: Harward University Press.

Hochschild, A. R. (1983). The Managed Heart: Commercialization of Human Feeling. Berkeley: University of California Press.

Jappe, A. (2015). "Il denaro ci pensa? Perché leggere oggi Sohn-Retel?," Dal pensiero critico. Filosofie e concetti per il tempo presente, ed A. Simoncini (Milno, Mimesis).

Mangiarotti, A. (2009). Generazione "né-né": settecentomila giovani "inattivi convinti." Milano: Corriere della Sera. Available online at: https://www. gennarocarotenuto.it/9495- generazione- $n$ - $n$ - settecentomila- giovani-inattiviconvinti-hanno-da-15-a-35-anni-niente-lavoro-niente-studio/ (accessed July 9, 2009).

Marazzi, C. (2005). "L’ammortamento del corpo-macchina," Reinventare il lavoro, eds J. L. Laville, M. Christian, L. R. Michele, C. Federico (Roma: Sapere), 107-126.

Marx, K. (1969). Il capitale: Libro I capitolo VI inedito. Risultati del processo di produzione immediato. Firenze: La Nuova Italia.

Marx, K. (1990). The Economic and Philosophic Manuscripts of 1844. London: Internatinal Publishers.

Marx, K. (2013). Capital, Volume 1. A Critical Analysis of Capitalistic Production. Hertford: Wordsworth Editions.

Mayer-Schonberger, V., and Cukier, K. (2013). Big Data: A Revolution That Will Transform How We Live, Work, and Think. London: John Murray Publisher.

Meda, D. (2016). The Future of Work. The Meaning and Value of Work in Europe. Geneva: Ilo Research Paper.

Mezzadra, S., and Nielsen, B. (2017). On the multiple frontiers of extraction: excavating contemporary capitalism. Cult. Stud. 31, 185-204. doi: 10.1080/09502386.2017.1303425
Morini, C. (2015). "Impermanence," in Piccola enciclopedia precaria. Dai Quaderni di San Precario, eds C. Morini and V. Paolo (Milano: AgenziaX), $39-52$.

Morini, C. (2019a). "Economia dell'interiorità e capitale antropomorfo. Produzione sociale, lavoro emozionale e reddito di base," in Lo sciopero delle donne. Lavoro, trasformazioni del capitale, lotte, eds A. Del Re, M. Critina, M. Bruna, and P. Lorenza (Roma: Manifestolibri), 111-120.

Morini, C. (2019b). Marx, tra di noi. Dentro e contro l'antropomorfosi del capitale. Available online at: http://effimera.org/marx-dentro-lantropomorfosi-delcapitale-cristina-morini/ (accessed August 15, 2019).

Morini, C., and Fumagalli, A. (2010). Life put to work: towards a life theory of value. Ephemera 10, 234-252.

Negri, A. (2016). Il comune come mezzo di produzione. Available online at: http:// www.euronomade.info/? $\mathrm{p}=7331$ (accessed August 10, 2019).

Pasquinelli, M. (2009a). "Google's PageRank Algorithm: a diagram of cognitive capitalism and the rentier of the common intellect," in Deep Search: The Politics of Search Beyond Google, eds K. Becker and S. Felix (London: Transaction Publishers).

Pasquinelli, M. (2009b). "Oltre le rovine della Città Creativa: la fabbrica della cultura e il sabotaggio della rendita," in L'arte della sovversione. Multiversity: pratiche artistiche contemporanee e attivismo politico, ed B. Marco (Roma: Manifestolibri), 147-158.

Pasquinelli, M. (2015). Italian operaismo and the information machine. Theory Cult. Soc. 32, 49-68.

Pie News Report. (2017). Deliverable 2.1. Available online at: http://pieproject.eu/ wp-content/uploads/2017/03/PIE_D2.1.pdf (accessed March 31, 2017).

Raunig, G. (2010). A Thousand Machines: A Concise Philosophy of the Machine as Social Movement. New York, NY: Semiotexte.

Raunig, G. (2016). Dividum: machinic capitalism and molecular devolution. New York, NY: Semiotexte.

Sohn-Retel, A. (1977). Intellectual and Manual Labour: A Critique of Epistemology. Atlantic Highlands, NJ: Humanities Press.

Srnicek, N. (2017). Platform Capitalism. Cambridge: Polity Press.

Vercellone, C., Alfonso, G., Francesco, B., and Paolo, V. (2017). Il comune come modo di produzione. Verona: Ombre Corte.

Villani, T. (2018). Corpi Mutanti. Tecnologie della selezione umana e del vivente. Roma: Manifestolibri.

Conflict of Interest: The authors declare that the research was conducted in the absence of any commercial or financial relationships that could be construed as a potential conflict of interest.

Copyright (c) 2020 Fumagalli and Morini. This is an open-access article distributed under the terms of the Creative Commons Attribution License (CC BY). The use, distribution or reproduction in other forums is permitted, provided the original author(s) and the copyright owner(s) are credited and that the original publication in this journal is cited, in accordance with accepted academic practice. No use, distribution or reproduction is permitted which does not comply with these terms. 
OPEN ACCESS

Edited by:

Annalisa Murgia,

University of Milan, Italy

Reviewed by:

Ivana Pais,

Catholic University of the Sacred

Heart, Italy

Valeria Pulignano,

KU Leuven, Belgium

*Correspondence:

Louis Florin

l.florin@uliege.be

Specialty section:

This article was submitted to Work, Employment and Organizations,

a section of the journal

Frontiers in Sociology

Received: 27 May 2019

Accepted: 24 April 2020

Published: 22 May 2020

Citation:

Florin L and Pichault F (2020)

Emerging Forms of Precariousness Related to Autonomy at Work: Toward

an Empirical Typology.

Front. Sociol. 5:34

doi: 10.3389/fsoc.2020.00034

\section{Emerging Forms of Precariousness Related to Autonomy at Work: Toward an Empirical Typology}

\author{
Louis Florin* and François Pichault \\ HEC Management School, University of Liège, Liège, Belgium
}

Societal, technological, and economical changes in the last decades have led to the development of new work arrangements located in a « gray zone 》 between standard employment and classical self-employment (Cappelli and Keller, 2013a; ILO, 2016; Katz and Krueger, 2016). Official labor market statistics must be adapted to provide researchers and policymakers with relevant data on this population (Gazier et al., 2016; National Academies of Sciences, Engineering and Medicine, 2017; ILO, 2018). Cappelli and Keller (2013b) point out that new work arrangements are characterized by changes in the management of the work relationships (with a growing intervention of labor market intermediaries) and in the way the work is supervised (from work processes to outcomes). The concept of autonomy thus becomes a central feature of new work arrangements leading to specific configurations of risks and opportunities for individual workers concerned. Autonomy can be divided in three main dimensions: work status, work content, and working conditions (Pichault and McKeown, 2019). International surveys such as the European Working Conditions Survey (EWCS) provide valuable data covering these dimensions of autonomy. Our paper is focused on a specific category of workers experiencing the ambiguities of autonomy at work: Independent Professionals (Ipros). Ipros provide various forms of intellectual work in the service sector through self-employment and are often regarded as a highly autonomous workforce (Leighton and Brown, 2014; McKeown, 2015) while they can also be subject to precarious situations regarding their economic dependency or freedom of choice (de Peuter, 2011; Standing, 2011; Bergvall-Kåreborn and Howcroft, 2013). The objectives of this paper are, first, to build a set of indicators likely to measure the various dimensions of autonomy, and, second, to provide an empirical typology of new work arrangements by using cluster analysis methods. Through the application of this analytical framework on the EWCS 2015 data, we observe various situations in terms of risk and opportunities related to autonomy, shedding light on unexpected precarious situations where Ipros face the risks of autonomy without getting the associated benefits. Our results provide a nuanced typology of empirical situations, overcoming such a dichotomic vision of non-standard work arrangements.

Keywords: autonomy, dependence, self-employed, typology, non-standard work arrangements, Ipros, cluster analysis 


\section{INTRODUCTION}

Societal, technological, and economical changes in the last decades led to the development of new employment arrangements that sits in a $\ll$ gray zone $\gg$ between classical statuses of self-employment and salaried work (Cappelli and Keller, 2013a; Eurofound, 2015; ILO, 2016; Katz and Krueger, 2016). As the need for insightful data on this population is growing, official labor market statistics still must be adapted to allow researchers and policymakers to catch the phenomenon (Gazier et al., 2016; National Academies of Sciences, Engineering and Medicine, 2017). The objectives of this paper are, first, to develop and test the validity of indicators of autonomy based on the European Working Conditions Survey 2015 and, second, to provide an empirical typology of employment arrangements by using cluster analysis methods.

\section{BACKGROUND}

\section{Official Statistics Typologies: the Classical Approach}

New forms of employment are commonly reported as employment arrangements that differ from the traditional openended salaried contract: fixed-term contract, part-time work, and self-employment (Everaere, 2014; Schmid, 2015; ILO, 2016). This classical approach allows statisticians produce regional or international comparisons, but fails to make visible the diversity of new forms of employment. Indeed, fixed-term contract, parttime work, and self-employment are still reported as new forms of employment even though they have represented a fair share of the working arrangements for a long time. They do not help understand emerging forms of employment. Moreover, there is a wide variety of employment arrangements that fit in the same working status. Under the self-employed status for example, we find arrangements going from economically dependent one-client subcontracting to multi-client and completely autonomous independent contracting or intermediated work relations. This approach thus fails in capturing the gray zone of working arrangements that share characteristics of both traditional statuses: self-employed and salaried work. Gazier et al. (2016) pointed out that the typology of employment arrangements in official statistics should be reviewed and that more relevant information should be produced, among others, on intermediated forms of employment (co-employment, subcontracting) and freedom of choice for contingent work. Cieslik (2015) showed that administrative business registers lack important information for understanding contemporary selfemployment. Other international organizations and researchers pointed out the shortcomings of the existing statistical data and developed new classifications. We can identify ad-hoc and generic approaches.

\section{Ad-hoc Classifications}

Some researchers have developed $a d$-hoc definitions to fit specific forms of employment such as the Independent Professionals, Interim management, Portfolio work, On-call workers, and so on (Eurofound, 2015; Katz and Krueger, 2016). These researches shed light on some specific parts of the workforce and provide a more refined and valuable insight to researchers and policymakers. However, many of the concepts used in these studies are not yet stabilized in the scientific community and are very dependent on the type of data used. This lack of international uniformization of definitions and categories between international organizations or researchers leads to a wide variety of listings of new forms of employment that brings some confusion. The lack of shared definitions and concepts and the non-exclusivity between categories usually prevent such methods to be generalized.

\section{Generic Typologies}

Some approaches take a more general perspective. Cappelli and Keller (2013b) suggest a typology of working arrangements that relies on the type of authority and control that the employer/client has over the worker. Their classification first distinguishes employment (where control is focused on the work process) and contract work (where control is focused on the outcomes) and secondly looks at the potential intervention of a third party to distinguish co-employment from direct employment or again direct contracting from subcontracting. New work arrangements are characterized by more control on the outcomes and shared supervision between different parties, sometimes becoming evanescent. In these conditions, autonomy at work becomes a central feature in many modern work arrangements. This notion will be at the core of our analysis and will be developed further in the paper.

Authority, autonomy and dependency have also played a role in rethinking international classifications of employment arrangements. The scientific and political debates around new forms of employment and their classification have led the 20th International Conference of Labor Statisticians organized by the International Labor Office (ILO) to review the International Classification of Professional Situation adopted in 1993 (CISP93). This classification is still the international reference for official statistics and international surveys. To respond to the increasing demand of relevant data on emerging work arrangements, a new classification has been adopted at the conference (ILO, 2018). This new classification (CISE-18) will consider the type of authority and the economic risk faced by workers to create new categories, such as the $\ll$ non-salaried dependents $\gg$. It also aims at shedding light on multiparty work relations. While this is certainly an important step for labor statisticians and decision-makers, the implementation of such new classification in official statistics and international surveys should unfortunately take some time.

\section{Surveys and Empirical Typologies}

For Desrosières (2005), as administrative data are made by the state to be able to manage, they better reflect the way the institutions work while surveys allow to explore society more specifically according to the needs of statisticians. International surveys such as the Labor Force Survey from Eurostat, the European Social Survey and the European Working Conditions Survey from Eurofound gather in-depth data about the labor situation of workers. By adding questions about quality of 
work, working conditions, vulnerability, autonomy, and risks, these surveys provide information that goes beyond work statuses. There has been a lot of work to develop indicators of job quality (Eurofound, 2012), or job vulnerability (Bazillier et al., 2016) based on these surveys. Since 2012, the indices of job quality developed by Eurofound have been included in many reports. They measure earnings, job prospect, intrinsic job quality (skills and discretion, social environment, physical environment, and work intensity) and working time quality.

For the 6th wave of the EWCS, following the debates regarding new forms of employment, Eurofound extended the number of questions asked to self-employed workers, by adding questions regarding their working situation, their economic dependency or their income (Eurofound, 2017a). Some recent work extended the job quality approach to all statuses (Eurofound, 2018a), showing that dependent and independent solo self-employed workers experience lower scores on employment prospects, skills and discretion, physical and social environment, and work intensity while self-employed workers with employees have a relatively high job quality.

This approach by indices has led to a new form of classification. To go further and look beyond statuses and/or theoretical classifications, some researchers tried to develop an empirical approach to classifying workers. Such empirical typologies are less based on predetermined conceptual definitions and more related to the scores resulting from various dimensions and indicators. As workers belonging to the same statistical category can have very different experiences in terms of employment arrangements, empirical classifications take a bottom-up approach that groups workers sharing similar scores on several dimensions together. These classifications use cluster analysis methods.

Cluster analyses based on job characteristics of salaried workers provide interesting typologies that show which categories of workers are at risk. The first cluster analysis performed by Eurofound on job quality indices identifies four clusters: high-paid good jobs, well-balanced good jobs, poorly balanced jobs, and low-quality jobs (Eurofound, 2012). Van Aerden et al. (2014) developed other measures of employment quality based on EWCS (employment instability, material rewards, worker's rights and social protection, working time arrangements, employability opportunities, collective organization, and power relations) in order to provide a typology of employment arrangements. Their aim is to show how various employment relationships differ from standard employment by postulating that de-standardization of employment is not only a matter of status but requires a multidimensional approach. Their classification identifies five clusters: Standard Employment Relationship-like jobs, instrumental jobs, precarious unsustainable jobs, precarious intensive jobs, and portfolio jobs. In Belgium, Vandenbrande et al. (2012) identified 22 sub-dimensions of job quality and conducted a cluster analysis that produced seven categories: saturated jobs, full-time balanced work, work with limited career prospects, work on flexible and unusual hours, emotionally demanding job, heavy repetitive work, and indecent work.
While these studies revealed the variety of employment situations and the de-standardization processes of salaried work, we still lack information about self-employed workers. Recently, a deeper focus on self-employment has been provided by Eurofound for the 6th EWCS 2015. Researchers have developed new classifications of self-employment using the self-perceived status, the magnitude of economic activity and the economic dependency (Eurofound, 2017b). However, as the self-perceived status is highly dependent on national contexts, they also developed an empirical classification of self-employed workers. Building on such variables as entrepreneurialism, economic and operational dependency and economic sustainability/precariousness, the analysis classifies self-employed workers in five clusters: employers, small traders and farmers, stable own-account workers, vulnerable workers, and concealed workers (Eurofound, 2017c). This approach allows policymakers and researchers identify which categories of self-employed workers are at risk. However, it seems that this classification reproduces existing categories (employers vs. solo) or sectors (farmers and traders) and therefore prevents identifying the main characteristics of new employment arrangements.

\section{Toward an Empirical Classification of Independent Professionals Based on Multiple Dimensions of Autonomy}

This has led to precious insights on the diversity of selfemployment situations. Yet, new forms of employment are characterized by significant changes in subordination links and in the way the work is supervised (Cappelli and Keller, 2013b). As shown in several empirical studies devoted to new forms of employment, the most relevant changes in this kind of jobs can be characterized by the concept of autonomy [Leighton and McKeown (2015), Bush and Balven (in press)]. According to the conceptual matrix provided by Pichault and McKeown (2019), autonomy can be divided in three main subdimensions: work status (how the access to social protection is guaranteed), work content (which kinds of work division and coordination mechanisms are provided), and working conditions (who is responsible for skills development, income generation, time and space arrangements).

Table 1 represents these different dimensions of autonomy. Regarding work status, we can notice various situations that fit in between employed and self-employed work, such as co-employment and work supported by third parties (like platforms). These options can be mixed with diverse modalities in terms of social protection, number of business partners, economic dependency and freedom of choice. The work content may be based on broad guidelines and low control which paves the way to job crafting, full responsibility regarding the working pace and load, flexible coordination mechanisms and strong support from the professional community against managerial intrusions. But the work content can also be based on tight controls, with few possibilities of job crafting, imposed working pace and load, rigid coordination mechanisms and no access to professional support against managerial intrusions. In terms 
TABLE 1 | Autonomy at work of Independent Professionals (from Pichault and McKeown, 2019).

\begin{tabular}{|c|c|c|c|}
\hline \multirow[t]{2}{*}{ High autonomy } & \multicolumn{3}{|c|}{$\Longleftrightarrow$ Low autonomy } \\
\hline & \multicolumn{3}{|c|}{ WORK STATUS } \\
\hline Independent contractor & Supported independent contractor & Temporary worker & Regular employee \\
\hline Private insurance & Insurance packages via third parties & Discontinuous access to social rights & Continuous access to social rights \\
\hline \multicolumn{2}{|c|}{ Diversity of clients } & \multicolumn{2}{|c|}{ Economic dependency/sole client } \\
\hline \multicolumn{2}{|c|}{ Deliberate choice } & \multicolumn{2}{|c|}{ Forced choice } \\
\hline \multicolumn{2}{|c|}{ Work pace, workload at own discretion } & \multicolumn{2}{|c|}{ Work pace, workload imposed by clients } \\
\hline \multicolumn{2}{|l|}{$\begin{array}{l}\text { Mutual adjustment } \\
\text { Standardization of norms }\end{array}$} & of outcomes & $\begin{array}{l}\text { Standardization of work processes } \\
\text { Direct supervision }\end{array}$ \\
\hline \multicolumn{2}{|c|}{$\begin{array}{l}\text { Strong support and/or access to shared expertise and } \\
\text { practices, high identification to a professional community }\end{array}$} & \multicolumn{2}{|c|}{$\begin{array}{l}\text { Few support and/or access to shared expertise and } \\
\text { practices, low identification to a professional community }\end{array}$} \\
\hline $\begin{array}{l}\text { Self-responsibility for time and space } \\
\text { arrangements }\end{array}$ & Access to shared facilities (co-working) & $\begin{array}{l}\text { Ad hoc time and space arrangements } \\
\text { resulting from interpersonal negotiations }\end{array}$ & $\begin{array}{l}\text { Predetermined work schedules } \\
\text { and space arrangements }\end{array}$ \\
\hline
\end{tabular}

High autonomy

of working conditions, the responsibility for skills development, income generation and space and time arrangements can be entirely left to the worker, facilitated by third-party organizations, negotiated with or imposed by the client. It is assumed that all these dimensions can vary independently from each other.

In order to avoid an implicit reproduction of sectorbased and/or job-based distinctions in our typology, such as in the Eurofound (2017c) study, we will focus our analysis on one single group of non-standard workers, supposedly more homogeneous: "independent professionals" (Ipros). Ipros provide various forms of intellectual work in the service sector through self-employment. The term Ipros covers activities such as copywriting, translating, IT, marketing, consulting, creative activities, etc. They are acknowledged as the fastest growing sector in the Western economies workforce. Over the last decade, they have been growing by $45 \%$ in the EU (Eurofound, 2015).

IPros are often presented as workers having deliberately chosen the self-employed status (Leighton and Brown, 2014). According to some surveys, they are motivated by autonomy, independence and choice in their work (Leighton and Brown, 2014; McKeown, 2015). The intellectual nature of their job, as opposed to manual work, is usually seen as allowing workers to enjoy higher levels of autonomy (Sandberg and Pinnington, 2009). It seems that traditional bureaucratic control is not easily applicable to such intellectual tasks (Thompson et al., 2009; Wynn, 2016). Other researchers however question this taken-for-granted association between intellectual work and autonomy. IPros do not always individually choose to work as self-employed. Their status sometimes results from constrained choices and might lead to precarious situations and economic dependency (de Peuter, 2011; Standing, 2011; BergvallKåreborn and Howcroft, 2013). Such contrasted results in the literature suggest a more nuanced approach in analyzing their work arrangements.

In this paper, we will build a series of indicators of autonomy according the various dimensions of Table 1, by referring to the 6th European Working Conditions Survey (2015); we will test their validity on the population of IPros. We will then use cluster analysis methods to provide an empirical typology of employment arrangements among Ipros, based on the multiple dimensions of autonomy at work.

\section{DATA AND METHODS}

\section{Data}

This study is based on a secondary analysis of publicly available data (Eurofound, 2018b). EWCS is one of the most comprehensive survey regarding autonomy and its subdimensions. To narrow down our analysis on the independent professionals, we used the operational definition of Ipros by Rapelli (2012): "Self-employed workers, without employees, which are engaged in an activity which does not belong to the farming, craft or retail sectors. They engage in activities of an intellectual nature and/or which come under service sectors." We therefore selected self-employed workers without employees in the following $\mathrm{NACE}^{1}$ codes: Information and communication ( $\mathrm{J}$ ), Financial and insurance activity (K), Real estate activities (L), Professional, scientific and technical activities (M), Administrative and support services

\footnotetext{
${ }^{1}$ Statistical classification of economic activities in the European community.
} 
TABLE 2 | Summary of the work autonomy sub-dimensions indicators.

\begin{tabular}{|c|c|c|}
\hline Indicators & $\begin{array}{l}\text { Questions in } \\
\text { EWCS } 2015\end{array}$ & Information used \\
\hline $\begin{array}{l}\text { Independence in the } \\
\text { contractual arrangement } \\
\text { (short: Contract) }\end{array}$ & Q8b & $\begin{array}{l}\text { Q8b. Select the category or categories which apply to your main paid job? - Sole director of own business -A } \\
\text { partner in a business or professional practice-Working for yourself-Working as a sub-contractor-Doing } \\
\text { freelance work - Paid a salary or a wage by an agency }\end{array}$ \\
\hline $\begin{array}{l}\text { Economic independency } \\
\text { (short: Econ. } \\
\text { independency) }\end{array}$ & Q9d, Q102 & $\begin{array}{l}\text { Q9d. Regarding your business, do you generally, have more than one client or customer? }- \text { Yes }- \text { No/Q102-What } \\
\text { proportion of revenue do you receive from your most important client? }-<50 \%--50 \text { to } 75 \%-\text { More than } 75 \%\end{array}$ \\
\hline $\begin{array}{l}\text { Choice for self-employed } \\
\text { work (short: Choice) }\end{array}$ & Q10 & $\begin{array}{l}\text { Q10-Self-employed, was it mainly your own personal preference or you had no better alternatives for } \\
\text { work? -Mainly through own personal preferences - No other alternatives for work-A combination of both }\end{array}$ \\
\hline $\begin{array}{l}\text { Autonomy in work } \\
\text { methods (short: Work } \\
\text { Methods) }\end{array}$ & Q54b, Q61i, Q61n & $\begin{array}{l}\text { Q54b. Are you able to choose or change your methods of work-Yes-No/Q61i-You are able to apply your own } \\
\text { ideas in your work? - Always -Most of the time-Sometimes - Rarely -Never/Q61n-You can influence } \\
\text { decisions that are important for your work? - Always-Most of the time-Sometimes-Rarely-Never }\end{array}$ \\
\hline $\begin{array}{l}\text { Autonomy in work pace } \\
\text { (short: Work Pace) }\end{array}$ & Q54c & Q54b. Are you able to choose or change your pace of work-Yes-No \\
\hline $\begin{array}{l}\text { Coordination mechanisms } \\
\text { (short: Coord. Mech) }\end{array}$ & Q50abcde & $\begin{array}{l}\text { Q50acde. On the whole, is your pace of work dependent on - the work done by colleagues - direct demands } \\
\text { from people such as customers, passengers, pupils, patients, etc. - numerical production targets or performance } \\
\text { targets - automatic speed of a machine or movement of a product - the direct control of your boss }\end{array}$ \\
\hline $\begin{array}{l}\text { Support/Access to shared } \\
\text { expertise (short: Support) }\end{array}$ & Q58, Q61a & $\begin{array}{l}\text { Q58. Do you work in a group or team that has common tasks and can plan its work? - Yes -No/Q61a Your } \\
\text { colleagues help and support you - Always - Most of the time-Sometimes-Rarely - Never }\end{array}$ \\
\hline $\begin{array}{l}\text { Responsibility for } \\
\text { generating income (short: } \\
\text { Earnings responsibility) }\end{array}$ & Q103abc & $\begin{array}{l}\text { Q103. What do your earnings from your main business include? - Income from self-employment such as own } \\
\text { business, profession or farm - Payments based on the overall performance of the company (profit sharing } \\
\text { scheme) or partnership where you work - Income from shares in the company you work for }\end{array}$ \\
\hline $\begin{array}{l}\text { Autonomy in time } \\
\text { arrangements (short: } \\
\text { Worktime) }\end{array}$ & Q42 & $\begin{array}{l}\text { Q42. How are your working time arrangements set? - They are set by the company/organization with no } \\
\text { possibility for changes - You can choose between several fixed working schedules determined by the } \\
\text { company/organization-You can adapt your working hours within certain limits (e.g., flextime)-Your working } \\
\text { hours are entirely determined by yourself }\end{array}$ \\
\hline
\end{tabular}

$(\mathrm{N})$, Education $(\mathrm{P})$, Human health and social work (Q), Arts, entertainment and recreation (R), and Other service activities (S).

In the 6th wave of the EWCS (Eurofound, 2018b), the sample of IPros consists of 1,345 workers in Europe. We used the weighting variable from the EWCS to control for survey design, post-stratification and supranational weights.

\section{Methods}

This methodological choice means that we were limited to a secondary analysis of existing data, not gathered in our conceptual perspective. This unavoidably led us to some redefinitions of our initial ambitions.

For each sub-dimension of the conceptual grid of autonomy presented in Table 1, we looked for specific questions that can provide us with the appropriate information to develop proxy indicators. However, the EWCS survey did not provide us with relevant questions regarding two dimensions presented in the conceptual grid. Regarding the work status dimensions, there is no question related to social rights and insurances. Regarding the work content, we were able to build proxy indicators for each dimension of the grid. For the working conditions, we could not develop an indicator for skills development as the questions regarding training are only quantitative (number of days spent in training) but do not inform us about the responsibility for training (is the worker the sole responsible for his/her skills development or do the client provide possibilities for training?). This was also the case with the responsibility for spatial arrangements. We were therefore condemned to refer to one single dimension (the management of working time) to build our indicator. Moreover, due to the lack of information about intermediated work relationship, we were not able to find information about some of the possibilities developed in the conceptual grid such as supported independent contracting or financial support offered by a third-party. Table 2 synthetizes the questions and information used in the construction of each indicator.

We then aggregated these questions to build synthetic indicators using a normalized scale from 0 (less autonomy) to 1 (more autonomy) for each sub-dimension ${ }^{2}$. We controlled the indicators by reviewing their distribution and descriptive statistics in order to avoid aberrant results.

First, we used univariate analyses of key dimensions to highlight the variety of Ipros' experience of autonomy (section Ipros' Experiences of Autonomy) and we tested the potential correlations between these dimensions (section Autonomy as a Multidimensional Concept). Second, we provided an empirical typology of new work arrangements by using cluster analysis methods (section Building an Empirical Typology).

\section{FINDINGS}

\section{Ipros' Experiences of Autonomy}

To understand the experience of autonomy by Ipros through the various dimensions of our matrix, we looked at distributions

\footnotetext{
${ }^{2}$ For the sake of brevity, we do not develop the calculation of each indicator in this paper. Would you be interested in this process, please contact the authors for a methodological Annex (in Supplementary Material).
} 

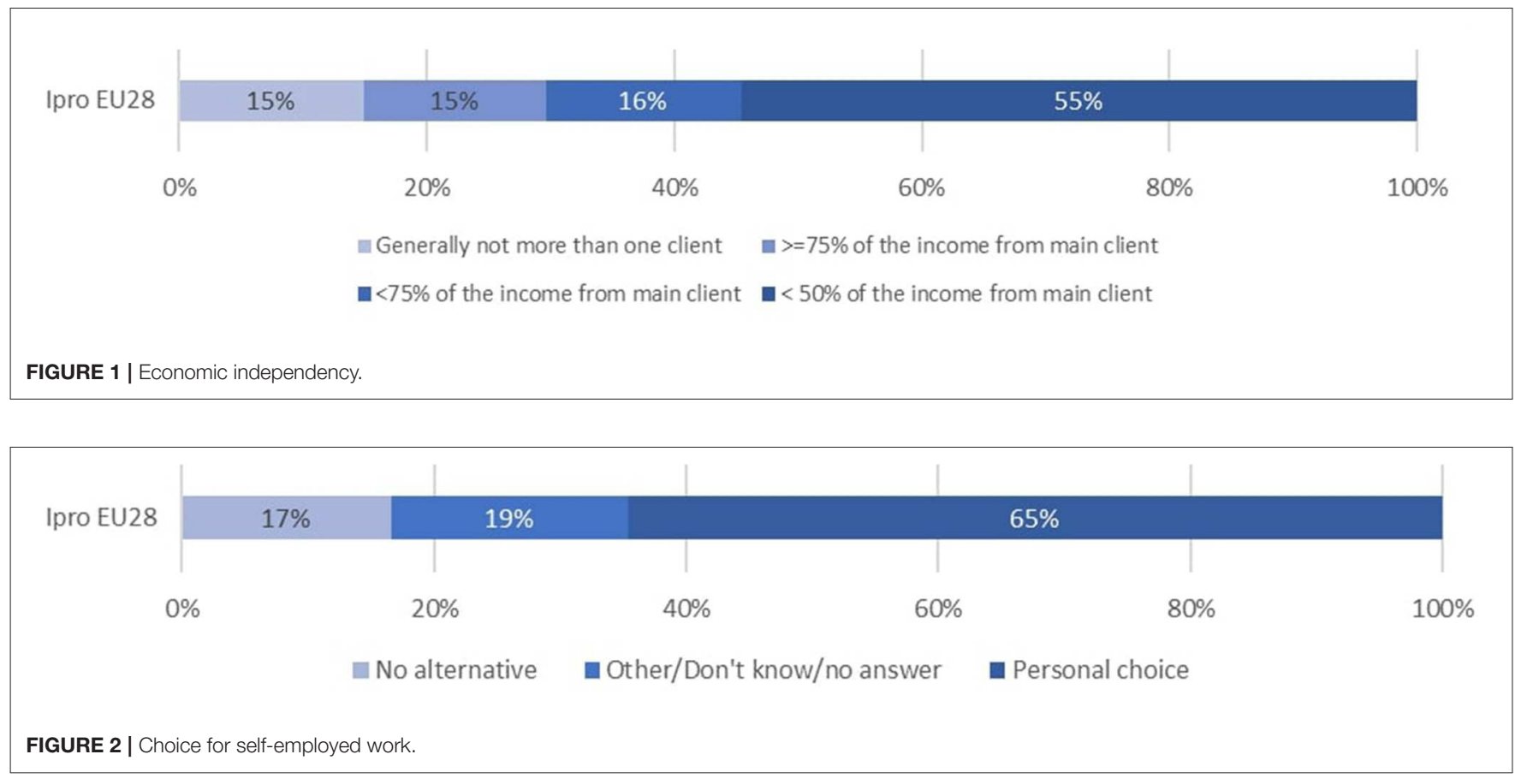

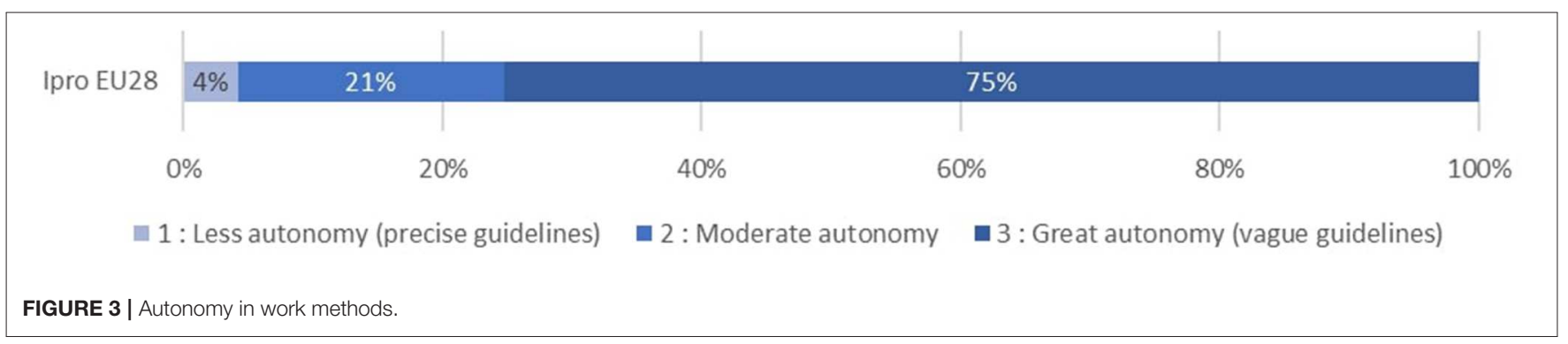

after having split continuous variables in classes to facilitate visualization and interpretation ${ }^{3}$. We select five dimensions that depict the high variety of I-Pros' experiences of autonomy ${ }^{4}$. Figure 1 denotes the strong proportion of IPros in a situation of economic dependency (30\%). Figure 2 demonstrates that at least $17 \%$ of IPros work as self-employed because they have no alternative. Figure 3 reveals that $25 \%$ of these workers have a low to moderate autonomy regarding the way they execute their tasks while, Figure 4 shows that the majority of Ipros have a limited access to support from colleagues and/or managers. Figure 5 points out that $29 \%$ of them are submitted to some kind of external control over their working time arrangements.

These results indicate that the Ipros' experiences of autonomy are diversified. While most of them seem to enjoy high levels of autonomy, there is a non-negligible part experiencing lower levels of autonomy on some dimensions. The second part of our analysis questions the relations between these dimensions.

\footnotetext{
${ }^{3}$ The classes relate to the original questions used for computing indicators shown in Table 2.

${ }^{4}$ Details of the distribution for each indicator are available in the methodological Annex (Supplementary Material).
}

\section{Autonomy as a Multidimensional Concept}

We then decided to test empirically whether the various sub-dimensions of the matrix can vary independently from each other. We conducted bilateral correlation analyses on these 9 sub-dimensions. Table 3 displays the correlation matrix.

The results show us that most sub-dimensions are not correlated $(r<0.10$ and/or $p>0.05)$ or weakly correlated $(r$ $<0.30)$. However, we observe an important correlation between autonomy in work methods and autonomy in work pace $(r=$ 0.432; $p<0.001$ ). Therefore, to avoid overweighting one factor in our cluster analysis and delivering misguided results due to collinearity, we decided to merge the indicators of work pace and methods into one single new construct calculated with the mean of the two dimensions.

These preliminary results show that the various subdimensions of our matrix are not systematically correlated. These results support the idea that autonomy at work must be considered as a multidimensional concept as we can hardly isolate specific variables likely to predict the others. Each dimension brings its own share of new information on the autonomy at work of IPros. 


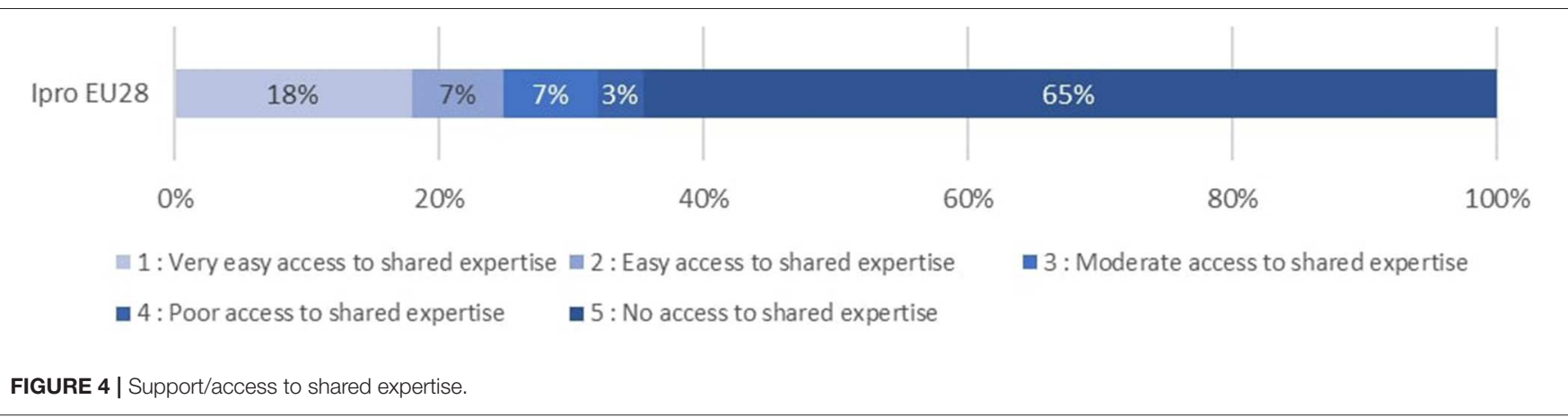

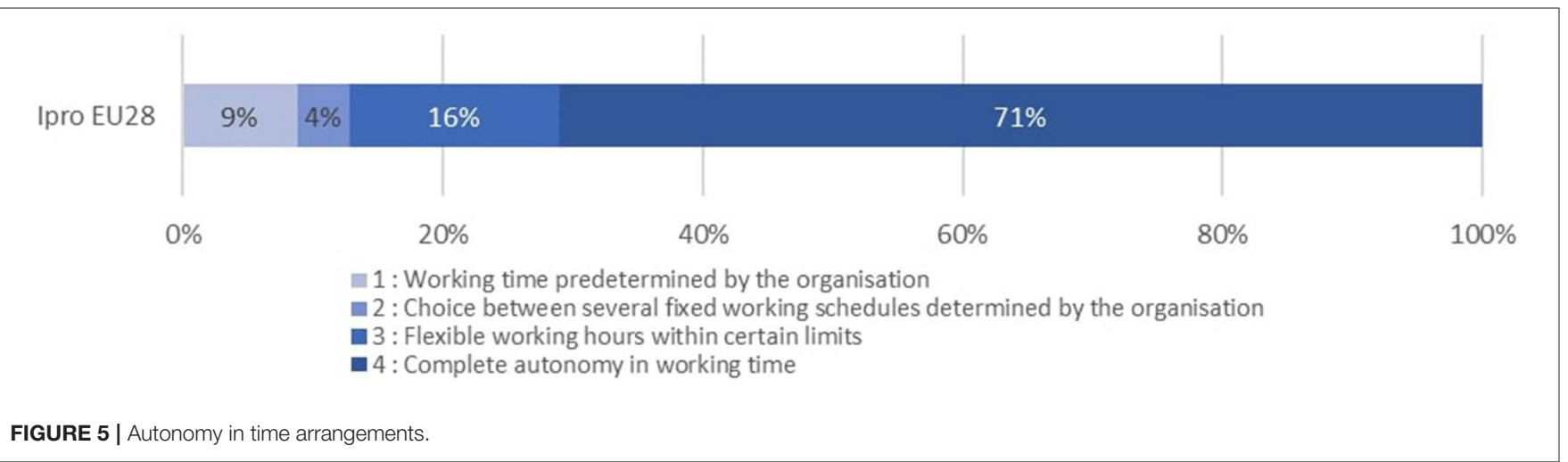

TABLE 3 | Indicators correlation matrix.

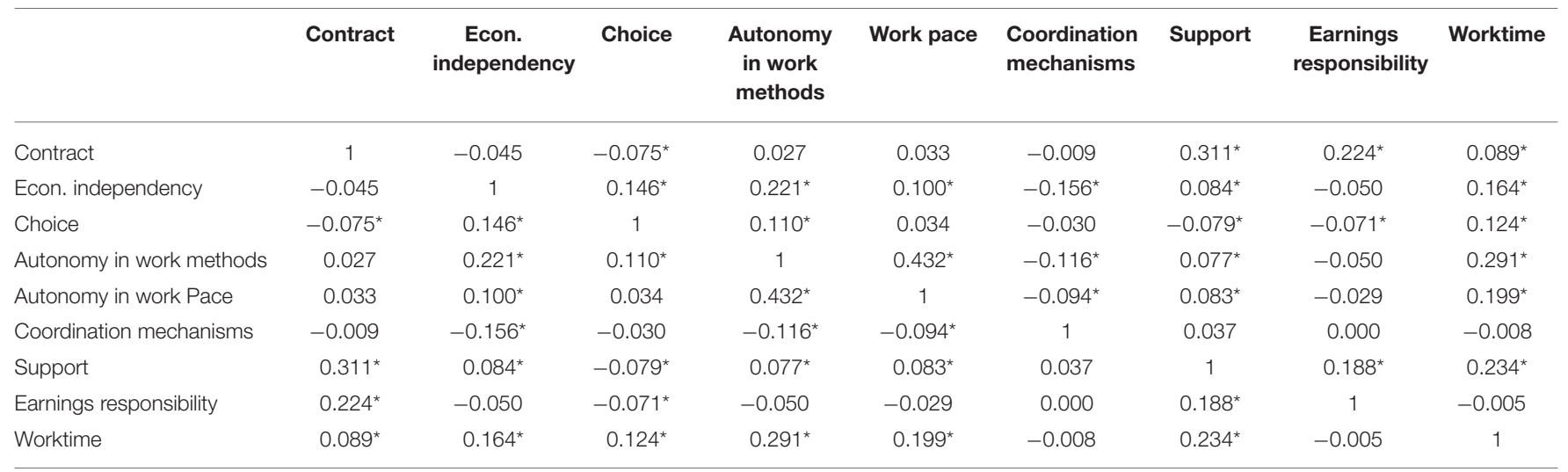

${ }^{*} p<0.01$ (bilateral).

\section{Building an Empirical Typology \\ Procedure}

Building on these indicators, we looked for groups of workers sharing the same patterns of results on the various dimensions of autonomy. We used a hierarchical clustering algorithm with a consolidation of the classes using k-means algorithm. The purpose of (hierarchical) cluster analyses is not to find a classification based on identification criteria (which is the goal of a conceptual classification) but rather to group individuals according to their similarity on multiple dimensions. The hierarchical clustering algorithm groups observations according to their similarity. The latter is calculated with Euclidian distance and Ward's linkage (Attewell and Monaghan, 2015). Hierarchical clustering is a bottom-up approach to clustering. In our case, each worker is considered as a single cluster at the beginning and then is successively merged in pairs of clusters that are the most similar on the different dimensions of autonomy until all clusters have been merged into one single cluster that contains all workers. Once the expected number of clusters is reached, the k-means algorithm calculates their center and categorizes each observation according to the closest cluster center. This consolidation of the hierarchical clustering methods is associated with more robust classifications. Before applying the clustering algorithms, indicators are standardized, missing values are imputed according to the proximity between individuals and the relations between the indicators (Josse and Husson, 2016), and 


\section{Cluster Dendrogram}

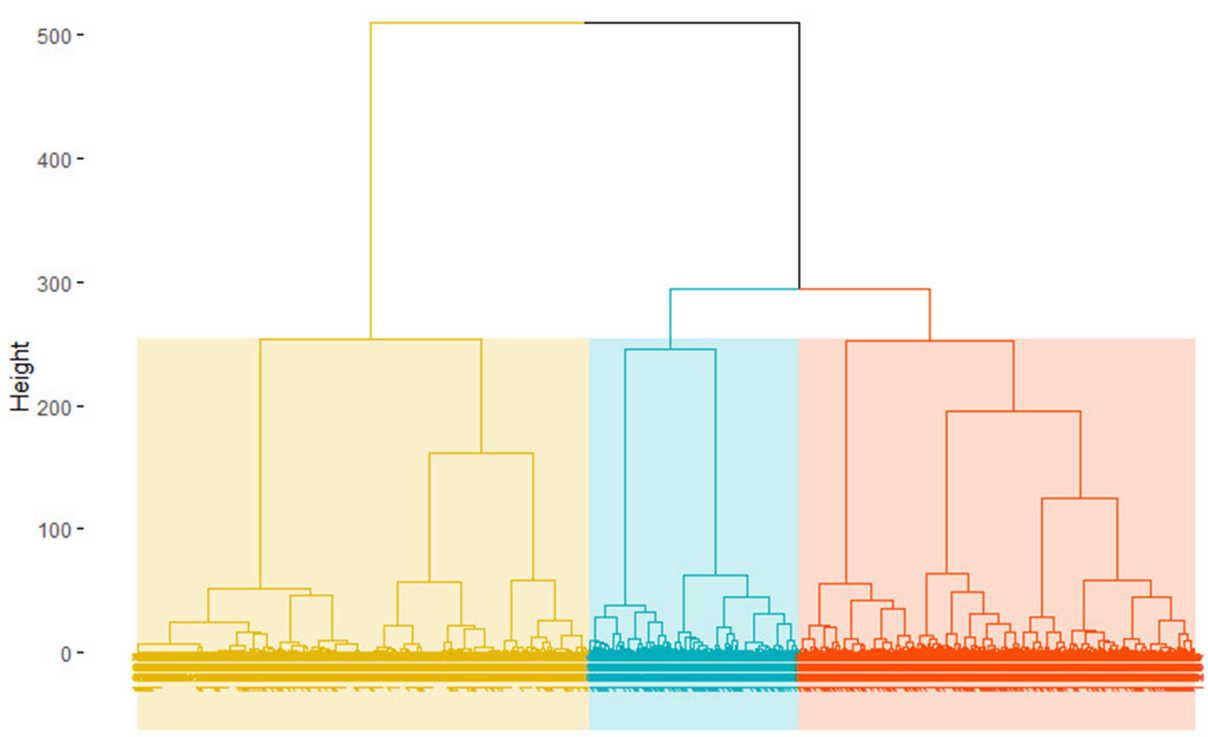

FIGURE 6 | Cluster dendrogram.

the relative weight of individuals (controlling for survey design, post-stratification, and supranational weights) is considered by using the weighting variable provided by Eurofound.

To select the optimal number of clusters, we looked for a significant breakdown in the gain of internal consistency of clusters (how similar are the members of one cluster). This can be done by calculating the heterogeneity of clusters, measured with the Total Within Sum of Squares (TWSS), and looking for a breaking point in the consistency gain, according to the "elbow" method (Attewell and Monaghan, 2015). There is no significant drop in TWSS that would prescribe the use of a specific number of clusters. Therefore, we relied on the interpretability of clusters to choose the number of categories to produce. We tested solutions from 2 to 7 clusters. The results with three clusters seem to produce the most interpretable clusters. Figure 6 displays the cluster dendrogram resulting from the three clusters option.

\section{Characteristics of the Clusters}

It is worth noting that we first conducted our analysis with four clusters. This analysis resulted in a similar structure with two groups differing from the main group of autonomous Ipros either on their level of dependency or support. In addition to these distinctions, we also had a fourth group that distinguished itself from the autonomous Ipros by a lower score on the choice for self-employment. This however appeared not sufficient to keep this group as a separate cluster. Even though the possibility to choose the self-employed status is stressed out as an important dimension in the literature on precariousness (Kautonen et al., 2010; Leighton and McKeown, 2015), our results show that it is not necessarily related to other dimensions of autonomy: the two clusters do not differ on other dimensions than choice. However, in the subsequent analyses, this fourth cluster of involuntary Ipros showed a higher proportion of female workers, a lower education, a lower level of work satisfaction and a lower belief that their job offers good prospects for career advancement. This shows that, even though the question of choice does not necessarily correlate with the other dimensions of autonomy, it remains associated with some socio-demographic profiles and levels of job satisfaction.

In a second step, the clustering analysis produced three clusters: the latter can be displayed on a factor map (Figure 7). This factor map synthetizes the information given by the eight indicators on two axes (principal components). We can observe the differences between the clusters according to their positions on the map in relation with the different indicators.

To reach a more precise understanding of our clusters, we can look at their means on each dimension of autonomy (cfr. Table 4). The difference between the means of the clusters were tested pairwise with a $t$-test. Our indicators do not always follow a normal distribution. However, the $t$-test is considered robust enough to handle non-normal distributions if the samples are large (Snijders, 2011).

The first cluster is made of Ipros who are autonomous on most dimensions. They enjoy a large autonomy in terms of work status, work content and working conditions. They correspond to the standard view of self-employed workers. We labeled this group as the "Autonomous IPros." They represent the majority of the Ipros in EU28 (59\%).

The second cluster is made of more economically dependent Ipros with less autonomy regarding their work methods, pace and working time arrangements while being self-responsible for their contract arrangements and the generation of income. They are less likely to choose the self-employed status. Conversely, they enjoy higher support from colleagues and business partners with whom they must coordinate. They represent $21 \%$ of our sample. This group is called the "Economically dependent Ipros." 


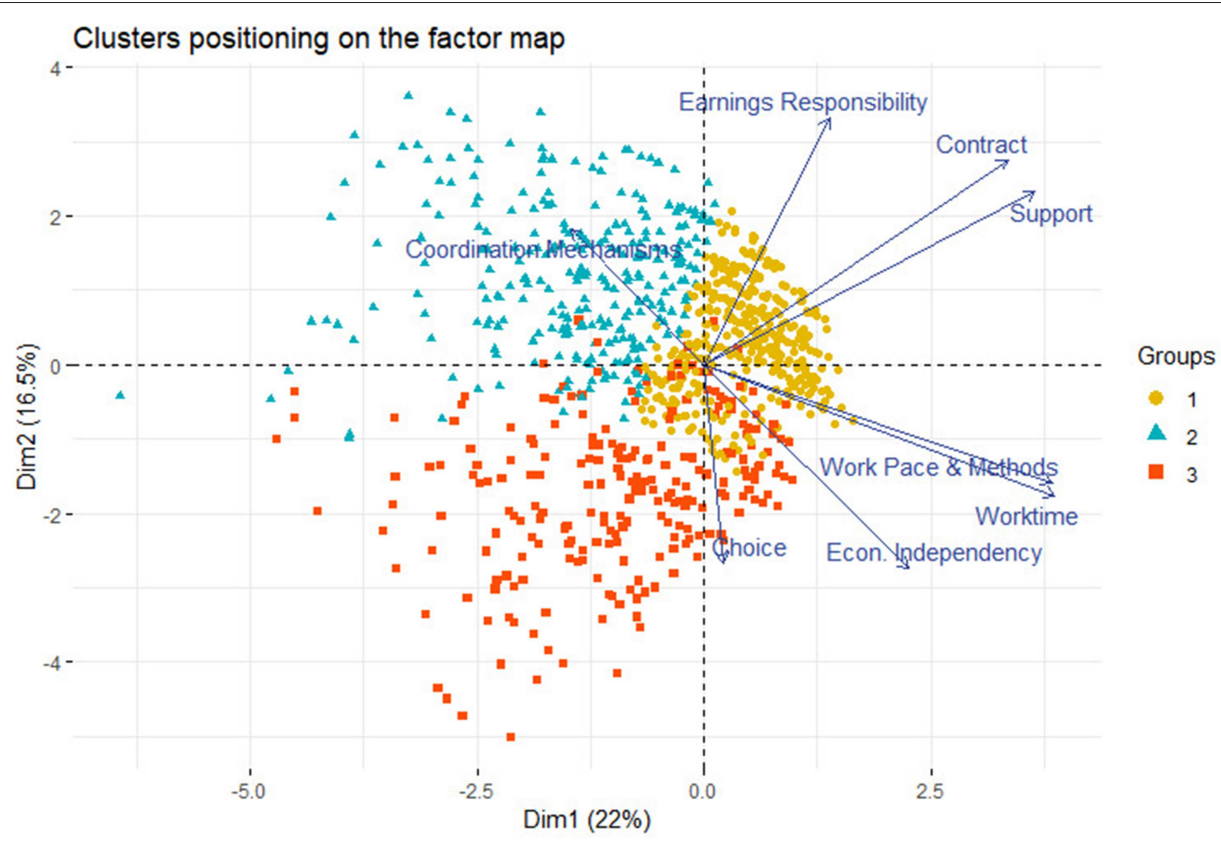

FIGURE 7 | Factor map with clusters.

TABLE $4 \mid$ Clusters means.

\begin{tabular}{lccc}
\hline & $\begin{array}{c}\text { Autonomous } \\
\text { Ipros } \\
\mathbf{N = 7 9 1}\end{array}$ & $\begin{array}{c}\text { Economically } \\
\text { dependent Ipros } \\
\mathbf{N = 2 8 4}\end{array}$ & $\begin{array}{c}\text { Supported } \\
\text { Ipros } \\
\mathbf{N = 2 7 0}\end{array}$ \\
\hline Contract & $1.00_{\mathrm{a}}$ & $0.99_{\mathrm{a}}$ & $0.88_{\mathrm{b}}$ \\
Econ. independency & $0.76_{\mathrm{a}}$ & $0.39_{\mathrm{b}}$ & $0.75_{\mathrm{a}}$ \\
Choice & $0.72_{\mathrm{a}}$ & $0.56_{\mathrm{b}}$ & $0.81_{\mathrm{c}}$ \\
Work pace and methods & $0.95_{\mathrm{a}}$ & $0.65_{\mathrm{b}}$ & $0.93_{\mathrm{a}}$ \\
Coordination & $0.54_{\mathrm{a}}$ & $0.68_{\mathrm{b}}$ & $0.57_{\mathrm{a}}$ \\
mechanisms & & & \\
Support & $0.87_{\mathrm{a}}$ & $0.58_{\mathrm{b}}$ & $0.53_{\mathrm{b}}$ \\
Earnings responsibility & $1.00_{\mathrm{a}}$ & $0.98_{\mathrm{b}}$ & $0.69_{\mathrm{c}}$ \\
Worktime & $0.95_{\mathrm{a}}$ & $0.55_{\mathrm{b}}$ & $0.87_{\mathrm{c}}$ \\
\hline
\end{tabular}

Values in the same row and subtable not sharing the same subscript are significantly different at $p<0.05$ in the two-sided test of equality for column means. Cells with no subscript are not included in the test. Tests assume equal variances. Tests are adjusted for all pairwise comparisons within a row of each innermost subtable using the Bonferroni correction.

The third cluster displays lower scores in terms of selfresponsibility in their contractual arrangements and generation of income while enjoying high autonomy in terms of work content. Such workers receive more support from colleagues and partners. This group accounts for about $20 \%$ of the sample. These workers may be considered as the "Supported Ipros."

\section{Clusters Description Using Variables From the Survey Demographics and activity}

Some demographic variables and indicators of economic activity can be associated with each cluster (cfr. Table 5). Compared to the two other clusters, women are slightly underrepresented in the supported Ipros. In terms of education, the supported Ipros seems to have a lower proportion of lower-educated workers. Autonomous Ipros are concentrated in "other" service activities (32\%) while economically dependent Ipros are more present in health and social work sectors (22\%). Supported Ipros are prevailing in professional, scientific and technical activities (30\%).

\section{Independence}

Table 6 displays the results of the clusters on two questions used by Eurofound to evaluate the dependency of self-employed workers. As expected, economically dependent Ipros have less authority than their counterparts regarding the possibility to hire or dismiss employees. Indeed, even though we focus on selfemployed workers without employees, not having the authority to hire an employee if required is an indicator of dependency or some sort of subordination according to Eurofound (2013). They, and the supported Ipros, are also more likely to be paid an agreed fee on a weekly or monthly basis, which is closer to a subordinated employment relationship.

\section{Self-employment situation}

Table 7 provides data on multiple questions regarding the subjective appreciations of the self-employment situation. Supported Ipros have a higher proportion (40\%) of workers who consider themselves as financially safe in case of a longterm sickness. Supported Ipros and Autonomous Ipros are in vast majority enjoying being their own boss. This tendency is still present but less pronounced for the economically dependent Ipros. Seven percent of the economically dependent Ipros say they dislike being their own boss while this proportion does not go above $1.5 \%$ in the two other clusters. More than half 
TABLE 5 | Demographic variables and economic activity in the different clusters.

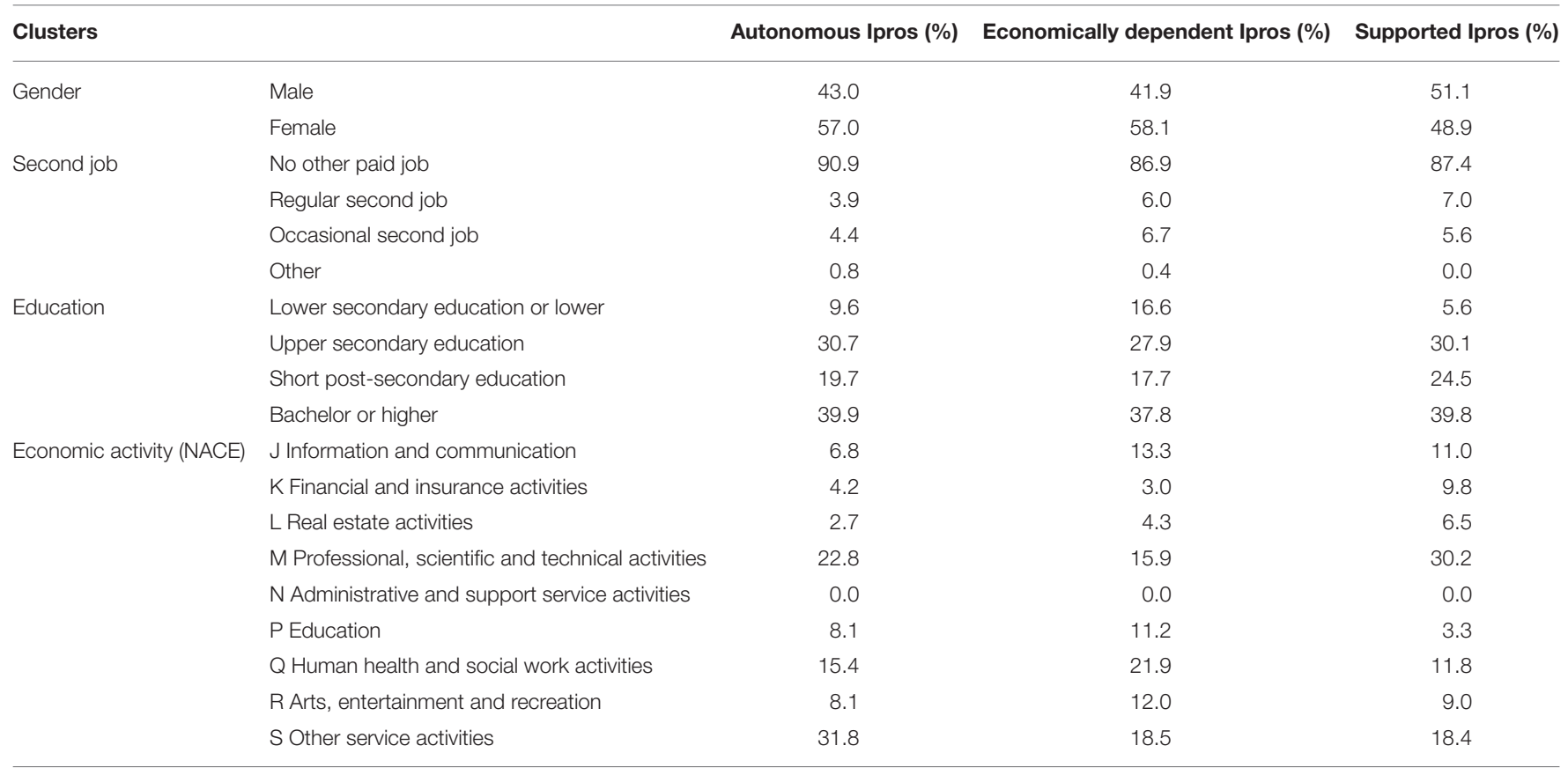

TABLE 6 | Independence variables in the different clusters.

\begin{tabular}{llccc}
\hline Clusters & & Autonomous Ipros (\%) & Economically dependent Ipros (\%) & Supported Ipros (\%) \\
\hline Q9a-have the authority to dismiss or hire employees & Yes & 65.1 & 36.5 & 63.5 \\
& No & 34.9 & 58.0 & 32.0 \\
Q9b-Get paid an agreed fee on a weekly or a monthly basis & Yes & 33.0 & 47.5 & 48.1 \\
& No & 67.0 & 41.9 \\
\hline
\end{tabular}

of the Supported Ipros and Autonomous Ipros consider it is easy to find new customers. Around 1 out of 5 workers in these clusters find it hard while, for the economically dependent, 1 out of 3 workers find it difficult. While the vast majority of the Autonomous Ipros (79\%) and Supported Ipros (65\%) strongly agree with the statement that they are making the most important decisions about how the business is run, this proportion drops at only $44 \%$ for the economically dependent Ipros. Moreover, $15 \%$ of the workers from this cluster disagree with this statement while it is never more than $3 \%$ for the two other clusters.

\section{Job satisfaction and prospects}

Table 8 shows that most IPros are satisfied with their working conditions. Almost half of the Supported Ipros and more than $40 \%$ of the Autonomous Ipros declare being very satisfied with their working conditions while this proportion remains under $30 \%$ for the economically dependent Ipros. More than half of the Autonomous and Supported Ipros also believes their job offers good prospects for career advancement. While it is the case for $<40 \%$ of the economically dependent Ipros.

\section{DISCUSSION}

While most IPros enjoy high levels of autonomy on the different dimensions of our grid, our univariate analysis of indicators also pointed that there is a non-negligible part of this population with lower scores on some dimensions. These lower scores entail negative situations already pointed out in the literature, such as being pushed toward self-employment (Fleming, 2017), being economically dependent (de Peuter, 2011; Standing, 2011; Bergvall-Kåreborn and Howcroft, 2013), having strict guidelines to follow or not being responsible for working time arrangements. But lower scores on some dimensions might have a positive impact on the work quality. A low score on the support dimension means that the worker enjoys less autonomy and accesses shared expertise and support from managers, colleagues, and/or teammates. Our approach therefore provides a more comprehensive vision of autonomy at work of IPros by using multiple dimensions on the same data.

This approach leads us better understand risks and opportunities associated with the work of Ipros. Workers with high levels of autonomy (the majority of Ipros) may indeed face the following risks: no (or discontinuous) access to social protection, low access to shared expertise and support, 
TABLE 7 | Self-employment situation variables in the different clusters.

\begin{tabular}{|c|c|c|c|c|}
\hline Clusters & & Autonomous Ipros (\%) & Economically dependent Ipros (\%) & Supported Ipros (\%) \\
\hline \multirow{3}{*}{$\begin{array}{l}\text { Q91a-if I had a long-term sickness, I would } \\
\text { be financially secure }\end{array}$} & Tend to agree & 16.8 & 12.1 & 20.7 \\
\hline & Tend to disagree & 21.7 & 21.9 & 19.5 \\
\hline & Strongly disagree & 35.7 & 36.2 & 22.9 \\
\hline & Neither agree nor disagree & 5.2 & 15.8 & 3.0 \\
\hline & Tend to disagree & 0.5 & 3.8 & 0.7 \\
\hline & Strongly disagree & 0.4 & 3.0 & 0.7 \\
\hline \multirow[t]{2}{*}{ Q91c-It is easy for me to find new customers } & Strongly agree & 17.0 & 16.1 & 16.7 \\
\hline & Tend to agree & 34.4 & 22.2 & 34.9 \\
\hline \multirow{5}{*}{$\begin{array}{l}\text { Q91d-I find it hard for me bearing the } \\
\text { responsibility for running my business }\end{array}$} & Strongly agree & 6.2 & 10.9 & 5.3 \\
\hline & Tend to agree & 14.8 & 15.5 & 15.9 \\
\hline & Neither agree nor disagree & 16.7 & 19.7 & 18.9 \\
\hline & Tend to disagree & 21.7 & 25.6 & 21.6 \\
\hline & Strongly disagree & 40.6 & 28.2 & 38.3 \\
\hline \multirow{5}{*}{$\begin{array}{l}\text { Q91e-I make the most important decisions on } \\
\text { how the business is run }\end{array}$} & Strongly agree & 79.4 & 44.7 & 65.5 \\
\hline & Tend to agree & 15.8 & 23.0 & 22.5 \\
\hline & Neither agree nor disagree & 3.5 & 16.8 & 8.2 \\
\hline & Tend to disagree & 0.8 & 9.4 & 1.5 \\
\hline & Strongly disagree & 0.5 & 6.1 & 2.2 \\
\hline
\end{tabular}

TABLE 8 | Job satisfaction and prospects in the different clusters.

\begin{tabular}{|c|c|c|c|c|}
\hline Clusters & & Autonomous Ipros (\%) & Economically dependent Ipros (\%) & Supported Ipros (\%) \\
\hline \multirow[t]{3}{*}{ Q88-Satisfaction with working conditions } & Very satisfied & 41.8 & 29.9 & 48.5 \\
\hline & Satisfied & 48.8 & 57.4 & 46.3 \\
\hline & Not at all satisfied & 1.6 & 2.1 & 0.0 \\
\hline \multirow{3}{*}{$\begin{array}{l}\text { Q89b-My job offers good prospects for } \\
\text { career advancement }\end{array}$} & Strongly agree & 21.2 & 14.6 & 37.0 \\
\hline & Tend to disagree & 11.2 & 18.0 & 10.1 \\
\hline & Strongly disagree & 13.3 & 22.3 & 8.8 \\
\hline
\end{tabular}

self-responsibility for skills development and for generating a steady income flow, etc. On the other side, high autonomy may also offer benefits in terms of freedom of choice for the job status, broader guidelines allowing job crafting, self-responsibility for workload, and work pace, self-responsibility for space, and time arrangements, etc.

However, Ipros may obtain lower scores on some dimensions of autonomy, which leads them face some risks such as: higher economic dependency, forced orientation to casual work, strict guidelines reducing the possibilities of job crafting, less responsibility over workload, and work pace, etc. There are however some benefits associated with low levels of autonomy. If most of them remain inaccessible to the majority of Ipros due to their self-employed status (secure legal status, continuous access to social protection), our results showed that a minority of these workers may enjoy support from their colleagues and managers.

Autonomous Ipros may be considered as autonomous on every dimension. They are their own boss, make the most important decisions about how their business is run, enjoy great levels of responsibility for their work content and working conditions and are relatively satisfied.

Individual situations of economically dependent Ipros are blended with high autonomy on most dimensions and lower scores on some dimensions. They are more likely to be 
dependent on one single business partner and, while this might bring advantages in terms of organizational support, they do not enjoy the same levels of autonomy as other Ipros when considering work content and working conditions: they are associated with lower job satisfaction scores and more precarious self-employment situations. This could result from purely transactional arrangements with client organizations. In this perspective, the use of contract work is just a question of business optimization, via cost reduction and/or flexible responses to market variations. Client organizations are not led to invest such short-term business relationships: work arrangements are mainly focused on performances and compliance with the terms and conditions of contracts, with low consideration on the development of human capital. This "low road strategy" (Gautié and Schmitt, 2010) is very frequent in mass-market industries.

Conversely, the positive scores obtained in the supported Ipros cluster probably originate from another attitude of client organizations: more emphasis is then put on skills development, individual commitment, self-determination rather than compliance with command-and-control systems, intensive communication and participation. Indeed, some organizations tend to develop such a "high road strategy" (Gautié and Schmitt, 2010) with Ipros, in order to build a genuine partnership with them due to the uniqueness of their human capital (Lepak and Snell, 1999). In line with previous research (Koene and van Riemsdijk, 2005; Coyle-Shapiro et al., 2006), a survey among 375 Ipros working in a large range of Australian organizations (McKeown and Cochrane, 2017) showed that organizational support-offered either by client organizations or labor market intermediaries-significantly predicts their affective commitment, which reinforces their potential contribution to organizational performances. Workers from Supported Ipros, who enjoy higher levels of autonomy on work content and working conditions while benefiting from more organizational support are also amongst the most satisfied with their working conditions and their self-employment situation.

\section{CONCLUSIVE REMARKS}

Therefore, the future of career management might be based on the ability of HR managers to grasp the various and changing ways through which Ipros look for and enact autonomy at work, in order to provide them with appropriate answers to the growing risks they experience in terms of access to social protection, forced orientation to the self-employment status, economic dependence on one single client, limited possibilities of job crafting, limited support to shared professional expertise, limited possibilities of skills development, discontinuity of incomes, etc. The choice of this "high road strategy" (Osterman, 2018), involving external workers in a more inclusive perspective, is not only based on "moral" considerations on what should be done in order to improve the job quality of Ipros. More and more HR managers become aware of the growing risks they may face when their company is using self-employment arrangements. Disloyal and opportunistic behaviors, lack of visibility on contractors, emergence of new labor market intermediaries, and quasi unions (Hirsch and Seiner, 2018), potential degradation of the service quality, negative signals sent to regular employees leading to disengagement (von Hippel and Kalokerinos, 2012), lack of collective learning and exchange (Grugulis and Stoyanova, 2011), loss of expertise and innovation, etc. are increasingly considered and lead to the development of "total workforce management" initiatives. A growing body of literature advocates for a better management of such a hybrid workforce (Cascio and Boudreau, 2017). Even if the dominant approach so far looks like a new rhetoric, mostly developed by consultants and HR technology vendors, it paves the way to a new role likely to be played by HR managers.

Younger and Smallwood (2016) point out that companies that consider external workers with the same attention as permanent workers get the highest commitment from this flexible workforce. The same argument was already highlighted in a study on temporary workers by Koene and van Riemsdijk (2005). Multiple empirical studies (Kuhn and Maleki, 2017; McKeown and Cochrane, 2017) argue that tailored initiatives including external workers (high road strategy) give modern organizations significant competitive advantages compared to those neglecting the contributions of external workers. In order to do so, HR managers have to learn new cooperation games, not only with internal actors (purchase, line and project managers, as suggested by Keegan et al., 2012) but also with their counterparts in other client organizations and with emerging third-party actors such as labor market intermediaries (Bonet et al., 2013; Lorquet et al., 2018) and quasi unions voicing the concerns of self-employed and freelance workers (Hirsch and Seiner, 2018).

We must keep in mind some limitations of this research while looking at its findings. First, our empirical test was based on a secondary analysis of existing data (EWCS). We were thus unable to find relevant information for each component of our conceptual framework. Further empirical investigations will be needed in order to gather more relevant primary data according to our analytical grid. Second, the use of crosssectional data makes it impossible to look at the evolution of self-employment arrangements over time. The exploratory character of our clustering methods gives us insights about associations between variables grouped in each cluster and other descriptive variables but these methods prevent us from identifying clear causal patterns. In line with our methodological choices, our argument is not positivist. We do not pretend to find objective existing categories of workers but to shed light on the variety of experiences of autonomy and the perception of risks associated with them. We also tried to use factual indicators in the construction of clusters. More subjective questions about contractual arrangements and job satisfaction are needed to better understand the concrete experiences of autonomy at work: some of them were used as illustrative variables to better highlight the differences between clusters.

Still, our results represent an important contribution to the literature on new forms of employment. Our findings bring a nuanced take on the binary considerations on autonomy at work of independent professionals, either presented as highly autonomous workers benefitting from flexible work arrangements or, conversely, associated with precarious work arrangements and painful working conditions. Our findings show the added value of an empirical typology that helps better understand the experience of autonomy 
in non-standard work arrangements and paves the way to the development of more appropriate policies, taking account of the diversity of IPros' working situations. It should be further validated on other datasets in order to identify relevant links between the employment arrangements for IPros and other variables such as the well-being or job quality.

\section{DATA AVAILABILITY STATEMENT}

The datasets generated for this study are available on request to the corresponding author.

\section{REFERENCES}

Attewell, P. A., and Monaghan, D. B. (2015). Data Mining for the Social Sciences: An Introduction, 1st Edn. Oakland, CA: University of California Press.

Bazillier, R., Boboc, C., and Calavrezo, O. (2016). Measuring employment vulnerability in Europe. Int. Labour Rev. 155, 265-280. doi: 10.1111/j.1564-913X.2014.00019.x

Bergvall-Kåreborn, B., and Howcroft, D. (2013). 'The future's bright, the future's mobile': a study of Apple and Google mobile application developers. Work Employ. Soc. 27, 964-981. doi: 10.1177/0950017012474709

Bonet, R., Cappelli, P., and Hamori, M. (2013). Labor market intermediaries and the new paradigm for human resources. Acad. Manage. Ann. 7, 341-392. doi: $10.5465 / 19416520.2013 .774213$

Bush, J. T., and Balven, R. M. (in press). Catering to the crowd: An HRM perspective on crowd worker engagement. Hum. Resour. Manage. Rev. 1053-4822. doi: 10.1016/j.hrmr.2018.10.003

Cappelli, P. H., and Keller, J. R. (2013a). A study of the extent and potential causes of alternative employment arrangements. Industr. Labor Relat. Rev. 66, 874-901. doi: 10.1177/001979391306600406

Cappelli, P. H., and Keller, J. R. (2013b). Classifying work in the new economy. Acad. Manage. Rev. 38, 575-596. doi: 10.5465/amr.2011.0302

Cascio, W. F., and Boudreau, J. W. (2017). "Chapter 26: Talent management of nonstandard employees," in The Oxford Handbook of Talent Management, eds D. G. Collings, K. Mellahi, and W. F. Cascio (Oxford: Oxford University Press), 494-520.

Cieslik, J. (2015). Capturing statistically the "intermediate zone" between the employee and the employer firm owner. Int. Rev. Entrepr. 13, 205-214.

Coyle-Shapiro, J. A. M., Morrow, P. C., and Kessler, I. (2006). Serving two organizations: Exploring the employment relationship of contracted employees. Hum. Resour. Manage. 45, 561-583. doi: 10.1002/hrm.20132

de Peuter, G. (2011). Creative economy and labor precarity: a contested convergence. J. Commun. Inquiry 35, 417-425. doi: 10.1177/0196859911416362

Desrosières, A. (2005). Décrire l'État ou explorer la société : les deux sources de la statistique publique. Genèses 58:4. doi: 10.3917/gen.058.0004

Eurofound (2012). Trends in Job Quality in Europe: A Report Based on the Fifth European Working Conditions Survey. Luxembourg: Publication Office of the European Union.

Eurofound (2013). Self-Employed or Not Self-Employed? Working Conditions of 'Economically Dependent Workers', Background Paper. Dublin.

Eurofound (2015). New Forms of Employment. Luxembourg: Publications Office of the European Union.

Eurofound (2017a). 6th European Working Conditions Survey: Overview Report (2017 Update). Luxembourg: Publications Office of the European Union.

Eurofound (2017b). Classifying Self-Employment and Creating an Empirical Typology. Luxembourg: Eurofound Working Paper.

Eurofound (2017c). Exploring Self-Employment in the European Union. Luxembourg: Publications Office of the European Union.

Eurofound (2018a). Does Employment Status Matter for Job Quality? Luxembourg: Publications office of the European Union.

\section{AUTHOR CONTRIBUTIONS}

FP has provided theoretical support, reviewing, and editing of the paper. LF was responsible for the data acquisition and analysis and drafting of the paper. All authors are responsible for the study design and methodology.

\section{SUPPLEMENTARY MATERIAL}

The Supplementary Material for this article can be found online at: https://www.frontiersin.org/articles/10.3389/fsoc.2020. 00034/full\#supplementary-material

Eurofound (2018b). European Working Conditions Survey Integrated Data File, 1991-2015. [Data Collection], 7th Edn. Luxembourg: UK Data Service. SN: 7363. doi: 10.5255/UKDA-SN-7363-7

Everaere, C. (2014). Les Emplois atypiques. Quelles réponses au besoin de flexicurité? Rueil-Malmaison: Liaisons.

Fleming, P. (2017). The human capital hoax: work, debt and insecurity in the era of uberization. Org. Stud. 38 691-709. doi: 10.1177/0170840616686129

Gautié, J., and Schmitt, J. (2010). Low-Wage Work in the Wealthy World. New York, NY: Russel Sage Foundation.

Gazier, B., Picart, C., and Minni, C. (2016). La diversité des formes d'emploi, rapport. Paris: Conseil National de l'information Statistique.

Grugulis, I., and Stoyanova, D. (2011). The missing middle: communities of practice in a freelance labour market. Work Employ. Soc. 25, 342-351. doi: 10.1177/0950017011398891

Hirsch, J., and Seiner, J. A. (2018). A modern union for the modern economy. Fordham Law Rev. 86, 1727-1783. doi: 10.2139/ssrn.2924833

ILO (2016). Non-Standard Employment Around the World: Understanding Challenges, Shaping Prospects. Available online at: http://www.ilo.org/wcmsp5/ groups/public/---dgreports/---dcomm/---publ/documents/publication/ wcms_534326.pdf (accessed October 18, 2017).

ILO (2018). "Résolution concernant les statistiques sur les relations de travail," in 20e Conférence internationale des statisticiens du travail (Genève).

Josse, J., and Husson, F. (2016). missMDA : A package for handling missing values in multivariate data analysis. J. Stat. Softw. 70. doi: 10.18637/jss.v070.i01

Katz, L. F., and Krueger, A. B. (2016). The rise and nature of alternative work arrangements in the United States, 1995-2015. National Bureau of Economic Research. Available online at: http://www.nber.org/papers/w22667

Kautonen, T., Down, S., Welter, F., Vainio, P., Palmroos, J., Althoff, K., et al. (2010). Involuntary self-employment as a public policy issue: a cross-country European review. Int. J. Entrepr. Behav. Res. 16, 112-129. doi: 10.1108/13552551011027002

Keegan, A., Huemann, M., and Turner, J. R. (2012). Beyond the line: exploring the HRM responsibilities of line managers, project managers and the HRM department in four project-oriented companies in the Netherlands, Austria, the UK and the USA. Int. J. Hum. Resour. Manage. 23, 3085-3104. doi: 10.1080/09585192.2011.610937

Koene, B., and van Riemsdijk, M. (2005). Managing temporary workers: work identity, diversity and operational HR choices. Hum. Resour. Manage. J. 15, 76-92. doi: 10.1111/j.1748-8583.2005.tb00141.x

Kuhn, K. M., and Maleki, A. (2017). Micro-entrepreneurs, dependent contractors, and instaserfs: understanding online labor platform workforces. Acad. Manage. Perspect. 31, 183-200. doi: 10.5465/amp.2015.0111

Leighton, P., and Brown, D. (2014). Future Working: The Rise of Europe's Independent Professionals (iPRos). Available online at: http://crse.co.uk/sites/ default/files/Future\%20Working\%20Full\%20Report.pdf (accessed May 13, 2020).

Leighton, P., and McKeown, T. (2015). The rise of independent professionals: their challenge for management. Small Enterpr. Res. 22, 119-130. doi: 10.1080/13215906.2015.1085627 
Lepak, D. P., and Snell, S. A. (1999). The human resource architecture: toward a theory of human capital allocation and development. Acad. Manage. Rev. 24, 31-48. doi: 10.5465/amr.1999.1580439

Lorquet, N., Orianne, J.-F., and Pichault, F. (2018). Who takes care of nonstandard career paths? The role of labour market intermediaries. Eur. J. Industr. Relat. 24, 279-295. doi: 10.1177/0959680117740425

McKeown, T. (2015). "What's in a name? The value of 'Entrepreneurs' compared to 'Self-Employed"' in The Handbook of Research on Freelancing and SelfEmployment (Dublin: Senate Hall Academic Publishing), 121-134.

McKeown, T., and Cochrane, R. (2017). Independent professionals and the potential for HRM innovation. Person. Rev. 46, 1414-1433. doi: 10.1108/PR-09-2016-0256

National Academies of Sciences, Engineering and Medicine (2017). Information Technology and the U.S. Workforce: Where Are We and Where Do We Go from Here? Committee on Information Technology, Automation, and the U.S. Workforce - Computer Science and Telecommunications Board - Division on Engineering and Physical Sciences. Washington, DC: National Academy Press.

Osterman, P. (2018). In search of the high road: meaning and evidence. ILR Rev. 71:334. doi: 10.1177/0019793917738757

Pichault, F., and McKeown, T. (2019). Autonomy at work in the gig economy: analysing work status, work content and working conditions of independent professionals. N. Technol. Work Employ. 34, 59-72. doi: 10.1111/ntwe. 12132

Rapelli, S. (2012). European I-Pros: A Study. Professional Contractors Group (PCG), UK. Retrieved from: http://rapelli.free.fr/documents/rapelli_pcg_en.pdf (accessed October 18, 2017).

Sandberg, J., and Pinnington, A. H. (2009). Professional competence as ways of being: an existential ontological perspective. J. Manage. Stud. 46, 1138-1170. doi: 10.1111/j.1467-6486.2009.00845.x

Schmid, G. (2015). Sharing risks of labour market transitions: towards a system of employment insurance: sharing risks of labour market transitions. Br. J. Industr. Relat. 53:70973. doi: 10.1111/bjir.12041
Snijders, T. A. B. (2011). Statistical Methods: Robustness. Oxford: University of Oxford.

Standing, G. (2011). The Precariat: The New Dangerous Class. London: Bloomsbury.

Thompson, P., Jones, M., and Warhurst, C. (2009). "From conception to consumption: creativity and the managerial missing link," in Creative Labour: Working in the Creative Industries, eds A. McKinlay and C. Smith (London: Palgrave), 51-71. doi: 10.1007/978-1-137-12173-8_3

Van Aerden, K., Moors, G., Levecque, K., and Vanroelen, C. (2014). Measuring employment arrangements in the European labour force: a typological approach. Soc. Indic. Res. 116, 771-791. doi: 10.1007/s11205-013-0312-0

Vandenbrande, T., Vandekerckhove, S., Vendramin, P., and Valenduc, G. (2012). Quality of Work and Employment in Belgium. Leuven: KU Leuven HIVA.

von Hippel, C., and Kalokerinos, E. K. (2012). When temporary employees are perceived as threatening: antecedents and consequences. Leader. Org. Dev. J. 33, 200-216. doi: 10.1108/01437731211203483

Wynn, M. T. (2016). Chameleons at large: Entrepreneurs, employees and firms the changing context of employment relationships. J. Manage. Org. 22, 826-842. doi: $10.1017 /$ jmo. 2016.40

Younger, J., and Smallwood, N. (2016). Agile Talent: How to Source and Manage Outside Experts. Cambridge MA: Harvard Business Review Press.

Conflict of Interest: The authors declare that the research was conducted in the absence of any commercial or financial relationships that could be construed as a potential conflict of interest.

Copyright (C) 2020 Florin and Pichault. This is an open-access article distributed under the terms of the Creative Commons Attribution License (CC BY). The use, distribution or reproduction in other forums is permitted, provided the original author(s) and the copyright owner(s) are credited and that the original publication in this journal is cited, in accordance with accepted academic practice. No use, distribution or reproduction is permitted which does not comply with these terms. 
OPEN ACCESS

Edited by:

Valeria Pulignano,

KU Leuven, Belgium

Reviewed by:

Emiliana Armano,

University of Milan, Italy

Gianluca De Angelis,

University of Bologna, Italy

*Correspondence:

Flora Bajard

flora.bajard@gmail.com

Specialty section:

This article was submitted to Work, Employment and Organizations,

a section of the journal

Frontiers in Sociology

Received: 27 June 2019

Accepted: 27 April 2020

Published: 27 May 2020

Citation:

Bajard F (2020) A "Hijacked Salaried Status" in French Cooperatives of Freelance Workers: The Political Meaning of Shifts Between Standard and Non-standard Employment.

Front. Sociol. 5:36

doi: 10.3389/fsoc.2020.00036

\section{A "Hijacked Salaried Status" in French Cooperatives of Freelance Workers: The Political Meaning of Shifts Between Standard and Non-standard Employment}

\author{
Flora Bajard * \\ Aix Marseille Univ, LEST (UMR 7317), Marseille, France
}

This article considers a specific sub-type of non-standard employment-self-employment-through a particular type of cooperative in France: the Business and Employment Cooperatives (BEC), i.e., collectives of freelance workers. BECs aim to provide an indefinite employment contract-and the social protection associated with it - to these individuals who therefore become "salaried entrepreneurs." To better understand the gray zones of work, where legal status, practices and identities are often disconnected, this inquiry is based on a qualitative approach to social actors' practices. It shows, on a meso level, how BECs "hijack" the standard wage-labor contract on the grounds that this is emancipatory and therefore drag it into a non-standard form of employment. In addition with this first shift between the legal framework and its interpretation, a second shift occurs as each member of the cooperative-a "false wage earner" - develops a singular relationship to the constraints related to such a contract. Through the notion of "praxis," combining both objective and subjective dimensions of work, we are able to systematize the analysis of qualitative data and identify the factors that influence such a diversity of appropriations: the relationship to conflictuality and political competence. Finally, this article highlights the conditions under which social actors make a wide range of appropriations of common legal frameworks, whose flexibility requires us to consider employment relationships as variant and creative practices rather than as "perfect" or "deviant" forms.

Keywords: self-employment, wage-labor, business and employment cooperative, indefinite employment contract, entrepreneur, non-standard employment, politicization, institutional change

\section{INTRODUCTION}

[We see] "a second way to the universal: no longer the overarching universal of a strictly objective method, but a sort of lateral universal which we acquire through ethnological experience and its incessant testing of the self through the other person and the other person through the self" (MerleauPonty, in Bachir Diagne, 2013, p. 16). 
This philosophical issue, rooted in a very different context, inspires us to examine the ties between the standard employment contract $^{1}$ and its non-standard variants ${ }^{2}$. Beyond the formal opposition between both forms, this article addresses the two kind of shifts that arise between standard and non-standard forms of work within a single legal framework-the indefinite employment contract. In order to do so, one has to consider not only "employment" conditions but also work in its very practical dimension, through the reality of workers' living and working conditions. Studying the "gray zones" of work may demonstrate the accuracy of this approach in a striking way as the main characteristic of the gray zones is to blur the traditional lines that usually help to describe the types (and sub-types) of employment.

Concerning independent work, which is at the core of this article, the frontier between wage labor and self-employment has contributed to the definition of the standard employment relationship (a full-time and indefinite employment contract) during the twentieth century ${ }^{3}$. Yet, some important evolutions have occurred within this dichotomy, as French jurist Supiot (2000) demonstrated. These transformations have ended dualist labor approaches (insiders vs. outsiders of labor markets; wageearning job vs. self-employment, i.e., standard and non-standard employment relationships). This expanding complexity of social and professional patterns ${ }^{4}$ has therefore led to a structural phenomenon of "decoherence" of employment standards: "The proliferation of areas of lawlessness and legal confusion, [and] also strategies for circumventing and gaming the multiplicity of existing rules" (Bureau and Dieuaide, 2018, p. 263). A gray zone can be understood as a public space where there is a "mediation between 'intangible' rights and duties a priori guaranteed by labor law, on the one hand, and crumbling interests that escape a priori from any procedural rationality, on the other hand. ... [It is a space] where balances are created by hybrid and implicit rules or non-constraining conventions (soft law). As a public space, a gray zone is a more or less informal deliberative space that combines, or even mixes, two different orders of legitimacy, in practice: one comes from institutions and the State, the other from the market and contractual reasoning" (Azaïs et al., 2017, p. 442) . $^{5}$

Thus, the issue of gray zones of work and employment are of high interest to sociologists as they suggest that formal limits and definitions are not sufficient to comprehend the current challenges raised by these evolutions. Therefore, we must particularly consider the reality of work if we now want to understand this. Not that we totally relativize the importance of objective frameworks, such as economic and legal constraints, but we assert that neither organizations nor statuses/standards

\footnotetext{
${ }^{1}$ Defined as "full-time, indefinite, as well as part of a subordinate and bilateral employment relationship" (International Labor Organization, 2016, p. 7).

${ }^{2}$ The ILO defines four types of non-standard work: temporary, part-time, agency, and economically dependent work.

${ }^{3}$ For example, in Western Europe, where social protection is intertwined with employment status-and the salaried status in particular-the separation between the two categories has generated a two-sided social protection system (which is based on different insurance funds).

${ }^{4}$ In terms of employment in the second labor market and living conditions. Regarding the diversity of empirical situations and narratives about non-standard work, see for example: Hipp et al. (2015).

${ }^{5}$ Our translation.
}

of employment fully determine workers' living conditions. This article is focused on this line of argument and uses the notion of "praxis," which aims to comprehend "work" through its practical dimension. The idea of praxis refers to the production of the self through labor in a unified conception of representations and practices. From this perspective, labor is not only the externalization of consciousness of the world but it can also be understood as a practical worldview or the constant daily practice of one's worldview. The notion therefore embraces objective constraints and subjective representations, and enables us to address the articulation between institutional frameworks and individual action at work (Dardot, 2015).

This first argument feeds a second, which implies distancing oneself from the normative approaches of the gray-zone phenomenon. This phenomenon often signifies a regression which may reverse the "forces of emancipation" (Bureau and Dieuaide, 2018, p. 275) and these transformations have taken place in a general context of the weakening of the social protection and salaried norm. Although wage labor still represents a major fraction of total employment, the standard employment relationship of the indefinite and fulltime labor contract is decreasing through several processes: new statuses ( 0 -h contracts, micro-entrepreneurship), technological changes (platform and gig economy), and ideological changes in collective and individual preferences and expectations (flexibility, autonomy, incentives for self-employment, etc.). The case of the solo self-employed offers an interesting insight into these trends. For example, some employment policies in Western Europe encourage people to consider the possibility of becoming a freelance worker, sometimes even part-time. Some legal statuses, like the "economically dependent autonomous worker" in Spain and the "auto-entrepreneur" in France, allow for more flexibility and pluriactivity. However, they also generate a greater precariousness ${ }^{6}$; one of the main illustrations of this is the bogus self-employment which proliferates throughout uberization processes. In self-employed relationships, we may therefore talk about the "self-employed precariat," which is "reflective of complex and diverse patterns of atypical work that is growing, ranging from casual working to temps, agency staff, own account workers and Uber drivers. The self-employed precariat do not enjoy employment rights and protections at work, or any of the implicit services associated with being an employee, such as payroll or workplace insurance-let alone pension or sick pay" (Conaty et al., 2016). To some extent, the many new solo selfemployed resemble the workers of the nineteenth century, selling their labor on a day-to-day or piecework basis, and this is why many researchers often refer to the gray zones of employment through the precariousness matrix ${ }^{7}$. However, it also seems necessary to seriously consider the "various sub-types of nonstandard employment" as bogus/dependent self-employment is

\footnotetext{
6"Precariousness" is a sociological category that deserves discussion but, in line with Cingolani, in this article it refers to the discontinuity of times and activities within socialization processes imposed unilaterally by managerial and productivity discourses and actors, i.e., a loss of autonomy and a new form of subjection (Cingolani, 2008, p. 109-111).

${ }^{7}$ Gray zones are often considered a regression in comparison with the standard employment relationship (see for example Bisom-Rapp and Coiquaud, 2017, p. 2).
} 
far different from other kinds of solo self-employment (Hipp et al., 2015, p. 368). Besides, along with other observers ${ }^{8}$, we argue that gray zones should not necessarily be considered a "shadowy part" of labor markets nor as chaotic situations for lacking political regulation (for developments on the same line of argument, see, for example, Bureau and Dieuaide, 2018, p. 262265). In fact, the non-standard employment relationship should not automatically be considered as a "lack" or a "failure" per se, as some political and institutional alternatives and responses also occur in the workplace. Rather, in this article, we wish to point out the ambivalence of these gray zones, their openness, and absence of institutional determinism that allows us to address the appropriation of such organizations by the actors. This article is focused on presenting arguments that explore the following three ideas: considering the reality of work, identifying sub-types of employment, and avoiding normative labels of categories of work and positions.

To this aim, the text reveals the findings of a study of a particular type of cooperative in France: Business and Employment Cooperatives (BECs), which can be described as collective groups of freelance workers ${ }^{9}$. Today, there are around 100 BECs in France, which represent around 10,000 freelance workers in total ${ }^{10}$. They are a very particular form of the gray zone of work which are thought by its promoters to be institutional innovations and responses to the precariousness and difficulties of the self-employed. The BEC includes different kinds of freelance workers and professionals who maintain their autonomy, while working under an indefinite employment contract and receiving a wage from the cooperative-with the social protection it provides. In other words, they benefit from the social protection of the wage-labor status, while avoiding the difficulties of self-employment: loneliness, weaker social protection, income discontinuity, etc. At the same time, they are not subordinate to any employer. This subordination which forms the basis of wage labor is at the core of this paradoxical status: they are "autonomous employees" (Grégoire and De Heusch, 2016), officially called "salaried entrepreneurs" since the Hamon law of 2014.

In the first part of this article, we show that the standard employment norm-wage labor and its indefinite employment contract-experiences a double "shift" in the BEC. The first type of shift occurs between the institutional rules of the standard employment relationship and the organizational rules of the BEC, which are created by "hijacking" the salaried contract. The second type of shift is developed through actors' individual practices

\footnotetext{
${ }^{8}$ See the work of Bureau and Dieuaide (2018).

${ }^{9}$ We use the term "freelance worker" in this text because the workers we are talking about are not real "self-employed" but belong to a cooperative as salaried workers (part 1). We also avoid the term "entrepreneur" as it conveys particular indigenous-political and economic-values. However, "entrepreneur," "autonomous worker," "freelance," and "solo self-employed" used in different contexts may describe very close-or even similar-situations; a single term may also mean different things depending on the speaker (part 2).

${ }^{10}$ According to the data provided by the two BEC Federations, Copéa and Coopérer pour entreprendre: https://www.copea.fr/index.php/qui-sommes-nous/ notre-histoire; https://cooperer.coop/.
}

via which they individually appropriate this already displaced and altered form of contract. Gradually, social actors'-whether they are BEC staff or entrepreneurs-practices create a diversity of shifts in comparison with the initial rules of the indefinite employment contract.

\section{MATERIALS AND METHODS}

In 2018 and 2019, we carried out in-depth interviews ${ }^{11}$, with an average time of $2 \mathrm{~h} 30$ each, with 16 entrepreneurs from three different BECs in France. We also interviewed 5 project managers from three BECs, as the permanent staff of these organizations. We complemented these interviews with observations made during events that brought together BEC representatives and members, as well as a few observations of building workers (masons, electricians, etc.) during their ordinary professional practices. The occupations of our interviewees come from very different sectors and positions within the social strata, as shown in Table 1. In addition, the situation of these entrepreneurs is quite different in terms of income (some barely survive with the minimum state insurance, whereas others, like Pierre, estimate their monthly net income to be more than $3,000 €$. Some depend on very few clients, like Eymeric who relies on a couple of contractors and rarely manages to win contracts with new customers, while others have multiple income sources, like Maïwenn who mixes training, individual therapy, and workshops. Also, some of them are project leaders, like Jeremy who has a genuine and wide customer portfolio and sometimes even sub-contracts part of his building works to his colleagues, whereas others have a very small professional network and rely on their colleagues to make their activity financially viable. In other words, our interviewees have very different power-relation positions within the workplace. Table 1 shows the main characteristics of the entrepreneur interviewees of our sample (not the BEC representatives and staff). The names of all interviewees and organizations have been changed to protect their anonymity.

This article is mainly based on the interviews that we conducted with freelancers, as the political management of the $\mathrm{BEC}$ is not at the core of this paper. The interviews were carried out at interviewees' homes or sometimes in other places, such as cafes or co-working spaces that some use as their personal office. Almost all interviews took place within the area of an important city in Southern France. The conversations included not only their job and career but also the private aspects of their lives, including their childhood, hobbies, way of life, and family life. The qualitative approach of our research enabled us to carry out a very deep analysis of the interviewees' social pathways and situations (Table 2). The disadvantage of this approach is that we lack space here to extend the examples and individual case studies. For methodological reasons, and in order to provide a structured and unified case study, we therefore base the second part of our article on three individuals. The

\footnotetext{
${ }^{11}$ Oral informed consent was obtained from the participants of this study.
} 
TABLE 1 | Interviews with French entrepreneurs in 2018-2019.

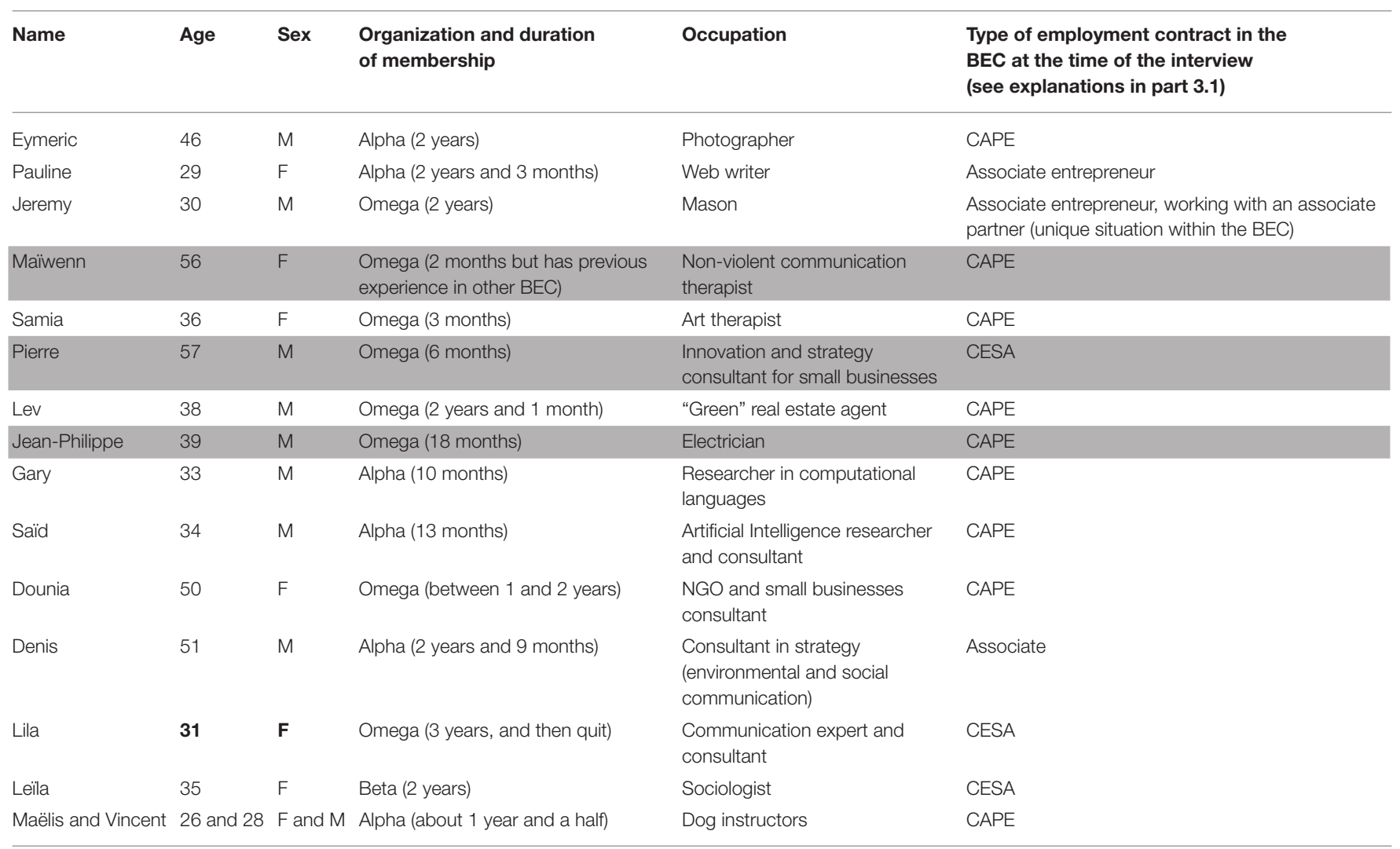

The three cases used for this article are highlighted in gray

TABLE 2 | The analytical framework elaborated from the notion of praxis in order to proceed the collected data.

\begin{tabular}{lll}
\hline $\begin{array}{l}\text { CONCEPTIONS OF... } \\
\text { (subjective dimension) }\end{array}$ & \multicolumn{1}{c}{$\begin{array}{c}\text { CONDITIONS } \\
\text { (objective dimension) }\end{array}$} \\
\hline $\begin{array}{l}\text { Wage-earning } \\
\text { status }\end{array}$ & $\begin{array}{l}\text { Economic and social } \\
\text { background }\end{array}$ & $\begin{array}{l}\text { Personal life } \\
\text { Income }\end{array}$ \\
& Position within power-employment & Patrimony/heritage \\
& relations & At the workplace \\
Cooperation & Political/civic/trade \\
& Working conditions & Use (or not) of social \\
& & protection \\
Political & & Position within the \\
views/conflictuality: & cooperative \\
- About society & When self-employed \\
- At the workplace & & When a wage earner
\end{tabular}

three cases analyzed here correspond to freelance workers who all belong to the same organization; when they refer to their BEC, they are therefore speaking about a single cooperative. However, the findings of our study are based on the whole sample of our research, and we selected these three cases to exemplify and provide evidence based on their diversity and illustrative capacity.

\section{RESULTS AND DISCUSSION}

\section{The "Hijacking" of the Salaried Contract Within "Cooperatives of Freelancers": a First Shift Between Standard and Non-Standard Employment}

Unlike the traditional model of agricultural or industrial cooperatives, in which all workers produce a common product or service, the BEC gathers different professional activities: for example, in one single BEC, there may be a gardener, an architect, an artist, a management consultant, etc. Above all, the BEC represents one of the highest levels of cooperativism: they are enterprises in which autonomous workers are salaried employees. In fact, some freelance cooperatives only offer shared services, for example, they mutualize tasks or competencies to market their services to customers, or they mutualize a common workingplace, but their members remain genuinely self-employed since each of them is paid by his/her contractor. Instead, in the BEC, self-employed people form cooperatives for shared services and also get paid by the cooperative, which produces invoices for their contractors and pays each member a wage. The members of the cooperative are therefore no longer genuinely self-employed workers although they consider themselves to be freelance because they work autonomously and dedicate themselves to their own personal project. Also, each of them has a wide autonomy within the different stages and dimensions of his/her 
work: the entrepreneurs decide how much they plan to earn, on which days and at which times, where and with whom they wish to work (whether they are clients or colleagues), and which strategy to develop to improve their competencies, etc. They are also entirely responsible for the economic viability of their activity. As the French Labor Code underlines, the salaried entrepreneurs are employees of the BEC, which is therefore responsible for their state insurance contributions and information about their health and working conditions ${ }^{12}$. However, entrepreneurs are given a high level of autonomy in their work, which also means less security. This flexibility and low level of support from the BEC is sometimes criticized by some entrepreneurs (see Bajard and Leclercq, 2019). In spite of these autonomous conditions, all entrepreneurs share the same company registration (SIRET) number and their individual sales generate a common sales revenue that makes the cooperative financially viable ${ }^{13}$. This enables, for example, the cooperative to employ a staff of people dedicated to administrative and organizational tasks, such as communication, accounting, etc. Finally, each freelance worker also may become a full member of the cooperative, which means that he/she belongs to a collective entity that relies on organizational and democratic rules and shares the added value generated within the cooperative. This is one of the main differences from "umbrella companies," which do not intend to implement cooperative principles and rules.

Three different steps constitute the classical "salariedentrepreneur" career within a cooperative. The CAPE contractContrat d'Appui au Projet d'Entreprise (Support Contract for the Business Project)—enables any member to combine income from his/her activity with a part-time job in a company or with unemployment benefits (or other State income). During that period, he/she capitalizes part of this income in a personal account within the BEC. When the professional activity is "on track" and the member has enough funds to steady and homogenize the income he/she has capitalized, he/she is then able to pursue the activity under a CESA contract-Contrat d'Entrepreneur Salarié Associé (Contract of Associate Salaried Entrepreneur, an indefinite employment contract)—which is the "core step" of the BEC model. For a freelance worker, working under this contract means officially becoming an employee of the cooperative. However, his/her wage depends on the volume of incomes capitalized in his/personal account and is defined by a contract that may be revised depending on the evolutions of the activity (see below). The last step consists of choosing whether or not to become an associate of the cooperative ${ }^{14}$. Eventually, these freelance workers avoid the difficulties of self-employment (loneliness, weaker social protection, income discontinuity, etc.), while not being subordinate to any employer. On a strictly legal point of view, they are all employees of the BEC and, consequently, may benefit from the social protection that exists

\footnotetext{
${ }^{12}$ Decree $\mathrm{n}^{\circ} 2015-1363$ of October 27, 2015 on Business and Employment Cooperatives and salaried entrepreneurs.

${ }^{13}$ This is in addition to a percentage - generally between 10 and $15 \%$-of their sales that each entrepreneur gives every month as a financial contribution toward the operation of the shared organization.

${ }^{14}$ For more details about these three steps, see Bureau and Corsani (2018, p. 285286).
}

in France for employees: pension, invalidity, maternity leave, etc. Indeed, social protection is a major issue as it constitutes the basis of such a model. Within the BEC landscape, the oxymoron "collective entrepreneurship" is a new category used by social actors in opposition to "individual entrepreneurship," meaning that being a freelance worker does not necessarily require one to work alone.

However, BECs develop different economic and political views. For instance, the first BEC conceives business in a way that does not fit with the "social philosophy that aims to make a 'self-entrepreneur' out of everyone;" their goal is to help people to create their own business while protecting them from the difficulties of self-employment (Bureau and Corsani, 2018, p. 285). BECs with the same (or similar) ideological worldviews tend to promote a vision of business based on reflexive actions, aiming to think through social and political issues (internal and collegial democracy, precariousness, work-leisure balance, gender equality, etc. $)^{15}$. The most emblematic examples of such viewpoints are probably Coopaname (France) and Smart (France, but linked to its parent-company in Belgium), which develop intellectual activities and knowledge through actionresearch, seminars, semi-academic activities (almost "think tanks"), and more ${ }^{16}$. For instance, Coopaname intends to reintroduce the "mutuality" principles ${ }^{17}$ and conceives the cooperative as a "shared company" which is not only composed of aggregated entrepreneurs but that also takes into account the way their activity produces a common value that might then be socialized (Veyer and Sangiorgio, 2018). Coming from a different perspective, some BECs highlight the way in which they boost the achievement of individual entrepreneurial projects or the added economic value they generate for the area. Although solidarity and community are almost always mentioned as important values of such organizations, they do not insist on the need to create either cooperative and self-organized entities or collective rules enacted through democratic decision-making processes led by the salaried entrepreneurs themselves. These BECs are not that different from an umbrella company. The BEC landscape is therefore polarized between, on one side, the idea of an "aggregated entrepreneurs' company" and, on the other side, the quest for "alternative narratives on work and employment" (Veyer and Sangiorgio, 2018, p. 62). This polarization is revealed by the issue of the ownership of wealth ${ }^{18}$, and is, for example,

\footnotetext{
${ }^{15}$ For an historical and precise analysis of this stream within the BEC movement, see Bureau and Corsani (2018).

${ }^{16}$ The BEC also represents the renewal of intermediary bodies, as some of them are legal advisers, employment intermediaries (e.g., the Belgian cooperative Smart through its agreement to hire Deliveroo riders between 2016 and 2018), and also represent workers on a political level (e.g., Smart takes part in collective bargaining on self-employed workers conditions on a European level, along with the European Confederation of Trade Unions).

${ }^{17}$ For details about emancipatory projects based on the Coopaname case, see Bureau and Corsani (2018, p. 286).

${ }^{18}$ Sangiorgio and Veyer propose an in-depth analysis of this issue within BECs and suggest an essential and enlightening difference between employment (the status that each freelance worker has, associated with a physical individual) and activity (autonomous units of production). Some BECs confuse these categories, which leads to the BEC acting as a support for individual projects and an aggregation of entrepreneurial businesses, whereas others, by distinguishing both notions, make
} 
reflected in the way each BEC conceives economic risks, develops the pedagogy of financial management toward its members, and does or does not promote its membership (Veyer and Sangiorgio, 2018, p. 61).

However, in spite of the wide range of political orientations within the BEC landscape, by associating autonomy with social protection (Veyer and Sangiorgio, 2006, p. 92), BECs are considered by some actors and analysts as emancipatory projects, innovative institutions, and "instituting factories" (Bureau and Corsani, 2018) through which workers invent new rights, collective action, and cooperation rules. The project managers as well as the salaried entrepreneurs generally all consideralthough in their own way-these organizations to be tools for emancipation, whether they aim to re-create continuity in freelancers' careers, offering new pooled and cooperation spaces, or simply help to achieve entrepreneurial dreams. In short, BECs are thought of as tools to emancipate individuals from a former condition that they do not want anymore (salaried job, autonomous but precarious work, isolated self-employment, bogus self-employment, etc.).

Two major consequences should be highlighted. First, if BECs are "instituting factories", it seems important to underline the process through which this is done. In their research, French authors Bureau and Corsani study the renewal or invention of new institutions in the gray zones of work and show how initiatives, such as the BEC "borrow from" other traditions (trade unions, cooperatives, etc.) and "recombine them in various ways" (Bureau and Corsani, 2018, p. 293). Indeed, the BEC rests on an old model, the cooperative, that first appeared during the nineteenth century and was legally instituted in France under the status of Scop-Société coopérative et participative. This model was reinterpreted in 1995 in France when the first BEC was set up and, later, when the status of salaried entrepreneur was institutionalized through the Hamon law of 2014. So, the BEC uses existing organizational and legal frameworks-the Scop and the standard indefinite employment contract-in order to follow current trends and aspirations: autonomy at work, selfemployment, and the ability to combine several jobs during one's life (instead of remaining in a wage-earning job under longtime employment). In other words, BECs "hijack" pre-existing rules $^{19}$, i.e., those of the indefinite long-term contract, which are now interpreted and used in order to give freelance workers salaried working conditions. To follow further on the same lines, we interpret the creation of the BEC through a process of "conversion" of the wage-labor institutions. "Conversion occurs when rules remain formally the same but are interpreted and enacted in new ways. This gap between the rules and their instantiation ... is produced by actors who actively exploit the inherent ambiguities of the institutions. Through redeployment, they convert the institution to new goals, functions, or purposes" [(Mahoney and Thelen, 2010), p. 17-18]. This conversion of existing rules-"working with existing materials to craft solutions

it possible to think through the added-value of each activity that will or will not be socialized.

${ }^{19}$ Bureau and Corsani also interpret this phenomenon as a form of "hacking" of the institutions of wage labor (Bureau and Corsani, 2018, p. 289). to new problems" (Mahoney and Thelen, 2010, p. 17-18)also occurred when BECs had to adapt their rules to the evolution of French labor law, which required, for example, having staff representatives. The BEC tried to do this even though the subordination relationship of salaried entrepreneurs is not the same as the situation of employees in traditional companies ${ }^{20}$. Another example of such adaptations is the use of the employment contract: the working time (full-time, halftime, etc.) is the main adjustment variable that enables both the BEC staff member and the freelance worker to mutually agree to adjust the latter's wage to his/her volume of activity. Since French labor law prevents employers from lowering hourly rates, i.e., wages, the BEC then uses the flexibility of the law to support the uncertainties of self-employment.

Second, and as a consequence, BECs drag the standard employment relationship of wage labor into a gray zone of employment (see Figure 1). We therefore observe a complete reversal of what usually occurs, that is to say an expanding influence of non-standard employment relationships-often accompanied by precariousness-in standard labor markets ${ }^{21}$. Of course, some criticisms are made of this type of economic model because of its potential ambiguity toward precariousness. Some observers note that Smart enables enterprises, such as Deliveroo to not hire workers, who therefore remain self-employed instead of being reclassified as employees (Drahokoupil and Piasna, 2019, p. 7 and 39). However, BECs generally appear as a kind of inverted-mirror configuration of bogus self-employment and uberization. While the latter implies subordination at the same time as assuming autonomous worker conditions and status, the BEC provides genuine autonomy to freelancers under a salaried status. We may think of salaried entrepreneurs as "false wageearners" because they consider themselves to be self-employed and yet they receive a pay slip.

This approach "makes gray zones themselves the issue and terrain of a radical, alternative process of institutionalization" (Bureau and Dieuaide, 2018, p. 273), of new rights, political visions, and uses of employment frameworks. The way actors "put the markets to the test" (Bureau and Dieuaide, 2018, p. 268) also advocates for a concrete and micro-scale analysis of political changes in the workplace. Such diversity and openness within the gray zones suggest that working and employment conditions also result from the creativity and interplay of objective frameworks and their subjective appropriations by social actors. However, this is not sufficient to understand the meaning of gray zones, and one may wonder what the effective practices are behind this framework. In fact, neither organizations or statuses, nor standards of employment are stable, and determined entities and their functions, effects, and meanings are also produced by the people who invest in them. On an individual level, it seems important to bear in mind the degree of freedom that actors always practice within the framework of institutions, and the heterogeneity of subjectivities and experiences in the workplace and within the course of one's working life. How

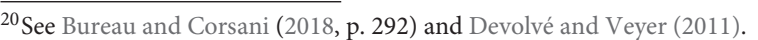

${ }^{21}$ For example, the situation-and mobilization-of Deliveroo bikers or Uber drivers.
} 


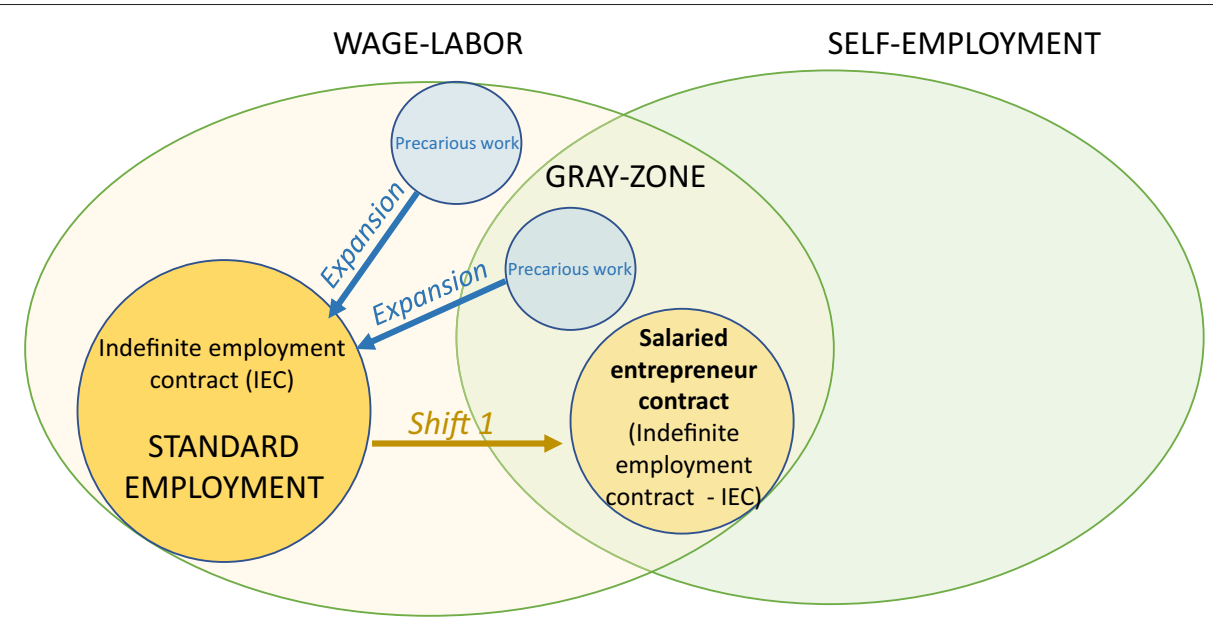

FIGURE 1 | The first type of shift between standard and non-standard work: the indefinite employment contract is introduced into a gray zone in contrast with the classical phenomenon of expansion of precariousness in standard work.

is the "hijacked" indefinite employment contract used and experienced by entrepreneurs? What are their dreams, ambitions, and representations of "emancipated" working conditions?

\section{When the Hijacked Contract Is Hijacked Again: the Diversity of Career Pathways, Aspirations, and Political Values of Salaried Entrepreneurs}

Some indigenous systematic associations are widespread in society by a number of actors including political leaders, the media and, of course, our interviewees. For example, they tend to lie together entrepreneurship and individual emancipation or freedom. On the opposing side, wage labor is commonly represented as a protective but also alienating status as it counters the individuals' autonomy at work and is based on economic exploitation. Instead, in order to analyze the complexity and transformation of work, we assert that we should now pay attention to the disconnection between legal statuses, social identity, and actors' practices. This phenomenon is widespread: for instance, one may be an autonomous employee (Grégoire and De Heusch, 2016), which means that in spite of being a wage earner, one may consider oneself to be a "freelance" worker from a subjective point of view and, de facto, manage one's activity (work content, skills and knowledge, schedules, and professional/private life balance). This is the case with "projectbased" work. A further example is an employee who may also have a part-time job that he/she carries out as a self-employed person; even if this job does not provide significant income, it represents a major identity anchor because it is through the job that the worker defines him/herself. This is the case for many creative and artistic workers, for example, who consider themselves to be a musician or a painter even though they are a teacher for the majority of their working hours (Perrenoud, 2007). On the opposing side, one may be a self-employed worker from the legal point of view but economically dependent and deprived of any autonomy in the workplace, such as bogus self-employed people. If we apply this to the case of BECs, one wonders what is meant exactly by working as a salaried entrepreneur? What is the aim of social actors who endorse such a status? In what range of diverse conditions do they work and what would represent ideal working conditions to them? What are their worldviews, dreams, and ambitions? ${ }^{22}$

The way the interviewees appropriate the same situation in different ways-the CAPE or CESA contract, or former professional status, such as that which they experienced as temporary agency workers, for instance-are major incentives to further explore work experiences. A single term ("wage earner," "entrepreneur," "temporary agency worker," etc.) may have a wide range of meanings. In this article, we show how categories are therefore not sufficient to analyze social phenomena per se based on the diversity of conceptions we observed during our fieldwork. In other words, it is necessary to consider the "double reality of work," as described by Bourdieu (1997), that is to say both the objective dimension of work and the subjective perceptions of it. The notion of "praxis" seems relevant to understand the mechanisms of such appropriations in a qualitative approach. In order to do this, one has to consider people's social pathways and situations in depth which requires a qualitative approach. This is why we have been elaborating an analysis framework which enables us to focus on the longitudinal aspects of people's careers, as well as the social diversity of their lives. Through these tools, we were able to analyze our interviews in a systematic way through the two dimensions of the praxis that finally covered the following aspects: work, living conditions and conflictuality, i.e., the consciousness of divisions that social actors possess and

\footnotetext{
${ }^{22}$ Emancipation, as an experience or an aspiration, and as freeing from a former condition, but also as exercising a genuine self-reliance (Berlan, 2016; Jacquot et al., 2019), actually refers to a wide range of practices and discourses among the people we interviewed (see below).
} 
where they position themselves in social stratification, as well as the generalization they are able to make about social issues.

Through these criteria, we were able to systematize the rich and abundant data produced from each interview. Several tendencies emerge and what follows are some examples of the diversity of views and practices developed by an individual. These appropriations on an individual level therefore involve a second type of "shift" in the original rules of the standard employment contract.

Jean-Philippe ${ }^{23}$ is a plumber in his late thirties who comes from a deprived background. Following his mother's death when he was just 2 years old, he was raised by his father, a boilermaker in a poor suburb of the city. After his father died, Jean-Philippe, then 17, spent the next 3 years in a children's/young person's institution. As he was not allowed to stay there once he turned 21, he had to find a way to earn a living very quickly, and he passed a 2-years course to become a plumber. He then experienced the wage-earning status between the ages of 20 to 37, mainly through temporary agency work. As he was an excellent plumber, he was very highly rated and could earn around $1,900 €$ per month. In 2015, he therefore decided to further develop his career (in terms of salary and skills) but, unlike most workers, he rejected the idea of obtaining a long-term contract in a company: first, because he considers bosses to be "crooks" making profit by underpaying their employees, and second, because he thinks that the competition between employees would have made it difficult for him as he considers himself to be a "big mouth." He also justifies this atypical position toward the standard employment contract by a fear of "getting bored and rusty." However, he did not want to become genuinely self-employed either because he does not feel comfortable with business relations and communication skills. He eventually discovered the BEC model and entered the cooperative in 2017 under a CAPE contract. JeanPhilippe is not interested in the cooperative for the ethical values it promotes nor for its internal democracy; he does not even differentiate between a BEC and an umbrella company. However, he is very happy with the autonomy he obtains through it, as well as the security and advantages it offers: a professional network, paperwork being done by the cooperative, and unemployment benefits as well as the ability to make unemployment benefit contributions for future eventualities. As he is a lone parent and is aware of life's difficulties, he cares very much about being "responsible." This means not only doing good work but also thinking about his entrepreneurial strategy in both the medium and long term, for example by avoiding undeclared work as much as possible. In fact, Jean-Philippe relies upon his own efforts to succeed. He despises politics even though he has clear political views, for example denouncing the stigmatizing and racist views toward inhabitants of the suburbs that are presented by what he calls the "television democracy." For the past 18 months, under the CAPE contract, he has therefore earned a living by combining unemployment benefit with the reimbursement of his expenses by the cooperative (as wage earners are allowed to do within any company in France). In parallel, the income he obtains from his work is deposited in his personal account in the BEC; he

${ }^{23}$ The names of the interviewees have been changed to protect their anonymity. thus hopes to become a salaried entrepreneur and sign a CESA contract within the next 6 months. Jean-Philippe's clients are of two types: the first are individuals who ask him to carry out plumbing work in their homes; the second is Jeremy, another member of the BEC, who works as a mason and sometimes asks Jean-Philippe to do the plumbing aspects of his work. He is thus Jeremy's sub-contractor, while maintaining strong autonomy in how he does his job as well as in deciding the amount that he invoices Jeremy for. As his business now works well, JeanPhilippe is also seriously considering the possibility of using subcontractors himself, for he explains that some members of the cooperative work as laborers for other members. He uses the term "solitary worker" to define himself: he says that "who leads in the cooperative [the CEO] does not need to be discussed" but does not consider himself to be a subordinate worker, or a "boss," or an "entrepreneur." The case of Jean-Philippe thus illustrates the different enshrined subordination relationships in which a freelancer may work and the unstable subjective and objective positions associated with this position.

Maïwenn is in her mid-fifties and works as a therapist in "non-violent communication." Maïwenn divides her job into three aspects: non-violent communication instructor, therapist, and consultant for health institutions. She settled in the city 5 years ago after a long career as a salaried worker, during which time she was a project manager in the Paris fashion industry for almost 20 years. After she realized that she did not wish to continue with that way of life-a well-paid job but one that did not fit with her ethical values-she decided to quit and retrain. She became a real estate agent in the south of France countryside while simultaneously learning the principles of "nonviolent communication." She then started a 5-years training program to become a specialist and eventually became a "nonviolent communication" therapist as a member of a BEC. During this time, she also continued working as an employee of a real estate agency in Paris. After a couple of years, she could not manage both jobs and therefore quit her freelance activity in the BEC. When she settled in the city, a year and a half ago, she ended her real estate agent job and employee status and became a freelancer in a second BEC, which then collapsed. Consequently, as a salaried entrepreneur, she was dismissed from this first BEC for economic reasons ( 2 months before the interview) and could then obtain unemployment benefits. At the time of the interview, the benefits were contributing to her income while she was working under a CAPE contract in a third cooperative. She needed to accumulate income (i.e., money coming in) in her personal BEC account in order to become a salaried entrepreneur again in the new BEC. She says that her income nowadays is "probably divided by three times" in comparison with her former income in the luxury fashion industry. Now, she considers herself an "entrepreneur," in the sense that the term refers to the ability to comply with a wealth of tasks that freelance work requiresfinding costumers, advertising, social media, management of relationships with clients, etc.-although she feels she lacks computing and social media skills in particular. However, unlike Jean-Philippe, who feels relieved that the cooperative is in charge of such tasks, Maïwenn's principal motivation to become a member of a cooperative is the possibility of doing training 
services as an instructor through the BEC's training agreement. Of course, she is very eager to participate in the BEC's activity as she is highly interested in the social and solidarity economy sector and democracy in cooperatives. She conceives the BEC as an entity that each member should be responsible for and she places a high value on individual wisdom to create an optimal organization (she describes herself as a "utopist"). She rejects the idea of hierarchy, competition, and control inside organizations (referring to Manufacturing Consent by Chomsky). Fundamentally, Maïwenn considers herself to be an autonomous worker, whatever her legal status. Throughout her entire career, her position in work power-relationships have always given her the opportunity to control her schedules and activity. Influenced by the "anarchist ideas" of her family background, she says: "I had been an employee for years, de facto, but in my mind, I never ever positioned myself as such." For example, she refuses to call the CEO of the cooperative a "boss" and rejects the idea to "put [herself] in any asymmetrical relationship." She does not make a point of being self-employed or an employee: she endorses her position as a member of a cooperative because she could not hope to carry out the three types of activity that she does if she worked as an employee in a single organization. Maïwenn is a perfect example of a pluriactive freelancer who, above all, cares about his/her personal autonomy regardless of his/her status. As she says, "The framework is just a tool; what matters most is what one does inside of it."

Pierre, who is in his late fifties, settled in the area two and a half years ago, and works as a consultant in enterprise business strategy. At the time of the interview, he had been selfemployed in this work area for 18 years and had joined the cooperative 6 months earlier, directly under a CESA contract, that is as a salaried entrepreneur. After Pierre obtained his political science degree from a selective university in 1984, he started working in public institutions and insurance companies. Apart from a single attempt to become a self-employed consultant during the 1990s-a brief experience which failed-he was an employee for 16 years, working as an expert in entrepreneurship and small businesses. In 1998, he started work in an insurance company in which he discovered a new organizational model based on horizontal governance and employees' individual skills and responsibility; he still considers it to be an "extraordinary experience" that profoundly changed his philosophical views on organizational rules in companies. At the beginning of the 2000s, he quit his salaried position and became a self-employed consultant, a job that he has been doing in the center of France for almost 18 years. During that time, he has never accepted the auto-entrepreneur status, as he would earn too much money (between around $120,000 €$ and $150,000 €$ per year, he says, which represents a minimum of $10,000 €$ of monthly gross incomes, and therefore, an average of $4,000 €$ of monthly net revenue). Pierre does not fear major life changes and fits the image of the flexible and adaptable entrepreneur. He describes his life as "nonlinear," including two marriages, some variations in his income, a move to the south of France, and several working experiences. For instance, 3 or 4 years ago, he decided to implement a new idea which involves software that enables small companies to better define their marketing strategy in relation to their networks. In order to implement this idea, Pierre devoted less time to his traditional activity of consultant, and began dedicating time and money to his new invention (for example, he sub-contracted the technical development of the software). Like Maïwenn, making his dream come true resulted in a substantial loss of income of around $50 \%$ to $60 \%$. He represents the typical figure of the entrepreneur who climbed the social ladder due to his taste for risk and innovation and he even considers himself to be an employer at times. He is very critical of employers' unions ("that kind of stuff pisses me off") because he believes that they are not really able to take effective action. However, he appreciates French president Macron's position, which he finds "innovative," and he frequents pro-Macron circles in the city. At the same time, Pierre does not feel at ease socializing with "high-ranking" people, and finds this "stilted." He also asserts that the first aim of any business should be human well-being, not profit. Pierre comes from a working-class family-his mother is a housewife and his father is a subordinate worker in a big French company-and this might explain why he places so much importance on social values. For instance he makes it a point of honor to decline business partners who neglect their employees' working conditions and security. The human dimension and innovative models of enterprise-based on horizontality and strategic networking-are two of his main concerns. He strongly dislikes a "slapdash" organization: this is one of the criticisms he makes of the cooperative to which he belongs and is why he wishes to commit himself further to building it up. "Network" is Pierre's leitmotiv as not only is it the core concept of his invention but it was also his first motivation to integrate a cooperative: when he arrived in the city in 2014, he suffered a lot from loneliness, especially at work. In a nutshell, Pierre is not interested in the cooperative model from a strictly legal point of view-the share of the labor value-but he thinks that "collective entrepreneurship" (as opposed to the traditional model of individual entrepreneurship) is the future of small businesses in France.

Jean-Philippe, Maïwenn and Pierre are representative figures of solo self-employed people in France at the current time: a plumber who illustrates the traditional highly skilled manual worker, a category that has declined in France over the last two decades [from $46.9 \%$ of the self-employed in 1994 to $34.3 \%$ in 2014 (Jansen, 2016, p. 6, based on Eurostat data and the EU Labour Force Survey $(1994,2004,2014)]$; and two professionals who embody the business and other service sectors that have been expanding very significantly [from $18.7 \%$ in 1994 to $34.2 \%$ in 2014 (Jansen, 2016, p. 6-9)]. In classical analyses, the selfemployed are assumed to be a relatively homogenous group with shared interests (autonomy at work, costs and rewards of working on one's own account, possible position of employer, entrepreneurial risks) ${ }^{24}$. For some analysts, worker-owners, in general, occupy a new and ambiguous emergent class position, different from that of conventional workers or of the petty bourgeoisie (Allen-Whitt and Rotschild-Whitt, 1986). Here also, our sample of interviewees is, by definition, a very particular subtype of the self-employed, as they all enjoy great autonomy at

${ }^{24}$ See a state of the art in Jansen $(2016$, p. 2$)$. 
work. To that extent, they cannot offer a viable generalization of other sub-types of the self-employed, especially those who experience dependent relationships with a single contractor, for instance.

About the similarities shared by our interviewees, and beyond these three cases, the widespread conception that administrative tasks are "dirty work" (Hughes, 1971) is shared by all our interviewees (because they feel they lack competency or that admin wastes time at the expense of their core activity). The recourse (or absence of recourse) to social rights and protection is relatively similar: the overwhelming majority of interviewees think about their unemployment benefits but often overlook other rights (maternity leave, health and safety, paid holidays, etc.) or do not mention them spontaneously. Alongside these common trends, it appears that interviewees do not distance themselves from the wagelabor contract per se, just as they are not attracted by selfemployment in itself: people are actually able to identify the advantages of one or other of these situations (e.g., unemployment benefits and the social protection of an indefinite employment contract) and devise strategies to combine them. This finding thus contradicts political discourses asserting that people nowadays tend to reject wage-labor work and aim to enter entrepreneurship. Considering these elements, most salaried entrepreneurs seem close to the "ascending figure" of the gray zones, "associated with a quasi-militant approach to the recognition of new work relationships that are not dependent on subordination (e.g., the figure of the hacker, or that of the entrepreneur-employee)" (Bureau and Dieuaide, 2018, p. 267, quoting Azaïs 2016). However, some fragmentations appear: in more recent studies, the heterogeneity of the selfemployed has been investigated by researchers. Here as well, through these three case studies it is interesting to observe the variations within that single sub-type of self-employment. They remind us of re-fragmentations, for example between "genuine self-entrepreneurs and subordinates" and "formal and informal sectors") observed in other gray zones, such as auto-entrepreneurship in Brazil (Rosenfield, 2018). They also advocate for alternatives to analytical oppositions between "entrepreneurship" and "precariousness" in the gray zones of work (Murgia and Azaîs, 2019). To that extent, our study converges with other findings which relativize the image of the self-employed as a homogeneous social class.

From this perspective, introducing the political dimension of work is useful. From a qualitative approach, the notion of "figures" proposed by Azaïs is interesting as it "makes it possible to explain the heterogeneity of the positions of actors in gray zones. In a manner of speaking, these figures represent a spectrum of ambiguous positions with regard to labor and employment institutions. They are positions that can be understood as being situated along a constraint vs. freedom' axis, depending on whether or not workers are forced to take such work, whether they accept it, defend it or even outwardly advocate it and act to bring about the new situation" (Bureau and Dieuaide, 2018, p. quoting Azaïs 2016). With different methodological views, Jansen's statistical analysis of the recent changes in the occupational and sectoral structure of self-employment in Western Europe show that "politically the self-employed are more heterogeneous than traditional classbased theories assume" (Jansen, 2016, p. 23). In his work, the "constraint vs. freedom" axis is also present through the notion of autonomy at work ${ }^{25}$ and job insecurity, both used to explain the political orientation of the self-employed in Europe. "People in solo self-employment are generally more likely to support welfare policies and (new) left parties-and oppose right-wing parties-as they are more insecure with respect to their income and/or job. ... Economic vulnerabilities might challenge the archetypical image of people in self-employment as an economic conservative, political right-wing class. This observation suggests that particular segments of self-employment may share the characteristics of other forms of 'atypical' work, not only with respect to labor market insecurities, but also regarding the political orientations associated with such insecurities" (Jansen, 2016, p. 22). To that extent, it is clear that our findings corroborate these sociological studies. Here, the "freedom vs. constraint" axis is also present at different levels, especially through two criteria:

- "working conditions": for instance, some earn a living by combining unemployment benefits and working under an indefinite employment contract-CESA-, while others are already financially stable and receive a comfortable wage.

- "position within power relations in the workplace": some are contractors, others sub-contractors; some have experienced "autonomous" work even though it was under an employee contract, while others know well what "having a boss" means.

First, an important finding is that in addition to objective conditions, the meaning that interviewees give to terms, such as "boss," "autonomy," "entrepreneur," "wage labor," "selfemployment," "cooperation," etc., is varied: in fact, these categories do not have a meaning per se. The in-depth interviews show that the interviewees give a different meaning to a single term. In particular, this depends on their past and social pathway, and the "freedom vs. constraints" axis needs to be considered as a longitudinal approach as this analytical framework fully explains most of freelancers' current representations. As we observed through the case studies, past experiences are decisive in understanding current conceptions that interviewees have of themselves: considering oneself as an "employer" or a "subaltern worker" sometimes means experiencing such positions, although not necessarily currently. This point therefore challenges the issue of identities at work and requires further investigation.

Second, an objective constraint may be viewed negatively or positively depending on the individual, for instance Jean-Philippe, who very much appreciates agency work for the freedom it provides, while avoiding the "dirty job" of

\footnotetext{
${ }^{25}$ Autonomy is a criteria widely used by analysts to observe self-employed political behavior: see for example see (Jansen, 2016, p. 11, quoting Kitschelt and Rehm 2014; Kohn 2015). However, Jansen shows that the degree of autonomy does not determine significantly political orientations of the self-employed (Jansen, 2016, p. 22), unlike economic vulnerabilities: "insecure self-employed workers tend to support new-left parties. ... [but] the right-wing political orientation of selfemployed workers is not stronger as they have more autonomy over their job" (Jansen, 2016, p. 19).
} 
administrative tasks. However, this form of work is generally considered precarious. Another example is the cooperative' rules. They may be perceived as constraints imposed from the top down that a member may respect (and at the same time avoid or circumvent): for instance, doing some informal work but not too much. Or they may be thought of as necessary and even desirable elements that members will go along with because they make the collective entity viable. This perception of rules and objective constraints also depends on people's relationship to cooperative ethical values, i.e., caring and knowing (or not) about them.

More generally, the difference between individual positions toward categories and objective constraints is caused by the multiplicity of political aspects which can be subsumed into two variables. The first is political competency through political ideas (some embrace anarchist philosophy while others promote economic liberal trends) and the "statutory dimension" of political competency [(Bourdieu, 1979, p. 466-479), the feeling one has to be able to position himself/herself on social and collective issues]. The second variable is conflictuality ${ }^{26}$ : perceiving and situating oneself in social conflictuality appears not only when the interviewees talk about what they experience in the workplace but also through general considerations. This complements Jansen's analysis, showing that the self-employed develop different political viewpoints depending on their position inside the labor market and the risks associated with it (Jansen, 2016). In the interviews, we can see the clear awareness that entrepreneurs have of their position in the social strata and how they adapt their entrepreneurial strategy to combine the rules of the BEC with their own interests (see Figure 2). This also provides complementary explanations to analyses of institutional changes and of the different ways in which social actors fulfill projects and career pathways within organizations. Compromise and compliance between the rules of a BEC and practices of individuals (Mahoney and Thelen, 2010), and margins of action and innovation (Bureau and Dieuaide, 2018, p. 273), are different paths to give substance to these possible ways of fulfilling freelance workers' projects. On a micro-scale analysis, considering different expressions of the political dimension may help us comprehend under which conditions people take these routes of change within institutions.

\section{CONCLUSION}

Some social scientists tend to automatically conclude that the social and solidarity economy sector is virtuous as they base their analysis on organizational and theoretical rules about the way it is supposed to work. This position is the mirror-image of normative approaches, making the gray zones of employment a space of "failures" of labor markets. Both approaches tend to analyze the reality of work as more or less "lacking,"

\footnotetext{
${ }^{26}$ More than to critical discourses per se, the expression of divisions related to social issues, as well as the generalization about social topics, constitute the basis of ordinary politicization, according to French politist (Leca, 1973), reinterpreted later through interactionist framework (Hamidi, 2006). This analytical framework is also ours, for it enables us to comprehend ordinary political phenomena far beyond the strict idea of political competency that relates to particular and restrictive skills and knowledge (Blondiaux, 2007).
}

depending on how much it corresponds with the theoretical model. This article shows that analyzing the practices of actors is a fertile way to avoid these problems. Of course, it remains important to temper the relativism toward objective frameworks and underline the crucial nature of legal constraints in the workplace. The recent multiple attempts to reclassify the selfemployed status of Uber drivers into employee contracts is evidence of the considerable importance of these objective aspects'. Nevertheless, wage labor, especially through the longterm indefinite employment contract, which represents one of the "purest" forms of standard employment relationships, may be interpreted in different ways'. The case of BECs confirms that gray zones are not necessarily chaotic and "although it deviates from what is empirically and normatively considered to be 'normal,' nonstandard employment is not necessarily 'bad' or 'precarious"' (Hipp et al., 2015, p. 367). Rather, this phenomenon appears to be a testimony to the ability of social actors to resist and challenge existing institutions and to invent new ones (Bureau and Dieuaide, 2018, p. 265).

BECs are anchored in a wider context of the renewal of experiences in trying to cope with the transformation of the labor market. Through worker-owned cooperatives, one can better understand the continuity between the renewal of industrial and entrepreneurial cooperativism as both are a common attempt to reposition workers in power relations within a context of increased flexibilization of labor markets. However, the case of BEC ignores the issue of the stability-or the vulnerability-of the position of "salaried entrepreneurs" in the labor market.

With respect to this issue, this article shows how the implementation of such contracts on an individual level creates several ways of experiencing work. So, rather than a "pure" form, we assert that the standard employment contract is nothing but a wide range of concrete-organizational and individualinterpretations. BECs veer between standard and non-standard employment relationships as, at a meso and organizational level, the standard norm is dragged into a gray zone (part 3.1). Then, through multiple negotiations and adjustments that freelance workers make around their employment contract, the meanings of "being member of a BEC" differ (part 3.2). Through the notion of praxis, which provides a systematized analytical framework for the ethnographic data, the political dimension appears as a crucial variable to explain variations between interviewees. We eventually subsume its variant forms through the notions of conflictuality and political competency. Besides, the concept of "social class" 27 is not outdated and in the gray zones of work, where legal statuses may be separated from identities and practices, it provides a pertinent factor of analysis, enabling actors to situate their own position and define their worldviews.

Regarding these methodological aspects, it is important to point out that the BEC case study introduces complementary

\footnotetext{
${ }^{27}$ At the first stage of our fieldwork, aiming to comprehend the relationships to wage labor and self-employment, we were not able to identify a need for racial or gender variables in the analysis. The people we met did not show signs of racialization; gender is probably more likely to be considered at a deeper analysis level to better understand issues such as working conditions, income, and the balance between working and private life.
} 


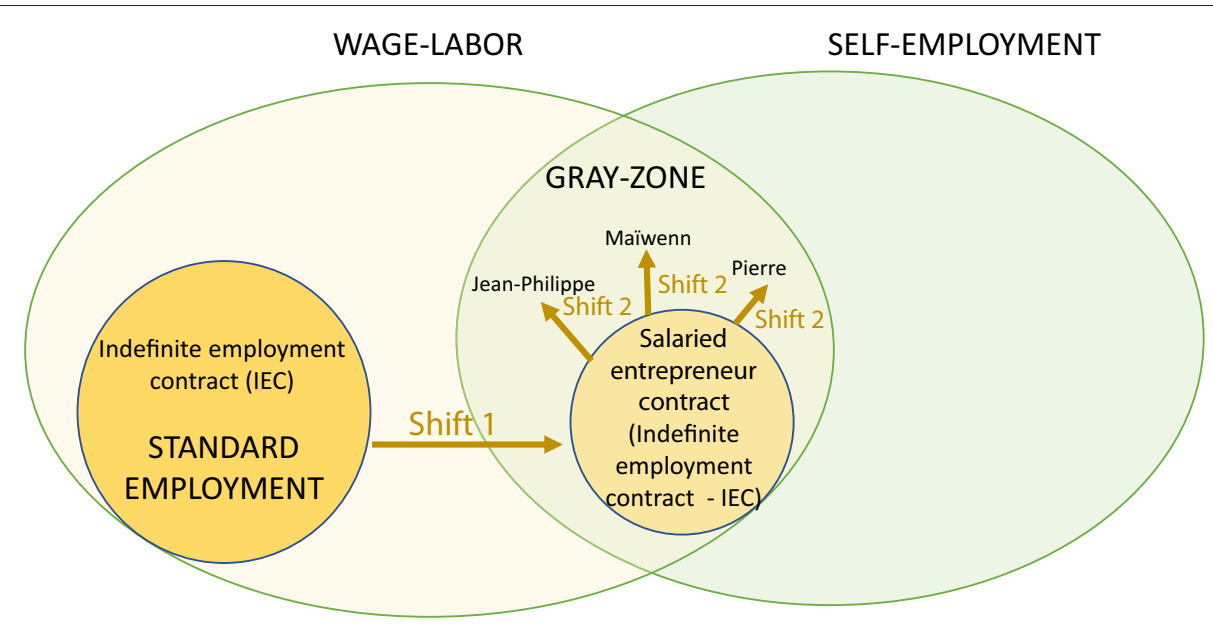

FIGURE 2 | The second type of shift occurs when individuals adapt the indefinite employment contract to their own entrepreneurial strategy.

qualitative guidelines for other inquiries. However, it is important to remember that this case study does not prevent us from considering a macro-scale analysis. First, this is because BECs remain experiments at a local level, even though they can then be articulated and even intertwined with legal evolutions of State and regional policies. Second, it is necessary to locate actors' practices in deeper trends, reached through statistical analysis.

So, on the one hand, the entrepreneurs enjoy less stability than the traditional figure of the self-employed (agricultural and craft workers, for instance) because, unlike the latter, the "new" self-employed are less likely to remain in this position and will return to an employee status or become unemployed (Jansen, 2016, p. 12, quoting Arum and Müller; Schulze Buschoff and Protsch). This means that being an "insider" of the labor market, due to an indefinite employment contract, does not provide per se sufficient stability if other working conditions are not assured. On the other hand, regarding the idea of the "wage society" analyzed by Castel (2002b), a large majority of entrepreneurs have a strong consciousness of the "social property" to which they are entitled due to salaried employment contracts ${ }^{28}$; to that extent, they therefore enjoy a moral and material security that the traditional self-employed lack. In particular, wage labor is considered by interviewees, whatever their political worldview, to be a serious and efficient alternative to the French "auto-entrepreneur" status and, in particular, the salaried entrepreneurs demonstrate a sharp awareness of their rights to unemployment benefits. These elements therefore contradict the idea promoted by public policies that, in the twenty-first century, workers massively seek to become independent and emancipate themselves from the "yoke" of wage-labor.

\footnotetext{
${ }^{28}$ Social property is, "on the one hand, generalization of the use of jointly held goods, which can neither be appropriated individually nor marketed, and which are in the service of all; on the other hand, generalization of personal protections constituted on the basis of work and no longer on the basis of a private patrimony" (Castel, 2002a, p. 328).
}

However, our inquiry also shows that, beyond this common attachment to the wage-labor contract, social actors implement individual and autonomous tactics to use it: entrepreneurs demonstrate precise accumulation strategies that they may implement due to the CAPE and CESA contracts, which enable them to use these benefits in the future if required. Although we may not develop these aspects in the present article, it is important to underline that, depending on organizational strategies and internal governance of each BEC, the training of entrepreneurs in the categories and rights attached to the wagelabor contract strongly differ between one BEC and another ${ }^{29}$. Whereas, in the "wage society," "the individual in society acquires social citizenship by taking part in the collective benefits and services guaranteed by the state" (Castel, 2002a, p. 328), our interviewees develop an ambiguous position toward it. The choice to work in a BEC does not result from philosophical and political expectations originally linked to the principles of the wage society, such as the reinforcement of interdependence between the members of society, the promotion of jointly held goods, etc. Rather, the promotion of the wage-labor contract and belonging to a BEC results, for many interviewees, from the individual consciousness of its benefits in terms of rights and personal protections. This articulation between these subjective worldviews and attachment to this objective framework is another area for further investigation.

Finally, does this "conversed" classical wage-labor contract remain a "standard" form of employment? Answering such a question requires to point out the impossibility of classifications. Furthermore, we make the assumption that there might be nothing but "hijacked," particular, altered, and creative practices, coexisting alongside other "hijacked," particular, altered, and

${ }^{29}$ Some BECs resemble "umbrella companies" and provide almost no training regarding "accidents at work," social insurance and sharing of the risks, history of cooperatives and societies of mutual solidarity, etc.; other BECs are considered as political alternatives to the neo-liberal philosophy and also aim to make their members more conscious and committed to the construction of a commonly shared worldview regarding these aspects. 
creative practices. Using and re-interpreting legal frameworks is not a specificity of BEC, and other types of contracts are used flexibly, with a margin of maneuver, or are subverted by social actors until the law endorses adjustments, these two phases being a constant and circular process, such as with flexible work in France (Kornig, 2003, p. 111-112). The issue of "purity" of labor and employment contracts, and the way it gives way to successive conversions, refers to the legal distinction between the law and the customs of law. From a philosophical and anthropological perspective, and to return to where we began this article, we quote the philosopher Bachir Diagne: "There is not an already constituted universality, with the stability of a telos overlooking, from its own self-assured exemplarity, anthropological proliferation and fluctuation" (Bachir Diagne, 2013, p. 16). Like this supposed pure universality opposed to its cultural variations, we argue that there is no "properly used" wage-labor employment relationship of which the opposite would be a "degraded form." From this conception, the salariedentrepreneur contract is just one manifestation of the wage-labor contract, which is a precise and constraining, but nevertheless flexible, "signifier" whose meaning and content would depend on actors' actions.

\section{DATA AVAILABILITY STATEMENT}

The datasets generated for this study will not be made publicly available. All qualitative data were collected on condition

\section{REFERENCES}

Allen-Whitt, J., and Rotschild-Whitt, J. (1986). Worker-owners as an emergent class: effects of cooperative work on job satisfaction, alienation and stress. Econ. Ind. Democr. 7, 297-317. doi: 10.1177/0143831X8673004

Azaïs, C., Dieuaide, P., and Kesselman, D. (2017). Zone grise d'emploi, pouvoir de l'employeur et espace public: une illustration à partir du cas Uber. RI/IR 72, 433-456. doi: 10.7202/1041092ar

Bachir Diagne, S. (2013). On the postcolonial and the universal? Rue Descartes 2, 7-18. doi: 10.3917/rdes.078.0007

Bajard, F., and Leclercq, M. (2019). Devenir entrepreneur.e en Coopératives d'Activités et d'Emploi: les 1001 visages de l'émancipation. J. Des Anthropol. 2019, 151-174. doi: 10.4000/jda. 8834

Berlan, A. (2016). Autonomie et délivrance. Repenser l'émancipation à l'ère des dominations impersonnelles. MAUSS. 2, 59-74. doi: 10.3917/rdm.048.0059

Bisom-Rapp, S., and Coiquaud, U. (2017). The role of the state towards the Grey zone of employment: eyes on Canada and the United States. Rev. Interv. Econom. 58. doi: 10.4000/interventionseconomiques.3555

Blondiaux, L. (2007). Faut-il se débarrasser de la notion de compétence politique? Rev. Fr. Sci. Polit. 57, 759-774. doi: 10.3917/rfsp.576.0759

Bourdieu, P. (1979). La Distinction. Critique Sociale du Jugement. Paris: Éditions de Minuit.

Bourdieu, P. (1997). Méditations Pascaliennes. Paris: Seuil.

Bureau, M.-C., and Dieuaide, P. (2018). Institutional change and transformations in labour and employment standards: an analysis of 'grey zones'. Transfer 24, 261-277. doi: 10.1177/1024258918775573

Bureau, M. C., and Corsani, A. (2018). Collective actions on the margins of the salariat. Transfer 24, 279-295. doi: 10.1177/1024258918775505

Castel, R. (2002a). Emergence and transformations of social property. Constellations 9, 318-334. doi: 10.1111/1467-8675.00285

Castel, R. (2002b). From Manual Workers to Wage Laborers. Transformation of the Social Question. New Brunswick, NJ: Transaction.

Cingolani, P. (2008). La Précarité. Paris: La Découverte. of anonymity. Requests to access these datasets should be directed to Flora Bajard, flora.bajard@gmail.com.

\section{ETHICS STATEMENT}

Ethical review and approval was not required for the study on human participants in accordance with the local legislation and institutional requirements. Written informed consent for participation was not required for this study in accordance with the national legislation and the institutional requirements. Written informed consent was not obtained from the individual(s) for the publication of any potentially identifiable images or data included in this article.

\section{AUTHOR CONTRIBUTIONS}

The author confirms being the sole contributor of this work and has approved it for publication.

\section{FUNDING}

This inquiry takes part of a Program about BECs and social protection, conducted by the author herself and socio-anthropologist Maya Leclercq (Sociotopie, France), and funded by the French Ministry of Labour and Solidarity (DREES-DARES).

Conaty, P., Bird, A., and Ross, P. (2016). Not Alone-Trade Union and Co-operative Solutions for Self-employed Workers. Co-operatives. Available online at: https:// www.uk.coop/NotAlone

Dardot, P. (2015). “De la praxis aux pratiques," in Dans Marx \& Foucault (Paris: La Découverte), 184-198.

Devolvé, N., and Veyer, S. (2011). La quête du droit : approche de l'instauration d'une représentation du personnel dans une coopérative d'activités et d'emploi. RECMA 319, 78-96. doi: 10.7202/1020808ar

Drahokoupil, J., and Piasna, A. (2019). Work in the Platform Economy: Deliveroo Riders in Belgium and the SMart Arrangement. European Trade Union Institute (ETUI). Available online at: https://www.etui.org/Publications2/WorkingPapers/Work-in-the-platform-economy-Deliveroo-riders-in-Belgium-andthe-SMart-arrangement

Grégoire, M., and De Heusch, S. (2016). Evolution et diversité des situations de travail : une analyse à travers les notions de $\ll$ travail autonome $\gg$ et de $\ll$ travail au projet $\gg$. Athènes: Communication pour les Journées Internationales de Sociologie du Travail.

Hamidi, C. (2006). Éléments pour une approche interactionniste de la politisation. Engagement associatif et rapport au politique dans des associations locales issues de l'immigration. Rev. Fr. Sci. Polit. 56, 5-25. doi: 10.3917/rfsp.561.0005

Hipp, L., Bernhardt, J., and Allmendinger, J. (2015). Institutions and the prevalence of nonstandard employment. Socioecon. Rev. 13, 351-377. doi: $10.1093 / \mathrm{ser} / \mathrm{mwv} 002$

Hughes, E. C. (1971). The Sociological Eye: Selected Papers. New Brunswick, NJ: Transaction Books.

International Labor Organization (2016). Non-standard Employment Around the World: Understanding Challenges, Shaping Prospects. Geneva: ILO.

Jacquot, L., Metzger, J. L., Bachet, L., Bureau, M. C., Defalvard, H., and Didry, C. (2019). Travail et émancipation. La Nouvelle Rev. Travail 14, 129-163. doi: $10.4000 /$ nrt.4936

Jansen, G. (2016). Self-employment as atypical or autonomous work: diverging effects on political orientations. Socio-Econ. Rev. 17, 381-407. doi: 10.1093/ser/mww017 
Kornig, C. (2003). La Fidélisation des intérimaires permanents. Une stabilioté négociée (Thèse pour l'obtention du doctorat de sociologie de l'EHESS). Paris: EHESS.

Leca, J. (1973). Le repérage du politique. Projet 71, 11-24.

Mahoney, J., and Thelen, K. (2010). Explaining Institutional Change: Ambiguity, Agency And Power. Cambridge: Cambridge University Press.

Murgia, A., and Azaïs, C. (2019). "Grey zones of work and employment in comparative perspective: the hybridisation of labour market statuses, individual careers and collective forms of representation," in Session for the International Labour Process Conference (Vienna: University of Vienna).

Perrenoud, M. (2007). Les Musicos. Enquête Sur Les Musiciens Ordinaires. Paris: La Découverte.

Rosenfield, C. L. (2018). Labour, self-entrepreneurship in Brazil and paradoxes of social freedom. Transfer 24, 337-352. doi: 10.1177/1024258918775535

Supiot, A. (2000). Les nouveaux visages de la subordination. Droit Soc. 2, 131-145. Available online at: https://www.college-de-france.fr/media/alainsupiot/UPL4919662935852082630_subordination.pdf
Veyer, S., and Sangiorgio, J. (2006). L'entrepreneuriat collectif comme produit et projet d'entreprises épistémiques: le cas des Coopératives d'Activités et d'Emploi. Rev. l'Entrepr. 5, 89-102. doi: 10.3917/entre.052.0089

Veyer, S., and Sangiorgio, J. (2018). Les parts congrues de la coopération : penser la question de la propriété dans les coopératives d'activités et d'emploi. L'exemple de la Scop Coopaname. RECMA 4, 55-69. doi: 10.3917/recma.350.0055

Conflict of Interest: The author declares that the research was conducted in the absence of any commercial or financial relationships that could be construed as a potential conflict of interest.

Copyright $\odot 2020$ Bajard. This is an open-access article distributed under the terms of the Creative Commons Attribution License (CC BY). The use, distribution or reproduction in other forums is permitted, provided the original author(s) and the copyright owner(s) are credited and that the original publication in this journal is cited, in accordance with accepted academic practice. No use, distribution or reproduction is permitted which does not comply with these terms. 


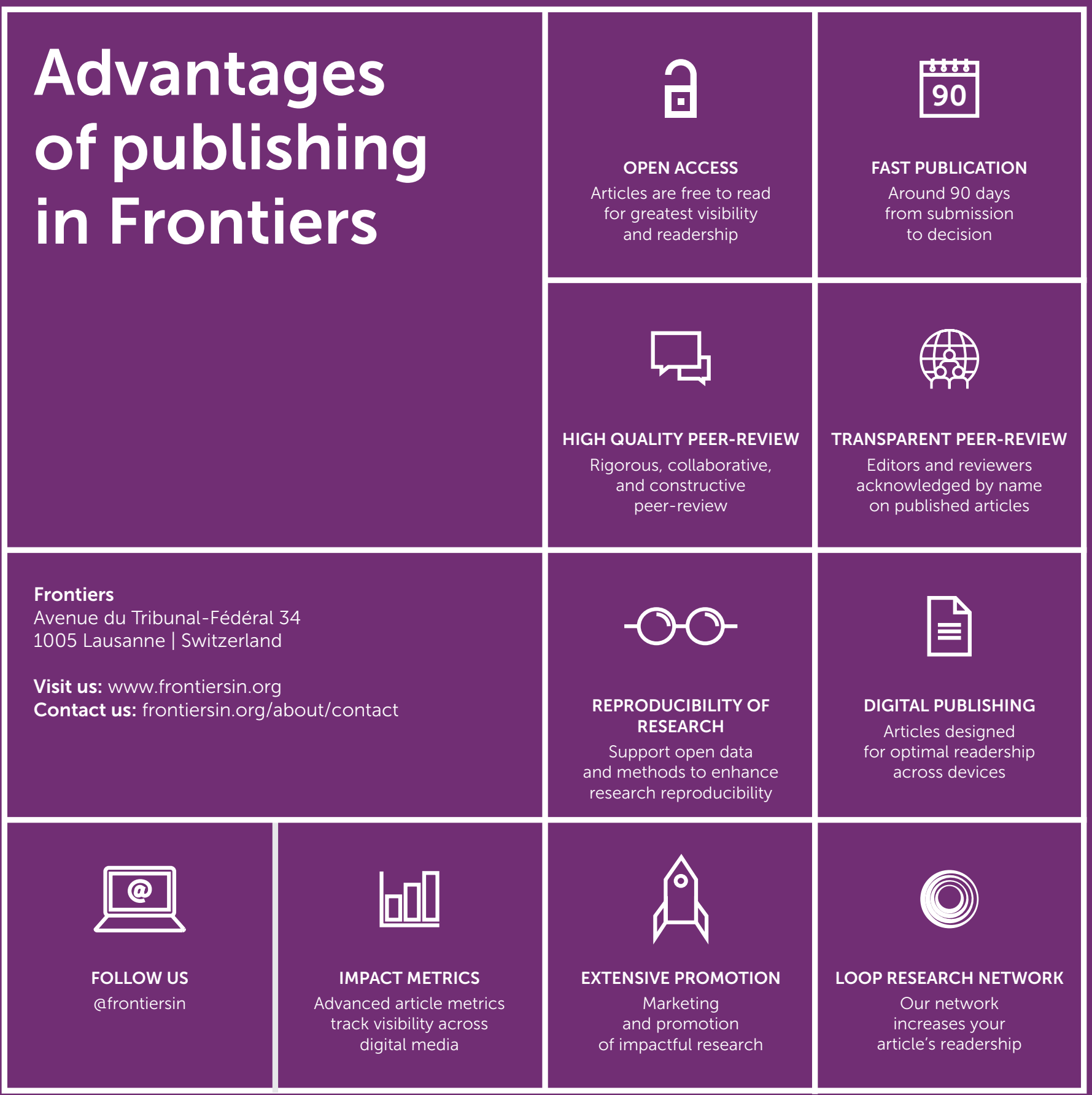

